Aus der Klinik für Gastroenterologie und gastrointestinale Onkologie (Prof. Dr. med. V. Ellenrieder) der Medizinischen Fakultät der Universität Göttingen

\title{
Präklinische Analyse von epithelialen und stromalen Markern in einem transgenen Mausmodell für Pankreaskarzinome
}

\author{
INAUGURAL-DISSERTATION \\ zur Erlangung des Doktorgrades \\ der Medizinischen Fakultät der \\ Georg-August-Universität zu Göttingen
}

vorgelegt von

Lukas Klein

aus

Twistringen 
Dekan:

Referent/in:

Ko-Referent/in:

Drittreferent/in:

Datum der mündlichen Prüfung:
Prof. Dr. Wolfgang Brück

Prof. Dr. Dr. med A. Neeße

.................................................. 
Hiermit erkläre ich, die Dissertation mit dem Titel "Präklinische Analyse von epithelialen und stromalen Markern in einem transgenen Mausmodell für Pankreaskarzinome" eigenständig angefertigt und keine anderen als die von mir angegebenen Quellen und Hilfsmittel verwendet zu haben.

Göttingen, den

(Unterschrift) 
Teile dieser Arbeit wurden publiziert in:

Hasselluhn MC*, Klein L*, Patzak MS, Buchholz SM, Ströbel P, Ellenrieder V, Mai-sonneuve P, Neesse A (2020): Stromal Features of the Primary Tumor Are Not Prognostic in Genetically Engineered Mice of Pancreatic Cancer. Cells 9, 58. *Shared first author

Hessmann E, Patzak MS, Klein L, Chen N, Kari V, Ramu I, Bapiro TE, Frese KK, Gopinathan A, Richards FM et al. (2018): Fibroblast drug scavenging increases intratumoural gemcitabine accumulation in murine pancreas cancer. Gut $\underline{67}, 497-507$

Klein L, Hessmann E, Bapiro TE, Frese K, Richards FM, Jodrell DI, Gress TM, Ellenrieder V, Neesse A (2016): Gemcitabine delivery and stromal component analysis in primary murine pancreatic tumours and liver metastasis. Pancreatology $\underline{16}, \mathrm{~S} 17 . \mathrm{EPC}$ conference abstract 


\section{Inhaltsverzeichnis}

Abbildungsverzeichnis ............................................................................................. III

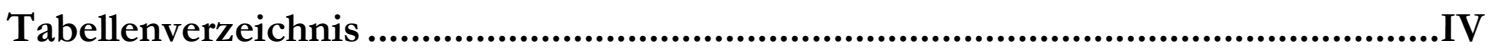

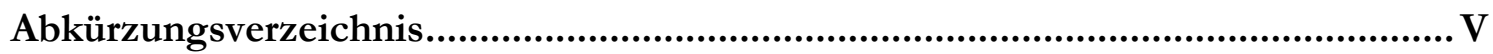

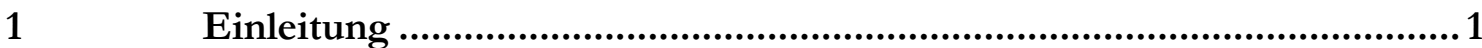

$1.1 \quad$ Das duktale Pankreaskarzinom: Epidemiologie und Klinik ..............................................1

1.2 Entstehungsmodelle des Pankreaskarzinoms .....................................................................

1.3 Krebsmodelle: von der Zellkultur zum Mausmodell .......................................................6

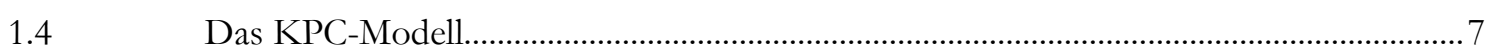

1.5 Stroma im Pankreaskarzinom: das Tumormikromilieu ....................................................11

1.5.1 Zelluläre Komponenten des Tumormikromilieus ..........................................................13

1.5.2 Extrazelluläre Komponenten des Tumormikromilieus ......................................................14

1.5.3 Das Stroma als Zielstruktur für neue Therapieansätze .........................................................17

1.6 Subtypisierung des Pankreaskarzinoms ...................................................................... 18

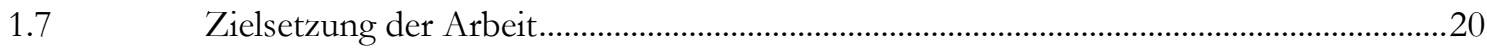

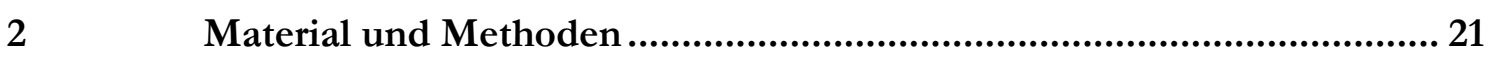

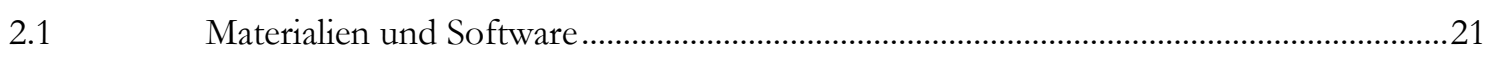

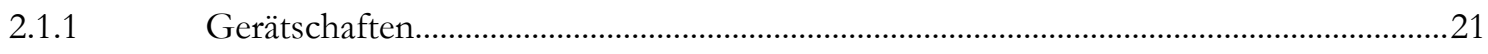

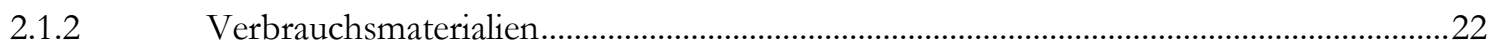

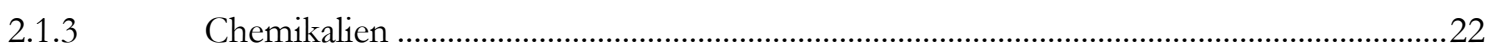

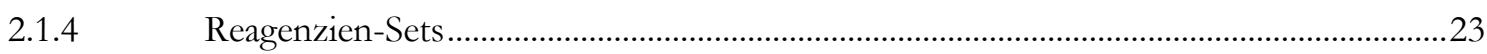

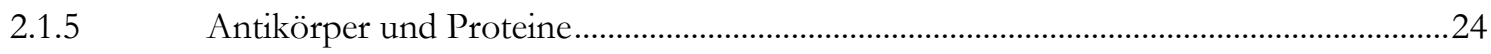

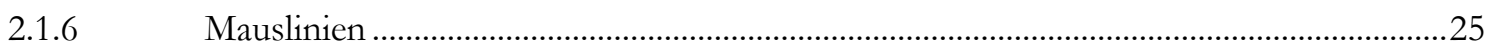

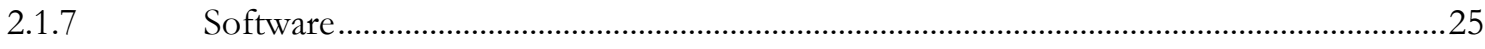

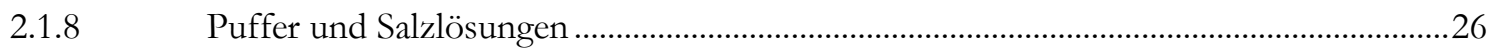

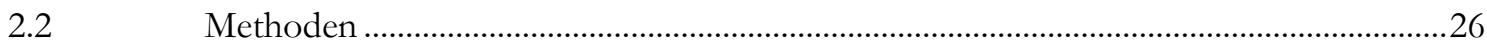

2.2.1 Gewebeentnahme, Fixierung und Einbettung ...........................................................26

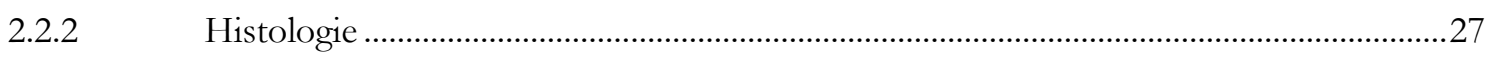

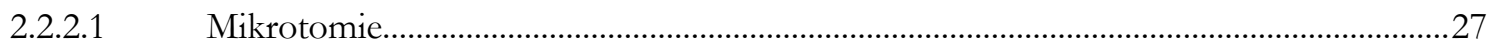

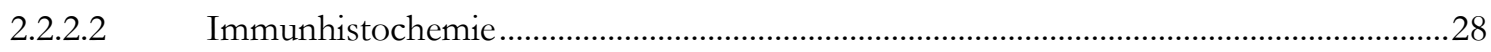

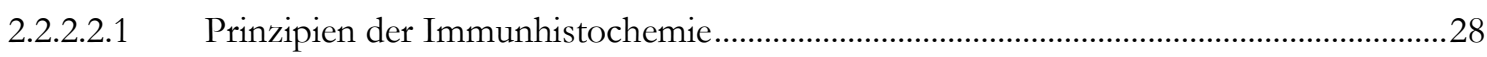

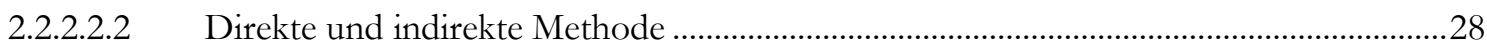

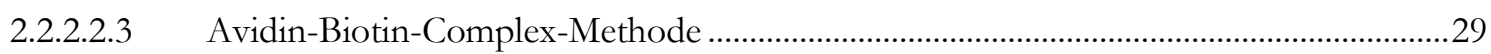

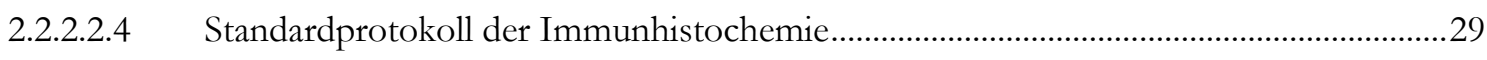

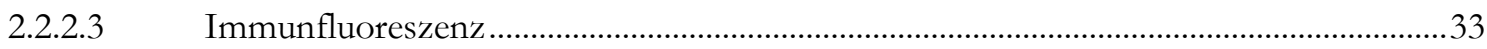

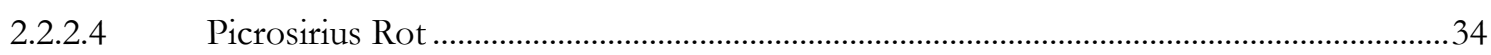


2.2.2.5 Auswertung und Quantifizierung der Histologie...........................................................34

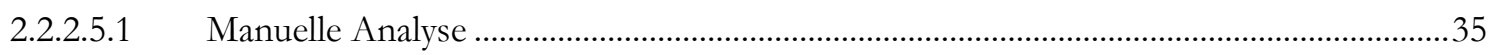

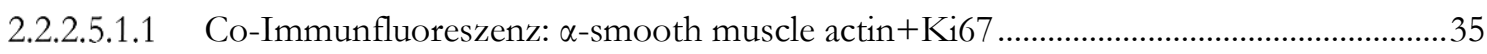

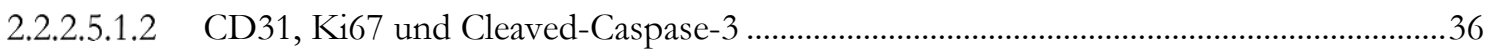

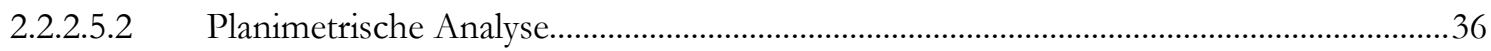

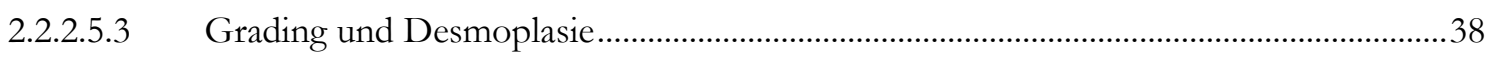

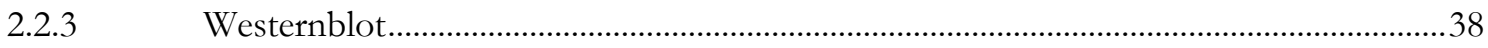

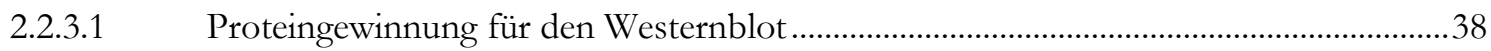

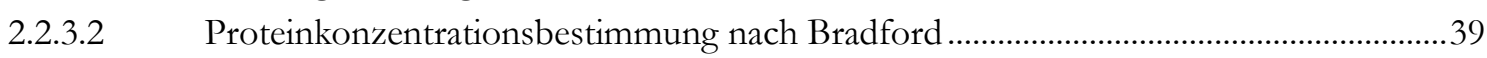

2.2.3.3 Theorie und Grundlagen des Westernblots...............................................................40

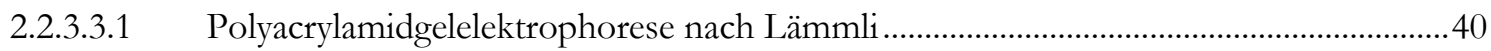

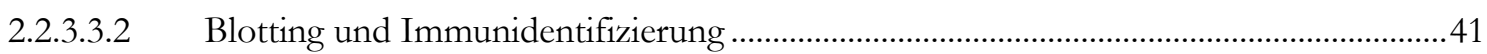

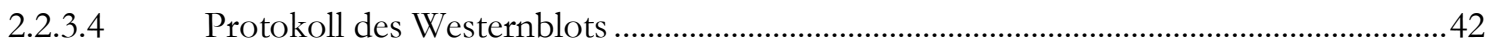

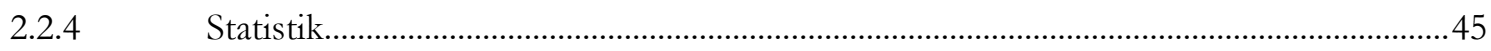

2.2.4.1 Zusammenhang zwischen Stromaparametern und Überleben......................................45

2.2.4.2 Stromavergleich von Primärtumor, Lebermetastase und normaler Leber .....................45

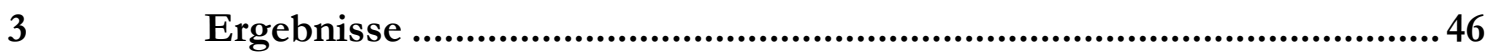

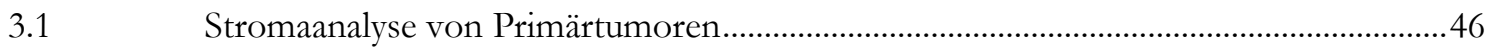

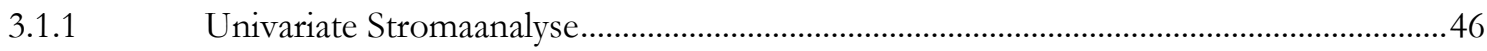

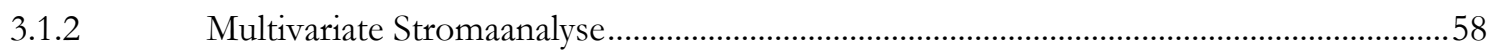

Vergleich von Primärtumoren und Lebermetastasen ....................................................61

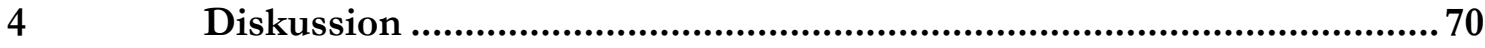

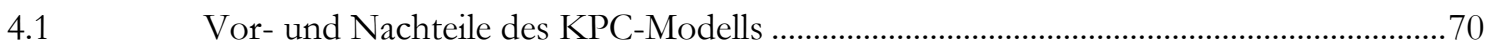

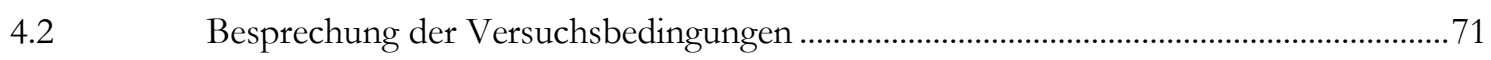

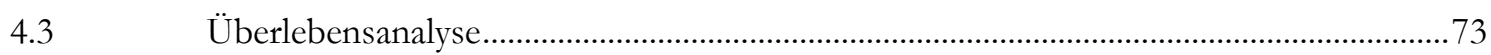

4.3.1 Besprechung des Studiendesigns und der Fragestellung ..............................................73

4.3.2 Auswirkungen der stromalen und epithelialen Parameter auf das Überleben ................74

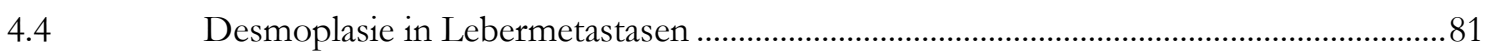

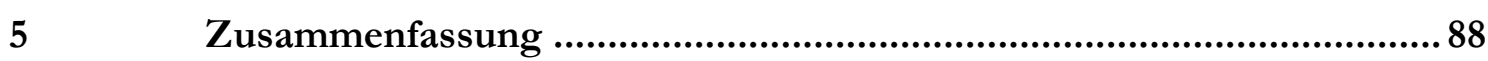

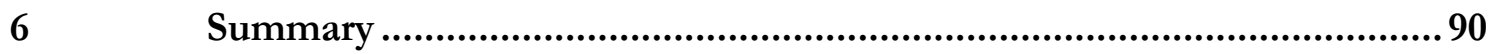

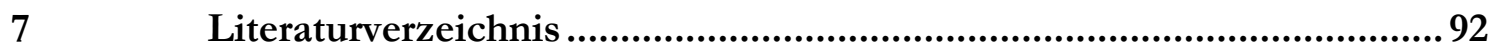




\section{Abbildungsverzeichnis}

Abbildung 1: Progressionsmodell des PDAC nach Hruban (2000) ........................................................5

Abbildung 2: Genetischer Hintergrund des KPC-Modells............................................................... 9

Abbildung 3: Hämatoxilin-Eosin-Färbungen von murinem und humanem Pankreaskarzinom .......11

Abbildung 4: Hyaluronsäurefärbung zur Bestimmung des Hyaluronsäuregehalts ...............................15

Abbildung 5: SPARC-Immunhistochemie zur Bestimmung der SPARC-Expression........................16

Abbildung 6: Situs einer KPC-Maus mit Pankreastumor ........................................................................27

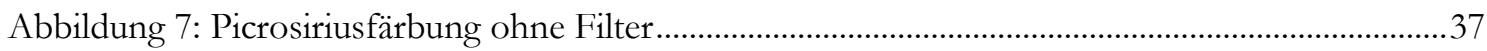

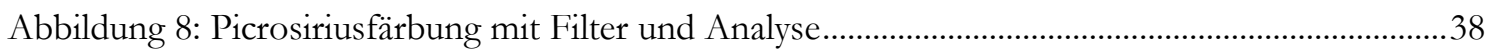

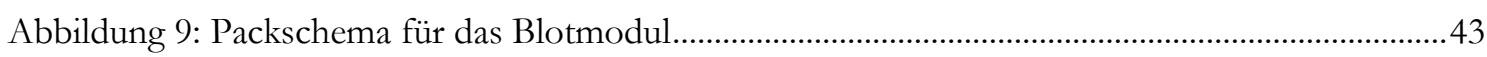

Abbildung 10: Gesamtüberleben der KPC-Mäuse ohne Gruppenvergleich .....................................46

Abbildung 11: Ki67-Färbung als Marker für die Proliferationsrate ...................................................48

Abbildung 12: Univariate Überlebensanalyse für die Proliferationsrate.............................................4 48

Abbildung 13: Cleaved-Caspase-3-Färbung als Marker für die Apoptoserate ....................................49

Abbildung 14: Univariate Überlebensanalyse für die Apoptoserate ....................................................49

Abbildung 15: Phosphohiston-H3-Färbung als Marker für die Mitoserate ........................................50

Abbildung 16: Univariate Überlebensanalyse für die Mitoserate........................................................50

Abbildung 17: Picrosiriusfärbung als Marker für Kollagen ..................................................................5 51

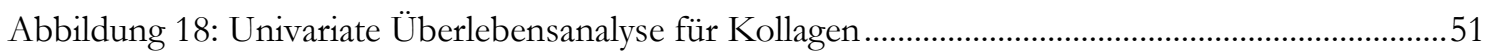

Abbildung 19: Univariate Überlebensanalyse für Hyaluronsäure ......................................................52

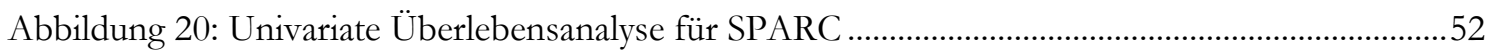

Abbildung 21: $\alpha$-smooth muscle actin-Färbung als Marker für aktivierte Fibroblasten ......................53

Abbildung 22: Univariate Überlebensanalyse für $\alpha$-smooth muscle actin...........................................53

Abbildung 23: Co-Immunfluoreszenz für $\alpha$-smooth muscle actin und Ki67 als Marker für die

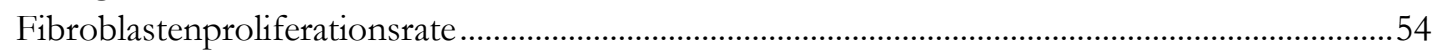

Abbildung 24: Univariate Überlebensanalyse für die Fibroblastenproliferationsrate..........................54

Abbildung 25: CD31-Färbung zur Identifizierung von Blutgefäßen ....................................................55

Abbildung 26: Univariate Überlebensanalysen für mittlere Gefäßdichte und mittlere Gefäßfläche .55

Abbildung 27: Beispielbilder für Grading und Desmoplasie...........................................................56

Abbildung 28: Univariate Überlebensanalysen für Grading und Desmoplasie....................................56

Abbildung 29: Überlebensanalyse bezüglich des aktivierten Stromaindex............................................57

Abbildung 30: Überlebensanalyse bezüglich Individuen mit hohen bzw. niedrigen Proliferations- und

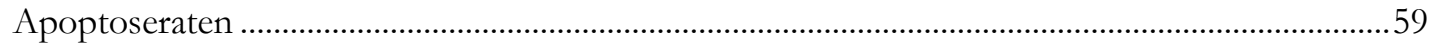

Abbildung 31: Hämatoxilin-Eosin-Färbungen von Primärtumor und Lebermetastase.......................61

Abbildung 32: Picrosirius-positive Fläche in \% als Marker für den Kollagengehalt in Primärtumor,

Lebermetastasen und normaler Leber ...................................................................................62

Abbildung 33: Picrosiriusfärbung für Primärtumor und Lebermetastase .........................................62

Abbildung 34: $\alpha$-smooth muscle actin-positive Fläche in \% als Marker für aktivierte Fibroblasten in

Primärtumoren und Lebermetastasen......................................................................................63

Abbildung 35: $\alpha$-smooth muscle actin-Färbung für Primärtumor und Lebermetastase ......................63 
Abbildung 36: Hyaluronsäure-positive Fläche in \% in Primärtumoren, Lebermetastasen und normalem Lebergewebe.

Abbildung 37: Hyaluronsäure-Färbung für Primärtumor und Lebermetastase

Abbildung 38: SPARC-positive Fläche in \% in Primärtumoren, Lebermetastasen und normaler Leber

Abbildung 39: SPARC-Färbung für Primärtumor und Lebermetastase. 65

Abbildung 40: CD31-positive Blutgefäße pro hochauflösendem 400x-Gesichtsfeld in Primärtumoren, Lebermetastasen und normaler Leber.

Abbildung 41: CD31-Färbung in Primärtumor, Lebermetastase und normalem Lebergewebe ........66

Abbildung 42: Cleaved-Caspase-3-positive Zellen pro hochauflösendem 400x-Gesichtsfeld als Apoptosemarker in Primärtumoren und Lebermetastasen....

Abbildung 43: Cleaved-Caspase-3-Färbung in Primärtumor und Lebermetastase.

Abbildung 44: Ki67-positive Zellen pro hochauflösendem 400x-Gesichtsfeld als Proliferationsmarker in Primärtumoren und Lebermetastasen ..................................................68

Abbildung 45: Ki67-Färbung in Primärtumor und Lebermetastase ....................................................68

Abbildung 46: Westernblot aus Tumorgewebe und normalem Lebergewebe von KPC-Mäusen .....69

\section{Tabellenverzeichnis}

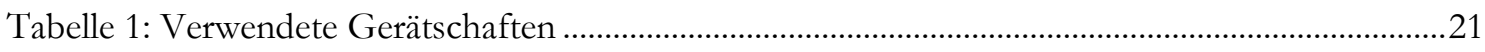

Tabelle 2: Verwendete Verbrauchsmaterialien ....................................................................................22

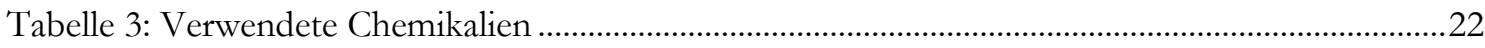

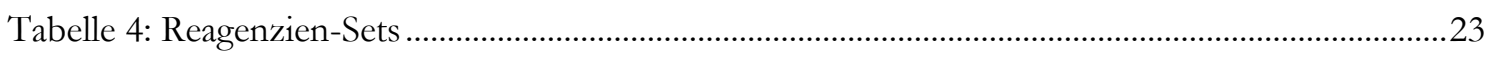

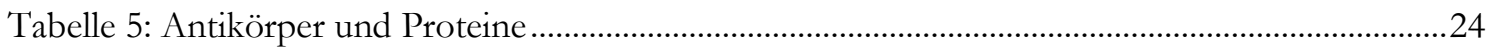

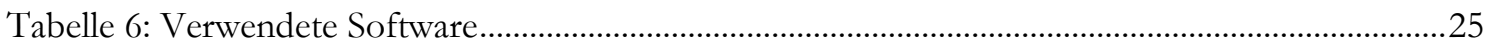

Tabelle 7: Verwendete Puffer und Salzlösungen .....................................................................................26

Tabelle 8: Färbespezifikationen der Immunhistochemie ................................................................32

Tabelle 9: Antikörper für Co-Immunfluoreszenz ..............................................................................33

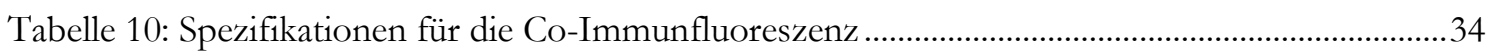

Tabelle 11: Übersichtsdarstellung der Quantifizierung ........................................................................35

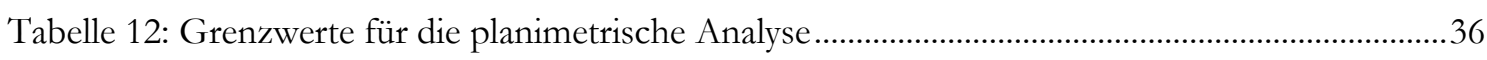

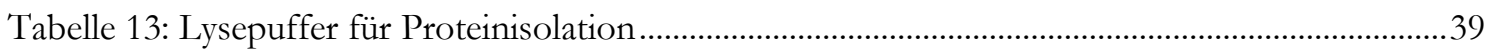

Tabelle 14: Lysereagenz für Proteinisolation aus Gewebe...............................................................39

Tabelle 15: Pipettierschema für die Proteinbestimmung nach Bradford ..........................................40

Tabelle 16: Antikörper und Konzentrationen für den Westernblot....................................................44

Tabelle 17: Übersicht über die univariaten Stromaanalysen ............................................................47

Tabelle 18: Cox-Proportional-Hazards-Regression, Vorwärtsselektion ...............................................58

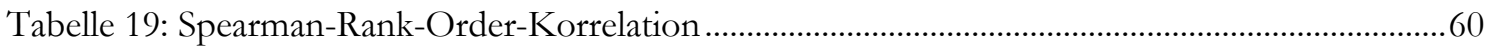




\section{Abkürzungsverzeichnis}

$1^{\circ} \mathrm{AK} \quad$ Primärantikörper

$2^{\circ} \mathrm{AK} \quad$ Sekundärantikörper

$\alpha$-SMA $\quad a$-smooth muscle actin

ABC Avidin-Biotin-Complex

bp Basenpaar

BRCA1/2 Brustkrebsgen 1/2 (engl. breast cancer gene 1/2)

BSA bovines Serumalbumin

CAFs Krebs-assoziierte Fibroblasten

CC3 Cleaved Caspase-3

CD31 cluster of differentiation 31

CIN chromosomale Instabilität

Co-IF Co-Immunfluoreszenz

CP chronische Pankreatitis

Cre Cre-Rekombinase

CTGF Bindegewebe-Wachstumsfaktor (engl. connective tissue growth factor)

DAB Diaminobenzidintetrahydrochlorid

EDTA Ethylendiamintetraessigsäure

EMT Epithelial-mesenchymale Transition

EZM Extrazellulärmatrix

FGF Fibroblasten-Wachstumsfaktor (engl. fibroblast growth factor)

FITC Fluoresceinisothiocyanat

$\mathrm{H}_{2} \mathrm{O}_{2} \quad$ Wasserstoffperoxid

HA Hyaluronsäure (engl. byaluronic acid)

HABP HA-bindendes Protein (engl. hyaluronic acid binding protein)

HE Hämatoxylin-Eosin

HGF Hepatozyten-Wachstumsfaktor (engl. hepatocyte growth factor)

HRP Meerrettichperoxidase (engl. horseradish peroxidase)

HSB Farbton (engl. bue), Sättigung (engl. saturation), Helligkeit (engl. brightness)

HSP90 Hitzeschockprotein 90

IF Immunfluoreszenz

IgG Immunglobulin $\mathrm{G}$

IHC Immunhistochemie

IL- Interleukin-

IPMN intraduktale papillär-muzinöse Neoplasie

KC LSL- $\underline{K r a s}^{\mathrm{G} 12 \mathrm{D} /+} ; \mathrm{Pdx}-1-\underline{\mathrm{Cre}}$

$\mathrm{kDa} \quad$ Kilodalton (Molekülmasse)

KI Konfidenzintervall

Konz. Konzentration

KPC LSL-ㅈas ${ }^{\mathrm{G} 12 \mathrm{D} /+}$; LSL-Trp53 $3^{\mathrm{R} 172 \mathrm{H} /+}$; Pdx-1-Cre

KRAS Kirsten rat sarcoma viral oncogene homolog

LSL Lox-Stopp-Lox

LW Leitungswasser 
M Molarität

MET Mesenchymal-epitheliale Transition

MLA mittlere Gefäßfläche (engl. mean lumen area)

MMPs Matrix-Metalloproteasen

MVD mittlere Gefäßdichte (engl. mean vessel density)

MZN muzinös-zystische Neoplasie

n. s. nicht signifikant

nab nanoparticle albumin-bound

$\mathrm{NaCl} \quad$ Natriumchlorid

$\mathrm{NaOH} \quad$ Natriumhydroxid

NL normale Leber

p53 Protein 53

PAGE Polyacrylamidgelelektrophorese

PBS Phosphat-gepufferte Salzlösung (engl. phosphate buffered saline)

PDAC duktales Adenokarzinom des Pankreas (engl. pancreatic ductal a denocarcinoma)

PDGF Plättchen-Wachstumsfaktor (engl. platelet derived growth factor)

PHH3 Phosphohiston-H3

PSCs Pankreassternzellen (engl. pancreatic stellate cells)

RBE Rekombinase-bindendes Element

RHAMM Rezeptor für Hyaluronsäure-vermittelte Motilität (engl. HA-mediated motility)

rpm Rotationen pro Minute

RT Raumtemperatur

SDS Natriumdodecylsulfat (engl. sodium dodecyl sulfate)

SPARC secreted protein acidic and rich in cysteine

TBST Tris-gepufferte Salzlösung (engl. Tris buffered saline) mit Tween20

TGF $\beta \quad$ transformierender Wachstumsfaktor $\beta$ (engl. transforming growth factor $\beta$ )

Tris Tris(hydroxymethyl)aminomethan

Trp53 Gen für Protein 53

Tween20 Polyoxyethylen-(20)-sorbitanmonolaurat 


\section{Einleitung}

\subsection{Das duktale Pankreaskarzinom: Epidemiologie und Klinik}

Das Pankreaskarzinom ist eine der bösartigsten und aggressivsten Krebserkrankungen des Menschen. Unter den Malignomen des Pankreas stellt das duktale Adenokarzinom des exokrinen

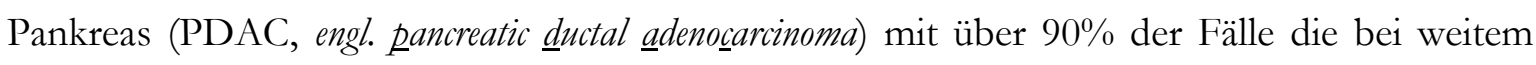
dominierende Entität dar (Siegel et al. 2016; Feldmann und Maitra 2008; American Cancer Society 2018).

Im Jahr 2014 erkrankten nach Angaben des Robert Koch-Instituts in Deutschland circa 17.100 Menschen an einem PDAC, womit es die sechst- bzw. zehnthäufigste Krebserkrankung bei Frauen bzw. Männern darstellt. Im gleichen Zeitraum stellt das PDAC die vierthäufigste zum Tode führende Krebserkrankung dar, was in seiner außergewöhnlich hohen Mortalitätsrate begründet liegt. So liegen Inzidenz (13,9 bzw. 10,4/100.000 (Männer bzw. Frauen, altersstandardisiert)) und Mortalität (13,0 bzw. 9,5/100.000 (Männer bzw. Frauen, altersstandardisiert)) sehr eng beieinander und ein Langzeitüberleben ist eine Seltenheit. Gleichfalls hält sich das Lebenszeitrisiko, am PDAC zu erkranken und daran zu versterben, mit je 1,7\% die Waage (Robert Koch-Institut 2017). Der Altersgipfel der Erkrankung liegt zwischen dem 60. und 75. Lebensjahr, wobei Frauen mit 75 Jahren im Mittel drei Jahre später erkranken als Männer (Beger et al. 2013; Robert Koch-Institut 2107). Für 2018 werden vom Robert Koch-Institut 19.000 Neuerkrankungen für Deutschland prognostiziert. Die Inzidenz- und Mortalitätsraten haben in den vergangenen Jahrzenten altersstandardisiert für Frauen leicht zugenommen, während sie für Männer weitestgehend konstant geblieben sind (Robert Koch-Institut 2017). Vergleichbare epidemiologische Zahlen liegen beispielsweise für die USA vor. Hier stiegen die altersstandardisierten Inzidenz- und Mortalitätsraten zwischen 2003 und 2012 in beiden Geschlechtern an (Howlader et al. 2015). Es wird prognostiziert, dass sich das PDAC bis 2020 zur dritt- und bis 2030 zur zweithäufigsten krebsassoziierten Todesursache in den USA entwickeln wird (Rahib et al. 2014). Auch für Deutschland wird prognostiziert, dass das PDAC bis 2030 die fünfthäufigste Krebsdiagnose darstellt und zur zweithäufigsten Krebstodesursache aufsteigen wird (Quante et al. 2016). Diese Entwicklung ist auf die diagnostischen und therapeutischen Erfolge der letzten Jahrzehnte und intensive Forschungsbemühungen bei den meisten soliden Krebserkrankungen zur Steigerung des relativen 5-Jahres-Überlebens zurückzuführen. So stieg die altersstandardisierte relative 5-Jahres-Überlebensrate für das PDAC in den USA im Zeitraum von 1975 bis 2011 von 2,5\% auf nur 7,8\%, im Mittel für alle Tumorentitäten stieg sie jedoch im gleichen Zeitraum von 48,9\% auf 68,7\% (Siegel et al. 2016; Howlader et al. 2015). In Deutschland nimmt die relative 5-Jahres-Überlebensrate für das PDAC mit 8\% bei Männern und 9\% bei Frauen den vorletzten Platz unter den soliden Krebserkrankungen ein und ist mit Blick auf die durchschnittliche relative 5-Jahres-Überlebensrate bei Krebserkrankungen von 59\% bei 
Männern bzw. 65\% bei Frauen als ausgesprochen niedrig einzuordnen (Robert Koch-Institut 2017).

Trotz unermüdlicher Forschungsbemühungen zum genetischen und pathologischen Verständnis sowie zu neuen Therapieansätzen haben diese nur ungenügend zu einer Verbesserung der Prognose für Patienten mit PDAC geführt. Ein wichtiger Grund für die überaus schlechte Prognose des PDAC ist das regelhafte Fehlen von Frühsymptomen. Häufig treten in der Initialphase unspezifische Symptome wie Rückenschmerzen, abdominelle Schmerzen, Ikterus, Völlegefühl, Gewichtsverlust und Thrombosen auf und führen häufig nicht direkt zur Verdachtsdiagnose „Pankreaskarzinom“ (Modolell et al. 1999; Porta et al. 2005). Im Gegensatz zu vielen anderen Krebserkrankungen existieren keine geeigneten Screening-Untersuchungen zur Früherkennung. Gemeinsam führen diese Tatsachen dazu, dass das PDAC in der Mehrzahl der Fälle erst in fortgeschrittenen Stadien diagnostiziert wird (Okano und Suzuki 2014; Porta et al. 2005). Zum Zeitpunkt der Erstdiagnose liegen bei über 80\% der Patienten bereits lokal fortgeschrittene oder metastasierte Stadien vor, die eine Operation, die einzige potenziell kurative Therapie, ausschlieBen (Doi et al. 2008; Amin et al. 2013; Hidalgo 2010). 80\% der PDAC liegen im Pankreaskopf und jeweils $10 \%$ in Körper und Schwanz, wobei Tumoren im Schwanz fast nie früh symptomatisch werden und bei Diagnosestellung um ein vielfaches wahrscheinlicher bereits ein fortgeschrittenes Stadium (T4) und damit Inoperabilität aufweisen (Sener et al. 1999). In einigen lokal fortgeschrittenen Stadien kann eine Operation noch sinnvollerweise vorgenommen werden, beispielsweise wenn Truncus coeliacus oder Arteria mesenterica superior nicht infiltriert sind. Das Ziel sollte jedoch immer die R0-Resektion, also der histologische Nachweis tumorfreier Schnittränder, sein (Leitlinie Pankreaskarzinom 2013). Auch die kleine Gruppe in kurativer Intention R0-resezierter Patienten erleiden in der Mehrzahl der Fälle Rezidive, das 5-Jahresüberleben liegt in diesen Fällen bei circa 24\% (Wagner et al. 2004; Oettle et al. 2007; Sener et al. 1999). Innerhalb von 6 Wochen nach der Operation sollte eine auf 6 Monate ausgelegte adjuvante Chemotherapie begonnen werden, da sich hierdurch sowohl das krankheitsfreie Überleben als auch das Gesamtüberleben verbessern lassen (Oettle et al. 2007; Stocken et al. 2005). Lange Zeit waren sowohl vorwiegend Gemcitabin als auch seltener die Kombination 5-Fluorouracil/Folinsäure der Standard für eine adjuvante Chemotherapie. Seit 2017 wird die Kombination aus Gemcitabin und Capecitabin, einer oral wirksamen Vorstufe von 5-Fluorouracil, als die Standardtherapie des PDAC betrachtet. Gegenüber der Gemcitabinmonotherapie ist das mediane Überleben bei dieser Kombination um zweieinhalb Monate länger, jedoch treten auch häufiger schwerwiegende Nebenwirkungen auf (Neoptolemos et al. 2017). Auch in palliativen Situationen kann durch eine Chemotherapie mit Gemcitabin gegenüber der besten supportiven Therapie sowohl das Gesamtüberleben verlängert als auch die Lebensqualität während dieser Phase verbessert werden. Die medianen Überlebenszeiten sind mit circa 6 bis 7 Monaten in diesem Kontext ausgesprochen niedrig, was die Aggressivität und Chemoresistenz des PDAC aufzeigt (Glimelius et al. 1996). Seit der Etablierung von Gemcitabin 1997 als Erstlinientherapie des PDAC in palliativer Intention wurden eine Reihe von unterschiedlichen Kombinationsthe- 
rapien mit Gemcitabin auf ihre Überlebensvorteile getestet. Mit Ausnahme des Tyrosinkinaseinhibitors Erlotinib, welcher das mediane Überleben um circa 2 Wochen verlängert, blieben alle diese Therapieregime erfolglos (Moore et al. 2007; Burris et al. 1997; Berlin et al. 2002). Erst in den letzten Jahren sind mit den Kombinationstherapien Gemcitabin + nab-Paclitaxel (nanoparticle albumin-bound-Paclitaxel) und dem FOLFIRINOX-Protokoll zwei alternative Therapieregime verfügbar, die das mediane Überleben auf 8,5 bzw. 11,1 Monate verlängern können. Allerdings gehen beide Therapien mit deutlich erhöhter Toxizität einher und können daher nicht jedem Patienten empfohlen werden (von Hoff et al. 2013a; Conroy et al. 2011).

Als gesicherte unabhängige Risikofaktoren für das PDAC gelten, neben hohem Alter, Tabakkonsum, starke Adipositas, hoher Alkoholkonsum und Diabetes mellitus Typ 2 (Robert KochInstitut 2017; American Cancer Society 2018). Außerdem besteht für Patienten mit einer chronischen Pankreatitis (CP) ein erhöhtes Risiko, am PDAC zu erkranken. So war das altersstandardisierte Risiko, ein PDAC zu entwickeln, bis zu 19-fach erhöht, wenn Patienten innerhalb der letzten 5 Jahre an einer CP litten. Es bleibt zu beachten, dass trotzdem nur 1,8\% bzw. 4-5\% der Patienten mit einer CP, unabhängig von ihrer Genese, in den auf die Diagnose der CP folgenden 10 bzw. 20 Jahren ein PDAC entwickelten. Für Patienten mit einer hereditären Pankreatitis war das relative Risiko 69-fach erhöht (Malka 2002; Lowenfels et al. 1993; Raimondi et al. 2010)

Verwandte ersten Grades haben ein erhöhtes Risiko, selbst am PDAC zu erkranken, wobei unklar ist, ob diesem Zusammenhang ein gemeinsamer genetischer Hintergrund zugrunde liegt oder geteilte lebensstilbedingte Risikofaktoren ausschlaggebend sind (Robert Koch-Institut 2017; Wolfgang et al. 2013). Die häufigste erbliche Ursache des PDAC stellt das familiäre Pankreaskarzinom dar. Das familiäre Pankreaskarzinom wird bei mindestens zwei Fällen von PDAC bei Verwandten ersten Grades angenommen, sofern nicht die Kriterien für ein anderes erbliches Krebssyndrom erfüllt werden. Dies trifft auf 1-3\% der Fälle von PDAC zu. Hinsichtlich Tumorhistologie und Erkrankungsalter unterscheidet sich das familiäre Pankreaskarzinom nicht von sporadischen Karzinomen, und außerhalb von Studien machen auch hier intensivierte Früherkennungsmaßnahmen keinen Sinn (Leitlinie Pankreaskarzinom 2013; Lu et al. 2015). In circa 5\% aller PDAC liegt der Erkrankung ein genetisch bedingtes Krebssyndrom zugrunde, welches sich durch Keimbahnmutationen in Tumorsuppressorgenen (TSG) und einer deutlichen Prädisposition für maligne Erkrankungen definiert. Hierzu zählen unter anderen das Lynch-Syndrom mit häufigen Mutationen in den DNA-Reparaturgenen MLH1 und MSH2, das hereditäre Brust- und Ovarialkarzinom-Syndrom mit Mutationen in den DNA-Reparaturgenen BRCA2 und BRCA1, das Peutz-Jeghers-Syndrom mit Mutation im TSG STK11 sowie das familiäre atypische Multiple-Mole-Melanom (FAMMM)-Syndrom mit Mutation im Gen p16/CDKN2A (Shi et al. 2009; Goggins et al. 1996; Hezel et al. 2006; Wolfgang et al. 2013). Häufig liegt die Penetranz des PDAC bei Patienten mit diesen Keimbahnmutationen relativ niedrig, sodass sich der klinische Verdacht auf familiäre Häufung nicht stellt und die zugrundeliegende Mutation nicht erkannt wird (Goggins et al. 1996). 


\subsection{Entstehungsmodelle des Pankreaskarzinoms}

In Anlehnung an die Progressionsmodelle für verschiedene Krebsarten wie beispielsweise dem Kolonkarzinom (Vogelstein et al. 1988) wurde im Jahr 2000 nach intensiver Forschung zu genetischen und histologischen Veränderungen auch für das PDAC ein solches Modell postuliert (Hruban et al. 2000). Das klassische Modell geht davon aus, dass das PDAC in seiner Entwicklung von einer azinär-duktalen Metaplasie ausgeht und über die schrittweise Akkumulation genetischer Veränderungen mehrere intraepitheliale Vorstufen durchläuft, bis schließlich ein invasives Karzinom resultieren kann. Diese Vorstufen werden als „pankreatische intraepitheliale Neoplasien" (PanINs) bezeichnet, in die Grade 1a/b, 2 und 3 eingeteilt und über die zunehmenden histologischen Veränderungen definiert. In den PanIN-1a/b-Läsionen treten erste epitheliale Veränderungen und (mikro-)papilläre Gangläsionen auf, bevor bei PanIN-2-Läsionen ein Verlust von Zellpolarität und moderate Kernatypien hinzukommen. Beide werden nach neuem Konsensus zu niedrig-gradigen Dysplasien zusammengefasst. Hochgradig veränderte PanIN-3-Läsionen werden auch als „Carcinoma-in-situ“ (CIS) bezeichnet, da sie mit signifikanten Kernatypien und vollständigem Polaritätsverlust bei erhaltener Kontinuität der Basalmembran einhergehen (Hingorani et al. 2003; Basturk et al. 2015). Es gibt genetische Veränderungen, die sich besonders häufig im Rahmen eines PDAC finden und sich teilweise auch (zeitlich) bestimmten Vorläuferläsionen zuordnen lassen. So kann eine aktivierende Mutation in dem (Proto-)Onkogen KRAS (Kirsten rat sarcoma viral oncogene homolog) typischerweise schon in frühen PanINs gefunden werden (30\% der PanINs-1) und findet sich in über $90 \%$ der invasiven PDAC. Zudem zeigen sich häufig Mutationen in anderen Komponenten der Ras/Raf/MapKaskade, weswegen Veränderungen in diesem Signalweg beinahe als obligatorisch für die Entstehung eines PDAC bezeichnet werden können (Feldmann und Maitra 2008; Hruban et al. 2000; Calhoun et al. 2003; Hingorani et al. 2003; Jones et al. 2008; Bailey et al. 2016). Im Laufe der Tumorprogression kommen weitere Mutationen oder epigenetische Modifikationen hinzu, meist in TSG wie $p 16 / C D K N 2 A / I N K 4 A$, $p 53$ und DPC4/SMAD4/MADH4. Die Häufigkeit dieser Mutationen nimmt mit dem Progressionsgrad der PanINs zu und ist bei invasiven Karzinomen am höchsten (Feldmann und Maitra 2008; Hingorani et al. 2005; Wilentz et al. 1998). Wie auch beim Kolonkarzinom ist zu betonen, dass nur der kleinste Teil der Vorläuferläsionen bei unklarer Latenz in ein invasives Karzinom übergeht (Hruban et al. 2000). Da es keine sinnvollen Screeningverfahren für PanINs gibt und daher die prognostische Relevanz unklar ist, ergeben sich aus diesen Erkenntnissen zur Entstehung des PDAC bis heute keine evidenzbasierten klinischen Konsequenzen. Es besteht allerdings Konsens, dass hochgradige Dysplasien (CIS) chirurgisch entfernt werden, wenn sie zufällig diagnostiziert werden (Basturk et al. 2015). 


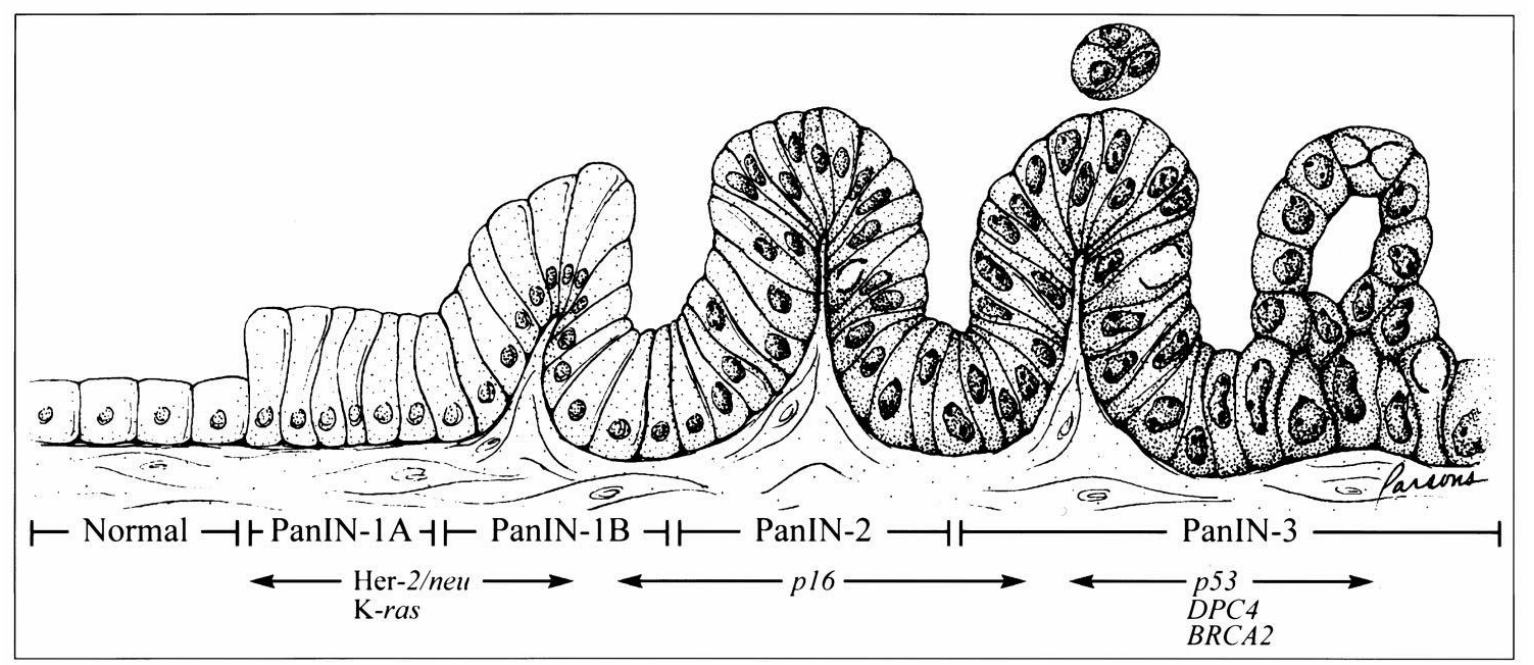

\section{Abbildung 1: Progressionsmodell des PDAC nach Hruban (2000)}

Normale Pankreasgangepithelzellen gehen über die präneoplastischen Zwischenstufen der PanINs in ein invasives PDAC über. Der zunehmende Verlust von typischer kubischer Epithelform und Zellpolarität geht parallel mit der Akkumulation typischer Mutation wie KRAS, Her-2/neu, $p 53$ und DPC4 einher. Die Verwendung erfolgt mit freundlicher Genehmigung des Verlags American Association for Cancer Research.

Zystische Pankreasneoplasien, insbesondere die intraduktale papillär-muzinöse Neoplasie (IPMN), sind ein sehr häufiger Zufallsbefund in der gesunden Bevölkerung, der mit zunehmendem Alter signifikant an Häufigkeit zunimmt (Kromrey et al. 2018). Für die beiden häufigsten duktalen zystischen Pankreasneoplasien, die IPMN und die muzinös-zystische Neoplasie (MZN) sind Adenom-Karzinomsequenzen mit einem Übergang in invasive duktale Pankreaskarzinome beschrieben. Sie sind als Präkanzerosen mit malignem Potential von benignen serösen zystischen Neoplasien und Pankreatitis-assoziierten Pseudozysten zu unterscheiden. IPMN werden je nach Lokalisation in Haupt- und Seitengangtyp unterschieden, wobei die Läsionen im Hauptgang deutlich häufiger maligne entarten (circa 50\% bei Diagnose bereits invasives Karzinom) und immer chirurgisch entfernt werden sollten (Tanaka et al. 2006; Esposito et al. 2012). Auch MZN sollten stets R0-reseziert werden, da sie in bis zu 15\% der Fälle mit einem duktalen Adenokarzinom assoziiert sind. Die Prognose für IPMN- oder MZN-assoziierte duktale Pankreaskarzinome ist jedoch besser als für primäre duktale Adenokarzinome (Tanaka et al. 2006; Esposito et al. 2012; Thompson et al. 1999). Sowohl IPMN als auch MZN gehen mit einer schrittweisen Akkumulation von typischen molekulargenetischen Veränderungen einher, die charakteristische Unterschiede zu der PanIN-PDAC-Sequenz aufweist. So ist beispielsweise die Frequenz der frühen $K R A S$-Mutationen in IPMN niedriger, was für KRAS-unabhängige Karzinomentstehung spricht, wohingegen GNAS1- und RNF43-Mutationen überwiegen (Beger et al. 2013; Esposito et al. 2012). 


\subsection{Krebsmodelle: von der Zellkultur zum Mausmodell}

Zur Erforschung von Krebs bedarf es adäquater Modelle dieser Erkrankung. Mittlerweile gibt es eine Reihe etablierter experimenteller Modelle, die alle ihren Stellenwert in der Krebsforschung haben und mit Vor- und Nachteilen einhergehen. Krebszellen lassen sich mit gut kontrollierten genetischen Veränderungen unter standardisierten Bedingungen mit relativ wenig Aufwand und kostengünstig in der Petrischale kultivieren. Bis heute sind sie von herausragender Bedeutung für die gewonnenen Erkenntnisse zur Krebsentstehung und Therapie. Allerdings stehen neoplastische Zellen in multiplen, zum Teil hochkomplexen Interaktionen mit benachbarten Zell- und Organsystemen. Diese Interaktionen lassen sich durch die standardisierten 2dimensionalen (2-D) Kulturbedingungen nur sehr begrenzt simulieren und viele Beobachtungen sowie daraus gewonnene Erkenntnisse müssen kritisch betrachtet werden (Frese und Tuveson 2007). Gerade das PDAC zeichnet sich durch die enorme Bedeutung der Interaktion von Tumor- und Stromazellen aus. 3D-Kulturen („,organotypic models“) von autonomen Tumorzellen gemeinsam mit Stroma- und Entzündungszellen begegnen dieser Herausforderung, indem sie das Tumormikromilieu zumindest teilweise nachbilden. Im Gegensatz zu Tiermodellen erlauben 3D-Kulturen relativ hohe Durchsatzraten bei leichter Manipulierbarkeit einzelner Zelltypen. Jedoch unterliegen auch sie Limitationen (Coleman et al. 2014). So sind noch immer wichtige Merkmale des PDAC wie die Gesamtheit aller Zelltypen (Immunzellen, Pankreasazinuszellen) nicht repräsentiert und es fehlt an einer Tumorvaskularisation. Auch lassen sich Angiogenese und Metastasierung nicht adäquat simulieren (Frese und Tuveson 2007). Darüber hinaus sind Untersuchungen hinsichtlich der Pharmakokinetik, Toxizität und Metabolisierung von Medikamenten nicht möglich (Gopinathan et al. 2015).

Mausmodelle von Krebserkrankungen spielen eine wichtige Rolle in der Erforschung von Tumorerkrankungen. Sie ermöglichen es, die Entstehung von Krebs und seinen Vorläuferläsionen zu verstehen und die Bedeutung und Auswirkung von häufigen Mutationen funktionell zu rekapitulieren. Weiterhin bieten Mausmodelle die Möglichkeit neue Therapieansätze in präklinischen Phasen in vivo zu erproben und sind damit nach der Zellkultur eine wichtige Etappe zur Vorbereitung klinischer Medikamentenstudien am Menschen.

Mäuse eignen sich aus mehreren Gründen besonders gut als Modellorganismen für menschliche Krankheiten. Sie lassen sich auf kleinem Raum mit relativ geringem Kosten- und Personalaufwand halten und vermehren sich auch unter Laborbedingungen schnell und zuverlässig. Die Labormaus Mus musculus hat große genetische und physiologische Ähnlichkeit zum Menschen und ist genetisch stabil. Das Mäusegenom wurde 2002 vollständig sequenziert und zeigte, dass 99\% der Gene der Maus homologe Entsprechungen im menschlichen Genom haben (Gopinathan et al. 2015; Guenet 2005; Waterston et al. 2002).

Einen Zwischenschritt von der Zellkultur zum transgenen Mausmodell stellen die Xenograftmodelle dar. Diese ermöglichen es menschliches Tumorgewebe oder Zelllinien in Mäuse mit kompromittiertem Immunsystem bei fehlendem Thymus (Nacktmäuse) zu transplantieren und dort Tumorwachstum sowie Therapieansprechen zu beobachten. Die subkutane Einbringung 
des Tumors (heterotop) lässt sich deutlich leichter durchführen und überwachen, während die Transplantation von Zellen oder Tumorgewebe in das Mäusepankreas (orthotop) es ermöglicht ein Tumormikromilieu zu simulieren. Hiermit kommen die Tumoren dem Tumormikromilieu im menschlichen PDAC recht nahe (Richmond und Su 2008) und ermöglichen es Phänomene wie Metastasierung, invasives Wachstum und Neoangiogenese zu beobachten. Verglichen mit transgenen Mausmodellen lassen sich Tumoren in Xenograftmäusen mit deutlich niedrigerem Aufwand und Kosten kultivieren und ermöglichen so höhere Durchsatzraten. So ist es denkbar aus einem Primärtumor (PT) mehrere patientenspezifische Xenograftmäuse zu erzeugen und in diesen das individuelle Ansprechen der Tumoren auf verschiedene Therapieregime zu überprüfen. Dies würde einen Schritt auf dem Weg hin zu einer personalisierten Tumorbehandlung darstellen (Frese und Tuveson 2007). In Studien bietet dieses Modell die Möglichkeit bestimmte Patientenkollektive zu identifizieren und gezielt zu behandeln. Die so identifizierten Patientenkollektive könnten somit von Therapien profitieren, die bei der Gesamtheit der Pankreaskarzinompatienten keinen signifikanten Effekt zeigen (Rubio-Viqueira et al. 2006; Richmond und Su 2008). Dennoch leidet auch dieses Modell unter Unzulänglichkeiten, wie dem Fehlen eines kompetenten Immunsystems und von Blut- und Lymphgefäßen, sowie der reduzierten genetischen Heterogenität des Transplantats gegenüber dem ausgedehnten PT im Menschen. Auch das Tumormikromilieu, welches von großer Bedeutung ist und den Therapieerfolg entscheidend beeinflusst (Feig et al. 2012; Neesse et al. 2015; Rhim et al. 2014), ist meist nur unzureichend und nicht mit seiner vollen Komplexität dargestellt (Frese und Tuveson 2007; Gopinathan et al. 2015). Diese Effekte mögen dazu beigetragen haben, dass Erkenntnisse aus präklinischen Studien sich in frühen klinischen Studien häufig nicht bestätigen ließen (Roberts et al. 2004; Johnson et al. 2001). Frese und Tuveson (2007) betrachten aus diesen Gründen Xenograftmodelle nicht als Mauskrebsmodelle im klassischen Sinne und schlagen die Bezeichnung „Tierkultur“ für diesen Zwischenschritt vor.

\subsection{Das KPC-Modell}

Mittlerweile steht eine Reihe verschiedener, zunehmend komplexerer Modelle mit unterschiedlichen Ansätzen zur Verfügung, die es ermöglichen, sehr spezifische genetische Veränderungen in einem lebenden Organismus zu unterschiedlichen Zeitpunkten der Organogenese zu simulieren. Dies ermöglicht es, den Einfluss dieser Mutationen auf Morbidität und Mortalität zu untersuchen und zielgerichtete Behandlungen zu erproben (Frese und Tuveson 2007).

Transgene Mausmodelle stellen die am weitesten entwickelten Krebsmodelle dar und werden vielfältig eingesetzt, um endogen Tumoren in verschiedenen Organen zu induzieren und in der Folge die Interaktion von Tumorzellen mit dem physiologischen Mikromilieu zu erforschen. Sie werden erzeugt, indem Mutationen in bekannte oder mutmaßliche (Proto-)Onkogene oder TSG eingefügt werden. Da die Wirkung der veränderten Gene (Transgene) zumeist nur in einzelnen Organen wie zum Beispiel im Pankreas untersucht werden soll, bedarf es Strategien, um die Expression der Onko- und Tumorsuppressorgene gewebespezifisch konditional zu aktivieren oder zu inaktivieren. 
Zunächst werden spezifische Rekombinasen an Promotorregionen von Transkriptionsfaktoren gekoppelt, die in der Embryonalentwicklung nach Möglichkeit ausschließlich in dem jeweiligen Gewebe aktiviert werden (Grindley et al. 2006). Für die Modelle des PDAC wurden die zwei Gene P48/PTF1 und PDX-1/IPF1 identifiziert, welche an den (Embryonal-)Tagen 8 und 9 in allen Pankreasprogenitorzellen exprimiert werden und für eine Entwicklung hin zu Pankreaszellen von entscheidender Bedeutung sind. Homozygote Deletionen sind bereits embryonal letal (PDX-1) oder aufgrund eines fehlenden Pankreas nicht dauerhaft lebensfähig (P48), weshalb nur ein Allel zum Transgen aus Promotorregion und den Exonbereichen der spezifischen Rekombinasen verändert wird (Hingorani et al. 2003; Hingorani et al. 2005). Allerdings sind beide Gene nicht nur im embryonalen Pankreas sondern auch im entstehenden Duodenum und Magen sowie anderen Geweben exprimiert und können bei genetischer Manipulation auch zu unerwünschten Auswirkungen in anderen Organen führen (Gades et al. 2008; Kawaguchi et al. 2002; Hingorani et al. 2005; Kim und MacDonald 2002). Auch scheint PDX-1 nach einem stochastischen Muster als Mosaik über das Pankreas verteilt exprimiert zu sein, wohingegen P48 gleichmäßig über das ganze Organ exprimiert wird (Hingorani et al. 2003; Kawaguchi et al. 2002).

Bei den spezifischen Rekombinasen handelt es sich in den meisten Modellen um die Cre-Rekombinase (Cre), ein $38 \mathrm{kDa}$ (Kilodalton)-Protein, welches ursprünglich aus der Bakteriophage P1 stammt (van Duyne 2001). Cre wird im Rahmen des Cre-LoxP-Systems vielfältig in der genetischen Modifikation von Zellen und Organismen eingesetzt und führt an DNA-Regionen, welche von zwei LoxP-Regionen flankiert werden, zu Deletionen, Inversionen oder Translokation. Die 34 Basenpaare (bp) umfassende LoxP-Regionen bestehen aus zwei je 14 bp großen palindromischen Sequenzen, als Rekombinase-bindende Elemente (RBE) bezeichnet, und einer dazwischenliegenden asymmetrischen 6 bp großen Crossover-Region. Bei Expression der CreRekombinase binden diese Proteine an beide RBE der beiden LoxP-Regionen und vermitteln das Schneiden und Rekombinieren der freien Strangenden, ähnlich einer Topoisomerase I. Je nach Ausrichtung der beiden LoxP-Regionen kommt es unter Verbleib einer einzelnen LoxPRegion zu einer Exzision und damit Deletion oder zu einer Inversion der flankierten Region (van Duyne 2001; Hingorani et al. 2003; Grindley et al. 2006).

In den meisten Fällen handelt es sich bei der LoxP-flankierten Region um eine Stopp-Kassette, welche zwischen Promotor und dem ersten Exon des veränderten bzw. zu untersuchenden Gens/Allels eingebracht wurde. Es resultiert eine Lox-Stopp-Lox(LSL)-Struktur in dem veränderten Allel. Diese Stopp-Kassette führt dazu, dass das betreffende Gen in Abwesenheit von Cre, wie in allen extrapankreatischen Zellen, nicht transkribiert wird und es resultiert ein $\mathrm{Zu}$ stand funktioneller Heterozygotie (Hingorani et al. 2005; Hingorani et al. 2003). In allen exokrinen pankreatischen Zellen wurde Cre durch Kopplung an einen der beiden Promotoren (z. B. $P d x$-1-Cre) embryonal exprimiert und führte zur Deletion des Stopp-Signals, welches zuvor die Expression des Transgens unterdrückt hatte. Die Mutation entfaltet ihre Wirkung nun gewebespezifisch und führt zur Entstehung von Karzinomen im Pankreas. 
Neben dem Cre-LoxP-System gibt es weitere Rekombinationssysteme wie beispielsweise das flp-FRT dual recombinase System oder Tetrazyklin-, Doxyzyklin- und Tamoxifen-induzierbare Systeme. Diese ermöglichen es, neben der örtlichen Expression auch den Expressionszeitpunkt des Transgens zu beeinflussen (Frese und Tuveson 2007; Guerra et al. 2007; Neesse et al. 2015) und die Expression von Onkogenen ein- und abzuschalten (Collins et al. 2012). Auch mittels CRISPR/Cas-System und Cre-exprimierender lentiviraler Vektoren lassen sich PDAC induzieren (Chiou et al. 2015). Alle diese Systeme stellen Erweiterungen und Ergänzungen dar, um maßgeschneiderte Krebsmodelle in der Maus zu erzeugen, mit dem Ziel die Entstehung, Progression und Heterogenität menschlicher Pankreastumoren möglichst wirklichkeitsgetreu abzubilden.

Für das PDAC existiert mittlerweile eine große Vielfalt an transgenen Mausmodellen mit unterschiedlichen Mutationen, die sich in grundlegenden Eigenschaften wie Zeitpunkt der Tumorentstehung, Ausbildung von PanINs und anderen präneoplastischen Läsionen, Überlebensdauer, Histologie und Metastasierungsmuster teils deutlich unterscheiden und bei speziellen Fragestellungen eingesetzt werden können (Gopinathan et al. 2015; Frese und Tuveson 2007). Das am weitesten verwendete Modell ist das LSL- $\underline{\operatorname{Kras}}{ }^{\mathrm{G} 12 \mathrm{D} /+} ; \mathrm{LSL}-\mathrm{Tr} \underline{\mathbf{p}} 53^{\mathrm{R} 172 \mathrm{H} /+} ; \mathrm{Pdx}-1-\underline{\mathbf{C}}$ re (KPC)Modell, welches 2005 von Hingorani et al. entwickelt wurde (Hingorani et al. 2005). In diesem Modell wird konditional unter Kontrolle des pankreasspezifischen Promotors PDX-1 die CreRekombinase exprimiert, welche zur Deletion zweier LoxP-flankierter Stopp-Kassetten führt, die zuvor die Expression des Onkogens $K R A S^{G 12 D}$ und des mutierten TSG Trp5 $3^{R 172 H}$ inhibiert haben (vgl. Abbildung 2). Beide Transgene sind ab dem Zeitpunkt der Cre-Expression, dem 8,5. Tag der Embryonalentwicklung, in einem Mosaik der exokrinen Pankreaszellen aktiv und führen mit fast 100\%iger Penetranz innerhalb von wenigen Monaten zur Entwicklung von invasiven und metastatischen PDAC in der Maus (Hingorani et al. 2005).
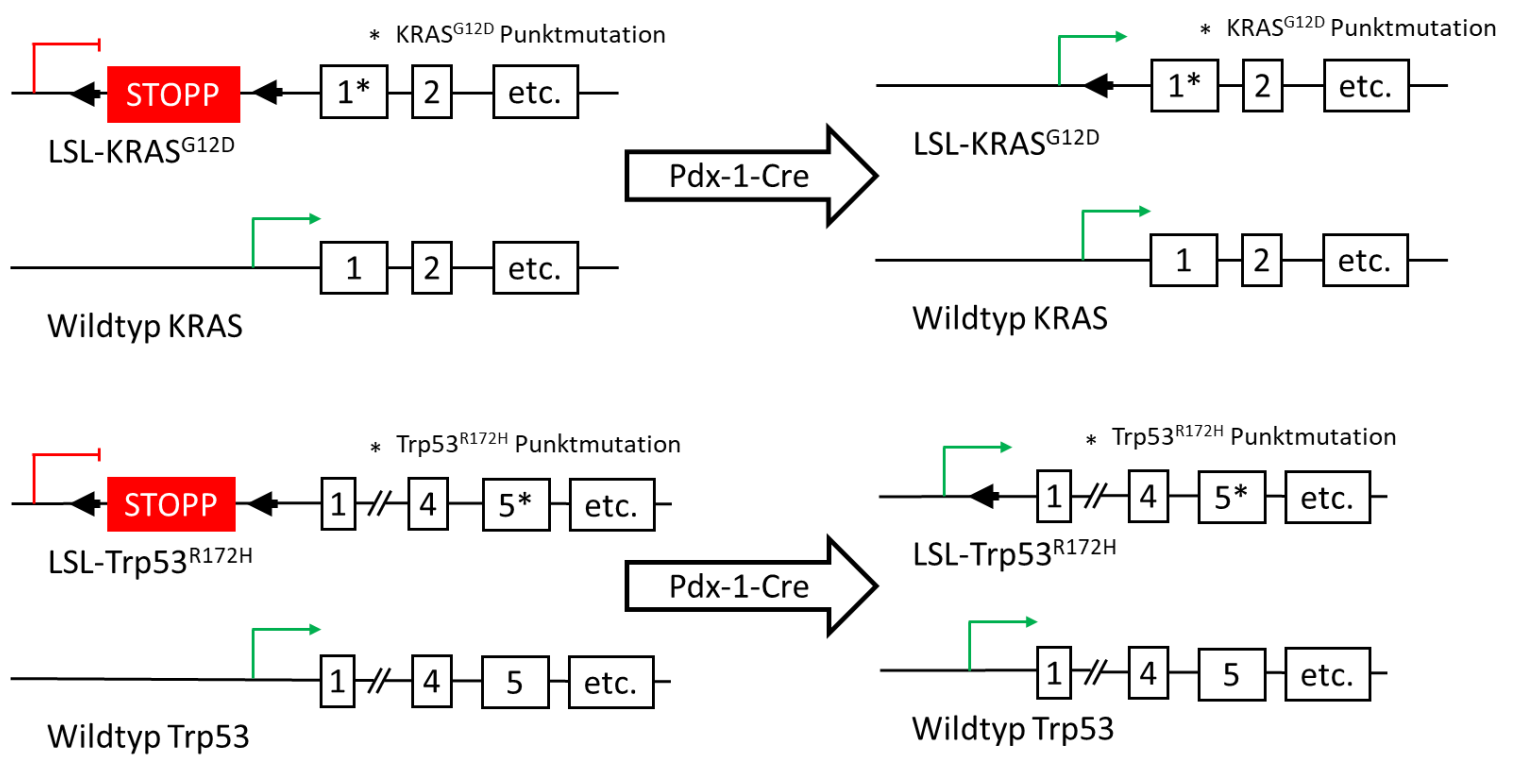

\section{Abbildung 2: Genetischer Hintergrund des KPC-Modells}

Allele mit den Punktmutationen KRASG12D und Trp53R172H wurden heterozygot in Codon 1 (KRAS) und Codon 5 (Trp53) eingefügt. Diesen vorgeschaltet ist jeweils ein Stoppcodon, welches von zwei LoxP- 
Regionen ( dazu, dass nur die Wildtypallele (grüner Pfeil), nicht jedoch die mutierten Allele (roter Stopppfeil) abgelesen werden. Die Mäuse sind in dieser Phase funktionell heterozygot für das KRAS-Wildtyp-Allel $\left(K R A S^{+/-}\right)$sowie das Trp53-Wildtyp-Allel (Trp53+/). Ab Tag 9 wird unter Einfluss von Pdx-1 die CreRecombinase exprimiert (siehe Pfeil), die jeweils das Stoppcodon sowie eine LoxP-Region herausschneidet und die Strangenden zusammenfügt. Die beiden Allele mit endogenen Punktmutationen werden nun ebenfalls abgelesen (grüne Pfeile), woraus ein heterozygot mutierter Zustand für $K R A S\left(\mathrm{Kras}^{\mathrm{G} 12 \mathrm{D} /+}\right)$ und $\operatorname{Trp} 53\left(\operatorname{Trp} 53^{\mathrm{R} 172 \mathrm{H} /+}\right)$ resultiert. Abbildung modifiziert nach Hingorani et al. 2005.

Von dem Protoonkogen KRAS ist bekannt, dass es in über 90\% der sporadischen Fälle von PDAC Punktmutationen im Codon 12 trägt und von entscheidender Bedeutung für Initiation, Progression und Erhalt des PDAC ist (Almoguera et al. 1988; Collins et al. 2012; Feldmann und Maitra 2008). Bei der häufigsten Punktmutation $K R A S^{G 12 D}$ sind nach Substitution von Glycin durch Asparaginsäure sowohl die intrinsische als auch die extrinsische GTPase-Funktion des KRAS-Proteins verloren gegangen. Dies führt zu einer anhaltenden (Protein-)Aktivität, welche einen dauerhaften Proliferationsstimulus auf die Zelle darstellt (Feldmann und Maitra 2008; Hingorani et al. 2003). Das Onkogen KRAS ist allein zumeist nicht ausreichend für die Entstehung von PDAC und bedarf weiterer Mutationen in Tumorsuppressorgenen wie beispielsweise CDKN2/INK4A, TRP53, SMAD oder BRCA2 (Hingorani et al. 2003; Neesse et al. 2015; Gopinathan et al. 2015; Aguirre et al. 2003). So entwickeln Mäuse, die konditional nur eine Mutation im KRAS tragen, zwar das volle Spektrum an PanINs aber nur mit unvollständiger Penetranz und erst nach langer Latenz auch invasive PDAC (Hingorani et al. 2003; Hingorani et al. 2005).

Das Protein p53 fungiert als Tumorsuppressor und ist an über 50\% aller Krebserkrankungen beteiligt, weswegen es den Beinamen „Wächter des Genoms“ trägt (Rassow et al. 2008). In menschlichen PDAC findet sich dieses TSG in 50-75\% der Fälle mutiert (Perez-Mancera et al. 2012). Am häufigsten findet sich eine Punktmutation im Codon 175, welcher die Punktmutation $\operatorname{Trp} 53^{\mathrm{R} 172 \mathrm{H}}$ in der Maus entspricht (Olive et al. 2004; Olivier et al. 2002). Diese inaktivierende Mutation wird auch im KPC-Modell verwendet und beschleunigt das Entstehen von invasiven und metastatischen PDAC deutlich im Vergleich zu Modellen ohne Trp5 $3^{\mathrm{R} 172 \mathrm{H}}$-Mutation (Hingorani et al. 2005). Im physiologischen Zustand wird p53 in allen Zellen auf gleichmäßig niedrigem Niveau gebildet, ubiquitinyliert und abgebaut. Bei Schäden der DNA wird p53 durch Proteinkinasen stabilisiert und führt als Transkriptionsfaktor je nach Konzentration zum Zellzyklusarrest oder zur Apoptose und bewahrt somit die Zelle vor der Akkumulation weiterer Mutationen und ungehemmter Proliferation (Rassow et al. 2008). Zusätzlich wird der Trp53Mutation auch ein dominant negativer Effekt zugeschrieben (Hingorani et al. 2005), indem sie mit einer strukturellen chromosomalen Instabilität (CIN) einhergeht. Diese strukturelle CIN geht über die numerische CIN hinaus, die bei homozygotem Verlust von $\operatorname{Tr} 55^{(--)} \mathrm{zu}$ beobachten ist. Im Kontext autonom proliferierender Zellgruppen und der durch Trp5 $53^{\mathrm{R} 172 \mathrm{H}}$ bedingten CIN kommt es stochastisch in einzelnen Zellen zum Verlust des verbleibenden Wildtyp-Allels $\left(\operatorname{Tr} 55^{\mathrm{R} 172 \mathrm{H} /}\right)$, was als Verlust der Heterozygotie bezeichnet wird. Dies verstärkt 
die CIN deutlich, und es kommt mit Translokationen und Deletionen zu weiteren Mutationen, die die Tumorentstehung vorantreiben (Hingorani et al. 2005).

Das KPC-Modell wird sehr häufig für In-vivo-Experimente von PDAC genutzt, da es besonders gut viele der Eigenschaften des menschlichen PDAC imitiert. KPC-Mäuse beginnen nach circa zweieinhalb Monaten erste Krankheitssymptome wie Kachexie, hämorrhagischen Aszites und palpable abdominelle Tumoren zu entwickeln. Bei der Gewebeentnahme nach durchschnittlicher Überlebenszeit von 5 Monaten findet sich ein fibrotischer, fester Pankreaskopftumor häufig mit begleitender Cholestase. Weiterhin metastasieren PDAC von KPC-Mäusen häufig in die Leber, seltener in die Lunge. Damit bilden sie das Metastasierungsmuster menschlicher Tumoren gut ab. KPC-Tumoren durchlaufen bei ihrer Entstehung das volle Spektrum an präinvasiven pankreatischen Vorläuferläsionen in Analogie zum menschlichen Tumor. Histologisch zeigt sich das Bild desmoplastischer Tumoren, in denen das Tumormikromilieu insgesamt sehr gut rekapituliert wird (Hingorani et al. 2005). Auch Vaskularisation und Perfusion sind im KPCModell übereinstimmend niedrig (Olive et al. 2009). Die große histomorphologische und molekulargenetische Ähnlichkeit der Maustumoren mit dem humanen Pankreaskarzinom machen das KPC-Modell zu einem unschätzbaren Instrument in der Erforschung des Tumorstromas und der Entwicklung von neuen Therapieansätzen.

\subsection{Stroma im Pankreaskarzinom: das Tumormikromilieu}

Das PDAC präsentiert sich intraoperativ als ein weißlich-gelber, fester und bindegewebiger Tumor. Unter dem Mikroskop zeigt sich, dass eine desmoplastische Stromareaktion über $90 \%$ der Tumormasse ausmacht und das histologische Bild gegenüber den eptithelialen Tumorzellen klar dominiert. In diesem Ausmaß unterscheidet das Tumorstroma das PDAC von vielen soliden Tumoren.
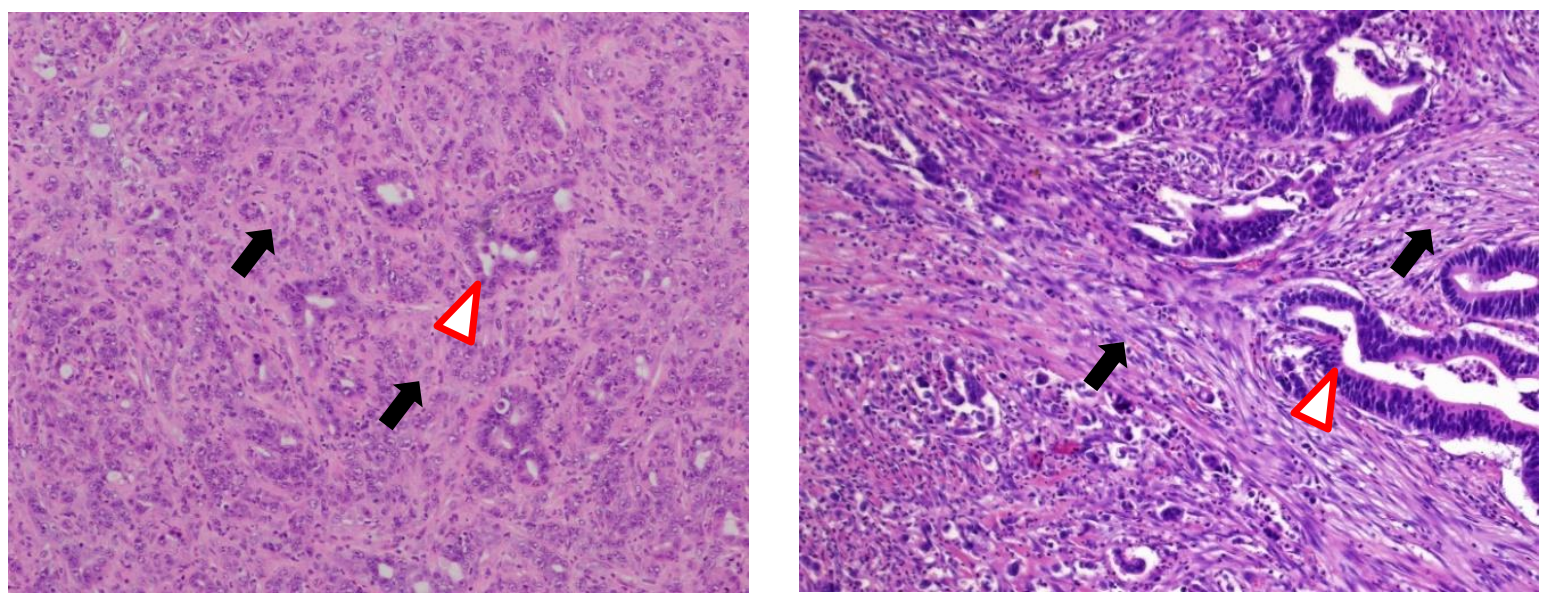

\section{Abbildung 3: Hämatoxilin-Eosin-Färbungen von murinem und humanem Pankreas- karzinom}

Gegenüberstellung von murinem (links) und humanem (rechts) Pankreaskarzinomgewebe in der HEFärbung. Der murine KPC-Tumor (links) ist mäßig differenziert (G2) und weist eine mäßiggradige Desmoplasie (D2) auf. Neben einigen höhergradigen PanINs (weiße Pfleilspitze mit roter Umrandung) 
sind Areale mit invasivem PDAC und einer umgebenden desmoplastischen Begleitreaktion (schwarze Pfleile) zu sehen. Im humanen Tumor (rechts) sind neben PanIN-3-Läsionen (weiße Pfleilspitze mit roter Umrandung) Areale mit invasivem Karzinom (schwarze Pfleile) zu sehen. Die desmoplastische Begleitreaktion ist ausgeprägter als im murinen Tumor und bildet um PanINs und invasives PDAC ausladende fibröse Septen.

Lange Zeit wurde das Stroma im PDAC nur als einfache Begleitreaktion auf die neoplastischen Zellen betrachtet. In den letzten Jahren ist es aber zu einem Paradigmenwechsel gekommen, da vielfältige Forschungsergebnisse nahelegen, dass das Tumorstroma aktiv in vielfältige pathophysiologische Prozesse der Tumorentstehung, Progression, Invasivität und Metastasierung eingreift und möglicherweise auch die Therapieresistenz der Pankreastumoren beeinflusst. Es wurde erkannt, dass nicht nur die Pankreaskarzinomzellen über multiple dysregulierte Signaltransduktionsmechanismen parakrin die Bildung und das Remodelling des Stromas steuern, sondern Fibroblasten, Immunzellen und andere zelluläre Komponenten des Stromas ihrerseits Wachstumsfaktoren, Interleukine und Matrix-Metalloproteasen (MMPs) sezernieren und somit parakrin auf Pankreaskarzinomzellen, andere Stromazellen und sich selbst wirken (Feig et al. 2012; Stromnes et al. 2014; Neesse et al. 2011; Bennewith et al. 2009). Dieses Phänomen wird auch treffend als Tumor-Stroma-Interaktion bezeichnet. Die Gesamtheit des Tumorstromas wird auch als Tumormikromilieu bezeichnet. Die Rolle des Tumormikromilieus ist jedoch komplex und bisher nicht ausreichend erforscht. Es existieren viele Daten, die darauf hindeuten, dass einzelne stromale Bestandteile Invasivität, Metastasierung und Wachstum des PDAC fördern. Gleichzeitig sind in letzter Zeit auch Studien veröffentlicht worden, in denen es unerwarteterweise unter gezielter Depletierung großer Teile des Stromas zur Ausbildung aggressiverer und schneller wachsender Tumoren kam. Dies legt nahe, dass das Tumorstroma sowohl fördernd als auch stabilisierend und hemmend auf den Tumor wirkt (Rhim et al. 2014; Özdemir et al. 2014; Cheng et al. 2013; Whatcott et al. 2015; Olive et al. 2009, 2009; Jacobetz et al. 2013; Neesse et al. 2015).

Durch die vielfältigen biochemischen und zellulären Interaktionsprozesse zwischen Immunzellen, aktivierten Fibroblasten und Tumorzellen wird eine profibrotische Entzündungsreaktion dauerhaft induziert. Interessanterweise lassen sich viele histomorphologische und molekulare Veränderungen, die im Stroma des PDAC gefunden werden können, auch im Kontext von Pankreatitis und Wundheilung nachweisen. In der Tat kann eine chronische Pankreatitis die Entstehung eines Pankreaskarzinoms begünstigen. Im Mausmodell kann eine artifiziell induzierte Entzündungsreaktion im Kontext einer KRAS-Mutation die Tumorentstehung im Pankreas beschleunigen (Guerra et al. 2007). Diesen Umstand bringt schon Dvoraks Aussage von vor gut über 30 Jahren zum Ausdruck, dass stromareiche Tumoren ,als eine Wunde, die nicht heile“ zu verstehen seien (Dvorak 1986; Chu et al. 2007; Sherman et al. 2014). 


\subsubsection{Zelluläre Komponenten des Tumormikromilieus}

Auf den ersten Blick lässt sich erkennen, dass das Tumorstroma keineswegs eine homogene Masse ist, sondern sich aus diversen Zelltypen und einer komplexen Extrazellulärmatrix (EZM) sowie löslichen Zytokinen und Wachstumsfaktoren zusammensetzt.

$\mathrm{Zu}$ den dominierenden Zellen gehören aktivierte Pankreassternzellen (PSC) sowie zahlreiche Immunzellen.

Aktivierte, sich in direkter Umgebung des Tumors befindende Fibroblasten, auch krebsassoziierte Fibroblasten (CAFs, engl. cancer associated fibroblasts) genannt, stellen eine heterogene Gruppe von Zellen dar, die sich aus verschiedenen Fibroblastenpopulationen rekrutiert. Ein relevanter Anteil der CAFs geht aus aktivierten Pankreassternzellen (PSCs, engl. pancreatic stellate cells) hervor, es werden jedoch auch mesenchymale Stammzellen aus dem Knochenmark rekrutiert, die sich anschließend zu CAFs differenzieren können (Mathew et al. 2016). Aktivierte PSCs findet man sowohl im PDAC als auch in entzündlichen Prozessen des Pankreas. Durch die Interaktion mit neoplastischen Zellen wird aus der aktivierten PSC ein CAF. Eine genaue Definition von CAFs ist jedoch bisher nicht vorhanden und die meisten zellulären Marker für CAFs sind auch in aktivierten PSCs exprimiert. PSCs wurden erstmals 1998 von Apte und Bachem als Vitamin-Aspeichernde Zellen beschrieben (Apte et al. 1998; Bachem et al. 1998). Im gesunden Pankreas machen die PSCs 4-7\% aller Zellen aus und speichern intrazellulär Vitamin A. Im Rahmen der Aktivierung durch Entzündungsmediatoren und Wachstumsfaktoren wie den transformierenden Wachstumsfaktor $\beta$ (TGF $\beta$, engl. transforming growth factor), Fibroblasten-Wachstumsfaktor (FGF, engl. fibroblast growth factor), Plättchen-Wachstumsfaktor (PDGF, engl. platelet derived growth factor), Bindegewebe-Wachstumsfaktor (CTGF, engl. connective tissue growth factor) und Hepatozyten-Wachstumsfaktor (HGF, engl. hepatocyte growth factor) verändern sich die PSC hin zu einem sternförmigen Phänotyp unter Verlust der Fetttröpfchen. Aktivierte PSCs exprimieren $\alpha$ smooth muscle actin ( $\alpha$-SMA) und sezernieren in großer Menge eine ganze Reihe von Proteinen der EZM wie Fibronektin, Laminin, Kollagen I, Kollagen III und MMPs (Bachem et al. 1998; Apte et al. 1998; Omary et al. 2007; Coleman et al. 2014; Neesse et al. 2011; Saotome et al. 1997). Weiterhin sezernieren sie Wachstumsfaktoren (PDGF, FGF) und Zytokine (IL-1, IL-6, Tumornekrosefaktor- $\alpha$ ), die autokrin wirkend den aktivierten Zustand aufrechterhalten und parakrin wirkend die Tumorprogression antreiben (Mahadevan und von Hoff 2007). Co-Kulturen von Pankreaskarzinomzellen und PSCs haben gezeigt, dass die Anwesenheit von PSCs oder konditionierten Medien zu niedrigeren Apoptoseraten, höheren Proliferationsraten und einer verbesserten Migration von Tumorzellen führen. PSCs proliferieren gleichfalls unter konditionierten Medien von Tumorzellen stärker und sezernieren mehr EZM-Proteine (Vonlaufen et al. 2008; Bachem et al. 2005). Diese Ergebnisse bestätigten sich für die orthotope Co-Injektion von Pankreaskarzinomzellen und PSCs, welche zu schnellerem Tumorwachstum und vermehrter Metastasierung sowie verstärkter Angiogenese führte (Vonlaufen et al. 2008). Außerdem konnte gezeigt werden, dass PSCs gemeinsam mit Pankreaskarzinomzellen migrieren und ebenfalls in Metastasen nachweisbar sind (Vonlaufen et al. 2008; Xu et al. 2010). 
Mehrere Studien deuten darauf hin, dass PSCs entscheidend dazu beitragen Stammzelleigenschaften in Pankreaskarzinomzellen auszubilden und so die Progression und Rezidivbildung zu befördern (Simeone und Maitra 2013; Hamada et al. 2012; Magee et al. 2012). Die genetische Abschaltung von aktivierten CAFs in transgenen Mausmodellen führte allerdings zur vermehrten Expression von Stammzellmarkern und Ausbildung höchst invasiver Karzinome, weswegen die Rolle von CAFs hier nicht endgültig geklärt ist (Özdemir et al. 2014).

Immunzellen stellen knapp die Hälfte aller Zellen im PDAC dar, womit ihnen eine wichtige Rolle im Tumormikromilieu zukommt (Clark et al. 2007). Das PDAC schafft es sich einer Kontrolle durch das Immunsystem zu entziehen, indem es die Immunantwort so steuert und umprogrammiert, dass supprimierende Immunzellen, wie regulierende T-Zellen und myeloische Suppressorzellen, zur Unterdrückung einer adäquaten Immunantwort durch zytotoxische TZellen führen. Auch tragen diese Zellen aktiv zur Tumorprogression bei. Zu dieser Immunsuppression tragen auch CAFs ganz entscheidend bei und eine zuvor ineffektive Immuntherapie kann durch Fibroblastendepletion ihre Wirkung entfalten (Feig et al. 2012; Neesse et al. 2015; Feig et al. 2013).

\subsubsection{Extrazelluläre Komponenten des Tumormikromilieus}

Neben den zellulären Komponenten besteht das Tumormikromilieu auch aus extrazellulären Komponenten wie Kollagen, Hyaluronsäure (HA, engl. hyaluronic acid), Proteoglykanen und Fibronektin sowie löslichen Mediatorsubstanzen und Proteinasen.

Hyaluronsäuren sind unverzweigte, langkettige Glykosaminoglykane, bestehend aus mehreren Tausend Disacchariden, die durch ihre biochemische Struktur in der Lage sind große Mengen Wasser zu binden und dadurch einen hohen interstitiellen Flüssigkeitsdruck zu erzeugen. Unter allen Molekülen der EZM wird HA die entscheidende Rolle bei der Erzeugung des überaus hohen Gewebedrucks im PDAC und der damit einhergehenden stark reduzierten Durchblutung zugesprochen (Provenzano et al. 2012; Jacobetz et al. 2013). Über Rezeptoren wie CD44 und CD168/RHAMM (Hyaluronan-mediated motility receptor) vermögen HA Signalwirkung auf andere Zellen auszuüben und sind in diversen Karzinomen mit Angiogenese, Chemoresistenz und Metastasierung assoziiert (Toole und Slomiany 2008; Sironen et al. 2011; Jacobetz et al. 2013). In menschlichen PDAC ist das Vorkommen von HA negativ mit dem Überleben korreliert (Cheng et al. 2013; Whatcott et al. 2015). Auch die am Auf- und Abbau der HA beteiligten Hyaluronsäuresynthetasen und Hyaluronidasen sind vielfältig regulierte Enzyme, die über Steuerung der Zusammensetzung der EZM am Stromaumbau aktiv beteiligt sind und zum Teil mitverkürztem Überleben einhergehen (Cheng et al. 2013). 

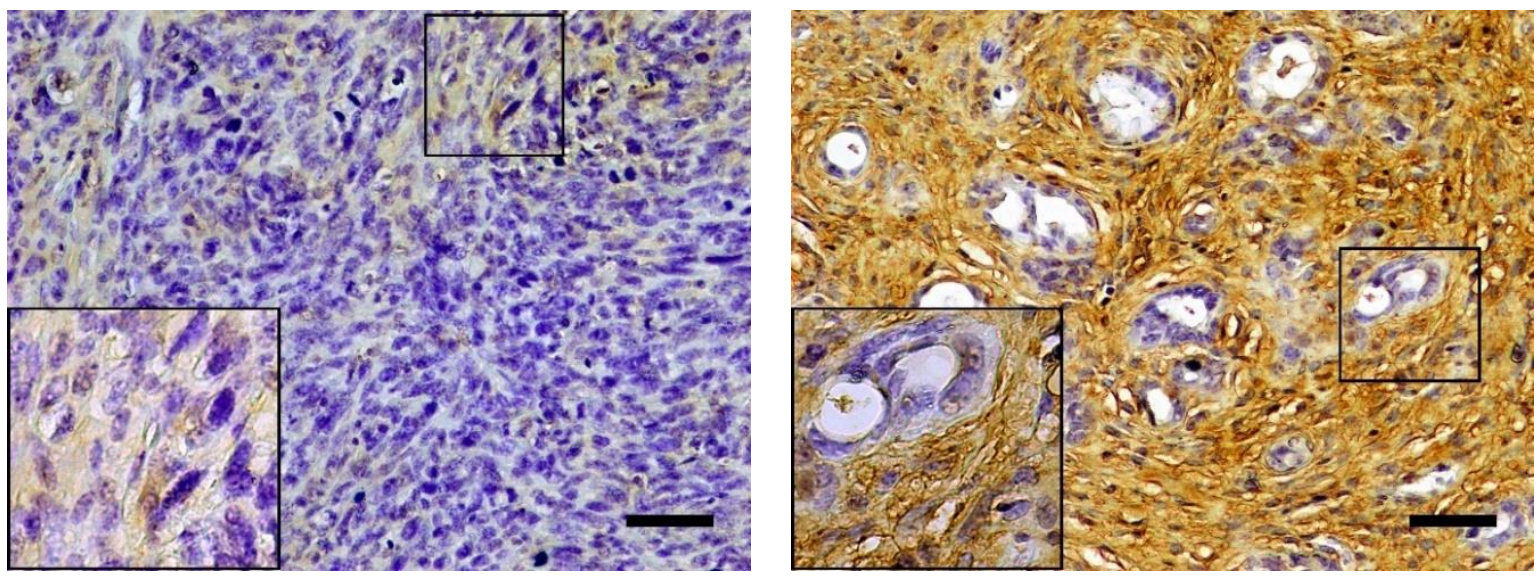

Abbildung 4: Hyaluronsäurefärbung zur Bestimmung des Hyaluronsäuregehalts

Gegenüberstellung von KPC-Tumoren mit niedriger (links) und hoher HA-Expression (rechts). Maßstab $50 \mu \mathrm{m}$.

Kollagen ist das häufigste Protein im menschlichen Körper. Es können rund 20 Kollagentypen unterschieden werden, die vielfältigste physiologische und pathophysiologische Funktionen wahrnehmen. Im gesunden Pankreas ist Kollagen (Typ IV) am Aufbau der Basalmembran beteiligt, wird sonst aber kaum exprimiert. Dies steht in klarem Kontrast zu der überschießenden Kollagensekretion im invasiven PDAC (Imamura et al. 1995). Neben HA tragen auch Kollagenfibrillen zur Erzeugung des interstitiellen Flüssigkeitsdrucks bei. Hierbei wirken Kollagenfibrillen synergistisch mit HA (Chauhan et al. 2013). Im PDAC wird Kollagen fast ausschließlich von Stromazellen exprimiert, allerdings unterscheidet sich das Kollagen in Tumoren von physiologisch synthetisiertem Kollagen. So sind „Tumorkollagenfibrillen“ linearisiert und häufiger quervernetzt. Die veränderte Fibrillenkonformation führt zu solideren Tumoren und veränderter Genexpression und Proliferation (Egeblad et al. 2010). Wie HA kann auch Kollagen als Signalmolekül wirken, indem es an Transmembranproteine wie Integrine bindet und so intrazelluläre Signalkaskaden auslöst (Moffitt et al. 2015; Stromnes et al. 2014).

Das secreted protein acidic and $\underline{\text { rich }}$ in cysteine (SPARC, auch Osteonectin) ist ein Protein, das an vielfältigen physiologischen Funktionen wie Embryonalentwicklung, Zellmigration, Wundheilung, Angiogenese, Zelldifferenzierung und Apoptose beteiligt ist und im gesunden Pankreasgewebe kaum exprimiert wird. In zahlreichen menschlichen Tumorentitäten sind für SPARC unterschiedliche und zum Teil gegensätzliche prognostische Bedeutungen bezüglich Überleben beobachtet worden (Vaz et al. 2015). Auch im PDAC wurde SPARC eine wichtige Rolle bei der Tumorinitiation, Progression, Zellmigration, Adhäsion, Metastasierung, Angiogenese, Proliferation und Umbau der EZM zugeschrieben. Im PDAC wird SPARC neben den Tumorzellen vornehmlich von CAFs exprimiert. SPARC kann in drei Strukturdomänen unterteilt werden und entfaltet über diese sowohl pro- als auch antitumorigene Effekte im PDAC (Kaleağasığlu und Berger 2014). Zwar gibt es keine klassischen SPARC-Rezeptoren, jedoch wurde für SPARC eine unüberschaubare Fülle von hemmenden und fördernden Einflüssen auf Signalwege von Wachstumsfaktoren wie TGF- $\beta 1$, VEGF und PDGF, Signalkaskaden wie 
Ras/Raf/MEK und NF- $x$ B sowie MMPs beschrieben (Vaz et al. 2015; Kaleağasioğlu und Berger 2014). Die meisten Expressionsstudien haben gezeigt, dass SPARC negativ mit dem Überleben und dem Therapieansprechen von operierten PDAC Patienten korreliert (Infante et al. 2007; Mantoni et al. 2008; Sinn et al. 2014; Kaleağasığlu und Berger 2014).
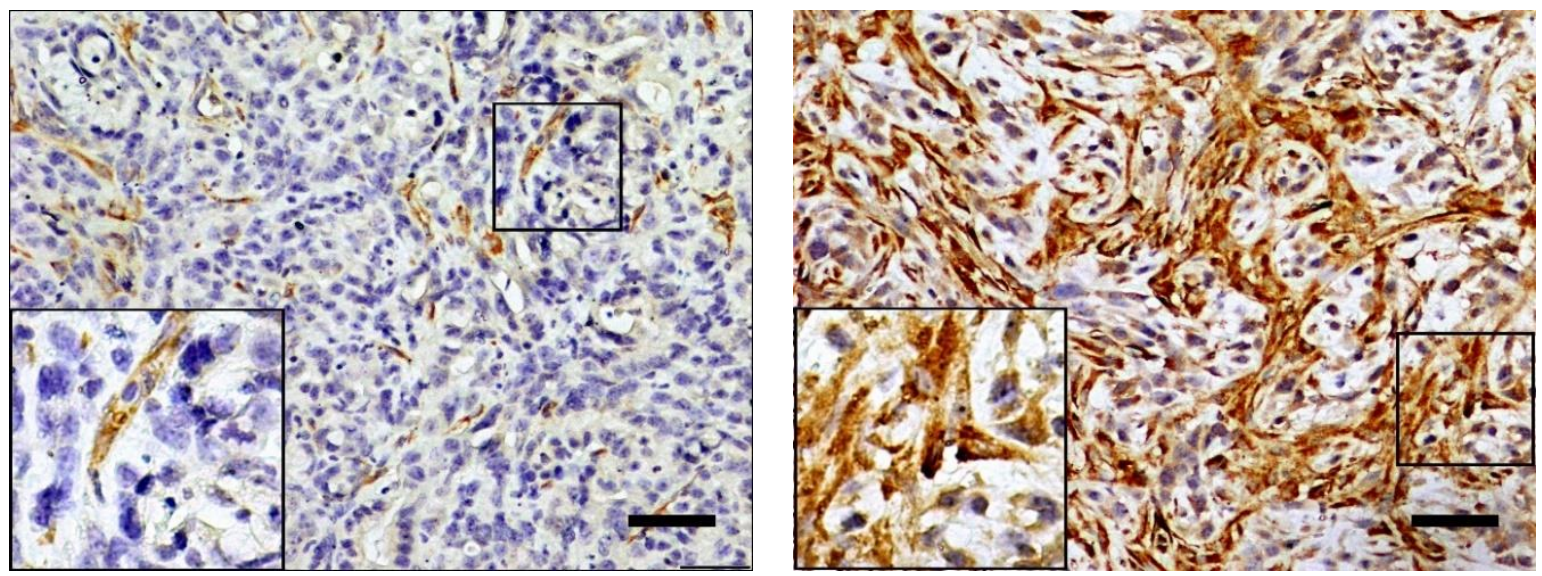

\section{Abbildung 5: SPARC-Immunhistochemie zur Bestimmung der SPARC-Expression}

Gegenüberstellung von KPC-Tumoren mit niedriger (links) und hoher SPARC-positiver Fläche (rechts). Maßstab $50 \mu \mathrm{m}$.

Die EZM macht das Pankreaskarzinom zu einem physikalisch sehr festen und schwer durchdringlichen Maschenwerk, in welches Stromazellen, Gefäße und Pankreaskarzinomzellen eingebettet sind. Trotz seiner Rigidität kann die EZM keineswegs als starres Gebilde betrachtet werden, sondern ist ein sich ständig wandelndes Konstrukt, welches hochkomplexen Umbauprozessen unterworfen ist (Neesse et al. 2015; Feig et al. 2012). Überexprimierte Signalkaskaden und die Akkumulation von diversen Wachstumsfaktoren führen zu dynamischen Veränderungen der sezernierten Proteine. Der Umbau der EZM wird entscheidend von MMPs geprägt, einer Familie von proteolytischen Enzymen, die mit einem zentralen Zink-Ion vielfältige Bestandteile der EZM abbauen können und so Invasivität, Migration und Metastasierung von Tumorzellen steigern. Neben Immunzellen und Pankreaskarzinomzellen werden die MMPs hauptsächlich von PSCs und CAFs sezerniert (Neesse et al. 2011; Feig et al. 2012; Chu et al. 2007). Im PDAC nehmen die beiden hochexprimierten Gelatinasen MMP-2 und MMP-9 eine wichtige Rolle ein. Sie hydrolysieren und spalten speziell das Kollagen IV, einen wichtigen Bestandteil der Basalmembran. Dadurch fördern sie die Invasivität der Pankreaskarzinomzellen und die Progression der Erkrankung (Jones et al. 1999; Chu et al. 2007; Ellenrieder et al. 2000). MMPs unterliegen komplexen Regulationsmechanismen durch Gewebeinhibitoren und Stimulatoren der MMPs und sind noch immer unzureichend verstanden (Neesse et al. 2011; Chu et al. 2007). Im Rahmen der Um- und Abbauprozesse entstehen vielfältige Spaltprodukte von Kollagenen, Proteoglykanen und Hyaluronsäuren, die durch Signalwirkungen auf andere Stromazellen und Pankreaskarzinomzellen stimulatorische und pro-angiogene Effekte entfalten können (Chu et al. 2007). 


\subsubsection{Das Stroma als Zielstruktur für neue Therapieansätze}

Ein klassisches Erklärungsmodell für das Versagen vieler Chemotherapien im PDAC ist das Tumorstroma, welches möglicherweise durch die ausgeprägte Hypovaskularität eine biophysikalische Barriere errichtet. Proteine der EZM wie, HA und Kollagen, erzeugen zudem einen hohen interstitiellen Flüssigkeitsdruck, der die Blutgefäße komprimiert und das Anfluten von Therapeutika kompromittiert (Olive et al. 2009; Jacobetz et al. 2013; Provenzano et al. 2012). In der Kombination aus Hypoperfusion und Hypovaskularisation resultieren niedrige Medikamentenkonzentrationen und ein hypoxisches Tumormikromilieu, welches eine Nische für sich langsam teilende Krebszellen, besonders Krebsstammzellen, darstellt (Feig et al. 2012; Penchev et al. 2012). Therapieansätze mit Hyaluronidasen (PEGPH20) zielen genau darauf ab, diese biophysikalische Barriere zu reduzieren und die verfügbaren Konzentrationen von Chemotherapeutika im PDAC zu erhöhen. In präklinischen Studien sowie ersten klinischen Studien wurden vielversprechende Ergebnisse erzielt (Jacobetz et al. 2013; Provenzano et al. 2012).

Kürzlich wurde als weitere mögliche Erklärung für die Chemoresistenz das Konzept vorgestellt, dass CAFs und PSCs einen großen Teil des Gemcitabins aufnehmen, intrazellulär akkumulieren und so die verfügbare Konzentration für die Pankreaskarzinomzellen reduzieren (Hessmann et al. 2018).

Trotz der Vielfalt von erprobten Substanzen schaffte es bisher keine anti-stromale Therapie in die klinische Routine, so scheiterten zum Beispiel MMP-Inhibitoren und anti-VEGFR-1/2/3Antikörper spätestens in Phase III Studien (Moore et al. 2003; Bramhall et al. 2002; Kindler et al. 2010; Kindler et al. 2011). Nach positiven Ergebnissen aus vorhergehenden Studien, insbesondere bei Tumoren mit hohem HA-Gehalt, läuft derzeit allerdings eine vielversprechende Phase III Studie (NCT027115804) zur Kombination von PEGPH20 mit Gemcitabin und nabPaclitaxel (Hingorani et al. 2018). Eine mögliche Ursache der Diskrepanz zwischen Ergebnissen präklinischer und klinischer Studien mag in der ungenügenden Stromareaktion in vielen Krebsmodellen begründet liegen (vgl. 1.3 und 1.4).

Angesichts der Erkenntnisse zum Tumormikromilieu und seiner Rolle im PDAC schien eine gezielte Stromadepletierung ein vielversprechender Therapieansatz zu sein. Allerdings wurden diese Erwartungen stark gedämpft als in zwei Studien in transgenen Mausmodellen eine frühe und radikale Stromadepletierung über Inhibierung des Hedgehog-Signalwegs bzw. induzierbare gentechnische Depletion von CAFs zu aggressiveren und weniger differenzierten Tumoren führte (Rhim et al. 2014; Özdemir et al. 2014). Eine Phase-I/II-Therapiestudie (NCT01130142) mit einem Hedgehog Inhibitor musste ebenso vorzeitig abgebrochen werden.

Aufgrund dieser Erkenntnisse werden nun zunehmend Stroma modulierende Ansätze verfolgt (Neesse et al. 2015; Rowley 2014). Vitamin A- und Vitamin D-Analoga scheinen im Zell- und Tiermodell einen modulierenden, antifibrotischen Effekt auf aktivierte Fibroblasten zu haben und bieten sich als mögliche Ansatzpunkte an. Vitamin-D-Rezeptoragonisten überführten aktivierte PSCs vom aktivierten, inflammatorischen in einen ruhenden Zustand, reduzierten in 
Kombination mit Gemcitabin im Mausmodell die Tumorgröße und führten zu höheren Gemcitabinkonzentrationen sowie zu deutlich verlängertem Überleben (Sherman et al. 2014; Froeling et al. 2011; Stromnes et al. 2014). Für den Angiotensin-II-Rezeptor-1-Antagonisten (AT ${ }_{1}$-Antagonist) Losartan wurde eine reduzierte Sekretion sowohl von HA als auch Kollagen I in orthotopen Mausmodellen berichtet, was in reduziertem „solidem Stress“, besserer Gefäßperfusion und erhöhten Chemotherapeutika- und Sauerstoffkonzentrationen resultierte. Auch das Überleben war in Kombination mit Gemcitabin verlängert. Somit stellen Sartane eine interessante Substanz für stromamodulierende Therapien dar, die bereits in klinischen Studien (NCT01821729, NCT01276613) erprobt werden. Die antifibrotischen Effekte der AT T$_{1}$-Antagonisierung werden vermutlich über reduzierte Signalwirkung von TGF- $\beta$ und CTGF vermittelt, welche die Aktivierung von Fibroblasten sowie Sekretion und Stabilisierung von EZM bewirken. Interessanterweise reduzierte eine gleichzeitige Inhibierung von $\mathrm{AT}_{1}$ und $\mathrm{AT}_{2}$, wie sie durch Angiotensin-konvertierendes Enzym-(ACE)-Hemmstoffe (engl. angiotensin converting enzyme, z. B. Lisinopril) verursacht wird, die antifibrotischen Effekte gegenüber der Gabe von $\mathrm{AT}_{1}$-Antagonisten. Dies deutet auf stromafördernde Effekte von $\mathrm{AT}_{2}$ hin (Chauhan et al. 2013) und führt erneut vor Augen, dass nur die genaue Kenntnis der vielen Stromakomponenten und ihrer Wechselwirkungen auch spezifische, zielgerichtete und erfolgreiche Therapien ermöglicht. Da viele der getesteten Substanzen als Monotherapie oder in Kombination mit Gemcitabin ohne ausreichenden Effekt blieben, ist es für die Zukunft denkbar, mit maßgeschneiderten Kombinationstherapien mehrere molekulare Zielstrukturen im Tumorstroma anzugehen und so schwache Effekte zu potenzieren (Feig et al. 2012).

\subsection{Subtypisierung des Pankreaskarzinoms}

Mittlerweile wurden einige histologische Stromaparameter als prognostisch relevante Marker für das Patientenüberleben identifiziert (Jamieson et al. 2011). Große Erfolge wurden allerdings in den letzten Jahren in der Subtypisierung des PDAC nach genetischen und molekularen Gesichtspunkten erzielt. Hierbei wurden mittels genomweiter Sequenzierung und Genexpressionsanalysen von PT und Metastasen sowie Zelllinien einzelne Subtypen des PDAC mit gemeinsamem Mutationshintergrund oder ähnlicher Genexpression gefunden, wie sie auch für Krebserkrankungen von Brust, Lunge und Blase (Slamon et al. 2001; Lynch et al. 2004; Cancer Genome Atlas Research Network 2014) beschrieben wurden. Diese Subtypen orientieren sich in der Genexpression meist an verschiedenen Zelltypen des Pankreaskarzinoms wie Progenitorzellen sowie exokrinen und mesenchymalen Zellen und gehen mit unterschiedlichen Überlebensraten, Therapieansprechen und Abhängigkeit von spezifischen Mutationen wie KRAS einher (Waddell et al. 2015; Collisson et al. 2011; Moffitt et al. 2015; Bailey et al. 2016; Biankin et al. 2012). So identifizierten Collisson et al. (2011) aufgrund von Transskriptionsprofilen drei Subtypen, wobei der klassische Subtyp im Vergleich mit dem quasi-mesenchymalen Subtyp mit besserer Prognose, höherer Abhängigkeit von KRAS-Mutationen sowie besserem Ansprechen auf Erlotinib und schlechterem Ansprechen auf Gemcitabin-Therapie assoziiert war. Auch eine Assoziation 
zu histomorphologischen Kriterien und Differenzierungsgrad liegt diesen Subtypen nahe. Mittlerweile wurde eine ganze Reihe genetischer Subtypen mit prognostischer Relevanz beschrieben, die sich in weiten Teilen auch überschneiden (Moffitt et al. 2015). Ziel dieser Arbeiten war es, im PDAC mit seiner hohen genetischen Heterogenität und Instabilität Gruppen zu identifizieren, die zuverlässiger als klinische und histologische Parameter eine Prognoseabschätzung und eine Wirksamkeitsabschätzung von Therapieregimen ermöglichen. So scheint es denkbar, Therapien nur den Patienten zukommen zu lassen, die auch davon profitieren und auf diese Weise Nebenwirkungen für andere Patienten zu vermeiden. Auch könnten so Patientenkollektive identifiziert werden, die von neuen Substanzen oder Ansätzen wie beispielsweise Immuntherapien profitieren, welche aber in der Gesamtheit aller PDAC-Patienten keine ausreichende Wirkung haben (Bailey et al. 2016). Dazu bedarf es der Berücksichtigung dieser Subtypen bei kommenden Medikamentenstudien und gegebenenfalls auch der Neubeurteilung älterer Studien. So konnten Waddell et al. (2015) für den ,instabilen“ Subtyp, welcher insbesondere mit Mutationen in DNA-Reparaturgenen wie BRCA2 einhergeht, ein deutlich besseres Ansprechen auf platinhaltige Therapien beobachten, welche außerhalb des stark nebenwirkungsbehafteten FOLFIRINOX-Protokolls nicht wirksam waren (Poplin et al. 2009).

Mittels virtueller Mikrodissektion und der Zuordnung zu bestimmten Tumorkompartimenten konnte auch das Tumorstroma untersucht werden. Es wurde ein Genexpressionsmuster gefunden, welches aktiviertes Stroma charakterisiert und von „normalem“, ruhendem Stroma abgrenzt. In normalem Stroma wurden die Gene für Marker der PSCs wie Vimentin, Desmin und $\alpha$-SMA besonders stark exprimiert, während aktiviertes Stroma bestimmte Chemokine, MMPs und SPARC vermehrt exprimierte. Aktiviertes Stroma geht mit einem um neun Monate verkürzten medianen Überleben gegenüber Patienten mit „normalem“ Stroma einher (15 Monate vs. 24 Monate; HR 1,94) (Moffitt et al. 2015).

Die genetische Subtypisierung des PDAC birgt großes Potential für die personalisierte Krebsmedizin, hat jedoch auch Limitationen, die beachtet werden müssen. So sind die genom- und exomweiten Sequenzierungen und Genexpressionsanalysen ausgesprochen aufwendig, teuer und stehen oftmals nicht in klinisch angemessenen Zeiträumen zur Verfügung (Waddell et al. 2015). Auch wurden mittlerweile diverse Subtypen identifiziert, die sich zwar zu großen Teilen überschneiden, aber nicht deckungsgleich sind. Es bedarf weiterer Untersuchungen mit großen Stichproben, um Überschneidungen der genetischen und molekularen Subtypen mit klinischen, pathologischen und histologischen Parametern zu überprüfen. Um effizient klinische Studien durchführen zu können, sollten sinnvollerweise aus der Vielfalt an Subtypen einige identifiziert werden, welche dann auf Therapieansprechen geprüft werden. Bei allem Potential ist es derzeit nicht absehbar, wann genetische und molekulare Subtypisierungen regelhaft in der Klinikroutine zum Einsatz kommen werden. 


\subsection{Zielsetzung der Arbeit}

Im menschlichen PDAC wurden vielfältige Studien zur Identifizierung von klinischen und histologischen Parametern durchgeführt, die das Überleben sowie weitere relevante Kriterien wie Metastasierung, Rezidivrate und Komplikationen beeinflussen. Neben epidemiologischen Faktoren, Tumordurchmesser, Grading und genetischen Subtypen wurden auch stromale Marker identifiziert (beispielsweise Fibroblastendichte), die mit den Überlebenszeiten bei PDAC Patienten korrelieren. Mit Einführung der KPC-Maus ist seit gut 10 Jahren ein Krebsmodell verfügbar, in dem die desmoplastische Reaktion des PDAC weitestgehend wirklichkeitsgetreu rekapituliert wird. Erstaunlicherweise wurde in bisherigen Arbeiten niemals die genaue Zusammensetzung des Tumorstromas und die prognostische Auswirkung einzelner epithelialer und stromaler Marker auf das Überleben der Mäuse untersucht und mit bestehender Literatur aus humanen Pankreaskarzinomen verglichen.

Ziel dieser Arbeit ist es, die Zusammensetzung des Tumormikromilieus im KPC-Mausmodell zu quantifizieren und die Komponenten einzeln und im Rahmen einer multivariaten Cox-Regression auf eine prognostische Aussage bezüglich des Überlebens hin zu überprüfen. Dabei wird das Stroma mit seinem zellulären sowie seinem azellulären Kompartiment histologisch mit jeweils mehreren Markern untersucht. Zusätzlich werden auch epitheliale Proliferations- und Apoptosemarker untersucht. Die Ergebnisse werden mit Blick auf Erkenntnisse aus menschlichen Tumoren diskutiert. In der Vergangenheit hatten viele neue Therapieansätze zuvor in Krebsmodellen wie der Zellkultur und Xenograftmäusen vielversprechende Ergebnisse erzielt, die sich in der Therapie am Menschen nicht reproduzieren ließen. Dies führt deutlich vor Augen, dass es Modellorganismen braucht, die die Erkrankung wirklichkeitsgetreu rekapitulieren. Diese Arbeit möchte einen Beitrag zu einer genaueren Charakterisierung der desmoplastischen Reaktion des KPC-Modells leisten, um somit das präklinische Potential und mögliche Limitationen, auch mit Blick auf zukünftige Interventionsstudien, besser beurteilen zu können.

Ein zweiter Aspekt der Arbeit besteht in der vergleichenden Betrachtung von Metastasen und PT im KPC-Modell. Mit der KPC-Maus liegt ein Modell vor, welches die häufige und frühe Metastasierung des menschlichen PDAC sowie sein typisches Metastasierungsmuster in die Leber, rekapituliert. Die folgende Arbeit untersucht die Frage, ob und inwiefern sich Lebermetastasen (LM) und PT mit Blick auf ausgewählte Stromamarker unterscheiden. Dabei werden neben histologischen Markern auch die Proteinexpression von zellulären und azellulären Stromakomponenten in beiden Kompartimenten verglichen und die Ergebnisse mit Blick auf menschliche Metastasen diskutiert. 


\section{Material und Methoden}

\subsection{Materialien und Software}

\subsubsection{Gerätschaften}

Tabelle 1: Verwendete Gerätschaften

\begin{tabular}{|c|c|c|}
\hline Gerätschaft & Hersteller & Firmensitz \\
\hline Arium pro (Wasseranlage) & Sartorius & Göttingen \\
\hline Cadenza System Shandon Sequenza & Thermo Shandon Limited & Cheshire, UK \\
\hline Eismaschine AF80 & Scotsman & $\begin{array}{l}\text { Vernon Hills, IL, } \\
\text { USA }\end{array}$ \\
\hline Feinwaage PCB2000-1 & Kern und Sohn GmbH & Ballingen \\
\hline Feinwaage PT210 & Sartorius & Göttingen \\
\hline $\begin{array}{l}\text { Fluoreszenzmikroskop Leica } \\
\text { DMi8/CTR advancerd }\end{array}$ & Leica Mikrosysteme & Wetzlar \\
\hline Kühlzentrifuge PerfectSpin 24 Plus & Peqlab & Erlangen \\
\hline Leica EL6000 (Fluoreszenzlichtquelle) & Leica Mikrosysteme & Wetzlar \\
\hline Mikroskop BX43 & Olympus Europa & Hamburg \\
\hline Mikrowelle NN-E209W & Panasonic & Kadoma, Japan \\
\hline Mini Gel Tank (PAGE) & $\begin{array}{l}\text { Invitrogen/Life Technolo- } \\
\text { gies Corporation }\end{array}$ & Carlsbad, CA, USA \\
\hline $\begin{array}{l}\text { Motorisches Rotationsmikrotom } \\
\text { RM2255 }\end{array}$ & Leica Mikrosysteme & Wetzlar \\
\hline Heizblock für Objektträger OTS 40 & Medite GmbH & Burgwedel \\
\hline pH-Meter FiveEasy Plus & Mettler-Toledo AG & $\begin{array}{l}\text { Schwerzenbach, } \\
\text { Schweiz }\end{array}$ \\
\hline Photomer PHOmo & $\begin{array}{l}\text { Autobio Labtec Instru- } \\
\text { ments Co. Ltd. }\end{array}$ & Zhengzhou, China \\
\hline Pipetierhilfe Pipetus-akku & Hirschmann Laborgeräte & Eberstadt \\
\hline Pipetten $(10 ; 100 ; 200 ; 1.000 \mu \mathrm{l})$ & Eppendorf & Hamburg \\
\hline $\begin{array}{l}\text { PowerPac HC (Spannungsgerät für } \\
\text { Gelelektrophorese) }\end{array}$ & BioRad & Hercules, CA, USA \\
\hline Trockenschrank/Inkubator UN55Pa & Memmert & Schwabach \\
\hline Vortexmischer Reax 1 & Heidolph & Schwabach \\
\hline Wasserbad GFL 1052 & $\begin{array}{l}\text { Gesellschaft für Labor- } \\
\text { technik }\end{array}$ & Burgwedel \\
\hline
\end{tabular}




\subsubsection{Verbrauchsmaterialien}

Tabelle 2: Verwendete Verbrauchsmaterialien

\begin{tabular}{|c|c|c|}
\hline Verbrauchsmaterialien & Hersteller & Firmensitz \\
\hline (Menzel-)Deckgläser 24×24-60 mm & $\begin{array}{l}\text { Gerhard Menzel B.V. \& } \\
\text { Co. KG }\end{array}$ & Braunschweig \\
\hline $\begin{array}{l}\text { 96-Well Polystyrene Plates, Corner } \\
\text { Notch }\end{array}$ & $\begin{array}{l}\text { Thermo Fisher Scientific } \\
\text { Inc. }\end{array}$ & $\begin{array}{l}\text { Waltham, MA, } \\
\text { USA }\end{array}$ \\
\hline Auslaufpipetten $(10-25 \mathrm{ml})$ & Sarstedt & Nümbrecht \\
\hline Mikrotomklingen S35 & Feather & Osaka, Japan \\
\hline $\begin{array}{l}\text { Nitrocellulose Blotting Membrane } \\
106000020,45 \mu \mathrm{m}\end{array}$ & GE Healthcare & $\begin{array}{l}\text { Buckinghamshire, } \\
\text { UK }\end{array}$ \\
\hline $\begin{array}{l}\text { NuPAGE 4-12\% Bis-Tris-Gel; } 1.0 \text { mm; } \\
10 \text { Well }\end{array}$ & $\begin{array}{l}\text { Invitrogen/Life Technolo- } \\
\text { gies Corporation }\end{array}$ & $\begin{array}{l}\text { Carlsbad, CA, } \\
\text { USA }\end{array}$ \\
\hline Objektträger Superfrost PLUS & $\begin{array}{l}\text { Gerhard Menzel B.V. \& } \\
\text { Co. KG }\end{array}$ & Braunschweig \\
\hline $\begin{array}{l}\text { Objektträgerhalterung (Cadenza System) } \\
\text { Shandon Coverplate }\end{array}$ & Thermo Shandon Limited & Cheshire, UK \\
\hline Pipettenspitzen $(10 ; 200 ; 1.000 \mu \mathrm{l})$ & Eppendorf & Hamburg \\
\hline Reagiergefäße (Multiplyß) 0,2 ml; 1,5 ml & Sarstedt & Nümbrecht \\
\hline Röhrengefäß $15 \mathrm{ml} ; 50 \mathrm{ml}$ & Sarstedt & Nümbrecht \\
\hline Rotimount Aqua & $\begin{array}{l}\text { Carl Roth GmbH \& Co. } \\
\text { KG }\end{array}$ & Karlsruhe \\
\hline Whatman Chromatography Paper 3MM & $\begin{array}{l}\text { Thermo Fisher Scientific } \\
\text { Inc. }\end{array}$ & $\begin{array}{l}\text { Waltham, MA, } \\
\text { USA }\end{array}$ \\
\hline
\end{tabular}

\subsubsection{Chemikalien}

Tabelle 3: Verwendete Chemikalien

\section{$\begin{array}{lll}\text { Chemikalien } & \text { Hersteller } & \text { Firmensitz }\end{array}$}

\begin{tabular}{|c|c|c|}
\hline $\begin{array}{l}\text { Albumin bovine fraction } \\
\text { (BSA) pH7 Cat\# } 11930.03\end{array}$ & Serva Electrophoresis $\mathrm{GmbH}$ & Heidelberg \\
\hline $\begin{array}{l}\text { Albumin Standard 2mg/ml } \\
\text { (Cat\#: 23209) }\end{array}$ & Thermo Fisher Scientific Inc. & Waltham, MA, USA \\
\hline $\begin{array}{l}\text { Amersham ECL Western } \\
\text { Blotting Analysis RPN2109 }\end{array}$ & GE Healthcare & Buckinghamshire, UK \\
\hline Citronensäure Monohydrat & Carl Roth GmbH \& Co. KG & Karlsruhe \\
\hline $\begin{array}{l}\text { EDTA (Ethylendiamintetraes- } \\
\text { sigsäure) }\end{array}$ & Acros Organics & New Jersy, USA \\
\hline
\end{tabular}


Chemikalien

\begin{tabular}{|c|c|c|}
\hline Ethanol $(99 \%)$, vergällt & $\begin{array}{l}\text { ChemSolute / TH. Geyer GmbH } \\
\text { \& Co. KG }\end{array}$ & Renningen \\
\hline Goat Serum X0907 & Dako Denmark A/S; Agilent & $\begin{array}{l}\text { Glostrup, Denmark; } \\
\text { Santa Clara, USA }\end{array}$ \\
\hline Hämatoxilinlösung (Mayer) & Sigma-Aldrich & St. Louis, MO, USA \\
\hline $\mathrm{NaCl}$ & Merck KGaA & Darmstadt \\
\hline $\mathrm{NaOH}-\mathrm{Plätzchen}$ & E. Merck & Darmstadt \\
\hline $\begin{array}{l}\text { Nonfat dried milk powder } \\
\text { A0830,0500 }\end{array}$ & AppliChem & Darmstadt \\
\hline PBS Dulbecco (L182-01) & Biochrom & Berlin \\
\hline Roticlear (für die Histologie) & Carl Roth GmbH \& Co. KG & Karlsruhe \\
\hline $\begin{array}{l}\text { Salzsäure 37\%; 2N Maßlösung } \\
(2 \mathrm{~mol} / \mathrm{l})\end{array}$ & Carl Roth GmbH \& Co. KG & Karlsruhe \\
\hline Tris $>99,9 \%(121,1 \mathrm{~g} / \mathrm{mol})$ & Carl Roth GmbH \& Co. KG & Karlsruhe \\
\hline Tris- $\mathrm{HCl}>99 \%(157,6 \mathrm{~g} / \mathrm{mol})$ & Carl Roth GmbH \& Co. KG & Karlsruhe \\
\hline Tween 20 & Sigma-Aldrich & St. Louis, MO, USA \\
\hline Wasserstoffperoxid 30\% & Carl Roth GmbH \& Co. KG & Karlsruhe \\
\hline $\begin{array}{l}\text { wässrige Eosinlösung } \\
\text { HT110232-1L }\end{array}$ & Sigma-Aldrich & St. Louis, MO, USA \\
\hline
\end{tabular}

\subsubsection{Reagenzien-Sets}

Tabelle 4: Reagenzien-Sets

\begin{tabular}{lll} 
Reagenzien-Sets & Hersteller & Firmensitz \\
\hline $\begin{array}{l}\text { ImmPACT DAB Peroxidase (HRP) } \\
\text { Substrate (Cat\#: SK-4105) }\end{array}$ & $\begin{array}{l}\text { VECTOR LABORATO- } \\
\text { RIES, Inc. }\end{array}$ & Burlingame, CA, USA \\
\hline $\begin{array}{l}\text { Picrosirius Red Stain Kit 500ml (Cat\#: } \\
\text { 24901-500) }\end{array}$ & Polysciences, Inc. & Warrington, PA, USA \\
\hline "DAPI-Mount": VECTASHIELD & VECTOR LABORATO- & Burlingame, CA, USA \\
$\begin{array}{l}\text { Antifade Mounting Medium with } \\
\text { DAPI (Cat\#: H-1200) }\end{array}$ & RIES, Inc. & \\
\hline VECTASTAIN ABC Kit (Goat IgG) & VECTOR LABORATO- & Burlingame, CA, USA \\
(Cat\#: PK-4005) & RIES, Inc. & \\
\hline VECTASTAIN ABC Kit (Mouse & VECTOR LABORATO- & Burlingame, CA, USA \\
IgG) (Cat\#: PK-4002) & RIES, Inc. & \\
\hline
\end{tabular}




\begin{tabular}{|c|c|c|}
\hline $\begin{array}{l}\text { VECTASTAIN ABC Kit (Rabbit } \\
\text { IgG) (Cat\#: PK-4001) }\end{array}$ & $\begin{array}{l}\text { VECTOR LABORATO- } \\
\text { RIES, Inc. }\end{array}$ & Burlingame, CA, USA \\
\hline $\begin{array}{l}\text { Coomassie (Bradford) Protein Assay } \\
\text { Kit }\end{array}$ & $\begin{array}{l}\text { Thermo Fisher Scientific } \\
\text { Inc. }\end{array}$ & Waltham, MA, USA \\
\hline NuPAGETM LDS Sample Buffer (4x) & $\begin{array}{l}\text { Invitrogen/Life Technol- } \\
\text { ogies Corporation }\end{array}$ & Carlsbad, CA, USA \\
\hline $\begin{array}{l}\text { NuPAGETM MOPS SDS Running } \\
\text { Buffer (20X) }\end{array}$ & $\begin{array}{l}\text { Invitrogen/Life Techno- } \\
\text { logies Corporation }\end{array}$ & Carlsbad, CA, USA \\
\hline NuPAGETM Transfer Buffer (20X) & $\begin{array}{l}\text { Invitrogen/Life Techno- } \\
\text { logies Corporation }\end{array}$ & Carlsbad, CA, USA \\
\hline $\begin{array}{l}\text { Mouse on Mouse (M.O.M. }{ }^{\text {TM }} \text { ) Block- } \\
\text { ing Reagent (Cat\#: MKB-2213) }\end{array}$ & $\begin{array}{l}\text { VECTOR LABORATO- } \\
\text { RIES, Inc. }\end{array}$ & Burlingame, CA, USA \\
\hline
\end{tabular}

\subsubsection{Antikörper und Proteine}

Tabelle 5: Antikörper und Proteine

\begin{tabular}{|c|c|c|c|}
\hline Antikörper/Proteine & Spezies & Hersteller & Firmensitz \\
\hline $\begin{array}{l}2^{\circ} \text { AK Rabbit Anti-Goat } \\
\text { HRP conjugates (P0449) }\end{array}$ & Kaninchen & $\begin{array}{l}\text { Dako Denmark A/S; } \\
\text { Agilent }\end{array}$ & $\begin{array}{l}\text { Glostrup, Denmark; } \\
\text { Santa Clara, CA, } \\
\text { USA }\end{array}$ \\
\hline $\begin{array}{l}2^{\circ} \mathrm{AK} \text { Rabbit Anti-Mouse } \\
\text { HRP conjugates (P0161) }\end{array}$ & Kaninchen & $\begin{array}{l}\text { Dako Denmark A/S; } \\
\text { Agilent }\end{array}$ & $\begin{array}{l}\text { Glostrup, Denmark; } \\
\text { Santa Clara, CA, } \\
\text { USA }\end{array}$ \\
\hline $\begin{array}{l}2^{\circ} \mathrm{AK} \text { Swine Anti-Rabbit } \\
\text { HRP conjugates (P0217) }\end{array}$ & Schwein & $\begin{array}{l}\text { Dako Denmark A/S; } \\
\text { Agilent }\end{array}$ & $\begin{array}{l}\text { Glostrup, Denmark; } \\
\text { Santa Clara, CA, } \\
\text { USA }\end{array}$ \\
\hline $\begin{array}{l}\text { Alexa Fluor }{ }^{\circledR} 488 \text { conju- } \\
\text { gate, anti-Mouse IgG2a }\end{array}$ & $\begin{array}{l}\text { Ziege, } \\
\text { polyklonal }\end{array}$ & $\begin{array}{l}\text { Invitrogen; Thermo } \\
\text { Fisher Scientific Inc. }\end{array}$ & Waltham, MA, USA \\
\hline $\begin{array}{l}\text { Alexa Fluor® } 568 \text { conju- } \\
\text { gate, anti-Rabbit IgG }\end{array}$ & $\begin{array}{l}\text { Esel, } \\
\text { polyklonal }\end{array}$ & $\begin{array}{l}\text { Invitrogen; Thermo } \\
\text { Fisher Scientific Inc. }\end{array}$ & Waltham, MA, USA \\
\hline $\begin{array}{l}\text { Anti-Mouse SPARC Anti- } \\
\text { body (Cat\#: AF942) }\end{array}$ & $\begin{array}{l}\text { Ziege, } \\
\text { polyklonal }\end{array}$ & R\&D Systems, Inc. & $\begin{array}{l}\text { Minneapolis, MN, } \\
\text { USA }\end{array}$ \\
\hline $\begin{array}{l}\text { Anti-CD31 Purified Rat } \\
\text { Anti-Mouse (Cat\# 553370) }\end{array}$ & $\begin{array}{l}\text { Ratte, } \\
\text { monoklonal }\end{array}$ & BD Pharmingen ${ }^{\mathrm{TM}}$ & $\begin{array}{l}\text { Franklin Lakes, NJ, } \\
\text { USA }\end{array}$ \\
\hline $\begin{array}{l}\text { Anti-Fibronectin (Cat\# } \\
\text { ab2413) }\end{array}$ & $\begin{array}{l}\text { Kaninchen, } \\
\text { polyklonal }\end{array}$ & Abcam AG & Cambridge, UK \\
\hline Anti-HSP90 (E289) (WB) & $\begin{array}{l}\text { Kaninchen, } \\
\text { polyklonal }\end{array}$ & $\begin{array}{l}\text { Cell Signaling Tech- } \\
\text { nology, Inc. }\end{array}$ & Danvers, MA, USA \\
\hline $\begin{array}{l}\text { Anti-phospho-Histone H3 } \\
\text { (Ser10), (Cat\# 06-570) }\end{array}$ & $\begin{array}{l}\text { Kaninchen, } \\
\text { polyklonal }\end{array}$ & $\begin{array}{l}\text { Upstate/ Merck Mil- } \\
\text { lipore }\end{array}$ & Billerica, MA, USA \\
\hline
\end{tabular}




\begin{tabular}{|c|c|c|c|}
\hline Antikörper/Proteine & Spezies & Hersteller & Firmensitz \\
\hline $\begin{array}{l}\text { Cleaved Caspase-3 } \\
\text { (Asp175) (5A1E) Rabbit } \\
\text { mAb (Cat\#: } 9661 \text { und } \\
\text { 9664L) }\end{array}$ & $\begin{array}{l}\text { Kaninchen, } \\
\text { monoklonal }\end{array}$ & $\begin{array}{l}\text { Cell Signaling Tech- } \\
\text { nology, Inc. }\end{array}$ & Danvers, MA, USA \\
\hline $\begin{array}{l}\text { Hyaluronic Acid Binding } \\
\text { Protein, Bovine Nasal Carti- } \\
\text { lage, Biotinylated, } \\
\text { (Cat\#: 385911-50UG) }\end{array}$ & Bovin/Rind & Merck Millipore & Billerica, MA, USA \\
\hline $\begin{array}{l}\text { Ki-67, Rabbit Monoclonal } \\
\text { Antibody, Clone SP6 } \\
\text { (Cat\#: RM-9106-S0) }\end{array}$ & $\begin{array}{l}\text { Kaninchen, } \\
\text { monoklonal }\end{array}$ & $\begin{array}{l}\text { Thermo Fisher Sci- } \\
\text { entific Inc. }\end{array}$ & Waltham, MA, USA \\
\hline $\begin{array}{l}\text { Monoclonal Mouse Anti- } \alpha- \\
\text { Smooth Muscle Actin, } \\
\text { Clone 1A4 (Cat\#: M0851) }\end{array}$ & $\begin{array}{l}\text { Maus, } \\
\text { monoklonal }\end{array}$ & $\begin{array}{l}\text { Dako Denmark A/S } \\
\text { (jetzt: Agilent) }\end{array}$ & $\begin{array}{l}\text { Glostrup, Denmark } \\
\text { (jetzt: Santa Clara, } \\
\text { CA, USA) }\end{array}$ \\
\hline $\begin{array}{l}\text { Mouse Ki-67 Antigen, } \\
\text { monoclonal, Clone TEC-3 } \\
\text { (Cat\# M7249) }\end{array}$ & $\begin{array}{l}\text { Ratte, } \\
\text { monoklonal }\end{array}$ & $\begin{array}{l}\text { Dako Denmark A/S } \\
\text { (jetzt: Agilent) }\end{array}$ & $\begin{array}{l}\text { Glostrup, Denmark } \\
\text { (jetzt: Santa Clara, } \\
\text { CA, USA) }\end{array}$ \\
\hline $\begin{array}{l}\text { Purified Mouse Anti-hu- } \\
\text { man-E-Cadherin, (Cat\# } \\
\text { 610181) }\end{array}$ & Maus & $\begin{array}{l}\text { BD Transduction } \\
\text { Laboratories }^{\mathrm{TM}}\end{array}$ & $\begin{array}{l}\text { Franklin Lakes, NJ, } \\
\text { USA }\end{array}$ \\
\hline
\end{tabular}

\subsubsection{Mauslinien}

Alle in dieser Arbeit untersuchten KPC-Mäuse wurden in Cambridge (UK) gemäß dortigen Tierversuchsanträgen gehalten. Sie wurden keiner Therapie unterzogen. Die Mäuse wurden regelmäßig beobachtet und bei Erreichen eines der folgenden Endpunktkriterien getötet. Die Pankreastumoren wurden entnommen und in Paraffin eingebettet. Folgende Endpunktkriterien waren laut Tierversuchsantrag im Vorfeld festgesetzt worden: Aszitesbildung, Gewichtsverlust (>10\%), Körpertemperaturabfall, Piloerektion, Inaktivität oder auffälliges Sozialverhalten.

\subsubsection{Software}

Tabelle 6: Verwendete Software

\begin{tabular}{lll} 
Software & Hersteller & Firmensitz \\
\hline $\begin{array}{l}\text { Apache Open Office 4.1.1 } \\
\text { (Writer und Calc) }\end{array}$ & $\begin{array}{l}\text { Apache Software Founda- } \\
\text { tion }\end{array}$ & Forest Hill, MD, USA \\
\hline $\begin{array}{l}\text { AUTOsoft (Steuer- und } \\
\begin{array}{l}\text { Auswertesoftware für } \\
\text { PHOmo }\end{array}\end{array}$ & $\begin{array}{l}\text { Autobio Labtec Instruments } \\
\text { Co. Ltd. }\end{array}$ & Zhengzhou, China \\
\hline $\begin{array}{l}\text { cellSens Entry (Mikrosko- } \\
\text { piersoftware) }\end{array}$ & Olympus Europa & Hamburg
\end{tabular}




\begin{tabular}{lll} 
Software & Hersteller & Firmensitz \\
\hline Fiji (ImageJ) & $\begin{array}{l}\text { Wayne Rasband (bis 2010 } \\
\text { für das National Institute of } \\
\text { Mental Health), Johannes } \\
\begin{array}{l}\text { Schindelin, Curtis Rueden, } \\
\text { Albert Cardona, Mark Hiner } \\
\text { et al. (open source) (Schin- } \\
\text { delin et al. 2012) }\end{array}\end{array}$ & $\begin{array}{l}\text { Laboratory for Optical and } \\
\text { Computational Instrumenta- } \\
\text { tion (LOCI), University of } \\
\text { Wisconsin-Madison, WI, }\end{array}$ \\
\hline GraphPad Prism 6 & GraphPad Software, Inc. & La Jolla, CA, USA \\
\hline $\begin{array}{l}\text { Leica LAS X 1.x (Mikrosko- } \\
\text { piersoftware) }\end{array}$ & Leica Mikrosysteme & Wetzlar \\
\hline $\begin{array}{l}\text { Microsoft Office 2016 } \\
\text { (Word und Excel) }\end{array}$ & Microsoft Corp. & Redmond, WA, USA \\
\hline Statistica 13.0 & StatSoft & Tulsa, OK, USA \\
\hline
\end{tabular}

\subsubsection{Puffer und Salzlösungen}

Tabelle 7: Verwendete Puffer und Salzlösungen

\begin{tabular}{lll} 
Citratpuffer, $\mathbf{p ~ H 6}$ & TE-Puffer, $\mathbf{p ~ H 9}$ & TBST, pH 7,4 \\
\hline $\begin{array}{l}\text { 2,1 g Citronensäuremono- } \\
\text { hydrat }(10 \mathrm{mM})\end{array}$ & $1,211 \mathrm{~g}$ Tris $(10 \mathrm{mM})$ & $7,88 \mathrm{~g}$ Tris-HCl $(50 \mathrm{mM})$ \\
\hline & $0,372 \mathrm{~g}$ EDTA $(1 \mathrm{mM})$ & $8,76 \mathrm{~g} \mathrm{NaCl}(150 \mathrm{mM})$ \\
\hline & & $1 \mathrm{ml}$ Tween20 $(0,1 \%)$ \\
\hline $\mathrm{H}_{2} \mathrm{O}(1 \mathrm{Liter})$ & $\mathrm{H}_{2} \mathrm{O}(1 \mathrm{Liter})$ & $\mathrm{H}_{2} \mathrm{O}(1 \mathrm{Liter})$ \\
\hline $\begin{array}{l}\mathrm{NaOH} \text { zum Einstellen des } \\
\text { pH-Wertes }\end{array}$ & $\begin{array}{l}\mathrm{HCl} \text { zum Einstellen des } \mathrm{pH}- \\
\text { Wertes }\end{array}$ & $\begin{array}{l}\mathrm{HCl} \text { zum Einstellen des } \mathrm{pH}- \\
\text { Wertes }\end{array}$ \\
\hline
\end{tabular}

alle Angaben pro Liter; TBST (Tris-gepufferte Salzlösung (engl. Tris-buffered saline) mit 0,1\% Tween20); TE-Puffer (Tris-EDTA-Puffer)

\subsection{Methoden}

\subsubsection{Gewebeentnahme, Fixierung und Einbettung}

Die Entnahme, Fixierung und Einbettung der KPC-Gewebe wurden in Cambridge von Mitarbeitern der Tuveson-Arbeitsgruppe durchgeführt. Die Formalin-fixierten und in Paraffin eingebetteten Pankreaten und Lebern wurden mir freundlicherweise von Dr. Neeße überlassen. Formaldehyd führt zu einer Quervernetzung bei weitestgehender Erhaltung von Antigenstrukturen (Lang 2013). Auf diese Weise behandelte Gewebe sind über viele Jahre konserviert und können immunhistologisch untersucht werden. 


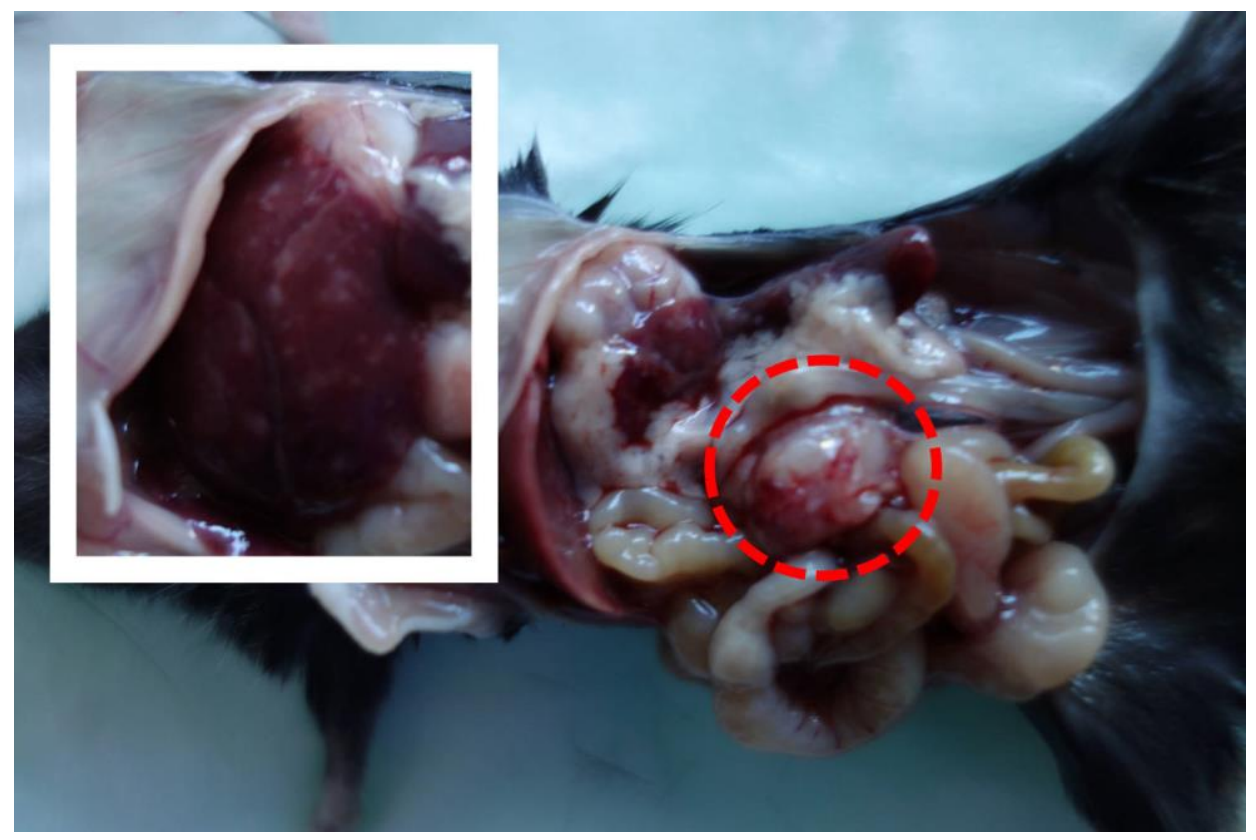

\section{Abbildung 6: Situs einer KPC-Maus mit Pankreastumor}

Sicht auf den geöffneten Situs einer KCP-Maus bei der Nekropsie. Im vergrößerten Pankreas ist prominent ein weißlicher Tumor mit Einblutungen zu sehen (roter Kreis). Der Tumor ist derb und hart. Eingefügt wurde ein Bild der Leber derselben Maus. An der Leberoberfläche sind kleine fokale Läsionen zu sehen, bei denen es sich um Metastasen des Pankreastumors handelt.

\subsubsection{Histologie}

Innerhalb der Färbung wurde versucht die Bedingungen für alle Schnitte möglichst konstant zu halten. Hierfür wurden alle Schnitte in je ein oder zwei Chargen gefärbt und mit den entsprechenden Lösungen sowie Primär- und Sekundärantikörperverdünnungen aus einem gemeinsamen Ansatz behandelt.

\subsubsection{Mikrotomie}

Die zu untersuchenden Pankreastumoren und Lebern der Mäuse lagen in Paraffinblöcken eingebettet vor. Für die histologischen Färbungen wurden von diesen Blöcken mit einem Rotationsmikrotom $4 \mu \mathrm{m}$ dünne Schnitte aus Stellen mit genügend großem Tumordurchmesser angefertigt. Die Paraffinschnitte wurden in 30\% Ethanol aufgefangen und, wenn sie keine signifikanten Risse und Stauchungen im Gewebe aufwiesen, in ein auf $37^{\circ} \mathrm{C}$ vorgeheiztes Wasserbad überführt um sich dort auszudehnen. Nach circa 10 Minuten wurden die Schnitte mit einem Adhäsions-Objektträger aus dem Wasserbad aufgenommen und nach mehrmaligem, kräftigem Schütteln zur Reduzierung von Wasserblasen unter dem Gewebe auf den Heizblock zum Trocknen gelegt. Alle Objektträger wurden über Nacht bei $37{ }^{\circ} \mathrm{C}$ im Trockenschrank gelagert um Wasserblasen unter Gewebe und Paraffin zu trocknen. Die fertigen Schnitte wurden bis zu ihrer Färbung bei Raumtemperatur (RT) trocken, dunkel und vor Staub geschützt in einem Setzkasten gelagert. Der Zeitraum zwischen Schneiden und Färben betrug jeweils weniger als drei Monate. 


\subsubsection{Immunhistochemie}

\subsection{Prinzipien der Immunhistochemie}

Die Immunhistochemie (IHC) ist eine Methode, die es ermöglicht Antigene wie beispielsweise Proteine oder Oligosaccharide durch die Verwendung von spezifischen, markierten Antikörpern in histologischen Präparaten nachzuweisen. Hierzu wird die hohe Affinität von Antikörpern gegen Epitope ausgenutzt, die im Idealfall zu einer starken und spezifischen Bindung der Antikörper an das Antigen führen. Das Vorhandensein von gebundenen Antikörpern wird nach einem Waschvorgang durch einen Detektionsmechanismus nachgewiesen. Spezifisch gebundene Antikörper führen dazu, dass ein Signal durch den Detektionsmechanismus nur dort nachweisbar ist, wo das Antigen bzw. Epitop vorhanden ist. Es gibt verschiedene Detektionsmechanismen, die dazu dienen den Antikörper „sichtbar“ zu machen. In der Lichtmikroskopie werden häufig an Antikörper gekoppelte Enzyme wie zum Beispiel Meerrettichperoxidase (HRP, engl. horseradish peroxidase) oder alkalische Phosphatase verwendet, deren Reaktionsprodukte optisch nachweisbar sind (Ross und Pawlina 2011; Lang 2013). Als Substrat der HRP wird in der Regel Diaminobenzidintetrahydrochlorid (DAB) verwendet, das oxidiert wird und hierbei ein braunes, polymeres, unlösliches Farbprodukt bildet (Lang 2013).

\subsection{Direkte und indirekte Methode}

Sowohl in der IHC als auch der Immunfluoreszenz (IF) (siehe 2.2.2.3) wird zwischen der direkten und der indirekten Methode unterschieden. Bei der direkten Methode ist das Enzym bzw. das Fluorochrom an den Antikörper gebunden, welcher auch das Epitop bindet. In der vorliegenden Arbeit wurde in allen IHC-Versuchen (sowie dem Westernblot) die indirekte Methode verwendet. Bei der indirekten Methode wird zunächst das Gewebe mit einem spezifisch gegen das Antigen gerichteten Antikörper („Primärantikörper“) behandelt. Im Idealfall sollte der Primärantikörper $\left(1^{\circ} \mathrm{AK}\right)$ nicht aus der Spezies stammen, aus der das zu färbende Gewebe stammt, ansonsten müssen besondere Vorsichtsmaßnahmen unternommen werden um eine unspezifische Bindung und daraus resultierende hohe Hintergrundfärbung zu vermeiden (vgl. M.O.M Kit für $\alpha$-SMA). Zuvor sollte eine Blockierung unspezifischer Epitope mittels verschiedener Tierseren vorgenommen werden. Nach mehreren Waschschritten zur Beseitigung von nicht oder unspezifisch gebundenen $1^{\circ} \mathrm{AK}$ wird im nächsten Schritt das Gewebe mit einem zweiten Antikörper („Sekundärantikörper“) behandelt, welcher spezifisch gegen die Fc-Region von IgG der Spezies gerichtet ist, aus der der $1^{\circ} \mathrm{AK}$ gewonnen wurde. Der Sekundärantikörper $\left(2^{\circ} \mathrm{AK}\right)$, an welchen das Enzym (HRP) oder Fluorochrom gekoppelt ist, bindet somit an die Fc-Region des $1^{\circ} \mathrm{AK}$ und detektiert das Vorhandensein des nachzuweisenden Antigens. Da stets mehrere $2^{\circ} \mathrm{AK}$ an einen $1^{\circ} \mathrm{AK}$ binden kommt es bei der indirekten Methode zu einer Signalverstärkung und einer Erhöhung der Sensitivität (Ross und Pawlina 2011; Wachtler 2005; Lang 2013).

In der IHC werden überwiegend IgG Antikörper tierischen Ursprungs verwendet, wobei häufig verwendete Spezies Maus, Ratte, Kaninchen und Ziege sind. Es werden polyklonale und monoklonale Antikörper unterschieden, die sich in Gewinnung, Spezifität und Preis unterscheiden. 
Polyklonale Antikörper werden aus Seren von Tieren gewonnen, denen im Vorfeld das Antigen verabreicht wurde und deren Immunsystem in der Folge spezifische Antikörper gegen die verschiedenen Epitope dieses Antigens gebildet haben. Die verschiedenen Antikörper gehen auf unterschiedliche B-Lymphozyten-Stämme zurück und adressieren jeweils einen anderen Abschnitt des nachzuweisenden Antigens. Aus den Seren der Tiere werden die Antikörper extrahiert, aufgereinigt und, wenn als Sekundärantikörper verwendet, biotinyliert bzw. mit einem Detektionsmolekül (Fluorochrom) konjugiert (Lang 2013; Ross und Pawlina 2011). Monoklonale Antikörper stammen von einer Zellreihe, die auf einen einzigen B-Lymphozyten zurückgeht, welcher durch Fusion mit einer Myelomzelle immortalisiert wurde. Dieser Zellhybrid wird in Zellkultur gehalten und produziert identische Antikörper, welche aus dem Zellüberstand gewonnen werden können. Der Vorteil monoklonaler Antikörper liegt in ihrer gleichbleibenden, chargenunabhängigen Qualität und der daraus folgenden besseren Reproduzierbarkeit von Ergebnissen (Ross und Pawlina 2011; Lang 2013).

\subsection{Avidin-Biotin-Complex-Methode}

Die Avidin-Biotin-Complex(ABC)-Methode ist die am häufigsten gebrauchte und auch hier verwendete Methode in der IHC um das Enzym für die Nachweisreaktion an den Antikörper zu binden. Hierfür wird sich die starke Affinität von Avidin, einem Molekül aus dem Hühnereiweiß, für Biotin zunutze gemacht. Avidin besteht aus vier gleichen Untereinheiten, welche jeweils fest an ein Molekül Biotin binden. Sowohl die $2^{\circ} \mathrm{AK}$ und die HA-bindenden Proteine (HABP, engl. byaluronic acid binding protein) als auch die HRP sind biotinyliert und binden hierüber beide gleichermaßen an eine der vier Untereinheiten des Avidinmoleküls, welches hierdurch zur Brücke zwischen Sekundärantikörper und Enzym wird. In dieser Arbeit wurde stets mit den Vectastain ${ }^{\circledR}$ ABC Kits von Vector Laboratories gearbeitet. Diese enthalten, je nach verwendetem Primärantikörper, speziesspezifische biotiniylierte anti-Immunglobulin Sekundärantikörper sowie zwei Reagenzien: Avidin DH (Reagenz A) und biotinylierte HRP H (Reagenz B). Beide Reagenzien werden gemeinsam je 1:100 in TBST verdünnt und die Lösung dann für 30 Minuten zum Inkubieren bei RT stehengelassen. Hierbei bilden sich Komplexe, bestehend aus Avidinmolekülen und den Biotinmolekülen der HRP. Von der inkubierten Lösung werden nach 30 Minuten je $200 \mu \mathrm{l}$ auf die Schnitte gegeben, nachdem zuvor die unspezifisch bzw. nicht gebundenen $2^{\circ} \mathrm{AK}$ durch dreimaliges Waschen mit TBST beseitigt wurden. Die Avidinmoleküle der Komplexe binden nun mit ihren freien, noch nicht an Biotin gebundenen Untereinheiten an die biotinylierten Stellen der $2^{\circ} \mathrm{AK}$, wodurch eine Vielzahl an HRP-Molekülen an einen $2^{\circ} \mathrm{AK}$ konjugiert werden und es zu einer Signalverstärkung kommt (Lang 2013).

\subsection{Standardprotokoll der Immunhistochemie}

Im Folgenden wird das für die IHC verwendete Standardprotokoll beschrieben. Abweichungen und Besonderheiten wie die verwendeten Puffer und Anitkörperkonzentrationen für die einzelnen Färbungen sind in Tabelle 8 (siehe Seite 32) zusammengefasst. Nach diesem Protokoll wurden die Färbungen für SPARC, HA, $\alpha$-SMA, CD31, Ki67 und CC3 (Cleaved Caspase-3) 
angefertigt. Anstelle von Antikörpern wurde für HA auf ein Gemisch aus zwei biotinylierten HABP zurückgegriffen, weswegen man nicht von IHC im eigentlichen Sinne sprechen kann. Bis auf folgende Besonderheiten gleicht das Färbeprotokoll aber dem der IHC, weswegen es hier beschrieben wird. Der Demaskierungsschritt ist für HA nicht nötig, weshalb im Anschluss an das Rehydrieren der Gewebe direkt das Blockieren der endogenen Peroxidase mit 3\% Wasserstoffperoxid $\left(\mathrm{H}_{2} \mathrm{O}_{2}\right)$ vorgenommen wurde. Nach Inkubation über Nacht mit HABP wurde am nächsten Tag nach dem Waschvorgang mit TBST kein $2^{\circ} \mathrm{AK}$ verwendet, sondern die Schnitte direkt mit dem fertig inkubierten AB-Complex (aus dem „Vectastain ${ }^{\circledR}$ ABC Kit Rabbit IgG“) behandelt. Alle anderen Schritte wurden wie im Protokoll der IHC durchgeführt:

Die verwendeten Puffer und Salzlösungen wurden nach den Protokollen aus Tabelle 7 (siehe Seite 26) hergestellt.

\section{Entparaffinieren}

$\mathrm{Zu}$ Beginn des Färbevorgangs wurden die Schnitte in einem Glasschiffchen für 2x 10 Minuten zum Entparaffinieren in Roticlear getaucht. Anschließend wurden die Gewebe einer Rehydrierung unterzogen, wobei die Schnitte eine absteigende Alkoholreihe durchliefen und je 4 Minuten in folgenden Ethanolkonzentrationen verweilten: 99\% (2x), 96\%, 80\%, 70\%, 50\%.

II Antigendemaskierung

Anschließend wurden die Schnitte mehrmals in Leitungswasser (LW) gespült und in einem Plastikschiffchen in Puffer überführt. Der Puffer (vgl. Tabelle 8, Seite 32) mit den Schnitten wurde in der Mikrowelle auf höchster Stufe zum Kochen gebracht. Ab dem Zeitpunkt, an dem der Puffer zu sieden begann, wurden die Schnitte weitere 5 Minuten im Puffer gekocht. Dieser Kochvorgang dient der Demaskierung von Antigenstrukturen, die während der Fixierung von Formalin-fixiertem Paraffin-eingebettetem Gewebe quervernetzt wurden und durch Formaldehyverbindungen Epitopveränderungen unterworfen waren. Diese Veränderungen werden beim Kochen teilweise wieder rückgängig und die Epitope den Antikörpern zugänglich gemacht. Man spricht hierbei von „hitzeinduzierter Epitopfreilegung“ (Lang 2013). Nach dem Kochvorgang wurden die Schnitte für weitere 10 Minuten im heißen Puffer in der Mikrowelle stehengelassen und anschließend für 20 Minuten zum Kühlen auf Eis gestellt. Besonders während der Antigendemaskierung aber auch während des gesamten Färbevorgangs muss sichergestellt werden, dass die Schnitte stets mit genügend Flüssigkeit (Puffer, Roticlear, Ethanol) bedeckt sind und zu keinem Zeitpunkt trockenfallen, da dies die Qualität der Färbung herabsetzen kann.

\section{Blockieren der endogenen Peroxidase}

Da als Detektionsenzym am $2^{\circ} \mathrm{AK}$ eine Peroxidase (HRP) verwendet wurde, musste im Vorfeld die im Gewebe vorhandene endogene Peroxidase irreversibel blockiert werden (Lang 2013). Hierzu wurden die Schnitte nach einem dreimaligen Waschvorgang in LW für 20 Minuten in $3 \% \mathrm{H}_{2} \mathrm{O}_{2}$ in deionisiertem Wasser inkubiert $\left(20 \mathrm{ml} 30 \% \mathrm{H}_{2} \mathrm{O}_{2}+180 \mathrm{ml} \mathrm{H}_{2} \mathrm{O}\right)$. Im Anschluss wurden die Schnitte erneut dreimal in $\mathrm{LW}$ gewaschen um alle Rückstände von $\mathrm{H}_{2} \mathrm{O}_{2}$ zu entfernen. 
IV Überfübren in das Cadenza System

Nach dem Waschen wurden die Objektträger aus dem Wasser genommen, zügig mit einem Tropfen TBST luftblasenfrei in die Haltevorrichtung eingesetzt und mit dieser in das Cadenza System überführt, wo sie dreimal mit $3 \mathrm{ml}$ TBST gespült wurden.

V Immunfärbung im Cadenza System

Die Schnitte wurden mit je $200 \mu$ des Blockierers, bestehend aus bovinem Serumalbumin (BSA) oder einem anderen tierischen Serum sowie Puffer (vgl. Tabelle 8), für je eine Stunde bei RT inkubiert. Durch die Serumproteine werden unspezifische Bindungsstellen von Gewebeproteinen für die eingesetzten $1^{\circ} \mathrm{AK}$ blockiert und dadurch die Hintergrundfärbung reduziert. Im Anschluss wurde jeder Schnitt mit $200 \mu \mathrm{l}$ des verdünnten $1^{\circ} \mathrm{AK}$ über Nacht bei $4{ }^{\circ} \mathrm{C}$ inkubiert. Am nächsten Tag wurden alle Schnitte viermal mit TBST gewaschen, um unspezifisch gebundene $\mathrm{AK}$ zu entfernen und anschließend mit je $200 \mu \mathrm{l}$ des verdünnten $2^{\circ} \mathrm{AK}$ für eine Stunde bei $37^{\circ} \mathrm{C}$ und geschlossenem Deckel inkubiert. Nach 30 Minuten wurde der AB-Complex angesetzt, bestehend aus je 1\% Reagenz A und Reagenz B in TBST, welcher für 30 Minuten bei RT stehen gelassen wurde. Nach der Inkubation mit dem $2^{\circ} \mathrm{AK}$ wurden die Schnitte viermal mit TBST gewaschen und mit $200 \mu \mathrm{l}$ des vorinkubierten AB-Complexes für weitere 60 Minuten bei RT inkubiert. Dann wurden die Schnitte wieder mit TBST gewaschen (3x) und aus dem Cadenza System in LW überführt.

\section{Entwickeln}

Die DAB-Lösung wurde aus dem ImmPACT ${ }^{\mathrm{TM}} \mathrm{DAB}$ Substrate-Kit nach Instruktion lichtgeschützt vorbereitet, wobei je $1 \mathrm{ml}$ des ImmPACT ${ }^{\text {TM }}$ DAB Diluent mit $30 \mu \mathrm{lmmPACT}{ }^{\text {TM }}$ DAB Chromogen gemischt wurde. Die Objektträger wurden aus dem Wasser genommen, horizontal in eine Haltevorrichtung gelegt und das Gewebe mit der vorbereiteten DAB-Lösung vollständig überschichtet. Nach Ablauf der Entwicklungszeit (siehe Tabelle 8) wurden die Schnitte wieder in Wasser gestellt, wodurch die Reaktion unterbrochen wurde und die Entwicklung endete. Dabei wurde darauf geachtet, dass alle Schnitte exakt gleichlang mit DAB entwickelt wurden um artifizielle Intensitätsunterschiede zu vermeiden.

VII Gegenfärbung und Eindecken

Nach der Entwicklung wurden alle Schnitte erneut dreimal mit LW gewaschen bevor sie für 3 Minuten in doppelt filtriertem Hämatoxylin gegengefärbt wurden. Im Anschluss wurden die Schnitte zum Bläuen für 5 Minuten in LW überführt, welches während dieses Vorgangs mehrmals gewechselt wurde. Abschließend wurden die fertig gefärbten Schnitte beim Durchlaufen einer aufsteigenden Alkoholreihe wieder dehydriert, wobei sie je 5 Minuten in folgenden Ethanolkonzentrationen verweilten: 70\%, 80\%, 96\% und 99\%. Zum Klären wurden die Schnitte je viermal für 5 Minuten in Roticlear getaucht, wodurch Brechungsunterschiede minimiert werden und es zu einer „Aufhellung“ kommt (Lang 2013). Nach dem Klären wurden die Schnitte unter Verwendung von Rotimount mit einem ausreichend großen Deckglas luftblasenfrei eingedeckt und über Nacht bei RT waagerecht zum Trocknen gelegt. 
Tabelle 8: Färbespezifikationen der Immunhistochemie

\begin{tabular}{|c|c|c|c|c|c|c|c|}
\hline 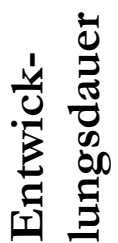 & 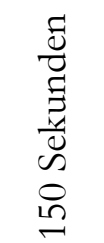 & 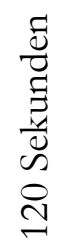 & 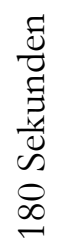 & 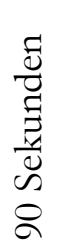 & 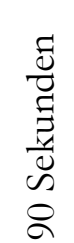 & 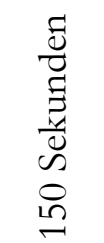 & 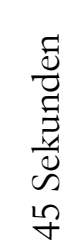 \\
\hline 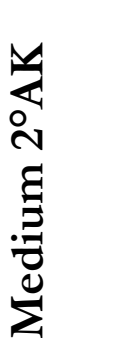 & 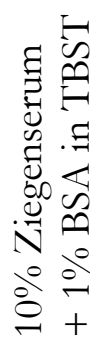 & 1 & 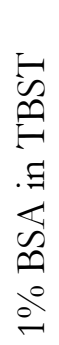 & 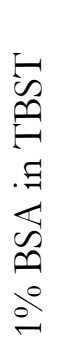 & 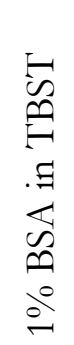 & 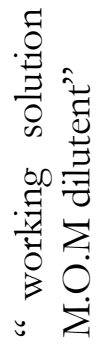 & 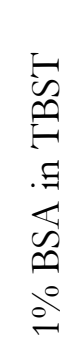 \\
\hline 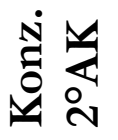 & 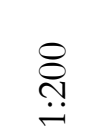 & 1 & $\underset{\stackrel{\leftrightarrow}{\leftrightarrow}}{\stackrel{\sim}{*}}$ & $\begin{array}{l}\stackrel{8}{\leftrightarrow} \\
\stackrel{\leftrightarrow}{\leftarrow}\end{array}$ & 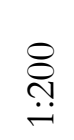 & $\begin{array}{l}\stackrel{\circ}{n} \\
\stackrel{\sim}{\sim}\end{array}$ & 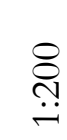 \\
\hline 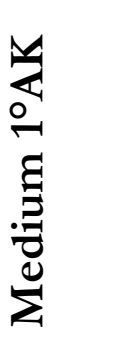 & 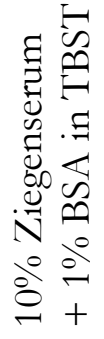 & 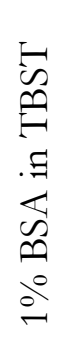 & $\begin{array}{l}5 \\
\infty \\
n \\
.1 \\
. \\
\infty \\
\infty \\
\infty \\
0 \\
0\end{array}$ & 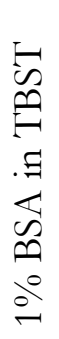 & 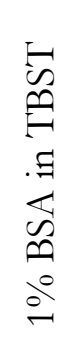 & 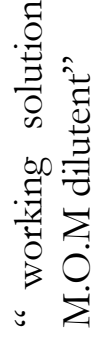 & 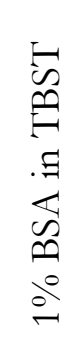 \\
\hline 련 & 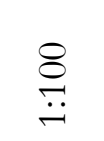 & $\begin{array}{l}\stackrel{8}{\Xi} \\
\stackrel{\bullet}{ت}\end{array}$ & $\begin{array}{l}8 \\
\stackrel{8}{\dddot{-}}\end{array}$ & $\begin{array}{l}\stackrel{8}{\circ} \\
\stackrel{\leftrightarrow}{-}\end{array}$ & 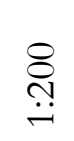 & 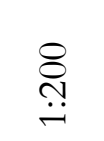 & $\begin{array}{l}8 \\
\stackrel{\leftrightarrow}{-}\end{array}$ \\
\hline 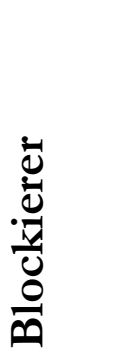 & 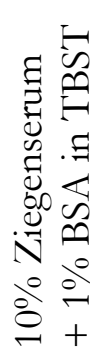 & 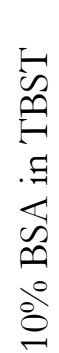 & 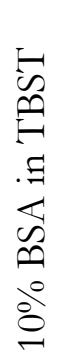 & 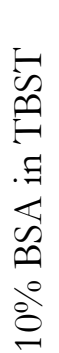 & 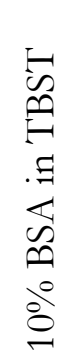 & 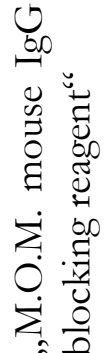 & 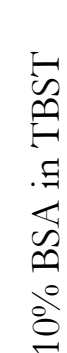 \\
\hline 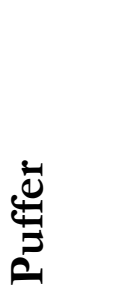 & 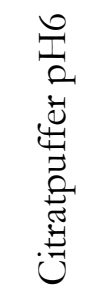 & , & 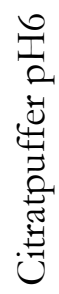 & 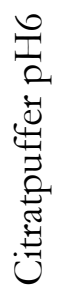 & 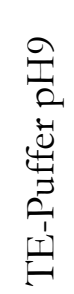 & 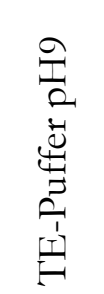 & 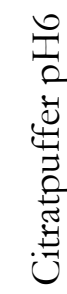 \\
\hline 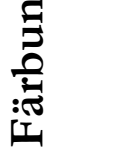 & 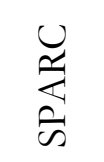 & 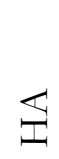 & $\overrightarrow{\tilde{\omega}}$ & 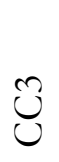 & $\begin{array}{l}\hat{0} \\
i \underline{1}\end{array}$ & 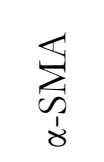 & $\frac{9}{I}$ \\
\hline
\end{tabular}




\subsubsection{Immunfluoreszenz}

Immunfluoreszenz (IF) ist der IHC vom Prinzip sehr ähnlich, jedoch erfolgt der Nachweis der $2^{\circ} \mathrm{AK}$ statt durch Enzyme mittels gekoppelter Fluorochrome wie zum Beispiel Fluoresceinisothiocyanat (FITC) (Lang 2013; Junqueira und Carneiro 2005). Fluorochrome sind Moleküle, die sich dadurch auszeichnen, dass sie nach Anregung mit einem bestimmten Wellenlängenspektrum Licht einer längeren, definierten Wellenlänge emittieren. Dieses Licht kann einen nachgeschalteten Filter passieren, detektiert werden und belegt so die Anwesenheit des $2^{\circ} \mathrm{AK}$ am Epitop. Der in dieser Arbeit verwendete $2^{\circ}$ AK Alexa Fluor ${ }^{\circledR} 488$ weist beispielsweise Maxima für Anregung und Emission von $495 \mathrm{~nm}$ bzw. $519 \mathrm{~nm}$ auf und liegt damit im grünen Bereich des sichtbaren Lichts.

Co-Immunfluoreszenz (Co-IF) ermöglicht es innerhalb eines Schnittes zwei (oder mehr) Antigene zu detektieren und damit zu prüfen, ob und welche Zellen bzw. Zellkompartimente beide Antigene enthalten. Hierfür werden $1^{\circ} \mathrm{AK}$ aus zwei unterschiedlichen Spezies sowie $2^{\circ} \mathrm{AK}$ mit unterschiedlichen Absorptions- und Emissionsspektren verwendet (siehe Tabelle 9).

Tabelle 9: Antikörper für Co-Immunfluoreszenz

\section{Typ Antigen Spezies Absorptions- und Emissionsmaxima}

\begin{tabular}{|c|c|c|c|}
\hline $\begin{array}{l}1^{\circ} \mathrm{AK} \\
\mathrm{IgG}\end{array}$ & $\alpha$-Smooth Muscle Actin & $\begin{array}{l}\text { Maus IgG, mono- } \\
\text { klonal }\end{array}$ & --- \\
\hline $\begin{array}{l}2^{\circ} \mathrm{AK} \\
\operatorname{IgG}\end{array}$ & $\begin{array}{l}\text { Alexa Fluor }{ }^{\circledR} 488 \text { conjugate, } \\
\text { anti-Maus IgG2a }\end{array}$ & Ziege IgG, polyklonal & $495 / 519 \mathrm{~nm}$ \\
\hline $\begin{array}{l}1^{\circ} \mathrm{AK} \\
\operatorname{IgG}\end{array}$ & $\mathrm{Ki}-67$ & $\begin{array}{l}\text { Kaninchen IgG, mo- } \\
\text { noklonal }\end{array}$ & --- \\
\hline $\begin{array}{l}2^{\circ} \mathrm{AK} \\
\operatorname{IgG}\end{array}$ & $\begin{array}{l}\text { Alexa Fluor }{ }^{\circledR} 568 \text { conjugate, } \\
\text { anti-Kaninchen } \operatorname{IgG}\end{array}$ & Esel, polyklonal & $578 / 603 \mathrm{~nm}$ \\
\hline
\end{tabular}

Für die IF wird das Protokoll der IHC mit den in Tabelle 10 beschriebenen Modifikationen befolgt. Die Behandlung mit $\mathrm{H}_{2} \mathrm{O}_{2}$ ist für die IF nicht nötig und wurde nicht durchgeführt. Da Chromogene lichtempfindlich sind und bei Lichtexposition ausbleichen, wurden alle Arbeitsschritte ab der Vorbereitung des $2^{\circ} \mathrm{AK}$ im Halbdunkel durchgeführt. Nach der Behandlung mit den beiden $2^{\circ} \mathrm{AK}$ und anschließendem Waschen mit TBST wurden alle Schnitte aus dem Cadenza-System herausgenommen, mit DAPI-Mount luftblasenfrei eingedeckt und über Nacht dunkel bei RT gelagert. DAPI (4',6-Diamidin-2-phenylindol) ist ein blauer Fluoreszenzfarbstoff, welcher sich an Doppelstrang-DNA anlagert und zuverlässig alle Zellkerne anfärbt. Die anschließende Lagerung fand im Dunkeln bei $4{ }^{\circ} \mathrm{C}$ statt, alle Bilder wurden innerhalb von drei Wochen aufgenommen. 
Tabelle 10: Spezifikationen für die Co-Immunfluoreszenz

\begin{tabular}{|c|c|c|c|c|c|c|}
\hline Antikörper & Puffer & Blockierer & $\begin{array}{l}\text { Konz. } \\
1^{\circ} \mathrm{AK}\end{array}$ & $\begin{array}{l}\text { Medium } \\
1^{\circ} \mathrm{AK}\end{array}$ & $\begin{array}{l}\text { Konz. } \\
2^{\circ} \mathrm{AK}\end{array}$ & $\begin{array}{l}\text { Medium } \\
2^{\circ} \mathrm{AK}\end{array}$ \\
\hline $\begin{array}{l}\text { Alexa Fluor® } \\
488\end{array}$ & \multirow{4}{*}{$\begin{array}{l}\underset{\hat{I}}{\theta} \\
\stackrel{I}{H}\end{array}$} & \multirow{4}{*}{ 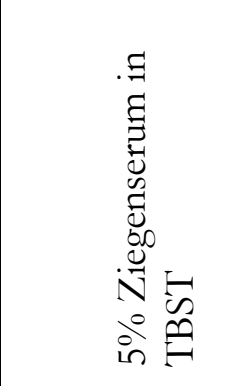 } & & & 1:1000 & \multirow{3}{*}{$10 \% \mathrm{BSA}$} \\
\hline $\begin{array}{l}\text { Alexa Fluor }{ }^{\circledR} \\
568\end{array}$ & & & & & 1:1000 & \\
\hline Ki67 & & & $1: 200$ & 5\% Zie- & & \\
\hline$\alpha$-SMA & & & $1: 250$ & in TBST & & \\
\hline
\end{tabular}

\subsubsection{Picrosirius Rot}

Alle Schritte für die Picrosirius-Rot-Färbung fanden in der feuchten Kammer statt. Die Schnitte wurden wie für die IHC beschrieben entparaffiniert, rehydriert und anschließend für 8 Minuten in doppelt filtriertem Hämatoxylin gefärbt. Im nächsten Schritt wurden sie für 10 Sekunden in angesäuertem Ethanol (250 $\mathrm{ml}$ 100\% Ethanol $+5 \mathrm{ml} 1 \mathrm{M} \mathrm{HCl})$ geschwenkt und nach gründlichem Waschen für 5 Minuten zum Bläuen in LW gestellt. Vor und nach der Inkubation für 2 Minuten in Lösung A (Phosphomolybdic Acid) wurden die Schnitte kurz mit deionisiertem Wasser gewaschen. In Lösung B (Picrosirius Red F3BA Stain) wurden die Schnitte 60 Minuten inkubiert und dann für 2 Minuten in Lösung C (1 N Hydrochloride Acid) überführt um schlussendlich für 45 Sekunden in 70\% Ethanol gewaschen zu werden. Dehydrierung, Klären und Eindecken wurde genau wie im IHC-Protokoll (siehe 2.2.2.2.4 Standardprotokoll der Immunhistochemie) beschrieben durchgeführt.

\subsubsection{Auswertung und Quantifizierung der Histologie}

Die Färbungen wurden quantitativ ausgewertet. Hierzu wurden je nach Färbung entweder angefärbte Strukturen manuell ausgezählt, oder die über einen Intensitätsgrenzwert als positiv definierten Flächen planimetrisch ausgewertet.

Die je n=49 Färbungen für Ki67, PHH3, CC3 und CD31 wurden nach Cambridge, UK geschickt und dort mit modernen Mikroskopen (Olympus BX51) und Scannern (Aperio XT automated scanning system) und Bildauswertungssoftware (Imagescope 10 software) automatisiert quantifiziert. Hier wurden pro Maus und Färbung je 30 Bilder analysiert. Die verwendete Software ermöglichte es aus der CD31-Färbung sowohl die mittlere Gefäßdichte (MVD, engl. mean vessel density) als auch die mittlere Gefäßfläche (MLA, engl. mean lumen area) zu ermitteln. Für die Vergleichsstudie zwischen Primärtumor und korrespondierenden Lebermetastasen wurden Ki67, CC3 und CD31 separat in Göttingen analysiert (vgl. Tabelle 11). 
Tabelle 11: Übersichtsdarstellung der Quantifizierung

\begin{tabular}{|c|c|c|c|c|c|c|c|c|c|}
\hline \multirow{2}{*}{ Färbung } & \multirow{2}{*}{$\begin{array}{l}\text { Anzahl } \\
\text { Mäuse }\end{array}$} & \multirow{2}{*}{$\begin{array}{l}\mathrm{m} \\
/ \mathrm{p}\end{array}$} & \multirow{2}{*}{$\begin{array}{l}\text { Vergrö- } \\
\text { Berung }\end{array}$} & \multicolumn{6}{|c|}{ Ø Anzahl Bilder pro Gewebe/Kompartiment } \\
\hline & & & & PT & $\min / \max$ & LM & $\min / \max$ & NL & $\min / \max$ \\
\hline SPARC & 46 & $\mathrm{p}$ & $100 \mathrm{x}$ & 42,7 & $14 / 105$ & & & & \\
\hline HA & 46 & $\mathrm{p}$ & $100 \mathrm{x}$ & 44,4 & $11 / 110$ & & & & \\
\hline Picrosirius & 46 & $\mathrm{p}$ & $100 \mathrm{x}$ & 51,9 & $17 / 115$ & & & & \\
\hline$\alpha$-SMA & 46 & $\mathrm{p}$ & $100 x$ & 61,2 & $23 / 95$ & & & & \\
\hline $\begin{array}{l}\alpha \text {-SMA } \\
+ \text { Ki67 }\end{array}$ & 46 & $\mathrm{~m}$ & $400 \mathrm{x}$ & 5 & $5 / 5$ & & & & \\
\hline $\begin{array}{l}\text { Picrosirius } \\
\text { (PT vs. LM) }\end{array}$ & 8 & $\mathrm{p}$ & $100 \mathrm{x}$ & 21.1 & $15 / 27$ & 11,4 & $3 / 46$ & 9.6 & $8 / 10$ \\
\hline $\begin{array}{l}\text { SPARC } \\
\text { (PT vs. LM) }\end{array}$ & 7 & $\mathrm{p}$ & $100 \mathrm{x}$ & 40,4 & 15/101 & 7,8 & $4 / 20$ & 10 & $9 / 11$ \\
\hline $\begin{array}{l}\text { HA } \\
\text { (PT vs. LM) }\end{array}$ & 8 & $\mathrm{p}$ & $100 x$ & 18 & $11 / 25$ & 8,5 & $4 / 17$ & 9,9 & $9 / 10$ \\
\hline $\begin{array}{l}\alpha-\text { SMA } \\
\text { (PT vs. LM) }\end{array}$ & 11 & $\mathrm{p}$ & $200 x$ & 10,3 & $7 / 11$ & 9,7 & $7 / 20$ & & \\
\hline $\begin{array}{l}\text { CD31 } \\
\text { (PT vs. LM) }\end{array}$ & 8 & $\mathrm{~m}$ & $400 x$ & 9,4 & $6 / 10$ & 9,8 & $9 / 10$ & 9,8 & $8 / 10$ \\
\hline $\begin{array}{l}\text { Ki67 } \\
\text { (PT vs. LM) }\end{array}$ & 6 & $\mathrm{~m}$ & $400 x$ & 10 & $10 / 10$ & 10 & $10 / 10$ & & \\
\hline $\begin{array}{l}\text { CC3 } \\
\text { (PT vs. LM) }\end{array}$ & 6 & $\mathrm{~m}$ & $400 x$ & 10 & $10 / 10$ & 10 & $10 / 10$ & & \\
\hline
\end{tabular}

Legende: (m) manuelle Analyse; (p) planimetrische Analyse; (PT) Primärtumor; (LM) Lebermetastase; (NL) normale Leber; (min/max) minimale/maximale Anzahl analysierter Bilder pro Maus; (vs.) versus Die untere Tabellenhälfte beschreibt den Stromavergleich zwischen Primärtumor und Metastasen.

\subsection{Manuelle Analyse}

Die Färbungen CD31, CC3, Ki67 und die Co-IF $\alpha$-SMA+Ki67 für den Kompartimentvergleich von PT und LM wurden manuell ausgezählt. Hierbei wurde für die Software Fiji, eine Weiterentwicklung des bekannten ImageJ, das Plug-In „CellCounter“(Cell_Counter-2.2.0) genutzt um gezählte Strukturen zu markieren. Die Anzahl der analysierten Bilder und die jeweils benutzte Vergrößerung ist in Tabelle 11 dargestellt.

\subsection{Co-Immunfluoreszenz: $\alpha$-smooth muscle actin+Ki67}

Von $\alpha$-SMA-reichen Tumorarealen wurden pro Maus fünf Bilder in 400x Vergrößerung ausgezählt. Dabei wurden unter Ausblendung des Ki67-Kanals zunächst alle Zellkerne markiert, die DAPI-positiv und vollständig von $\alpha$-SMA-positivem Signal umgeben waren. Sowohl positive Zellen in Blutgefäßen wie auch Artefakte wurden ignoriert. Unter Verwendung des Ki67-Kanals wurden anschließend alle Zellkerne gezählt, die im Vorfeld für $\alpha$-SMA markiert worden waren und eine positive Ki67-Färbung aufwiesen, und als „doppelt positiv“ definiert. Für jedes Bild wurde die Rate der doppelt positiven an allen $\alpha$-SMA-positiven Zellen berechnet. Diese Werte wurden pro Maus gemittelt und als $\alpha$-SMA+Ki67-Ratio bzw. als Fibroblastenproliferationsrate bezeichnet. Beispielhafte Bilder sind in 3.1.1 (Seite 54) abgebildet. 


\subsection{CD31, Ki67 und Cleaved-Caspase-3}

In den Gewebekompartimenten PT, LM und normales Lebergewebe (NL) wurden in Bildern in 400x Vergrößerung für CD31 die Blutgefäße und in 200x Vergrößerung für Ki67 und CC3 die positiven Zellkerne gezählt. Durchschnittlich wurden dabei pro Maus und pro Kompartiment jeweils 10 Bilder begutachtet. Alle Bilder wurden von repräsentativen, zufällig ausgewählten Regionen angefertigt. Die pro Bild gezählten Blutgefäße wurden für jede Maus und Kompartiment/Gewebetyp gemittelt. Wenn die LM das Bild nicht vollständig ausfüllten, wurde die Gefäß- bzw. Kernanzahl auf die Bildgröße normiert, indem sie durch den Anteil, den die Metastase vom Bild ausfüllte, dividiert wurde. Der Anteil der Metastase am Bild wurde vorher planimetrisch durch Umfahren und Ausmessen mittels Fiji-Software ermittelt (siehe 2.2.2.5.2).

\subsection{Planimetrische Analyse}

Die Planimetrie der Bilder der Färbungen SPARC, HA, Picrosirius Rot und $\alpha$-SMA erfolgte mit der Java-basierten open-source Software Fiji, einer Weiterentwicklung des etablierten ImageJ (Schindelin et al. 2012). Bei Aufnahme der Bilder wurde darauf geachtet, dass Belichtungszeit, Lichtintensität, Blendenöffnung, ISO und Kontrasteinstellung innerhalb einer Färbung identisch waren um artifizielle Sättigungs- und Intensitätsunterschiede zwischen einzelnen Bildern und Mäusen zu vermeiden und die Ergebnisse vergleichbar zu halten. Überfärbte Randbereiche, Nekrosen und Artefakte wurden nicht in die Analyse eingeschlossen. Im Vorfeld der endgültigen Analyse wurden Stichproben an Bildern voranalysiert um Sättigungs- und Intensitätsgrenzwerte für die einzelnen Färbungen zu finden, die das Vorhandensein von SPARC, HA, Kollagen und $\alpha$-SMA in allen Mäusen möglichst genau abbildeten. Hierbei konnten für die Färbungen entsprechende Grenzwerte festgelegt werden. Diese sind in Tabelle 12 dargestellt. Für SPARC ließ sich kein Grenzwert finden, der auf alle Mäuse gleichermaßen anwendbar gewesen wäre, ohne das Vorhandensein von SPARC für einzelne Mäuse deutlich zu über- oder unterschätzen. Hier wurde stattdessen für jede Maus nach Beurteilung mehrerer Einzelbilder ein individueller Grenzwert festgesetzt, der das Vorhandensein von SPARC möglichst gut abbildet.

Tabelle 12: Grenzwerte für die planimetrische Analyse

\section{Färbung Verfahren Grenzwerte}

\begin{tabular}{lll}
\hline HA & Color Threshold & HSB: H 0-45, S 25-255, B 0-255; pass \\
\hline SPARC & DAB Colour Deconvolution & $0-140 / 180(\min / \max )$ \\
\hline Picrosirius & Color Threshold & HSB: H 224-255, S 80-255, B 170-255, \\
& & pass \\
\hline$\alpha$-SMA & DAB Colour Deconvolution & $\begin{array}{l}0-140 \text { für die Stromaanalyse in PT } \\
\end{array}$ \\
& $0-120$ für den Vergleich von PT und LM \\
\hline
\end{tabular}

Legende: (HSB) Hue (engl. Farbton); Saturation (engl. Sättigung); Brightness (engl. Helligkeit); (pass) alle Werte innerhalb der angegebenen Grenzwerte werden berücksichtigt, nicht jedoch die Werte außerhalb der angegebenen Grenzen. 
Für die Analyse kamen zwei Verfahren zum Einsatz, die vergleichbar gute Ergebnisse lieferten. Das jeweils verwndete Verfahren ist aus Tabelle 12 ersichtlich. Entweder wurde über das PlugIn „Color Deconvolution“ (Colour_Deconvolution-2.0.0) der DAB-Kanal (brauner Farbton) isoliert und hier ein Intensiätsgrenzwert (Image Adjust Threshold) angesetzt oder es wurden über „Image Color Threshold“ im HSB-Farbraum Grenzwerte festgelegt, nach denen Pixel als positiv oder negativ definiert wurden. Die positiven Pixel wurden über „Analyze Analyze Particles“ ermittelt, durch die Gesamtzahl aller Pixel dividiert und als prozentuale Fläche betrachtet. Metastasen, die nicht das gesamte Bild ausfüllten, wurden auf die Bildfläche normiert (vgl. 2.2.2.5.1.2). Die Grenzwerte werden in Tabelle 12 dargestellt. Exemplarisch wird die Analyse mittels Color Threshold für Picrosirius in Abbildung 7 und Abbildung 8 dargestellt, wobei in letzterer mit kräftigem Rot all jene Pixel, die als Picrosirius-positiv eingeschätzt wurden, markiert sind. Die Analyse und Ausgabe der prozentualen Fläche ist ebenfalls in Abbildung 8 zu sehen. Da für Färbungen wie Picrosirius, SPARC und HA die gesamte Fläche des PT analysiert wurde und hierbei durchschnittlich 40 bis 50 Bilder pro Maus bei knapp 50 Mäusen zu analysieren waren, wurden hier Makros erstellt um den hohen Durchsatz an Bildern bewältigen zu können. Die genaue Anzahl von Bildern pro Kompartiment wird in Tabelle 11 dargestellt.

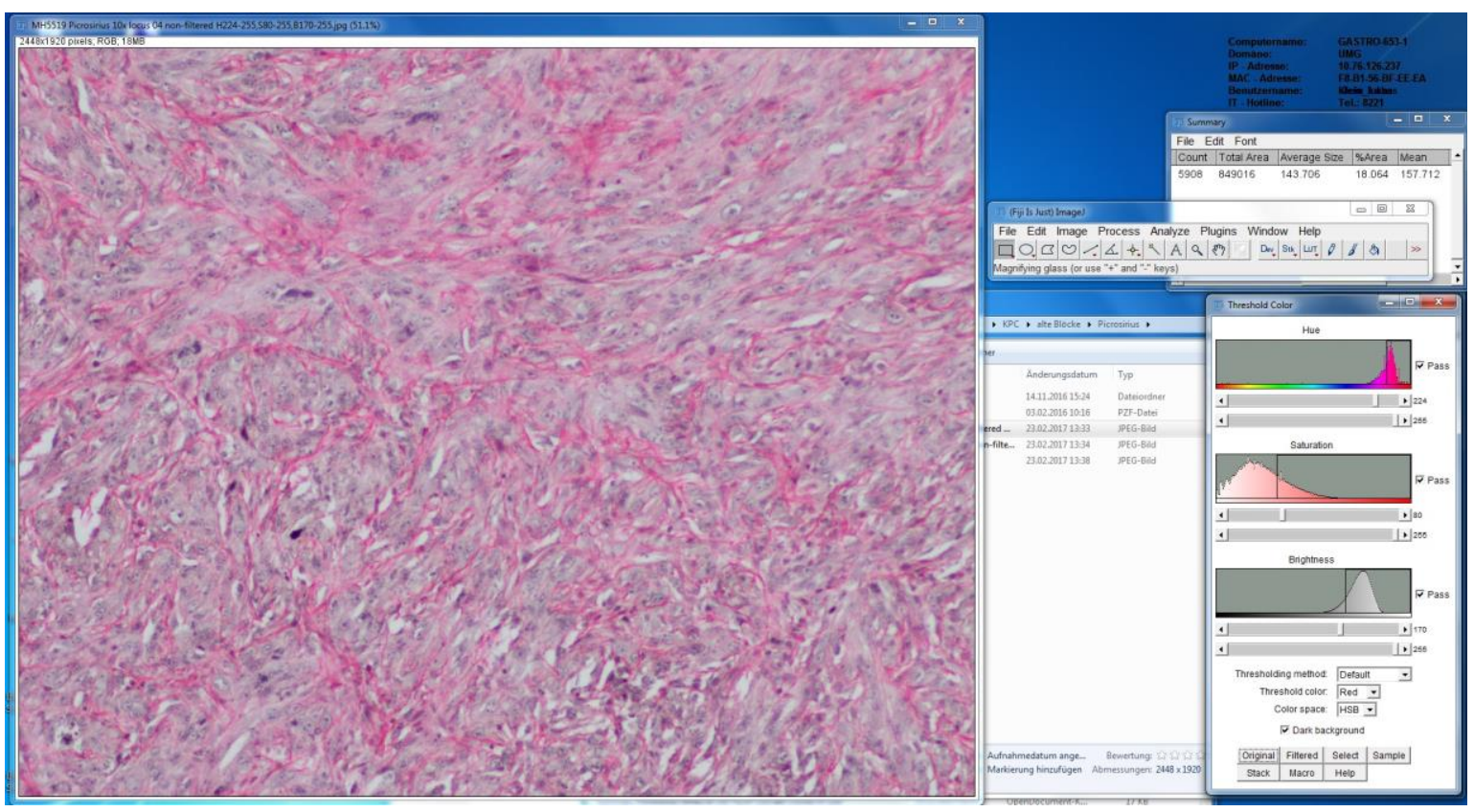

\section{Abbildung 7: Picrosiriusfärbung ohne Filter}

Picrosiriusfärbung im primären PDAC der KPC-Maus. Kollagenfasern stellen sich in Rot-Pink-Tönen dar. 


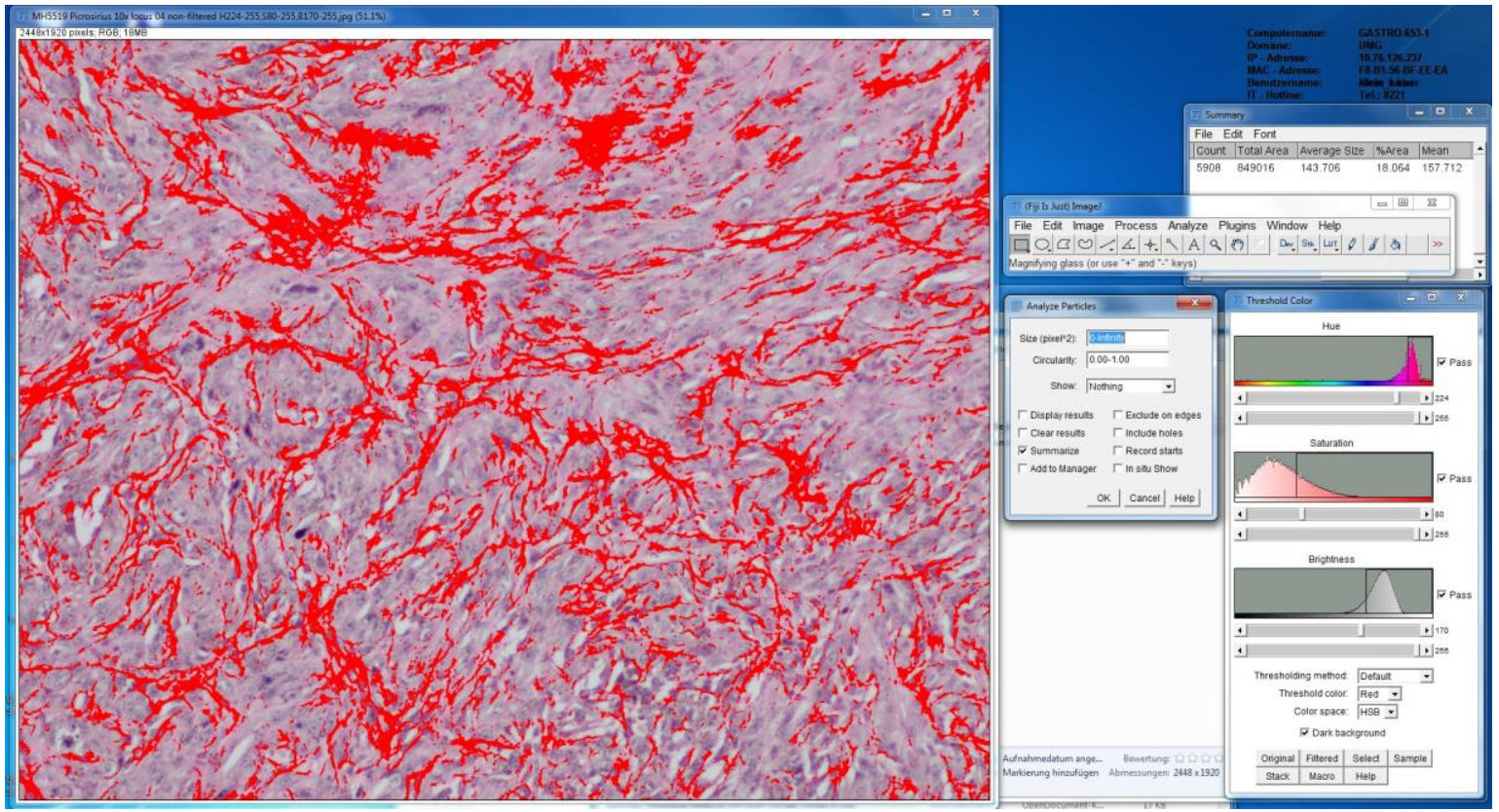

\section{Abbildung 8: Picrosiriusfärbung mit Filter und Analyse}

Mittels Fiji wird der zuvor für alle Schnitte festgelegte Filter mit den Grenzwerten über das Bild gelegt. Bei vergleichender Betrachtung mit dem Originalbild durch An- und Abschalten des Filters lässt sich erkennen, dass der Filter die Picrosiriusfärbung gut abdeckt. Hierbei werden keine bedeutenden Flächen übergangen oder fälschlicherweise positiv gewertet.

\subsection{Grading und Desmoplasie}

Gemeinsam mit Prof. Ströbel aus der Abteilung für Pathologie wurden die HE-Färbungen begutachtet. Freundlicherweise stellte er für jede KPC-Maus fest, ob ein invasives PDAC vorlag und welches Grading (G1-3) und welcher Desmoplasiegrad (D1-3) vorlagen. Mäuse ohne invasives Karzinom wurden nicht in die Analysen eingeschlossen.

\subsubsection{Westernblot}

\subsubsection{Proteingewinnung für den Westernblot}

Die Gewebe aus den KPC-Mäusen lagen gekühlt in flüssigem Stickstoff vor. Die Gewebeextraktion, insbesondere der Lebermetasen, war mit großer Sorgfalt vorgenommen worden. Alle folgenden Arbeitsschritte wurden auf Eis durchgeführt um eine Degradierung der Proben zu vermeiden. Aus dem Lysepuffer (vgl. Tabelle 13) wurde das Lysereagenz (vgl. Tabelle 14) frisch angesetzt, und von letzterem wurden je $500 \mu \mathrm{l}$ zu einem Gewebestück gegeben. Die Gewebe wurden mittels kleiner Metallkugel im Tissue Lyser für eine Minute lysiert und für 30 Minuten auf Eis gestellt. Nach der Zentrifugation bei 14.000rpm (Rotationen pro Minute) bei $4{ }^{\circ} \mathrm{C}$ für 15 Minuten wurde der Überstand in ein neues Plastikgefäß überführt und bei $-80{ }^{\circ} \mathrm{C}$ eingefroren oder direkt der Proteinkonzentrationsmessung zugeführt. 
Tabelle 13: Lysepuffer für Proteinisolation

Bestandteile des Lysepuffers

Mengen pro Liter

50 mM HEPES (pH 7,5-pH 7,9)

$11,92 \mathrm{~g}$

$100 \mathrm{mM}$ Natriumfluorid

$4,2 \mathrm{~g}$

$10 \mathrm{mM} \mathrm{Na}_{4} \mathrm{O}_{7} \mathrm{P}_{2} \times 10 \mathrm{H}_{2} \mathrm{O}$ (tetra-Natriumdiphosphat Decahydrat)

$4,46 \mathrm{~g}$

$150 \mathrm{mM} \mathrm{NaCl}$

$8,77 \mathrm{~g}$

$1 \mathrm{mM}$ Ethylenglycol-bis(aminoethylether)-N,N,N',N'-tetraessigsäure

$0,38 \mathrm{~g}$

10\% Glycerin

$100 \mathrm{ml}$

1\% TritonX-100

$10 \mathrm{ml}$

Tabelle 14: Lysereagenz für Proteinisolation aus Gewebe

Bestandteile des Lysereagenz

Ansatz:

Lysepuffer

$1 \mathrm{ml}$

$100 \mathrm{mM}$ Phenylmethylsulfonylflurid in Ethanol

$10 \mu \mathrm{l}$

25x cOmplete ${ }^{\circledR}$ (Proteaseinhibitor (Roche))

$40 \mu \mathrm{l}$

100 mM Orthovanadat

$10 \mu \mathrm{l}$

100 mM Natriumfluorid

$10 \mu \mathrm{l}$

\subsubsection{Proteinkonzentrationsbestimmung nach Bradford}

Die Methode zur Proteinbestimmung nach Bradford macht sich die Verschiebung im Absorbtionsspektrum des Farbstoffs Comassie Blue G-250 von $465 \mathrm{~nm}$ zu $595 \mathrm{~nm}$ in Anwesenheit von Protein zunutze. Gemessen wird die Zunahme der Absorbtion bei $595 \mathrm{~nm}$ als Maß für die Proteinkonzentration (Rehm und Letzel 2010).

Die Probe wurde langsam auf Eis aufgetaut und 1:26 in Ampuwa (doppelt destilliertes Wasser) verdünnt. Von einer im Vorfeld angefertigten Proteinstandardkurve bekannter Konzentration, einer internen Kontrolle und der Probe wurden in doppelter Ausführung je $5 \mu$ l in eine 96-WellPlatte pipettiert und pro Well $200 \mu$ l Coomassie Blue G-250 Protein Assay Reagent hinzugegeben. Das Pipettierschema ist in Tabelle 15 dargestellt. Die Proteinstandardkurve wurde zuvor durch Verdünnung von Standardalbumin in Ampuwa erstellt und die internen Kontrollen mit den Verdünnungen 1:7,25 und 1:13,5 jeweils frisch angesetzt. Nach 5 Minuten Inkubation bei RT wurde die Absorption bei $595 \mathrm{~nm}$ im Photometer gemessen. Anhand der Extinktionswerte in der Standardkurve wurde die Proteinkonzentration der Probe berechnet. 
Tabelle 15: Pipettierschema für die Proteinbestimmung nach Bradford

\begin{tabular}{|c|c|c|c|}
\hline Plattenposition & $\begin{array}{l}\text { Proteinkonzentration } \\
(\mathrm{mg} / \mathrm{ml})\end{array}$ & Albuminlösung 1mg/ml $(\mu \mathrm{l})$ & $\begin{array}{c}\text { Ampuwa } \\
(\mu 1)\end{array}$ \\
\hline A $1+2$ & 0 & 0 & 500 \\
\hline B $1+2$ & 0,03 & 15 & 485 \\
\hline C $1+2$ & 0,05 & 25 & 475 \\
\hline $\mathrm{D} 1+2$ & 0,1 & 50 & 450 \\
\hline $\mathrm{E} 1+2$ & 0,2 & 100 & 400 \\
\hline $\mathrm{F} 1+2$ & 0,4 & 200 & 300 \\
\hline $\mathrm{G} 1+2$ & 0,6 & 300 & 200 \\
\hline \multirow[t]{2}{*}{$\mathrm{H} 1+2$} & 0,8 & 400 & 100 \\
\hline & & Albuminlösung $2 \mathrm{mg} / \mathrm{ml}(\mu \mathrm{l})$ & \\
\hline $\begin{array}{l}\text { Interne Kontrolle } \\
1: 7,25\end{array}$ & 0,276 & 4 & 25 \\
\hline $\begin{array}{l}\text { Interne Kontrolle } \\
1: 13,5\end{array}$ & 0,148 & 4 & 50 \\
\hline
\end{tabular}

\subsubsection{Theorie und Grundlagen des Westernblots}

Westerblot ist ein Verfahren, welches es ermöglicht aus einem Proteingemisch wie beispielsweise Zell- oder Gewebelysaten einzelne Proteine isoliert nachzuweisen, zu identifizieren und gegebenenfalls auch zu quantifizieren.

\subsection{Polyacrylamidgelelektrophorese nach Lämmli}

In einem Vorschritt bedarf es zur isolierten Betrachtung einzelner Proteine eine Auftrennung. Diese Auftrennung wird in der Regel durch Elektrophorese in einer Gel-Matrix, typischerweise einem Polyacrylamidgel (PAGE für Polyacrylamidgelelektorphorese) in einer feuchten Kammer erreicht. Dabei wird die Wahl der Polyacrylamidkonzentration des Gels von der Proteingröße abhängig gemacht. Bei der diskontinuierlichen Gelelektrophorese nach dem Lämmli-System wird ein kurzes Sammelgel mit niedrigerem Acrylamidgehalt und neutralem pH-Wert von einem Trenngel unterschieden. Das Sammelgel dient der Konzentration der Proteine in einer gemeinsamen Ebene. Trenngele hingegen haben einen höheren Acryalmidgehalt und einen basischen pH-Wert. In ihnen findet die eigentliche Proteinauftrennung statt. Die Polyacrylamidkonzentration bedingt die Porengröße, die den bestimmenden Faktor für die Laufgeschwindigkeit der Proteine darstellt. Damit die Auftrennung im elektrischen Feld nach dem Molekulargewicht und nicht der Molekülladung stattfindet, wird die Probe mit dem Tensid Natriumdodecylsulfat (SDS, engl. sodium dodecyl sulfate) auf $95{ }^{\circ} \mathrm{C}$ erhitzt. Hierdurch entstehen SDS-Protein-Komplexe mit 
einem konstanten Masse-Ladungsverhältnis, da die anionischen SDS-Moleküle die Eigenladung der Proteine überdecken. Sie führen auch zu einer Aufhebung der Sekundär- und Tertiärstruktur (und gegebenenfalls Quartärstruktur) und dadurch einer Linearisierung der Proteine. Diese linearisierten, anionischen SDS-Proteinkomplexe wandern im (longitudinal) angelegten elektrischen Feld durch das Gel zur Anode und trennen sich nach der Molekülmasse auf. Kleine bzw. leichte Moleküle interagieren weniger stark mit der Polyacrylamidmatrix, werden dadurch weniger stark zurückgehalten und laufen in der gleichen Zeit weiter Richtung Anode als große Moleküle. Die Laufgeschwindigkeit hängt von der Spannung zur Erzeugung des elektrischen Feldes ab, die auf alle Proteine gleichermaßen wirkt. Als Referenz wird neben den Proben in der Regel ein Proteingemisch bekannter Zusammensetzung und Laufweite aufgetragen, wodurch die Banden der Proben später einem Molekulargewicht zugeordnet werden können (Rehm und Letzel 2010; Laemmli 1970).

\subsection{Blotting und Immunidentifizierung}

Die im Gel aufgetrennt vorliegenden Proteine müssen im nächsten Schritt, dem eigentlichen Blotting, auf eine Membran übertragen werden, wo sie immunologischen Nachweisverfahren zugänglich vorliegen. Der Proteintransfer findet bei Polyacrylamidgelen mittels Elektrotransfer statt, einem Verfahren bei dem senkrecht zu parallel liegendem Gel und Membran (Nitrozellulose- oder Nylonmembran) ein elektrisches Feld angelegt wird und die Protein-SDS-Komplexe diesem entsprechend aus dem Gel auf die Membran wandern. Zur Verbesserung der Leitfähigkeit werden in Puffer getränkte Filter und Schwämme zwischen Gel und Kathode sowie Membran und Anode gelegt. Das Bandenmuster bleibt beim Transfer auf die Membran erhalten. Es ist möglich alle Proteine auf der Membran temporär unspezifisch anzufärben (mittels Ponceau Rot) um die Anwesenheit der Banden (und des Referenzstandards) auf der Membran nachzuweisen. Eine genaue Identifizierung ist jedoch nur immunologisch möglich. Um die Proteine auf der Membran einer immunologischen Nachweistechnik mittels (spezifischer) Antikörper zugänglich zu machen, muss das SDS ausgewaschen werden, woraufhin die Proteine wieder weitestgehend ihre Sekundär- und Tertiärstruktur einnehmen und damit ihre spezifischen Epitope ausbilden. Wie auch in der IHC müssen vor Zugabe der $1^{\circ} \mathrm{AK}$ die unspezifischen Epitope der Membran und anderer Proteine durch Zugabe von Proteinen, welche nicht durch die Antikörper gebunden werden, blockiert werden. Dazu wird meist Milchpulver oder BSA verwendet. Wie in der IHC wird auch im Westernblot in der Regel die sekundäre Methode (vgl. 2.2.2.2.2) verwendet, wobei der Antikörpernachweis ebenfalls mittels gekoppeltem Enzym wie HRP durchgeführt wird. Die Peroxidase oxidiert Luminol, wodurch es einen lumineszenten Zustand einnimmt. Wenn diese Reaktion in Gegenwart von Phenolen stattfindet, wird die Lichtemission in etwa um den Faktor 1000 gesteigert. Das emittierte Licht hat ein Maximum bei einer Wellenlänge von $428 \mathrm{~nm}$ und kann mittels spezieller Kameras detektiert werden (Rehm und Letzel 2010). 
Sollen mehrere Proteinbanden identifiziert werden, wird in der Regel die Membran so zugeschnitten, dass die zu untersuchenden Proteine getrennt werden und jeweils mit einem $1^{\circ} \mathrm{AK}$ adressiert werden können. Sollten die erwarteten Banden zu nah beieinander liegen um dazwischen zu schneiden, müssen in mehreren Schritten die $1^{\circ} \mathrm{AK}$ und $2^{\circ} \mathrm{AK}$ durch mehrmaliges Waschen mit Puffern entfernt werden („Strippen“). Anschließend können neue $1^{\circ}$ - und $2^{\circ} \mathrm{AK}$ zugegeben werden und nach erneutem Waschen die gebundenen $2^{\circ} \mathrm{AK}$ nachgewiesen werden (Rehm und Letzel 2010). Es ist möglich die Färbeintensität gleicher Banden aus unterschiedlichen Proben zu quantifizieren und so die Konzentration der betrachteten Proteine semiquantitativ zu vergleichen (Densitometrie), ein rein qualitativer Vergleich ist jedoch häufig ausreichend.

\subsubsection{Protokoll des Westernblots}

\section{Probenpräparation}

Von den Tumorlysaten wurden für den Westernblot jeweils Mengen mit $1 \mu \mathrm{g}$ Protein entnommen und mit dem Ladungspuffer (100 $\mu$ l NuPage Sample Buffer 4x $+10 \mu$ l Mercaptoethanol) auf ein Volumen von $20 \mu \mathrm{l}$ aufgefüllt. Gelagert wurden die Proben während dieser Schritte auf Eis. Anschließend wurden die Proben gut durchgemischt und für 5 Minuten bei $95^{\circ} \mathrm{C}$ im Heizblock denaturiert.

II PAGE

Für die Proteinauftrennung wurden fertige Laufgele von Invitrogen mit einer Acrylamidkonzentration von 4-12\% verwendet. Die Gele wurden nach dem Entfernen der Klebestreifen in die Elektrophoresekammer eingespannt, der Kamm wurde vorsichtig entfernt, die Geltaschen gespült und schließlich wurden $20 \mu \mathrm{l}$ Probe bzw. $7 \mu \mathrm{l}$ des Markers mit den Referenzproteinen in die Geltaschen pipettiert. Die Kammer wurde bis zur Füllline mit Laufpuffer (50 $\mu$ l MOPS SDS Running Buffer $+950 \mu$ deionisiertes Wasser) gefüllt. Nach dem Aufsetzen des Deckels wurde die Elektrophorese für 60 Minuten bei $160 \mathrm{~V}$ gestartet. Die Elektrophorese wurde gestoppt sobald die vorderste Lauffront unten aus dem Gel hinauslief.

\section{Blotting}

Der Elektrotransfer der Proteine aus dem Gel auf die Nitrozellulosemembran wurde im Blotmodul vorgenommen. Hierzu wurden je zwei Schwämme und zugeschnittene Filterpapier in Transferpuffer (50 ml NuPAGE Transfer Buffer 20x + $100 \mathrm{ml}$ Methanol $+850 \mathrm{ml}$ deionisiertes Wasser) inkubiert und gemeinsam mit dem Gel sowie der Membran nach definiertem Schema in das Blotmodul eingesetzt (vgl. Abbildung 9). Dabei wurde sorgsam darauf geachtet, dass alle Schichten keine Unebenheiten und Luftblasen mehr enthielten und diese gegebenenfalls mittels Roller vorsichtig entfernt, ohne dabei Gel und Membran zu beschädigen. Wie auch in den folgenden Schritten wurde stets darauf geachtet, dass weder Gel noch Membran trockenfallen. Von dem Gel wurde im Vorfeld das Sammelgel abgetrennt und verworfen. Nachdem das Blotmodul mit der Anode als Deckel gut komprimiert und verschlossen wurde, wurde es in die 
Elektrophoresekammer eingesetzt. Die innere Kammer des Blotmoduls wurde mit Transferpuffer, die äußere Kammer mit deionisiertem Wasser $\left(4^{\circ} \mathrm{C}\right)$ gefüllt und der Blotvorgang bei $15 \mathrm{~V}$ für 90 Minuten gestartet.

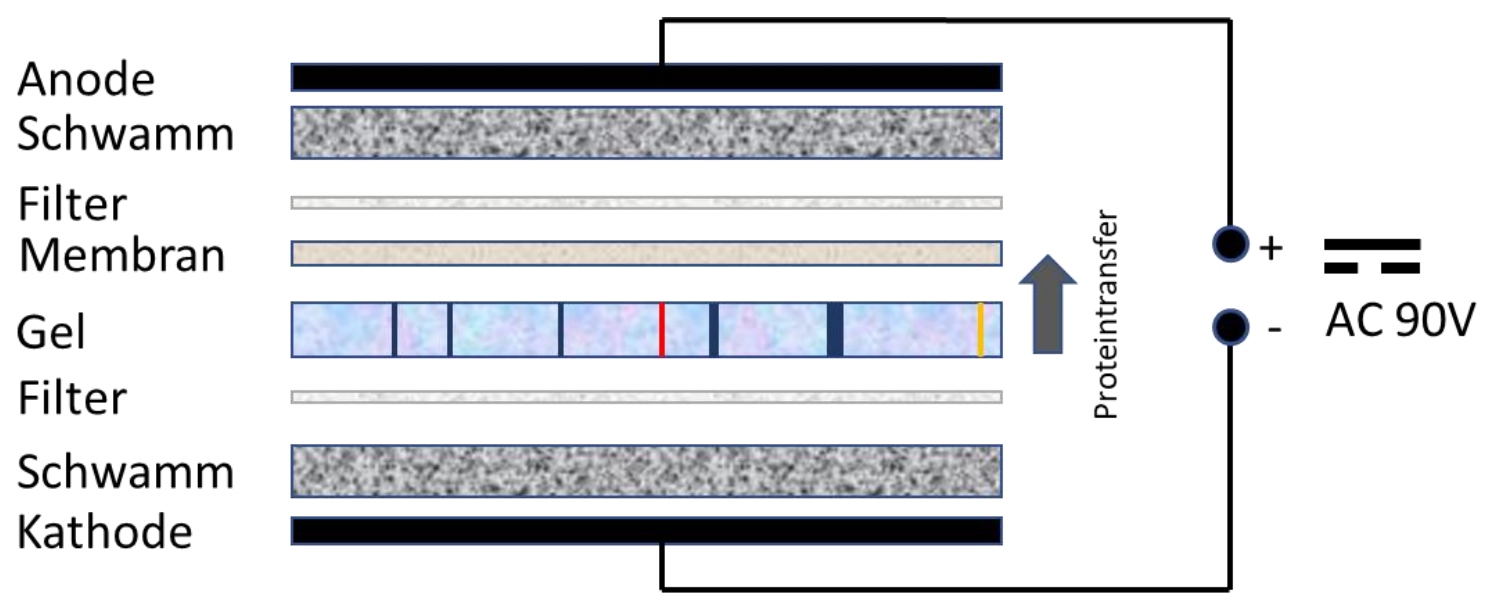

Abbildung 9: Packschema für das Blotmodul

Die Bestandteile wurden vorsichtig und unter Vermeidung von Unebenheiten und Luftblasen in das Blotmodul eingesetzt. Die Schwämme und die Filter wurden zuvor in Transferpuffer inkubiert. Der Proteintransfer findet vom Gel in Richtung der Anode auf die Nitrozellulosemembran statt. AC (Gleichstrom)

\section{Ponceau-Färbung der Membran}

Nach der Übertragung der Proteine aus dem Gel auf die Membran wurde der Erfolg dieses Schrittes mittels Ponceau S, einem roten Azofarbstoff, überprüft. Hierfür wurde die Membran für eine Minute in Ponceau S inkubiert. Die Markerbanden wurden mit einem Bleistift markiert. Anschließend wurden die Membranen für die Inkubation mit den $1^{\circ} \mathrm{AK}$ zugeschnitten bevor die Färbung mit TBST ausgewaschen wurde.

\section{$\mathrm{V}$ Inkubation mit $1^{\circ} \mathrm{AK}$}

Im nächsten Schritt wurde die Membran für eine Stunde in 5\% Blockmilch in PBST (5g Magermilchpulver $+100 \mathrm{ml}$ PBS (Phosphat-gepufferte Salzlösung) + 0,1 ml Tween20) unter ständigem Schwenken geblockt. Für HSP90 (Hitzeschockprotein 90) wurde das Blockieren in 5\% BSA in TBST (5 g BSA $+100 \mathrm{ml}$ TBST) durchgeführt. Anschließend wurden die Membranen über Nacht bei $4{ }^{\circ} \mathrm{C}$ mit dem $1^{\circ} \mathrm{AK}$ in $5 \%$ Blockmilch in PBST inkubiert. Die Inkubation mit dem $1^{\circ} \mathrm{AK}$ anti-HSP90 erfolgte in 5\% BSA in TBST. Die Konzentrationen der AK sind in Tabelle 16 dargestellt.

\section{Inkubation mit $2^{\circ} A K$}

Am nächsten Tag wurde die Membran einmal kurz und anschließend dreimal für 10 Minuten unter Schwenken in TBST gewaschen um unspezifisch gebundene $1^{\circ} \mathrm{AK}$ weitestgehend zu entfernen. Die $2^{\circ} \mathrm{AK}$ wurden 1:2000 in 5\% Blockmilch in PBST verdünnt und für eine Stunde bei RT auf die Membran gegeben. 


\section{Entwickeln}

Die Waschschritte wurden wie für den $1^{\circ} \mathrm{AK}$ wiederholt und die Färbung durch Zugabe von ECL-Detektionsreagenz (1 ml Lösung A + 1 ml Lösung B) entwickelt, wobei darauf geachtet wurde, dass die gesamte Membran überschichtet war. Die $2^{\circ} \mathrm{AK}$ waren bereits an HRP gekoppelt. Nach einer Minute Inkubationszeit wurden die Membranen für die Aufnahme der Bilder in Folie in den ECL CHEMOCAM IMAGER gelegt und zu verschiedenen Zeitpunkten mit unterschiedlicher Belichtungszeit Bilder aufgenommen.

Tabelle 16: Antikörper und Konzentrationen für den Westernblot

\section{Antikörper}

HSP90

SPARC

$\alpha$-SMA

Fibronektin

E-Cadherin

$2^{\circ}$ AK konjugiert mit HRP (Anti-Kaninchen; Anti-Ziege; Anti-Maus)

\section{Verdünnung}

$1: 5000$

$1: 2000$

$1: 1000$

$1: 1000$

$1: 2500$

$1: 2000$ 


\subsubsection{Statistik}

Das Signifikanzniveau wurde für alle Analysen auf $\alpha \leq 0,05$ festgesetzt.

\subsubsection{Zusammenhang zwischen Stromaparametern und Überleben}

In die Analyse zum Zusammenhang von stromalen zellulären und azellulären Markern mit dem Überleben der Mäuse wurden nur die 46 Mäuse mit invasivem PDAC, die die Endpunktkriterien erfüllt hatten, in die Statistik eingeschlossen. Für jede analysierte Stromakomponente wurde zunächst eine univariate Überlebenskurve berechnet. Hierbei wurde mittels Kaplan-MeierKurve ein Gruppenvergleich entlang des Medians zwischen Tieren mit hoher und niedriger Merkmalsausprägung durchgeführt. Alle erhobenen Parameter wurden auch in einer multivariaten Analyse auf einen Zusammenhang zum Überleben überprüft. Hierfür wurde mit Statistica12 eine Cox-Proportional-Hazards-Regression (Cox-Regression) mit einer Vorwärtsselektion durchgeführt. Der Grenzwert für die Aufnahme wurde auf $\mathrm{p} \leq 0,15$ gesetzt wurde. Das Signifikanzniveau für einen Zusammenhang wurde weiter mit $\alpha \leq 0,05$ angesetzt. Die Vorwärtsselektion nimmt, beginnend bei dem Parameter mit dem niedrigsten P-Wert, schrittweise immer einen weiteren Parameter in das Modell auf, bis kein weiterer Parameter die Bedingung $\mathrm{p} \leq 0,15$ erfüllt. Da bei Berücksichtigung zu vieler Parameter in der Cox-Regression fälschlicherweise signifikante Effekte beobachtet werden können, ist die Vorwärtsselektion das adäquate Rechenmodell. Die Ergebnisse einer Rückwärtsselektion und einer unselektierten Cox-Regression werden daher nicht aufgeführt, obwohl die Ergebnisse identisch bzw. sehr ähnlich waren. In die Cox-Regression können nur Mäuse eingeschlossen werden, für die alle Marker erhoben waren. Da bei einigen Mäusen einzelne Parameter fehlten und sich diese nicht sinnvoll nachbestimmen ließen, konnten nur n=40 Mäuse eingeschlossen werden.

Mittels einer Spearman-Korrelation in Statistica-12 wurden alle erhobenen Stromaparameter auf Korrelationen untereinander und zum Überleben überprüft.

\subsubsection{Stromavergleich von Primärtumor, Lebermetastase und normaler Leber}

Es wurden innerhalb von jeweils acht unbehandelten KPC-Mäusen die Verteilungen von SPARC, HA, $\alpha$-SMA, Kollagen und CD31-positiven Blutgefäßen zwischen den Gewebekompartimenten PT, LM und NL untersucht. Dafür wurden korrespondierende PT und LM sowie NL aus jeweils der gleichen Maus untersucht. Für $\alpha$-SMA wurden nur PT und LM miteinander verglichen. Hierfür wurden mit GraphPad Prism 6 gepaarte t-Tests zwischen den gemessenen Mittelwerten aus je zwei Gewebekompartimenten durchgeführt.

Ebenso wurde für die Verteilungen von CC3 und Ki67 zwischen PT und LM innerhalb von sechs Mäusen mittels gepaartem t-Test verglichen. 


\section{Ergebnisse}

\subsection{Stromaanalyse von Primärtumoren}

Von Prof. Ströbel (Abteilung für Pathologie) wurde bei drei Mäusen aus der Kohorte von $n=49$ KPC-Mäusen kein invasives PDAC diagnostiziert. Das entspricht einer Penetranz der Tumorentstehung von 93,9\%. Lediglich die Ergebnisse für die n=46 Mäuse mit invasivem Tumor wurden in die folgenden Analysen eingeschlossen.

Alle Parameter wurden wie in 2.2.2.5 beschrieben quantifiziert und die Ergebnisse den Mäusen und ihren zugehörigen Überlebenszeiten zugeordnet. Mittels Quantile-Quantile Plot (Statistica 12) wurde festgestellt, dass die Werte nicht optimal aber ausreichend normalverteilt sind.

\subsubsection{Univariate Stromaanalyse}

Die folgenden Daten sowie die Abbildungen sind in die Publikation Hasselluhn et al. (2020) eingeflossen. Die Abbildungen 10-29 wurden in Hasselluhn et al. (2020) veröffentlicht und unter CC-BY 4.0; https://doi.org/10.3390/cells9010058 lizensiert. Beispielhaft wurde die Abbildung 10 ausdrücklich mit diesen Informationen versehen, die Abbildungen 11-29 wurden ebenfalls von Lukas Klein erstellt und unterliegen der gleichen Creative Commons Attribution-Lizenz.

Im Vorfeld der univariaten Stromaanalyse wurde eine Kaplan-Meier-Kurve für alle eingeschlossenen KPC-Mäuse angefertigt. Diese zeigt mit Ausnahme von zwei Mäusen, die ungewöhnlich lange lebten, einen normalen Kurvenverlauf. Der Kurvenverlauf ist vergleichbar mit dem der ursprünglich von Hingorani et al. (2005) beschriebenen KPC-Maus.

\section{Ges a m tüberleben}

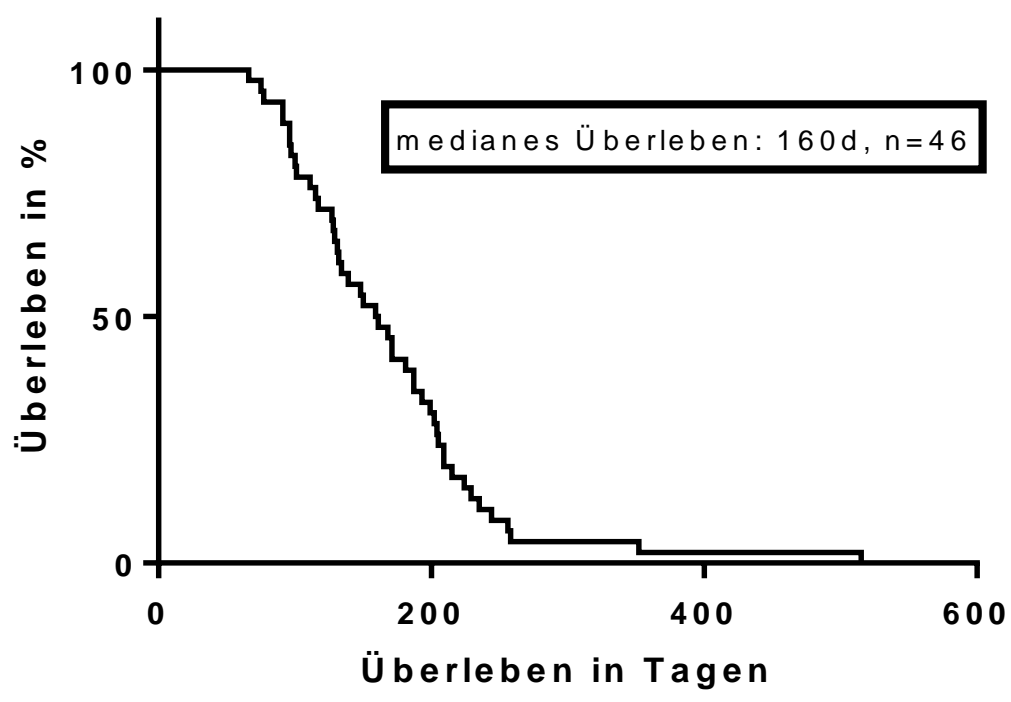

Abbildung 10: Gesamtüberleben der KPC-Mäuse ohne Gruppenvergleich

Abbildung von Lukas Klein aus Hasselluhn et al. (2020), lizensiert unter CC-BY 4.0; https://doi.org/10.3390/cells9010058 
Für die n=46 KPC-Mäuse mit invasivem PDAC wurde für die in Tabelle 17 aufgeführten Parameter ein Gruppenvergleich zwischen Mäusen mit hoher und niedriger Merkmalsausprägung durchgeführt. Hierfür wurde der Log-rank (Mantel-Cox) t-Test verwendet. Dabei wurde der Median als Grenzwert für die Einteilung in die Gruppen mit hoher und niedriger Ausprägung herangezogen. Bei der Betrachtung des Überlebens als abhängige Größe konnte für keinen der untersuchten (Stroma-)Parameter im KPC-Mausmodell ein signifikanter Einfluss beobachtet werden. Lediglich Ki67 ließ mit p=0,09 eine Tendenz in die Richtung eines protektiven Einflusses einer hohen Proliferationsrate erkennen. Die Ergebnisse können aus den jeweiligen Graphen (Kaplan-Meier-Kurven) abgelesen werden.

Weiterhin wurde eine univariate Cox-Regression für die in Tabelle 17 aufgeführten Parameter durchgeführt. Hier wurde gleichfalls für keinen Parameter ein signifikanter Zusammenhang zum Überleben gefunden. Die Ergebnisse sind in Tabelle 17 dargestellt. Es gilt zu beachten, dass diese Werte (insbesondere der p-Wert) nicht mit denen der folgenden Graphen übereinstimmen, da hier ein anderes Berechnungsverfahren angewandt wurde (Log-rank t-Test vs. univariate Cox-Regression).

Tabelle 17: Übersicht über die univariaten Stromaanalysen mittels univariater Cox-Regression

\begin{tabular}{|c|c|c|c|c|c|}
\hline & $\begin{array}{c}\text { Fallzahl } \\
\text { (n) }\end{array}$ & Mittelwert $\pm S D$ & Median [Q1-Q4] & $H R(95 \% K I)$ & $\begin{array}{c}\text { Signifikanz } \\
\text { des t-Tests }(p)\end{array}$ \\
\hline Ki67 & 44 & $10.6 \pm 4.8$ & 9.41 [7.05-12.9] & $0.68(0.43-1.05)^{*}$ & 0.08 \\
\hline CC3 & 43 & $0.80 \pm 0.98$ & $0.51[0.32-0.99]$ & $0.97(0.78-1.21)^{*}$ & 0.79 \\
\hline РНH3 & 45 & $0.41 \pm 0.27$ & $0.37[0.22-0.46]$ & $1.09(0.82-1.45)^{*}$ & 0.53 \\
\hline Picrosirius & 46 & $22.1 \pm 9.8$ & 21.9 [14.3-29.0] & $0.93(0.59-1.48)^{*}$ & 0.77 \\
\hline Hyaluronsäure & 46 & $13.2 \pm 8.5$ & $11.2[7.72-16.3]$ & $0.96(0.70-1.31)^{*}$ & 0.79 \\
\hline SPARC & 46 & $5.1 \pm 2.2$ & $4.63[3.48-6.18]$ & $0.89(0.59-1.36)^{*}$ & 0.61 \\
\hline$\alpha-S M A$ & 46 & $3.4 \pm 2.8$ & $2.81[1.72-4.49]$ & $0.90(0.63-1.28)^{*}$ & 0.56 \\
\hline$\alpha-S M A+K i 67$ & 46 & $6.7 \pm 3.4$ & $6.27[4.25-7.79]$ & $1.27(0.90-1.79)^{*}$ & 0.17 \\
\hline$M L A(C D 31)$ & 45 & $37.1 \pm 11.0$ & $34.6[30.5-46.4]$ & $0.75(0.45-1.25)^{*}$ & 0.27 \\
\hline$M V D(C D 31)$ & 45 & $173 \pm 64$ & 167 [121-219] & $0.98(0.58-1.66)^{*}$ & 0.79 \\
\hline Grading (G1-3) & 46 & - & - & $0.53(0.25-1.13)$ & 0.10 \\
\hline Desmoplasia (D1-3) & 46 & - & - & $1.88(0.91-3.87)$ & 0.09 \\
\hline$A S I$ & 46 & $0.23 \pm 0.35$ & $0.11[0.06-0.24]$ & $0.95(0.82-1.10)^{*}$ & 0.47 \\
\hline
\end{tabular}

Dargestellt sind für alle mittels univariater Cox-Regression analysierten Parameter der Median- und der Mittelwert sowie die Standardabweichung und das Interquartilsintervall (Q1-Q4). Ausgenommen sind hierbei das Grading und die Desmoplasie, da sich hierfür (nicht kontinuierliche Variablen) keine sinnvollen Mittelwerte berechnen lassen. Weiterhin sind die Hazard Ratio sowie die die Signifikanz (p-Wert) des verwendeten Log Rank (Mantel-Cox) tTests und die Anzahl (n) untersuchter Mäuse angegeben.

Legende: SD (Standardabweichun), Q1 (Quartil 1), HR (Hazard Ratio), KI (Konfidenzintervall), MVD (mittlere Gefäßdichte), MLA (mittleres Gefäßlumen), ASI (aktivierter Stromaindex), * kontinuiertliche Variablen. 
Ki67 ist ein nukleäres Protein, welches in allen aktiven Phasen des Zellzyklus (G1-, S-, G2- und M-Phase), nicht jedoch in der Ruhephase G0, von allen Zellen exprimiert wird. Die physiologische Bedeutung von Ki67 ist weitestgehend unklar. Die Expression in der G1-Phase wird kontrovers diskutiert. Nichtsdestotrotz wird Ki67 als bestes Markerprotein für die sogenannte „Wachstumsfraktion“ in Zellgeweben betrachtet (Alison 1995). Auch wenn der Begriff „Proliferationsmarker" kritisch betrachtet werden muss und kein Protein, auch nicht Ki67, diesem Begriff in seiner vollen Bedeutung gerecht werden kann, wird er doch regelhaft für Ki67 verwendet. Ki67 stellt heute den wichtigsten und etabliertesten Proliferationsmarker dar und spielt in der diagnostischen Einordnung und Prognoseabschätzung diverser Neoplasien eine entscheidende Rolle (Scholzen und Gerdes 2000; Gerdes et al. 1983).
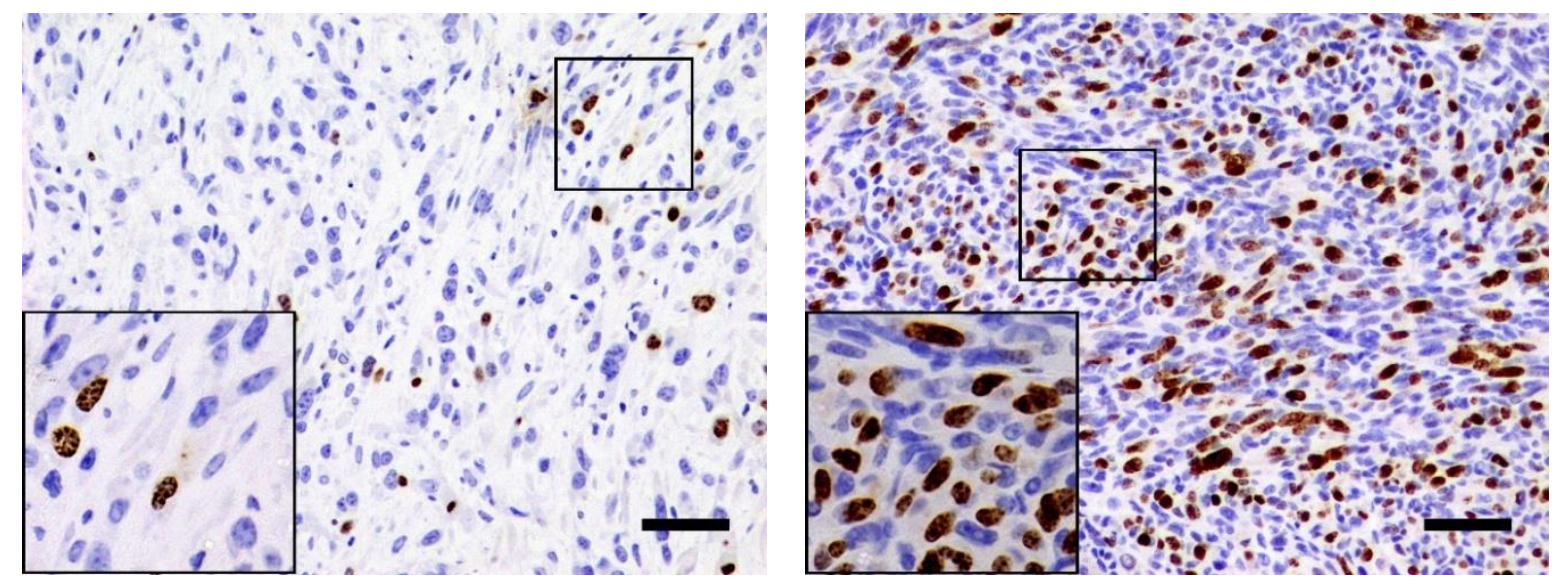

Abbildung 11: Ki67-Färbung als Marker für die Proliferationsrate

Gegenüberstellung von Tumoren mit niedriger (links) und hoher Ki67-Proliferationsrate (rechts). Die dunkel gefärbten Zellkeren werden als Ki67-positiv und damit als Teil der Wachstumsfraktion gewertet. Maßstab $50 \mu \mathrm{m}$.

Proliferationsrate (Ki67)

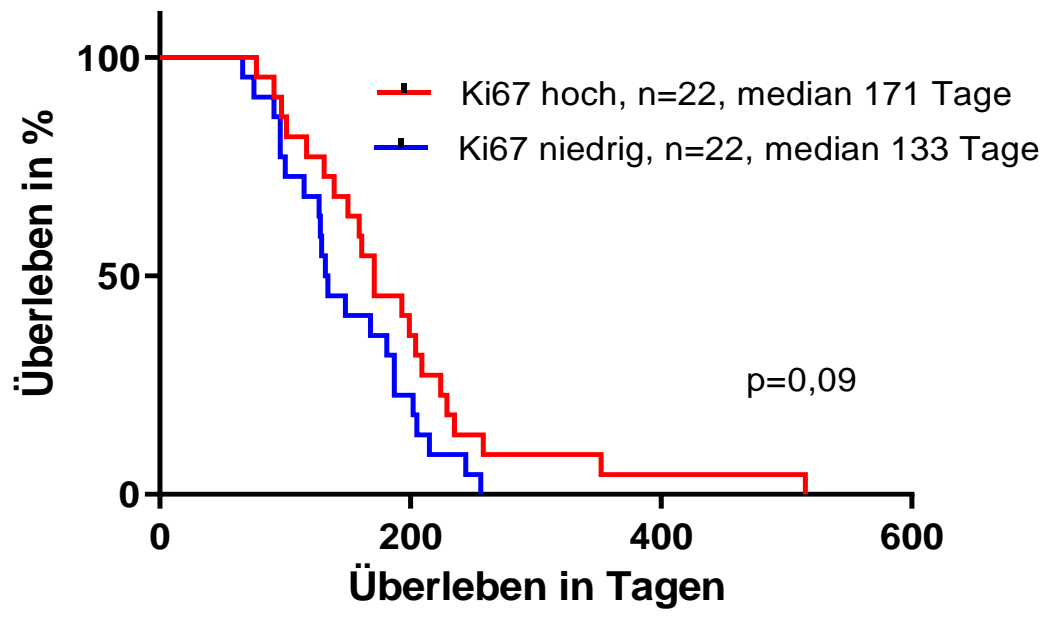

Abbildung 12: Univariate Überlebensanalyse für die Proliferationsrate

Gruppenvergleich von Individuen mit hoher und niedriger Proliferationsrate (Ki67). Der Überlebensunterschied zwischen beiden Gruppen ist nicht signifikant $(p=0,09) \cdot n=44$ 
Cleaved-Caspase-3 (CC3, engl. für ,gespaltene Caspase-3 ") ist die aus der Procaspase-3 herausgespaltene, aktive Caspase-3 und stellt einen wichtigen Marker zur Identifikation apoptotischer Zellen dar (Sabine et al. 2012). Die im Zytoplasma exprimierte Caspase-3 ist eine der Effektorcaspasen und wird sowohl über den extrinsischen als auch den intrinsischen Weg durch die Spaltung durch Initiatorcaspasen aktiviert. Caspase-3 aktiviert durch Spaltung die Procaspasen6 und -7, die ebenfalls zur Gruppe der Effektorcaspasen zählen. Die aktivierten Effektorcaspasen spalten hinter Aspartatresten diverse Proteine wie auch das Zytoskelett und die Kernmembran und führen so zur Apoptose (Rassow et al. 2008; Sabine et al. 2012). Die IHC-Färbung auf CC3 eignet sich aufgrund der grundlegenden Rolle im Apoptoseprozess daher gut als Marker zur Bestimmung der Apoptoserate.
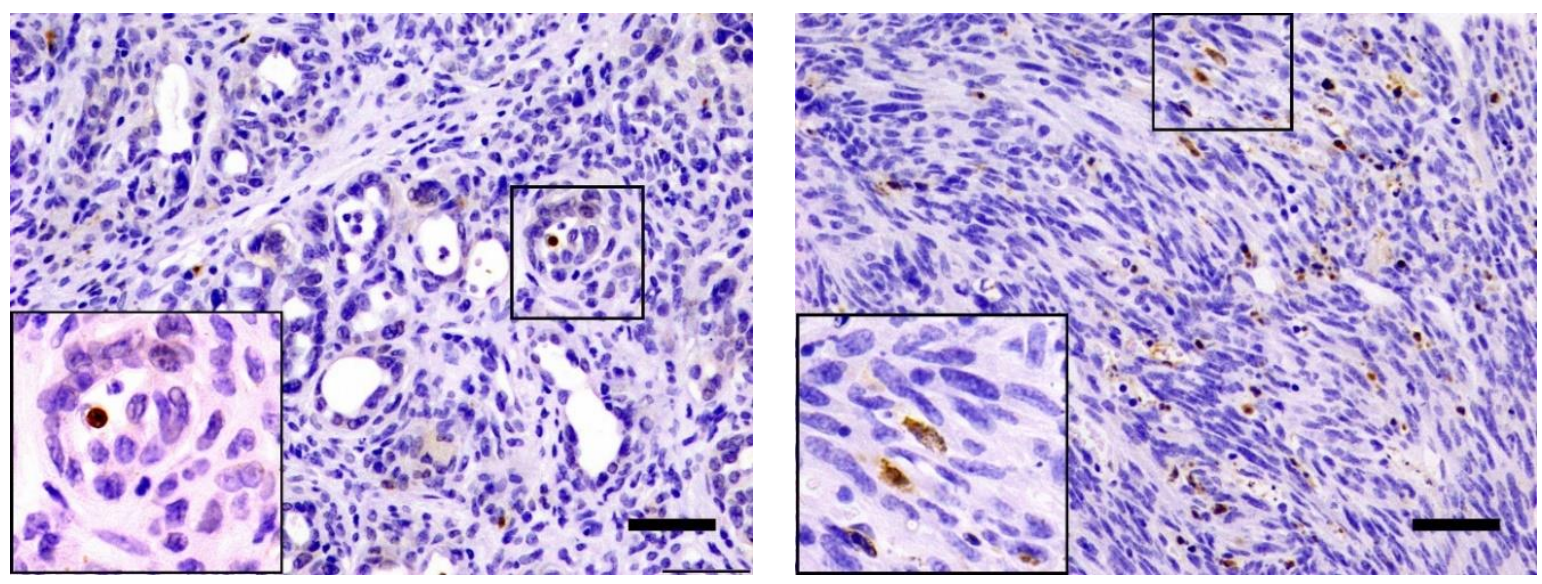

\section{Abbildung 13: Cleaved-Caspase-3-Färbung als Marker für die Apoptoserate}

Gegenüberstellung von Tumoren mit niedriger (links) und hoher CC3-Apopstoserate (rechts). Die dunkel gefärbten Zellkerne werden als CC3-positiv und damit als apoptotisch gewertet. Maßstab $50 \mu \mathrm{m}$.

\section{Cleaved Caspase 3 (CC3)}

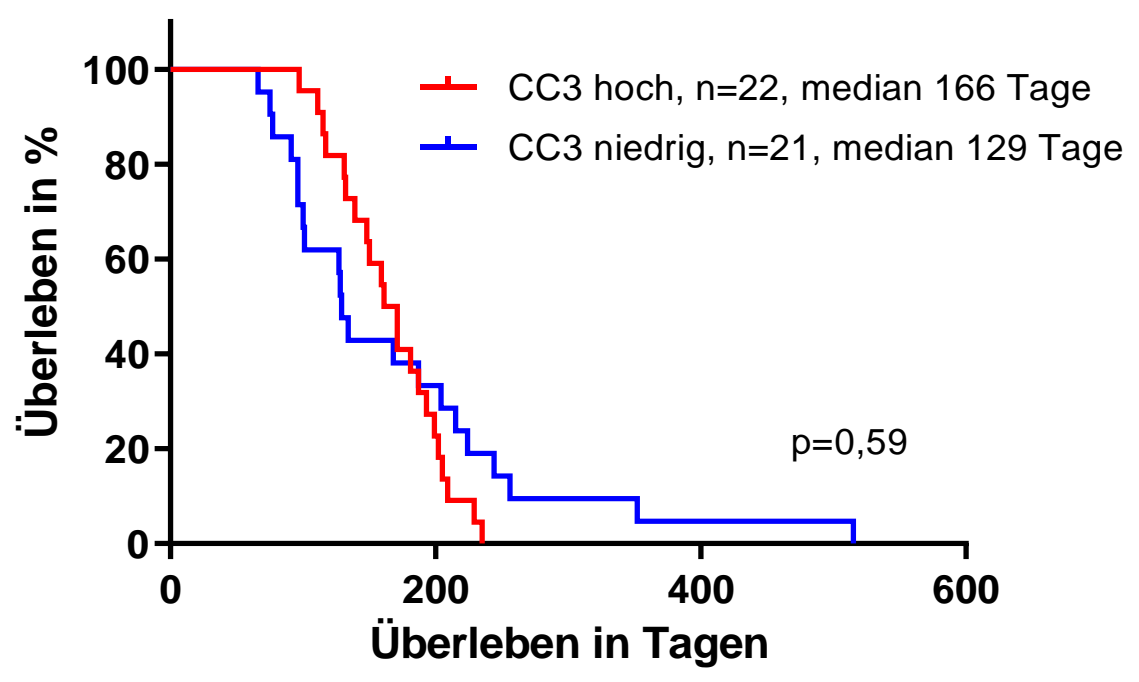

\section{Abbildung 14: Univariate Überlebensanalyse für die Apoptoserate}

Gruppenvergleich von Individuen mit hoher und niedriger Apoptoserate (CC3). Der Überlebensunterschied zwischen beiden Gruppen ist nicht signifikant. $n=43$ 
Im Gegensatz zu Ki67 wird der Mitosemarker Phosphohiston H3 (PHH3) als spezifisch für mitotisch aktive Zellen betrachtet. Mit der IHC für PHH3 wird das phosphorylierte Histon H3 angefärbt, welches zwischen der späten G2- und der frühen Telophase im phosphorylierten Zustand vorliegt. Dieses Intervall ist erheblich kürzer als für das Ki67-Protein. Somit liegt die Anzahl der so identifizierten mitotischen Zellen deutlich niedriger als für Ki67-Färbungen. Untersuchungen an Brusttumoren stellen im Vergleich der beiden Parameter heraus, dass PHH3 eine bessere und stabilere Übereinstimmung in der Bewertung durch verschiedene Untersucher hat als Ki67. Nichtsdestotrotz stellen beide Parameter geeignete Methoden dar um die proliferierende Zellen in der IHC zu adressieren, wobei die Ki67-Färbung alle proliferierenden Zellen adressiert und PHH3 zur Identifikation mitotischer Zellen geeignet ist (Kim et al. 2017; Scholzen und Gerdes 2000).
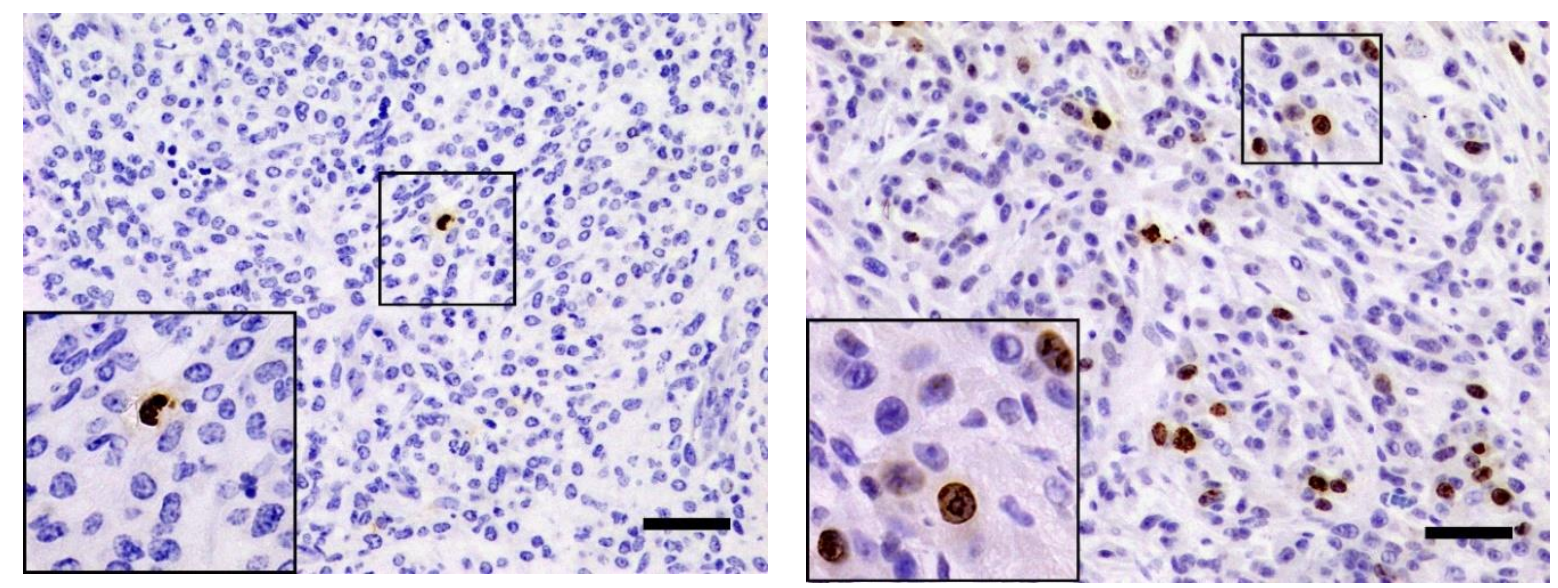

\section{Abbildung 15: Phosphohiston-H3-Färbung als Marker für die Mitoserate}

Gegenüberstellung von Tumoren mit niedriger (links) und hoher PHH3-Mitoserate (rechts). Die dunkel gefärbten Zellkerne werden als PHH3-positiv und damit als mitotisch gewertet. Maßstab $50 \mu \mathrm{m}$.

\section{Phosphohiston H3 (PHH3)}

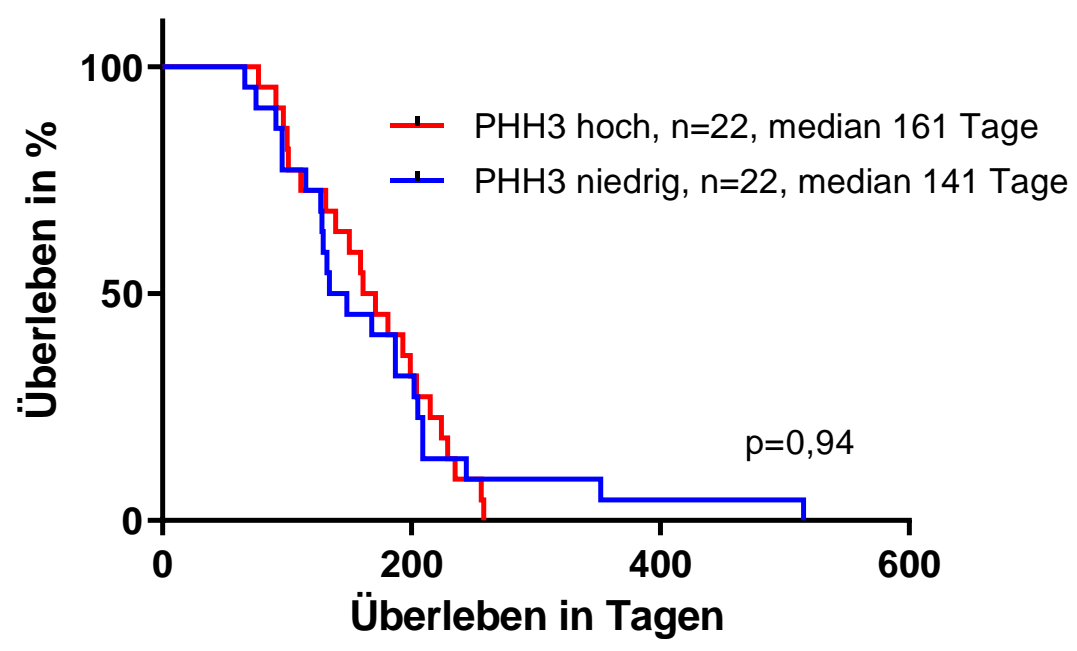

Abbildung 16: Univariate Überlebensanalyse für die Mitoserate

Gruppenvergleich von Individuen mit hoher und niedriger Mitoserate (PHH3). Der Überlebensunterschied zwischen beiden Gruppen ist nicht signifikant. $\mathrm{n}=44$ 
Picrosirius Rot stellt eine weitestgehend spezifische Färbung für Kollagenfibrillen Typ I, II und III dar, mit der der Kollagengehalt von Tumor und Stroma quantifiziert werden kann. Zwar ist Picrosirius Rot nur in der Polarisationsmikroskopie wirklich spezifisch für Kollagen, jedoch wurden für die klassische Lichtmikroskopie für die Maus keine relevanten unspezifischen Färbungen beschrieben. Deshalb ermöglicht die Färbung eine ausreichend genaue Quantifizierung von Kollagenfibrillen und stellt eine etablierte Kollagenfärbung dar (Junqueira et al. 1979).
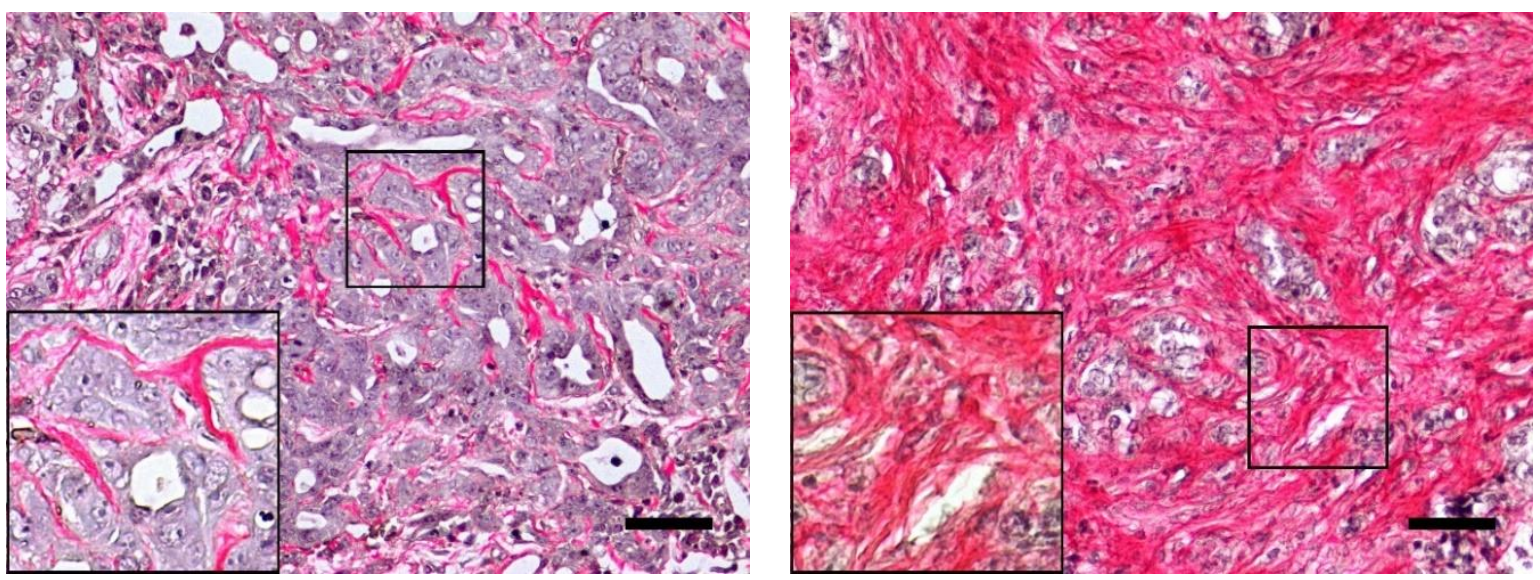

Abbildung 17: Picrosiriusfärbung als Marker für Kollagen

Gegenüberstellung von Tumoren mit niedriger (links) und hoher Picrosirius-positiver Fläche (rechts). Es lassen sich fibrillenförmig angeordnete Kollagenbündel erkennen. Der rechte Tumorbereich ist sehr kollagenreich, Kollagen füllt den Großteil der EZM aus. Der Kollagengehalt wurde über die planimetrische Vermessung roter Pixel erhoben (siehe 2.2.2.5.2). Maßstab $50 \mu \mathrm{m}$

\section{Picrosirius Rot}

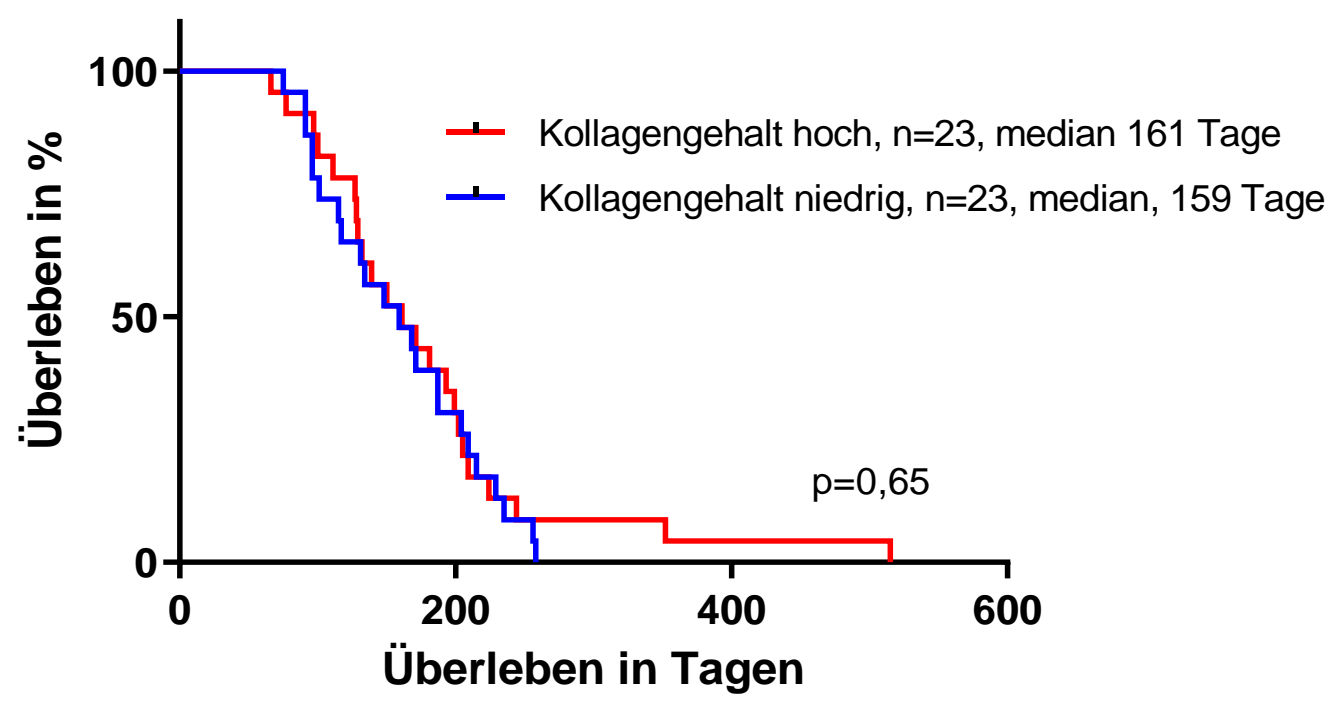

\section{Abbildung 18: Univariate Überlebensanalyse für Kollagen}

Gruppenvergleich von Individuen mit hohem und niedrigem Kollagengehalt (Picrosirius-positiv). Der Überlebensunterschied zwischen beiden Gruppen ist nicht signifikant. $\mathrm{n}=46$ 
Die Proteine SPARC und HA wurden in Abschnitt 1.5.2 bereits beschrieben. In Abbildung 4 und Abbildung 5 (Seite 15 und 16) sind beispielhaft hohe und niedrige SPARC- bzw. HA-Expressionen dargestellt.

\section{Hyaluronsäure (HA)}

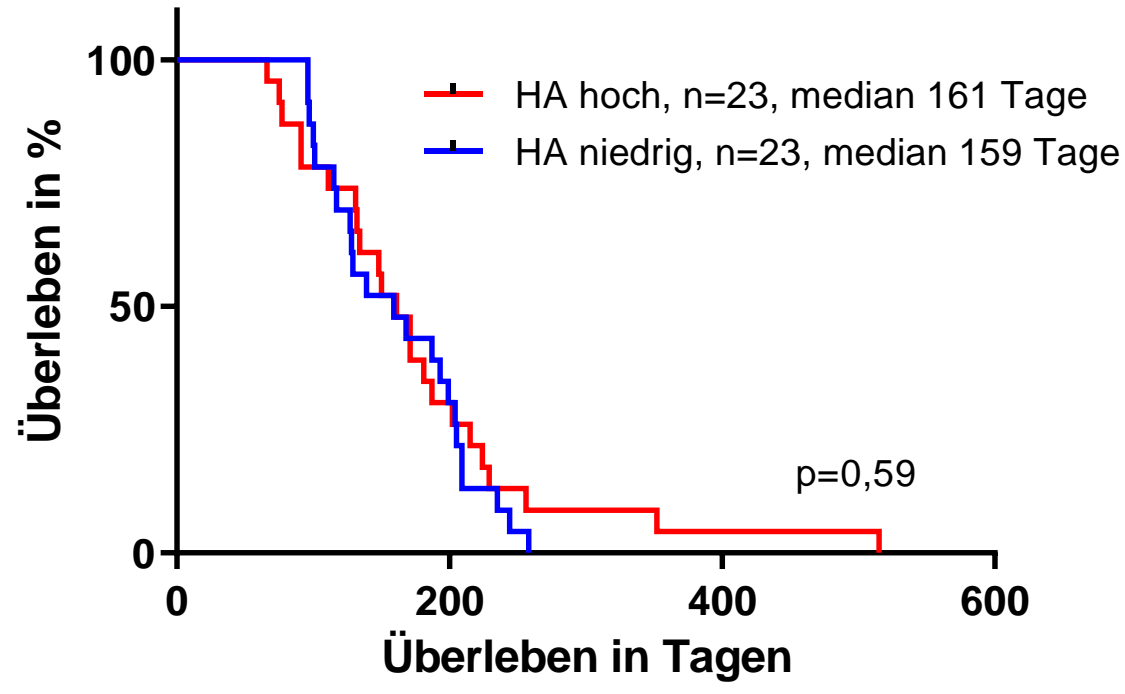

Abbildung 19: Univariate Überlebensanalyse für Hyaluronsäure

Gruppenvergleich von Individuen mit hohem und niedrigem Hyaluronsäuregehalt. Der Überlebensunterschied zwischen beiden Gruppen ist nicht signifikant. $\mathrm{n}=46$

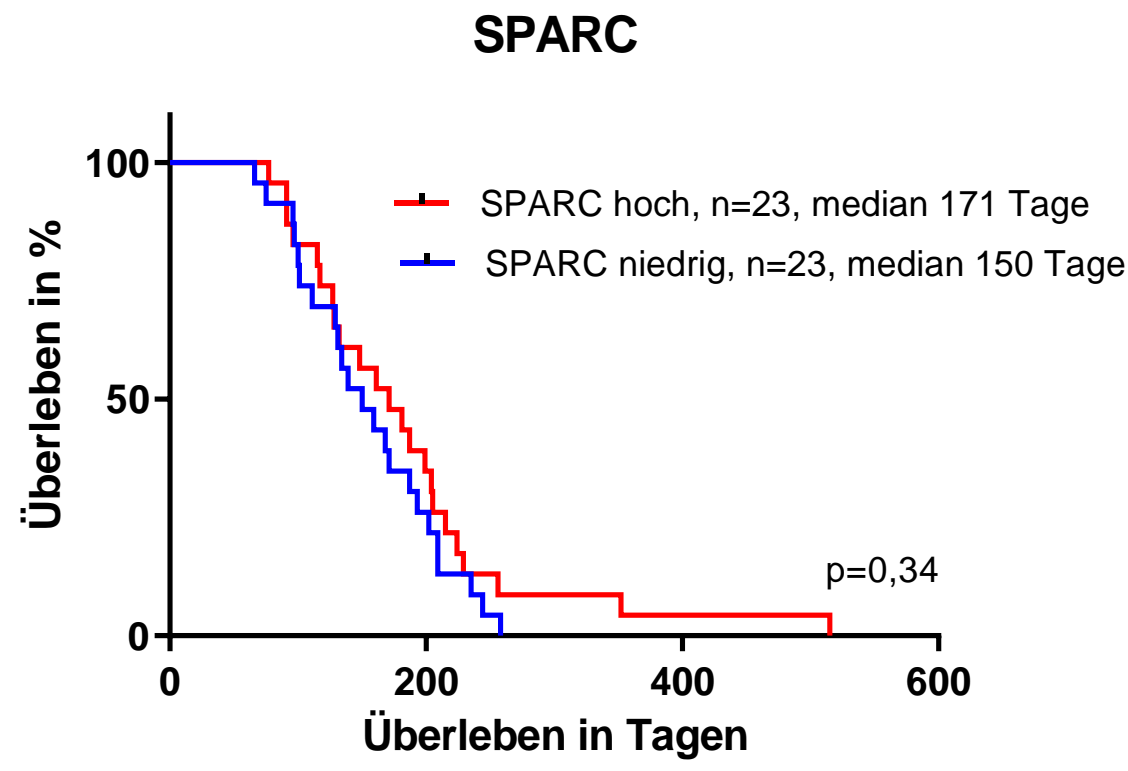

Abbildung 20: Univariate Überlebensanalyse für SPARC

Gruppenvergleich von Individuen mit hoher und niedriger SPARC-Expression. Der Überlebensunterschied zwischen beiden Gruppen ist nicht signifikant. $\mathrm{n}=46$ 
Das Protein $\boldsymbol{\alpha}$-smooth muscle actin ( $\boldsymbol{\alpha}$-SMA), auch Alpha-Actin-2 genannt, gehört zur Familie der sechs Aktingene und ist ein wichtiges Strukturprotein des Zytoskeletts. Die Proteine der Aktinfamilie sind an Prozessen wie Muskelkontraktion, Zellmotilität, Formveränderung und Zellteilung beteiligt. $\alpha$-SMA wird nach der Aktivierung von Fibroblasten wie den hepatischen und pankreatischen Sternzellen exprimiert. Damit ist $\alpha$-SMA ein geeignetes Ziel zur Identifizierung von aktivierten Fibroblasten, wie sie die Gruppe der CAFs darstellt. Ruhende PSCs bzw. Fibroblasten werden mit dieser Färbung nicht erfasst (Rassow et al. 2008; Stromnes et al. 2014; Apte et al. 1998).
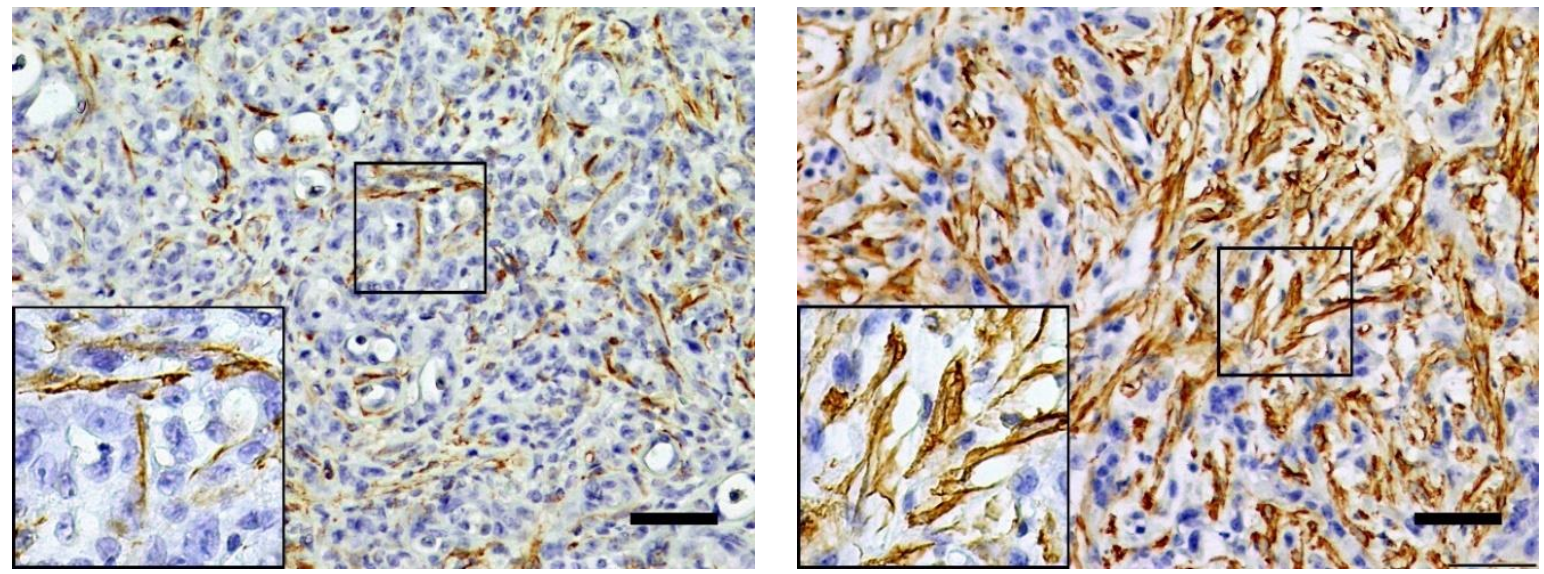

Abbildung 21: $\alpha$-smooth muscle actin-Färbung als Marker für aktivierte Fibroblasten Gegenüberstellung von Tumoren mit niedriger (links) und hoher $\alpha$-SMA-positiver Fläche (rechts). Es lassen sich einzelne, dunkel angefärbte, aktivierte Fibroblasten abgrenzen. Die Dichte der aktivierten Fibroblasten wurde über die planimetrische Vermessung brauner Pixel erhoben. Maßstab $50 \mu \mathrm{m}$.

a-Smooth Muscle Actin (G-SMA)

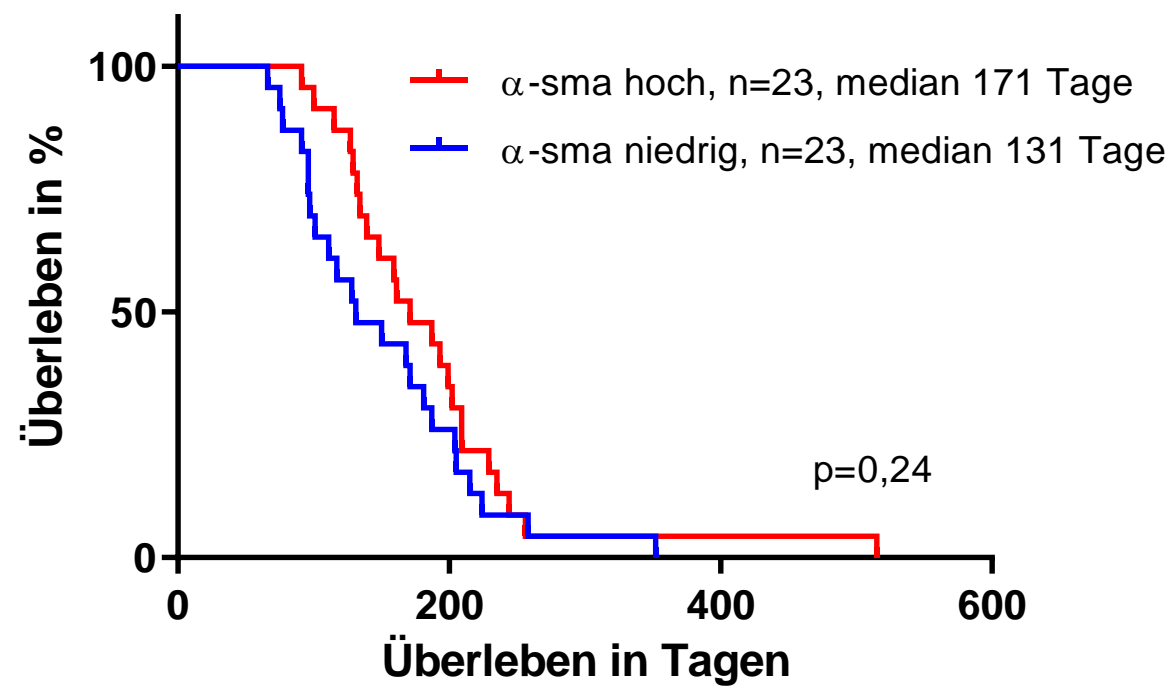

Abbildung 22: Univariate Überlebensanalyse für $\alpha$-smooth muscle actin Gruppenvergleich von Individuen mit hoher und niedriger $\alpha$-SMA-Expression. Der Überlebensunterschied zwischen beiden Gruppen ist nicht signifikant. $\mathrm{n}=46$ 
Zellen, die sowohl $\alpha$-SMA, den Marker aktivierten Fibroblasten, als auch den Proliferationsmarker Ki67 exprimieren, können als proliferierende CAFs betrachtet werden. Dies ermöglicht die Bestimmung der Fibroblastenproliferationsrate (vgl. 2.2.2.5.1.1).
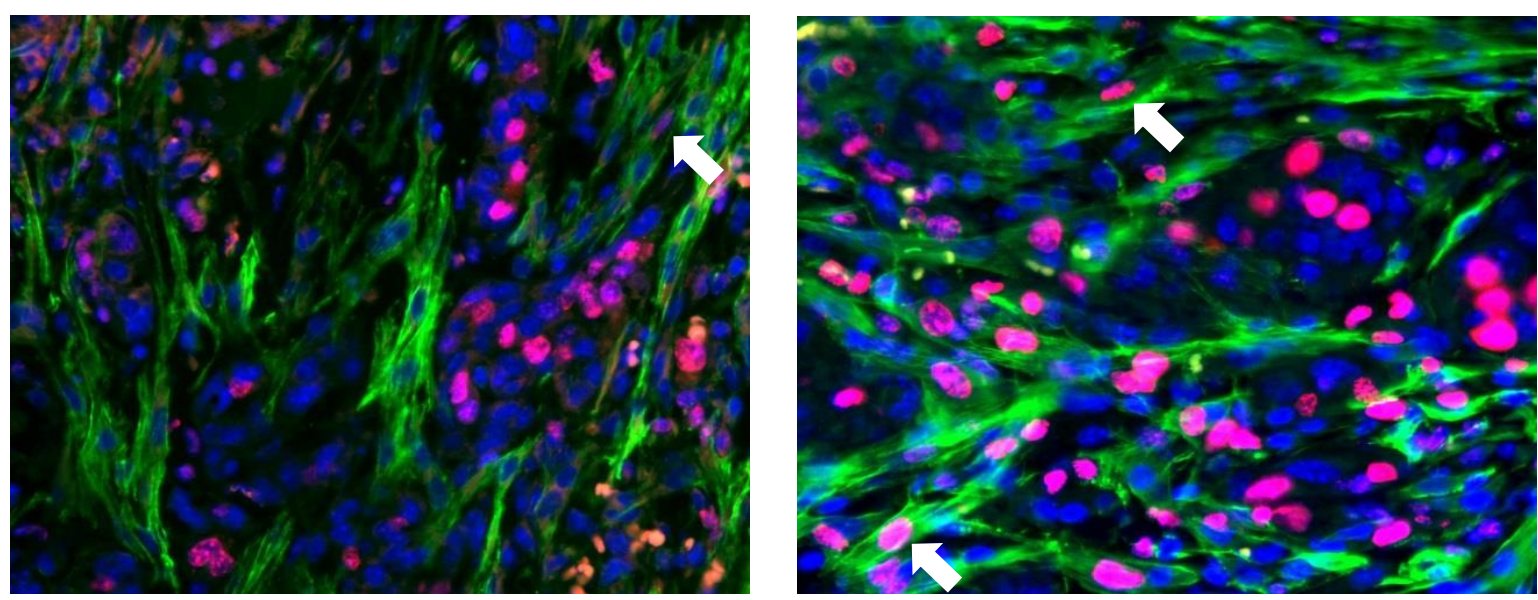

Abbildung 23: Co-Immunfluoreszenz für $\alpha$-smooth muscle actin und Ki67 als Marker für die Fibroblastenproliferationsrate

Gegenüberstellung von Tumoren mit niedriger (links) und hoher Fibroblastenproliferationsrate (rechts). Zellen, die sowohl positiv für $\alpha$-SMA sind als auch einen Ki67-positiven Zellkern aufweisen, werden als proliferierende Fibroblasten gezählt. Zur Bestimmung der Fibroblastenproliferationsrate wird diese Zahl ins Verhältnis gesetzt zur Gesamtheit aller aktivierten Fibroblasten ( $\alpha$-SMA-positive Zellen). Beispielhaft sind drei Zellen mit weißen Pfeilen markiert.

\section{Fibroblastenproliferationsrate (C-SMA+Ki67)}

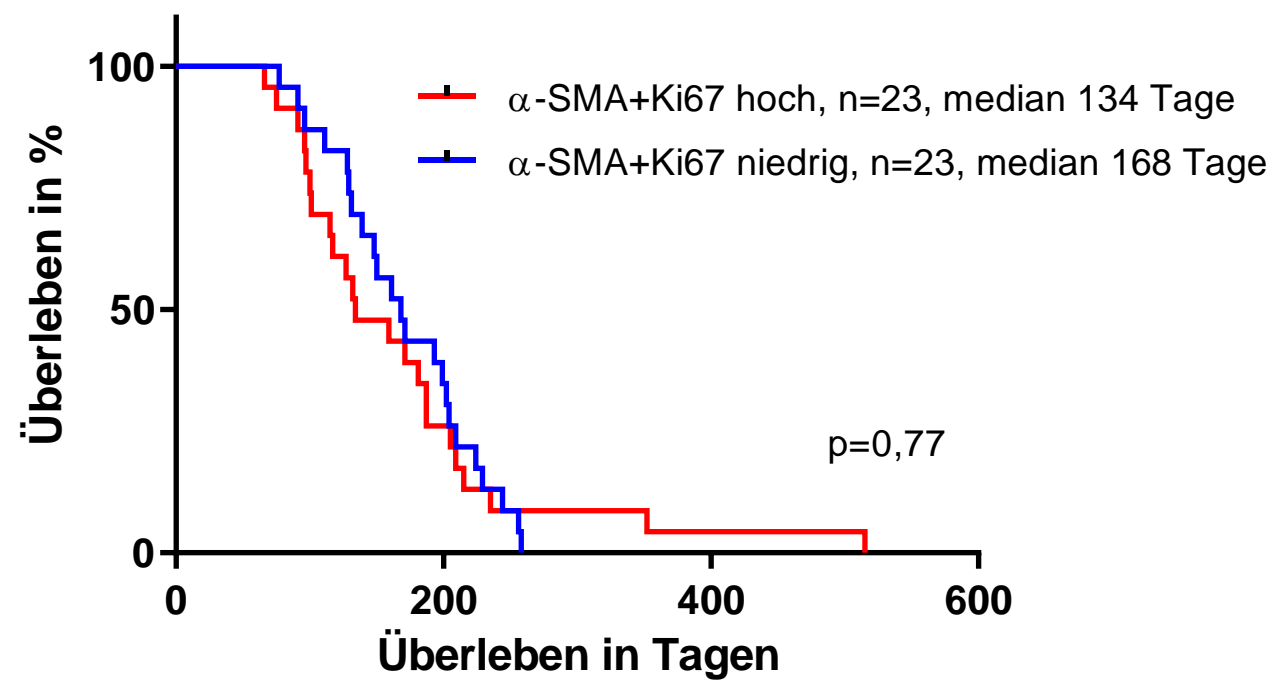

Abbildung 24: Univariate Überlebensanalyse für die Fibroblastenproliferationsrate Gruppenvergleich von Individuen mit hoher und niedriger Fibroblastenproliferationsrate (für $\alpha$ SMA+Ki67). Der Überlebensunterschied zwischen beiden Gruppen ist nicht signifikant. $n=46$ 
CD31 (cluster of differentiation 31), auch bekannt als Thrombozyten-Endothelzellen-Adhäsionsmolekül oder PECAM-1, ist ein 130kDa Oberflächenprotein, welches Homologien zur Immunglobulin-Superfamilie aufweist und auf Endothelzellen, Thrombozyten und verschiedenen Leukozyten exprimiert wird. Die CD31 Expression auf Endothelzellen ist entscheidend beteiligt an der Adhäsion und Transmigration von Leukozyten sowie der Aufrechterhaltung der Endothelzellbarriere (Lertkiatmongkol et al. 2016). Die verbreitete Expression von CD31 auf Endothelzellen macht es zu einer guten Zielstruktur zur Anfärbung von Endothelzellen bzw. Gefäßen mittels IHC. Die Färbung mit anti-CD31-Antikörpern ist eine etablierte Methode zur Messung von Gefäßdichte und Gefäßlumen.
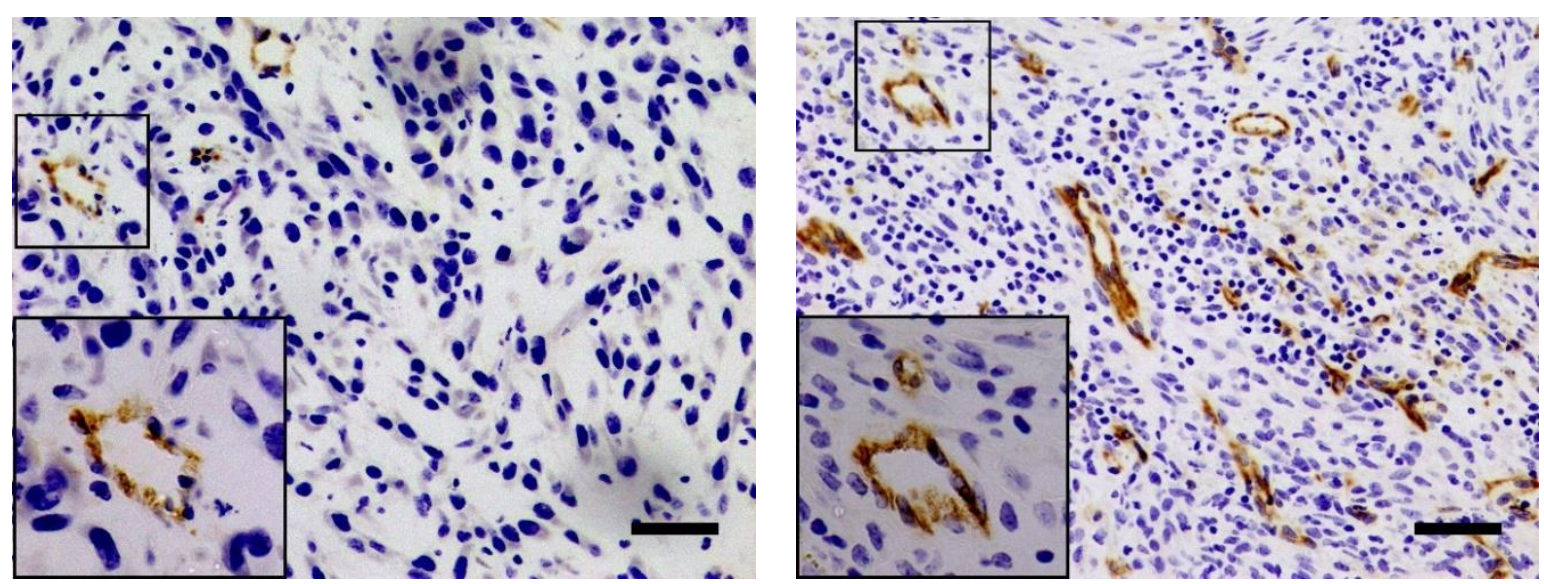

Abbildung 25: CD31-Färbung zur Identifizierung von Blutgefäßen

Gegenüberstellung von Tumoren mit niedriger (links) und hoher Dichte CD31-positiver Gefäße (rechts). Es lassen sich einzelne, dunkel angefärbte Blutgefäße abgrenzen. Analysen in Cambridge ergaben neben der Gefäßdichte (MVD) auch das mittlere Gefäßlumen (MLA). Maßstab $50 \mu \mathrm{m}$.
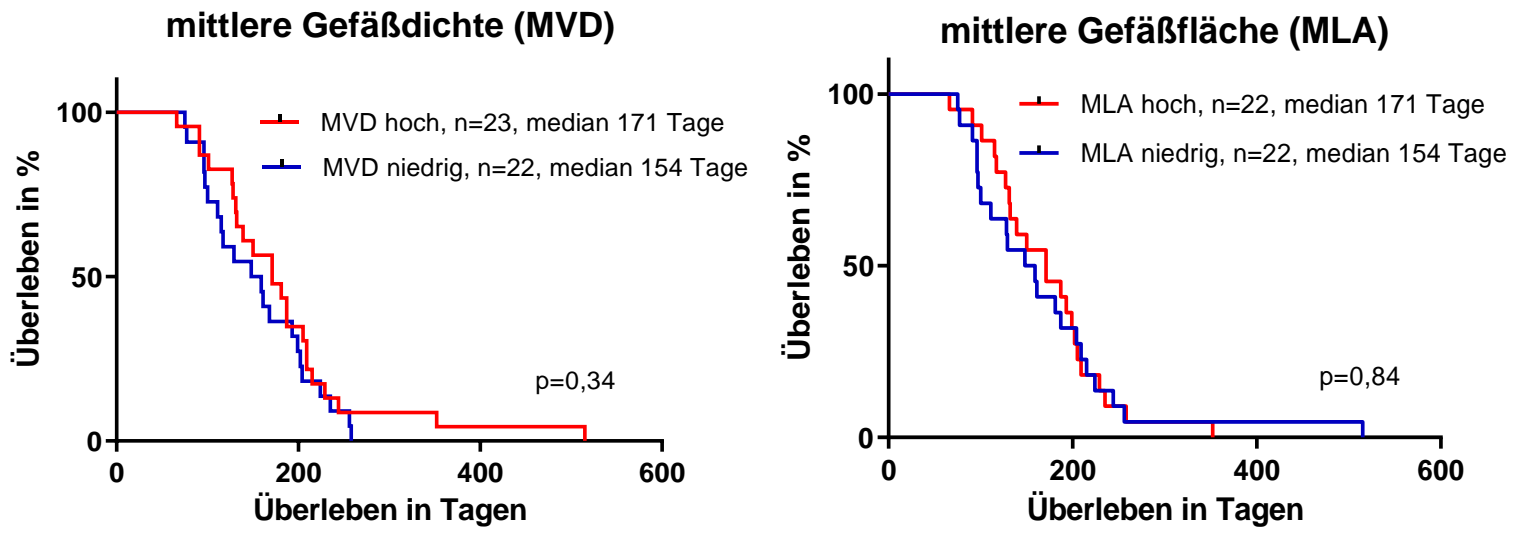

\section{Abbildung 26: Univariate Überlebensanalysen für mittlere Gefäßdichte und mittlere} Gefäßfläche

Gruppenvergleich von Individuen mit hoher und niedriger mittlerer Gefäßdichte (MVD, links) und hoher sowie niedriger mittlerer Gefäßfläche (MLA, rechts). Der Überlebensunterschied zwischen beiden Gruppen ist in beiden Fällen nicht signifikant. $n=44$ bzw. $n=45$ 

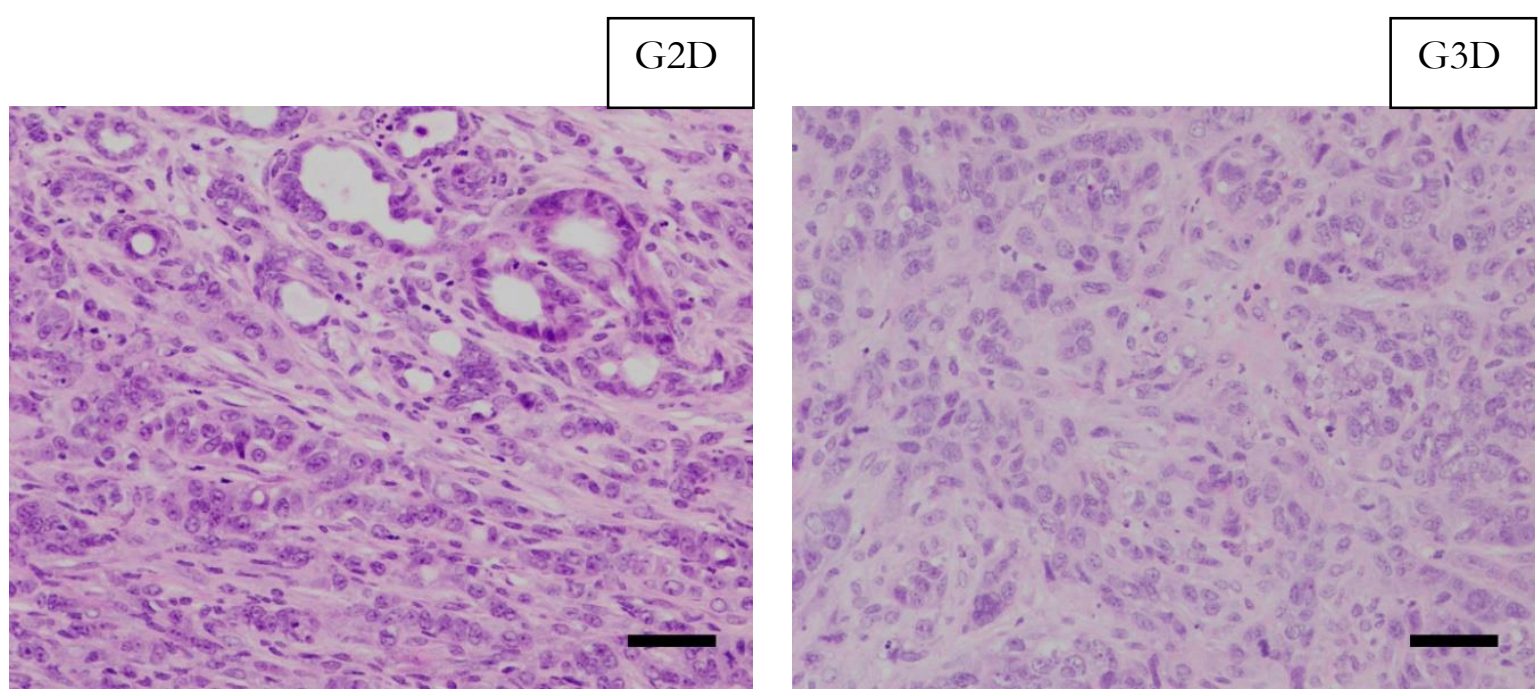

Abbildung 27: Beispielbilder für Grading und Desmoplasie

Gegenüberstellung von mäßig differenzierten (G2) Tumoren mit mäßiggradiger Desmoplasie (D2) (links) und undifferenzierten (G3) Tumoren mit geringgradiger Desmoplasie (D1) (rechts) in der HEFärbung. Maßstab $50 \mu \mathrm{m}$
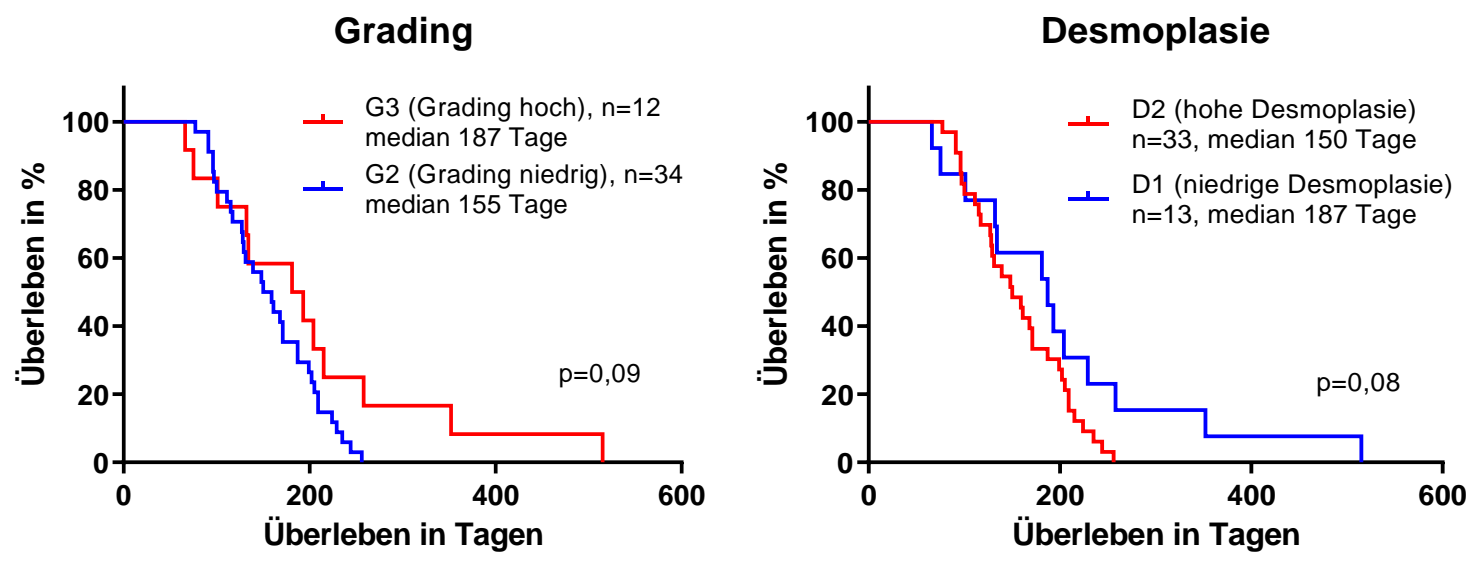

\section{Abbildung 28: Univariate Überlebensanalysen für Grading und Desmoplasie}

Gruppenvergleich von Individuen mit mäßig differenzierten (G2) und undifferenzierten (G3) Tumoren (Grading; linke Abbildung) und geringgradiger (D1) und mäßiggradiger (D2) Desmoplasie (rechte Abbildung). Der Überlebensunterschied zwischen beiden Gruppen ist sowohl bezüglich Grading als auch Desmoplasie nicht signifikant. $\mathrm{n}=46$ 
In Anlehnung an den von Erkan et al. (2008) beschriebenen aktivierten Stromaindex (ASI) wurde der Score für alle Mäuse mit invasivem PDAC berechnet. Der ASI ist definiert als Verhältnis von $\alpha$-SMA-positiver Fläche zu Kollagen-positiver Fläche und wurde anhand der Ergebnisse der planimetrischen Analysen der $\alpha$-SMA- und der Picrosiriusfärbungen errechnet. Wie von Erkan et al. beschrieben, wurden zunächst das oberste Quartil der ASI-Werte, also die Mäuse mit den 25\% höchsten ASI, mit dem untersten Quartil verglichen. Die Ergebnisse sind in Abbildung 29 dargestellt. Für diesen Vergleich zeigte sich, wie auch für den anschließend durchgeführten Vergleich anhand des Medians, kein signifikanter Überlebensvorteil einer Gruppe.

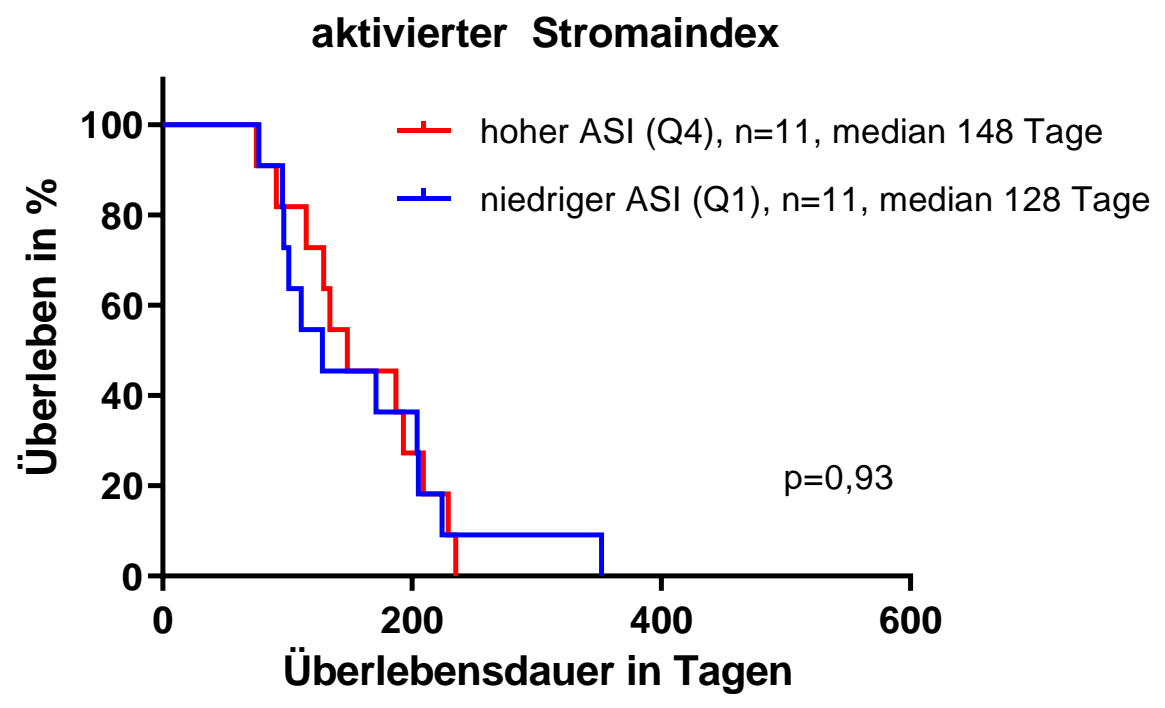

\footnotetext{
Abbildung 29: Überlebensanalyse bezüglich des aktivierten Stromaindex

In Anlehnung an Erkan et al. (2008) wurde das Überleben von KPC-Mäusen mit dem höchsten Quartil (Q4, die obersten 25\%, $\mathrm{n}=11$ ) und dem untersten Quartil (Q1, die untersten 25\%, $\mathrm{n}=11$ ) der Werte für den aktivierten Stromaindex (ASI) verglichen. Die Mäuse mit den 25\% höchsten ASI (Q4) hatten ein um 40 Tage längeres Überleben als Mäuse mit den 25\% niedrigsten ASI (Q1), wobei die Differenz deutlich nicht signifikant ist (Q4 148 Tage vs. Q1 128 Tage, $\mathrm{p}=0,93)$.
} 


\subsubsection{Multivariate Stromaanalyse}

Für die n=46 Mäuse mit invasiv wachsendem PDAC wurden alle 13 auszuwertenden Parameter in eine Übersichtstabelle übertragen und diese in Statistica eingearbeitet. Aus diesem Datensatz wurde anschließend eine multivariate Cox-Regression mit Vorwärtsselektion berechnet (siehe auch 2.2.4.1). Die in die Berechnungen eingeschlossenen Parameter sind identisch mit denen der univariaten Analysen und aus Tabelle 17 ersichtlich. Die Ergebnisse der vorwärtsselektierten Cox-Regression sind in Tabelle 18 dargestellt.

Tabelle 18: Cox-Proportional-Hazards-Regression, Vorwärtsselektion

\begin{tabular}{lcccccc} 
& $\begin{array}{c}\text { Parameter- } \\
\text { schätzer }\end{array}$ & $\begin{array}{c}\text { Standard- } \\
\text { fehler }\end{array}$ & P-Wert & $\begin{array}{c}\text { Hazard- } \\
\text { Ratio }\end{array}$ & \multicolumn{2}{c}{$\begin{array}{c}\text { 95\% KI } \\
\text { Hazard-Ratio }\end{array}$} \\
\hline Ki67 & $-0,13$ & 0,044 & 0,0039 & 0,88 & 0,807 & 0,960 \\
\hline $\boldsymbol{P H H 3}$ & 1,67 & 0,695 & 0,0162 & 5,314 & 1,361 & 20,75 \\
\hline $\boldsymbol{M V D}(\boldsymbol{C D 3 1 )}$ & $-0,0051$ & 0,003 & 0,0929 & 0,995 & 0,989 & 1,00086 \\
\hline $\boldsymbol{\alpha - S M A + K i 6 7}$ & 0,20 & 0,071 & 0,0057 & 1,217 & 1,059 & 1,40 \\
\hline $\boldsymbol{H A}$ & $-0,05$ & 0,026 & 0,0734 & 0,955 & 0,909 & 1,004 \\
\hline
\end{tabular}

Legende: In der Berechnung der Vorwärtsselektion erfüllten die fünf aufgeführten Parameter die Einschlusskriterien. Parameter, die das Signifikanzniveau von $\mathrm{p}<0,05$ unterschritten haben, wurden grün unterlegt und können formal als statistisch bedeutsam angesehen werden. Da die Hazard-Ratio von besonderem Interesse für Interpretation des Einflusses auf das Überleben ist, wurde diese Spalte blau unterlegt. Aufgrund einzelner fehlender Werte konnten nur $n=40$ Mäuse in die Cox-Regression einbezogen werden. Abkürzungen siehe Abkürzungsverzeichnis.

Die ebenfalls durchgeführte Berechnung der Rückwärtsselektion der Cox-Regression lieferte bei einem Ausschlussniveau von $\mathrm{p} \leq 0,15$ exakt die gleichen Ergebnisse wie die Vorwärtsselektion, was für stabile Ergebnisse steht. Die anschließend durchgeführte unselektierte Cox-Regression, in der alle Effekte ohne Einschlussniveau berücksichtigt wurden, lieferte sehr ähnliche Ergebnisse zu den ersten Berechnungen. Beide Regressionen werden nicht aufgeführt, da sie keinen zusätzlichen Erkenntnisgewinn bringen und die Vorwärtsselektion das am besten geeignete Rechenmodell darstellt.

Die Hazard-Ratio (HR) gibt das Risiko (eines Individuums) an zu versterben in Relation zu Individuen, bei denen der beobachtete Parameter um eine ganze Einheit niedriger liegt. Dies bedeutet am Beispiel der Ki67-Gesamtproliferationsrate, dass eine Erhöhung dieser Proliferationsrate um 1\% gegenüber einem Individuum mit durchschnittlicher Proliferationsrate mit einem 0,88-fachen Risiko zu versterben einhergeht. Sie haben also ein 12\% niedrigeres Risiko zu versterben. Eine $H R>1$ bedeutet somit ein höheres, eine $H R<1$ ein geringeres Risiko zu versterben gegenüber der Vergleichsgruppe. 
In der Vorwärtsselektion ließ sich für die Ki67-Proliferationsrate ein positiver Zusammenhang zum Überleben identifizieren (HR 0,88; 95\% KI 0,81-0,96; p $\leq 0,004$ ). Hingegen wurde für die Mitoserate, gemessen durch die PHH3-Rate (HR 5,31; 95\% KI 1,36-20,75; $\mathrm{p} \leq 0,02$ ), und für die Fibroblastenproliferationsrate, gemessen durch die $\alpha$-SMA+Ki67-Ratio (HR 1,22; 95\% KI 1,064,40; $\mathrm{p} \leq 0,006)$, ein negativer Zusammenhang zum Überleben gefunden. Für die mittlere Gefäßdichte (MVD) (HR 0,995; KI 0,989-1,001; $\mathrm{p} \leq 0,1)$ und den Hyaluronsäuregehalt (HR 0,96; 95\% KI 0,91-1,00; $\leq \leq 0,08)$ ließen sich zwar keine signifikanten Ergebnisse erkennen, jedoch kann hier möglicherweise auf eine Tendenz geschlossen werden, die bei Erhöhung der Stichprobe potenziell auch einen positiven Zusammenhang zum Überleben erkennen ließe. Allerding ist die HR mit 0,99 für HA und 0,96 für die MVD so nahe bei 1, dass bezweifelt werden muss, ob ein potenzieller Effekt überhaupt von Bedeutung wäre. Beide Werte müssen daher sehr kritisch diskutiert werden.

Angesichts negativer Ergebnisse für Ki67 und PHH3 in den univariaten Überlebensanalysen, sowohl mittels Kaplan-Meier-Kurven als auch bei univariater Cox-Regression, und gleichzeitig signifikanten Effekten in der multivariaten Analyse mittles Cox-Regression, führten wir zur weiteren Überprüfung der statistischen Bedeutsamkeit, insbesondere mit Blick auf mögliche Kolinearitätseffekte, folgenden Analyse durch:

Es wurden folgende vier Gruppen gebildet und ein Gruppenvergleich mittels Kaplan-MeierKurve durchgeführt

\section{Proliferations- und Apoptoserate, kombiniert}

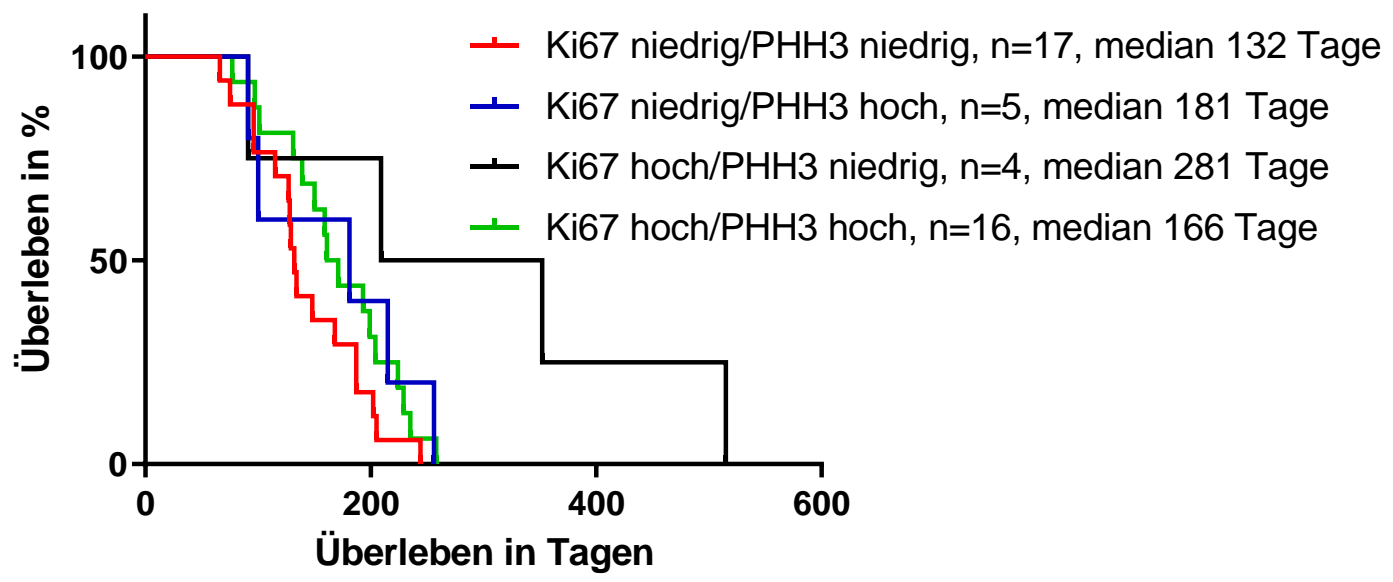

\footnotetext{
Abbildung 30: Überlebensanalyse bezüglich Indiviuen mit hohen bzw. niedrigen Proliferations- und Apoptoseraten

Darstellung der Überlebenzeiten von Mäusen mit hoher bzw. niedriger Proliferationsrate und gleichzeitig hoher bzw. niedriger Apoptoserate. Es zeigt sich für die Gruppe mit hoher Proliferations- und niedriger Apoptoserate ein deutlich längeres medianes Überleben (281 Tage vs. 132-181 Tage) gegenüber den Vergleichsgruppen.
} 
Hier zeigte sich insbesondere für die Gruppe mit hohem Ki67 und niedrigem PHH3 ( $n=4)$ ein deutlich längeres Überleben, während in den anderen drei Gruppen, welche die große Mehrheit der beobachteten Individuen beinhalten, relativ ähnliche Überlebenszeiten gesehen wurden. Es ist wahrscheinlich, dass die vier Individuen bei der gemeinsamen Betrachtung aller Parameter in der multivariaten Analyse entscheidend zu den signfikanten beobachteten Effekten für Ki67 und PHH3 in der multivariaten Cox-Regression beitragen. Eine genauere Betrachtung der einzelnen Ki67- und PHH3-Werte für diese Individuen ergab zwar keinen Grund diese aus der Analyse herauszunehmen, jedoch lässt die Tatsache, dass vier Individuen maßgeblichen Einfluss auf die statistische Signifikanz der beobachteten Effekte haben, begründete Zweifel an der Robustheit des multivariaten Modells zu (vgl. Diskussion).

Die Spearman-Rank-Order-Korrelation überprüft alle in die Cox-Regression einfließenden Parameter sowie das Überleben auf Korrelationen untereinander. Dabei wurden sieben Paare mit einer signifikanten Korrelation identifiziert. Korrelationskoeffizienten zwischen 0 und +1 sprechen für eine positive Korrelation, Werte zwischen 0 und -1 für eine negative Korrelation. Je größer der Korrelationskoeffizient ist, desto stärker ist die Korrelation der beiden Parameter. Die Ergebnistabelle liest sich beispielhaft so, dass das Grading und die Desmoplasie mit einem Korrelationskoeffizienten von -0,83 stark negativ miteinander korreliert sind. Ein hohes Grading geht mit einem niedrigen Grad an Desmoplasie einher, während Tumoren mit einem niedrigen Grading stärker desmoplastisch sind.

Tabelle 19: Spearman-Rank-Order-Korrelation

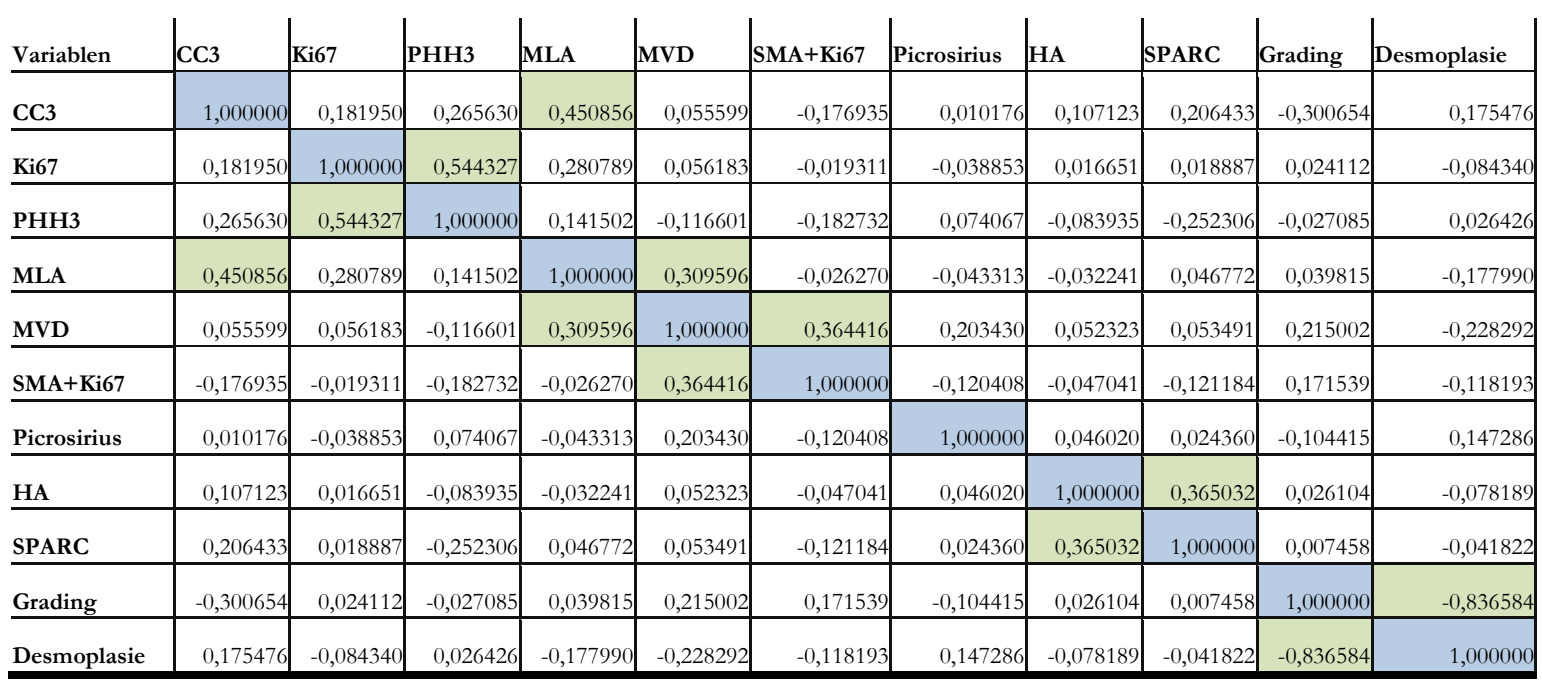

Legende: Mittels Spearman-Rank-Order-Korrelation werden alle Parameter, die auch in die multivariate Überlebensanalyse einfließen, auf eine Korrelation untereinander geprüft. Alle signifikanten Korrelationen $(p<0,05)$ sind grün hinterlegt. Paarungen der gleichen Variablen wurden blau hinterlegt.

MVD (mittlere Gefäßdichte), MLA (mittleres Gefäßlumen), weitere Abkürzungen siehe Abkürzungsverzeichnis 


\subsection{Vergleich von Primärtumoren und Lebermetastasen}

Die vergleichende histologische Betrachtung von stromalen Parametern zwischen PT und ihren korrespondierenden LM erfolgte nach den beschriebenen Methoden für folgende Parameter: CC3, PHH3, Ki67, CD31, $\alpha$-SMA, HA und Picrosirius. Dabei wurden zwischen 6 und 11 unbehandelte KPC-Mäuse untersucht, die im Vorfeld in der HE-Färbungen ausreichend große Metastasen aufwiesen. Für einige Stromamarker konnten niedrigere Expressionslevel in LM als in PT gefunden werden, für andere Marker konnte sich kein Unterschied nachweisen lassen. Alle Parameter, die auch mit histologisch gesundem Lebergewebe verglichen wurden, zeigten deutliche bindegewebige Veränderungen sowohl in PT als auch Metastasen, während sich im normalen Lebergewebe kaum Kollagen, HA, SPARC und $\alpha$-SMA nachweisen ließ.

Diese Daten sowie die Abbildungen sind bereits in eine Publikation eingeflossen (Hessmann et al. 2018) und wurden auf der 48. Jahrestagung des European Pancreatic Clubs im Rahmen eines Vortrags präsentiert (Klein et al. 2016).
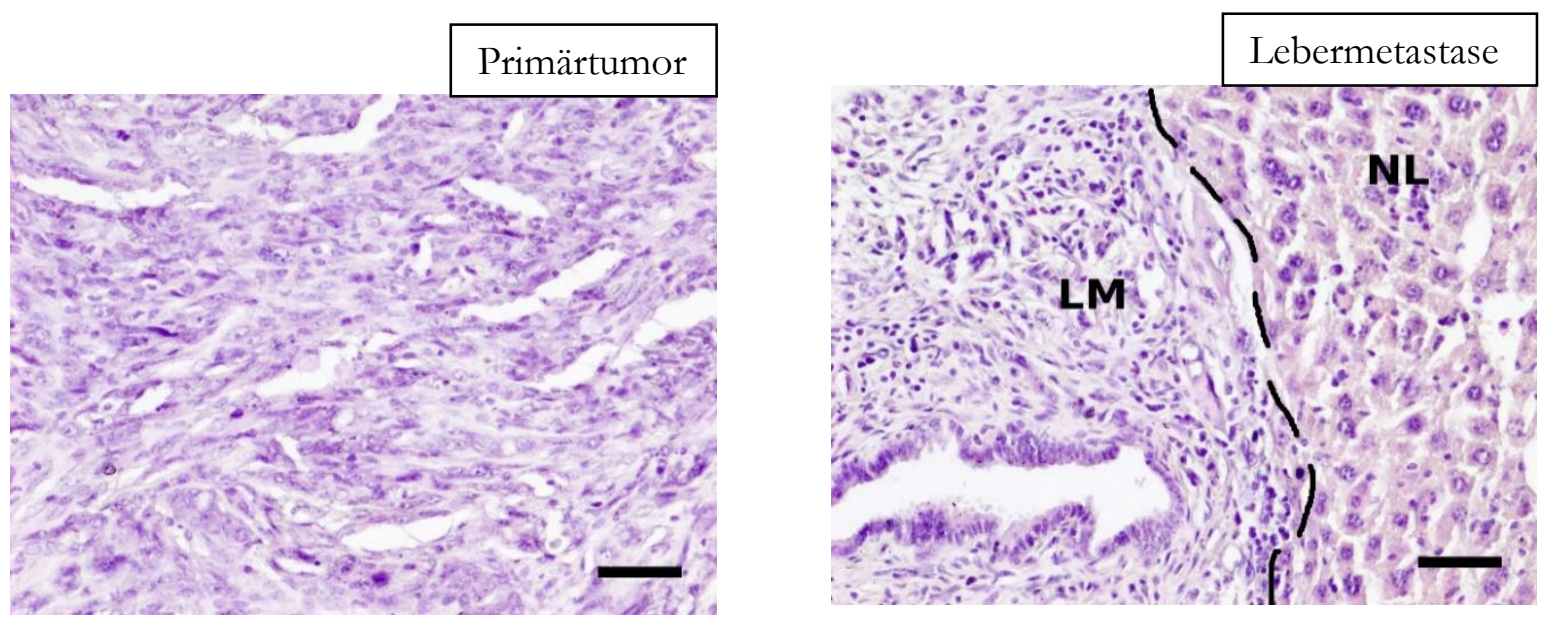

Abbildung 31: Hämatoxilin-Eosin-Färbungen von Primärtumor und Lebermetastase

HE-Färbungen von repräsentativen Arealen in PT (links) und Lebermetastase (LM) mit angrenzendem normalem Lebergewebe (NL) (rechts). Beide Tumorkompartimente stellen sich deutlich desmoplastisch dar. Maßstab $50 \mu \mathrm{m}$.

Abbildung von Lukas Klein aus Hessmann et al. (2018), lizensiert unter CC-BY 4.0; http://dx.doi.org/10.1136/gutjnl-2016-311954 
In der Picrosiriusfärbung fanden sich in LM 40\% weniger Fläche mit positivem Signal, was einen deutlich reduzierten Kollagengehalt in LM gegenüber PT darstellt (LM 8,0\% 95\% KI 3,013,0 vs. PT 13,6\% 95\% KI 7,9-19,2; p<0,006). Das normale Lebergewebe wies so gut wie kein Kollagen auf (NL 0,9\%).

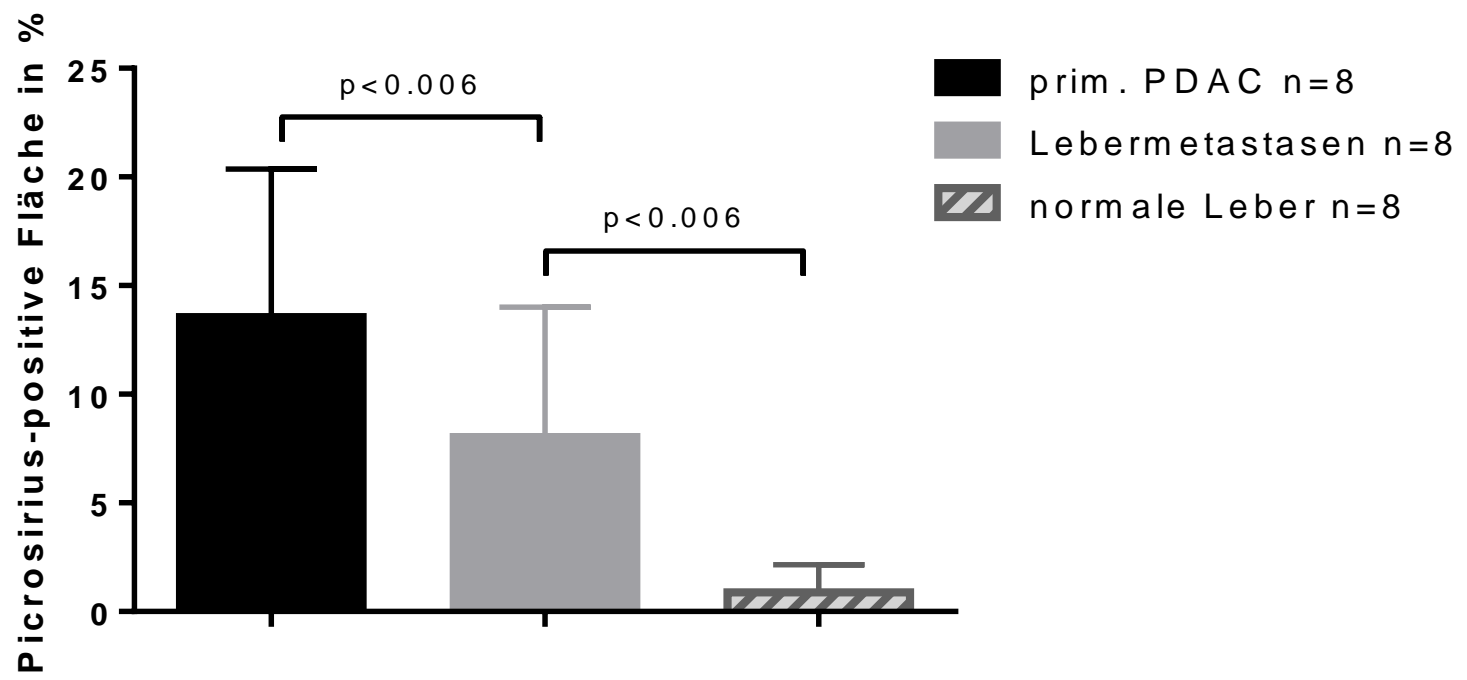

Abbildung 32: Picrosirius-positive Fläche in \% als Marker für den Kollagengehalt in Primärtumor, Lebermetastasen und normaler Leber

Abbildung von Lukas Klein aus Hessmann et al. (2018), lizensiert unter CC-BY 4.0; http://dx.doi.org/10.1136/gutjnl-2016-311954
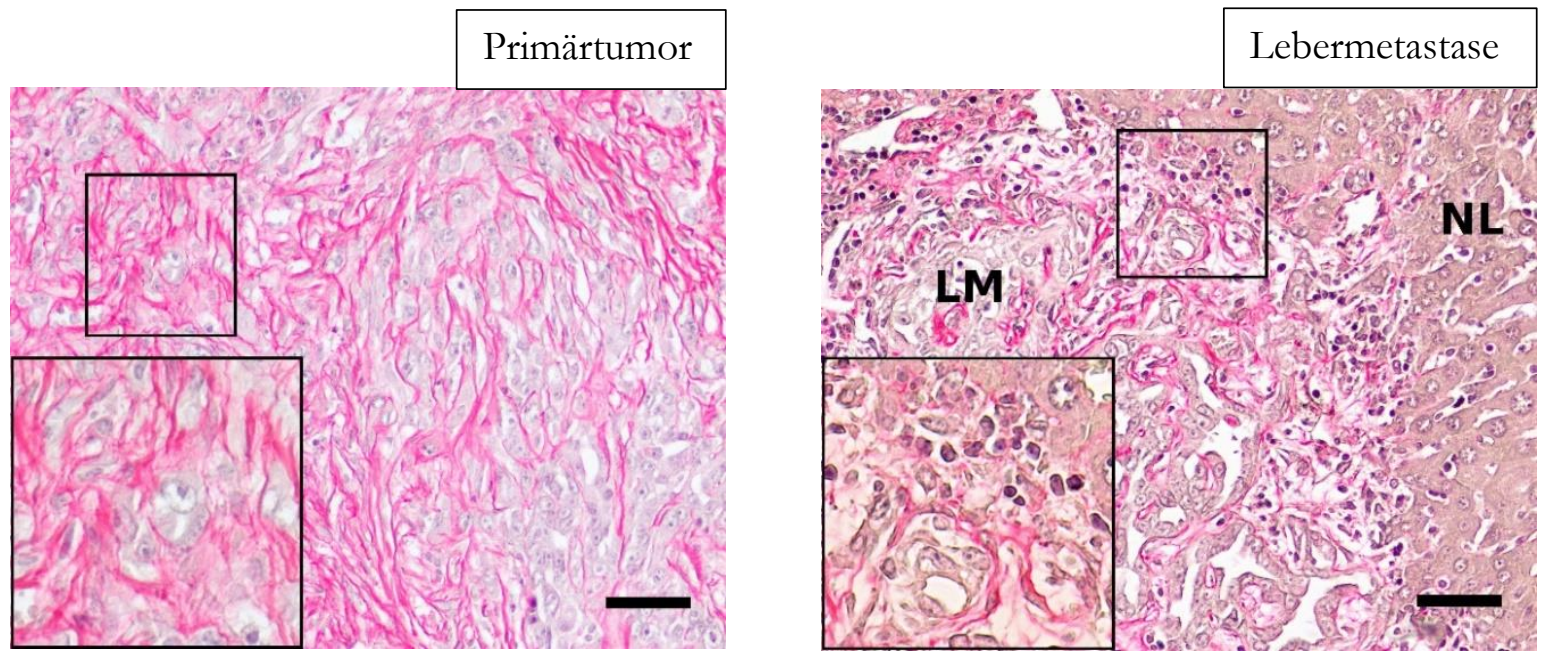

Abbildung 33: Picrosiriusfärbung für Primärtumor und Lebermetastase

Gegenüberstellung von Picrosiriusfärbungen in repräsentativen Arealen in PT (links) und Lebermetastase (LM) mit angrenzendem normalem Lebergewebe (NL) (rechts). Maßstab $50 \mu \mathrm{m}$.

Abbildung von Lukas Klein aus Hessmann et al. (2018), lizensiert unter CC-BY 4.0; http://dx.doi.org/10.1136/gutjnl-2016-311954 
Die Fibroblastendichte (aktivierte Fibroblasten) wurde durch die Anwesenheit von $\alpha$-SMA bzw. die $\alpha$-SMA-positive Fläche ermittelt und auch hier präsentierten sich die Metastasen stromaärmer als die PT der gleichen Maus. So war die Fibroblastendichte in Metastasen circa 40\% niedriger (LM 7,3\% 95\% KI 5,2-9,3 vs. PT 11,8\% 95\% KI 8,9-14,7; p<0,003).

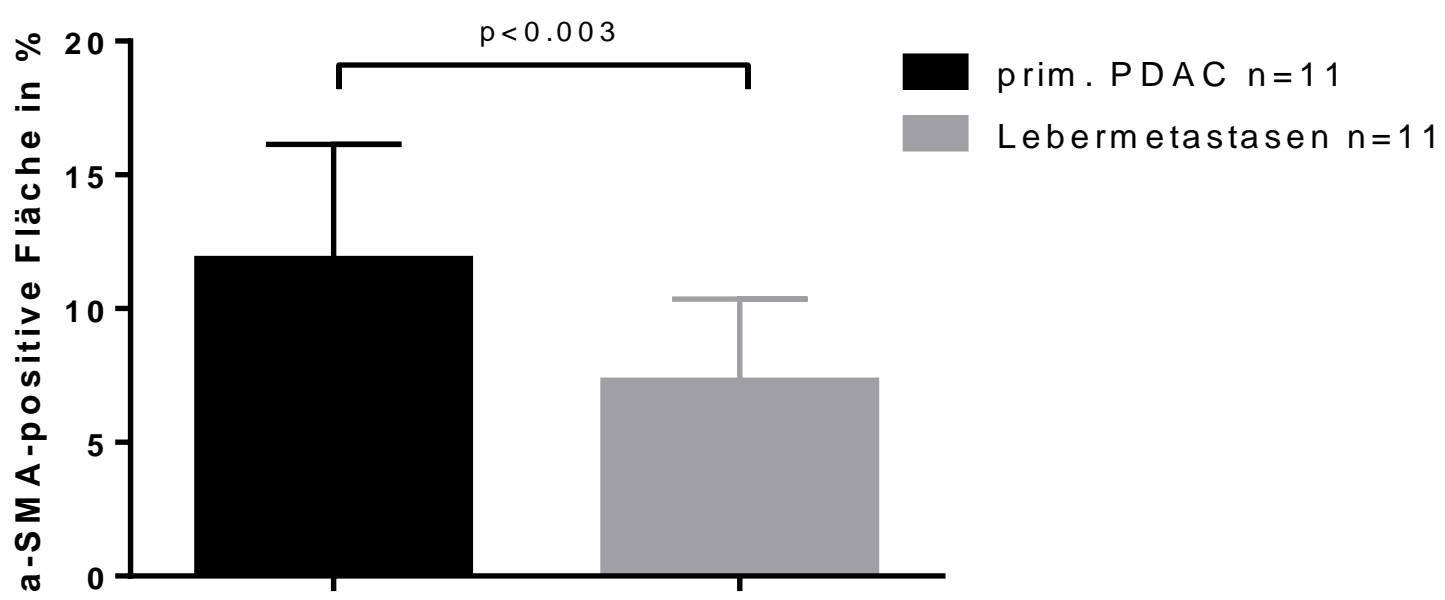

Abbildung 34: $\alpha$-smooth muscle actin-positive Fläche in \% als Marker für aktivierte Fibroblasten in Primärtumoren und Lebermetastasen

Abbildung von Lukas Klein aus Hessmann et al. (2018), lizensiert unter CC-BY 4.0; http://dx.doi.org/10.1136/gutjnl-2016-311954
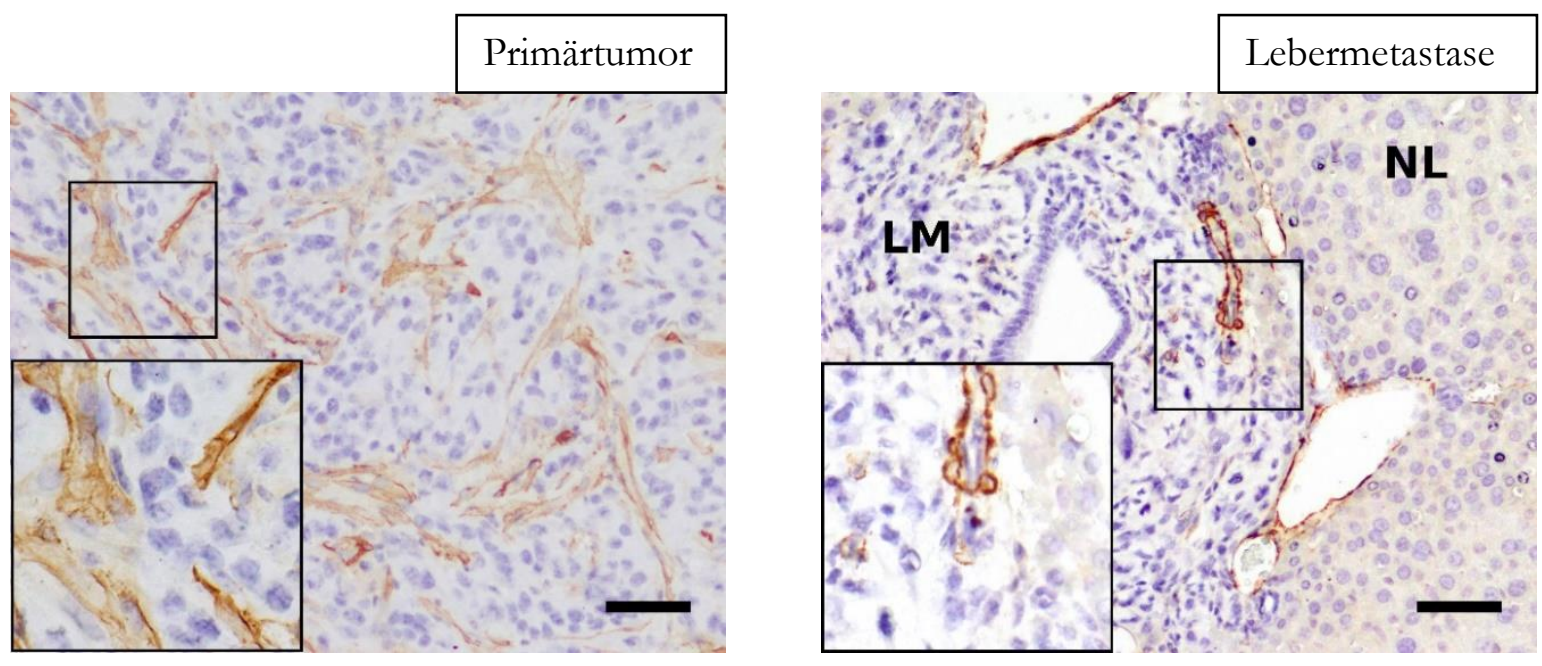

Abbildung 35: $\alpha$-smooth muscle actin-Färbung für Primärtumor und Lebermetastase

Gegenüberstellung von $\alpha$-SMA-Färbungen in repräsentativen Arealen in PT (links) und Lebermetastase (LM) mit angrenzendem normalem Lebergewebe (NL) (rechts). Maßstab $50 \mu \mathrm{m}$.

Abbildung von Lukas Klein aus Hessmann et al. (2018), lizensiert unter CC-BY 4.0; http://dx.doi.org/10.1136/gutjnl-2016-311954 
Überraschenderweise zeigte sich für das EZM-Protein HA ein gegenläufiger Trend, bei dem die LM circa doppelt so viel HA exprimierten wie die PT (LM 34,2\% 95\% KI 27,2-41,3 vs. PT 17,8\% 95\% KI 11,9-23,6; $\mathrm{p}<0,002)$. Normales Lebergewebe hingegen exprimierte wie erwartet gar keine HA $(0,015 \%)$.

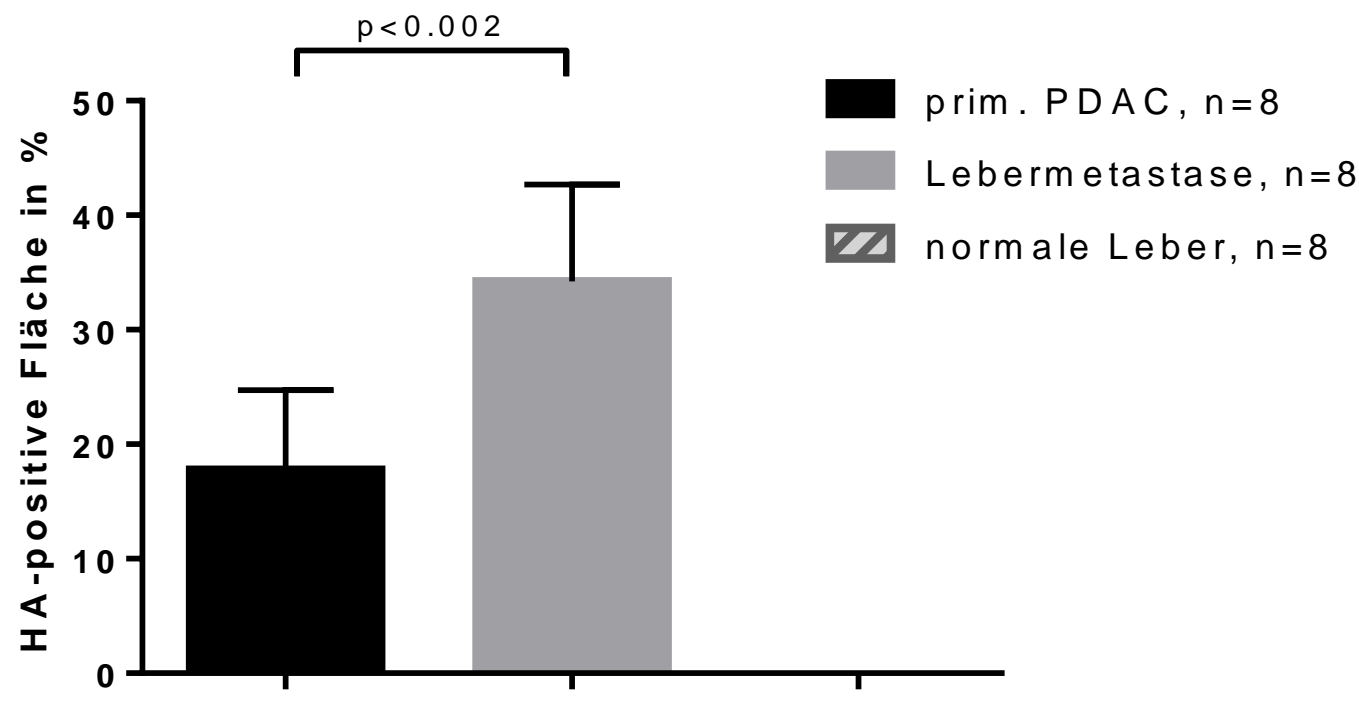

Abbildung 36: Hyaluronsäure-positive Fläche in \% in Primärtumoren, Lebermetastasen und normalem Lebergewebe
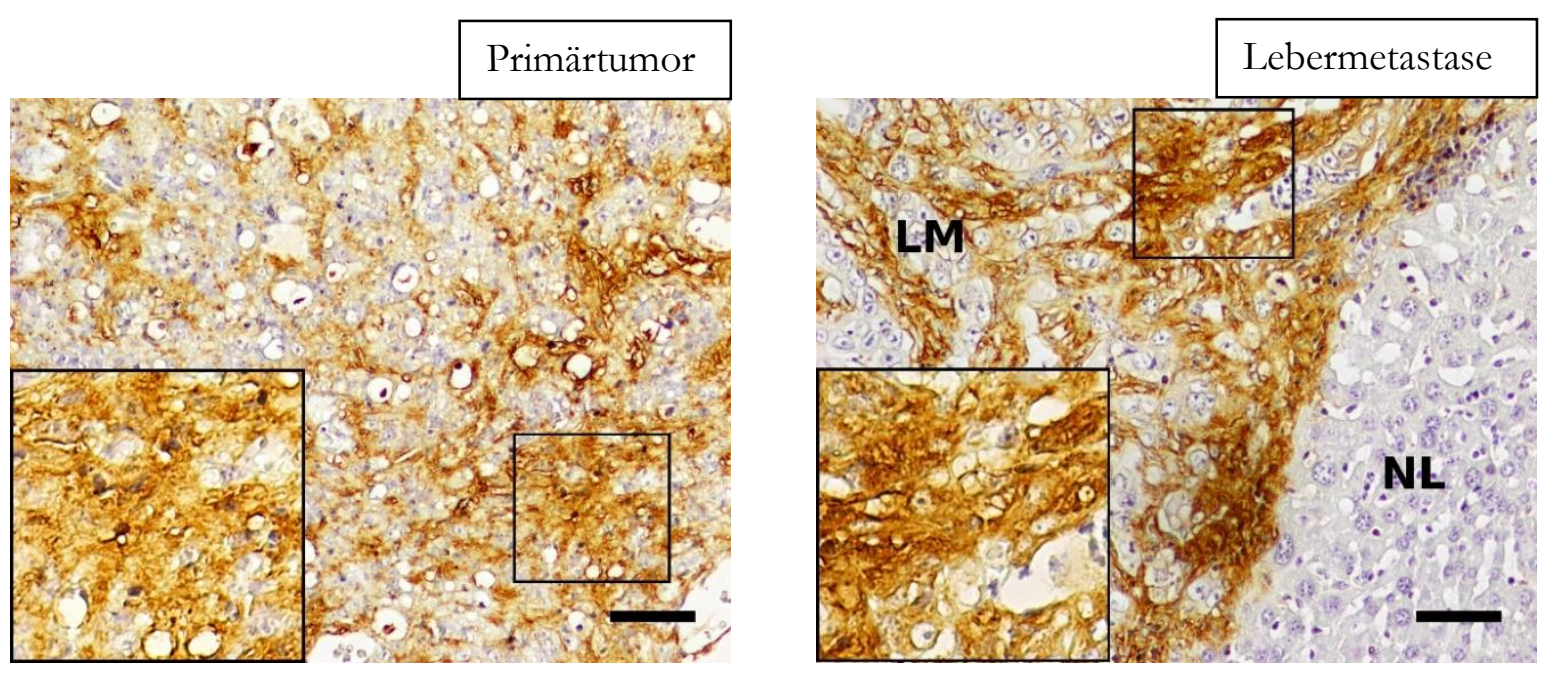

Abbildung 37: Hyaluronsäure-Färbung für Primärtumor und Lebermetastase

Gegenüberstellung von HA-Färbungen in repräsentativen Arealen in PT (links) und Lebermetastase (LM) mit angrenzendem normalem Lebergewebe (NL) (rechts). Maßstab $50 \mu \mathrm{m}$. 
Obwohl sich beim Mikroskopieren der Verdacht stellte, dass die SPARC-Expression in Metastasen deutlich niedriger sei, zeigte die Quantifizierung keine signifikanten Unterschiede. Gleichwohl war eine Tendenz in diese Richtung erkennbar. So lag die mittlere SPARC-Expression in Metastasen circa 10\% unter der in PT (LM 4,3\% 95\% KI 1,8-6,8 vs. 4,9\% 95\% KI 3,36,5; n.s.). Lebergewebe hingegen exprimierte wie erwartet sehr geringe Mengen SPARC (NL $0,9 \% 95 \%$ KI $0,5-1,3)$.

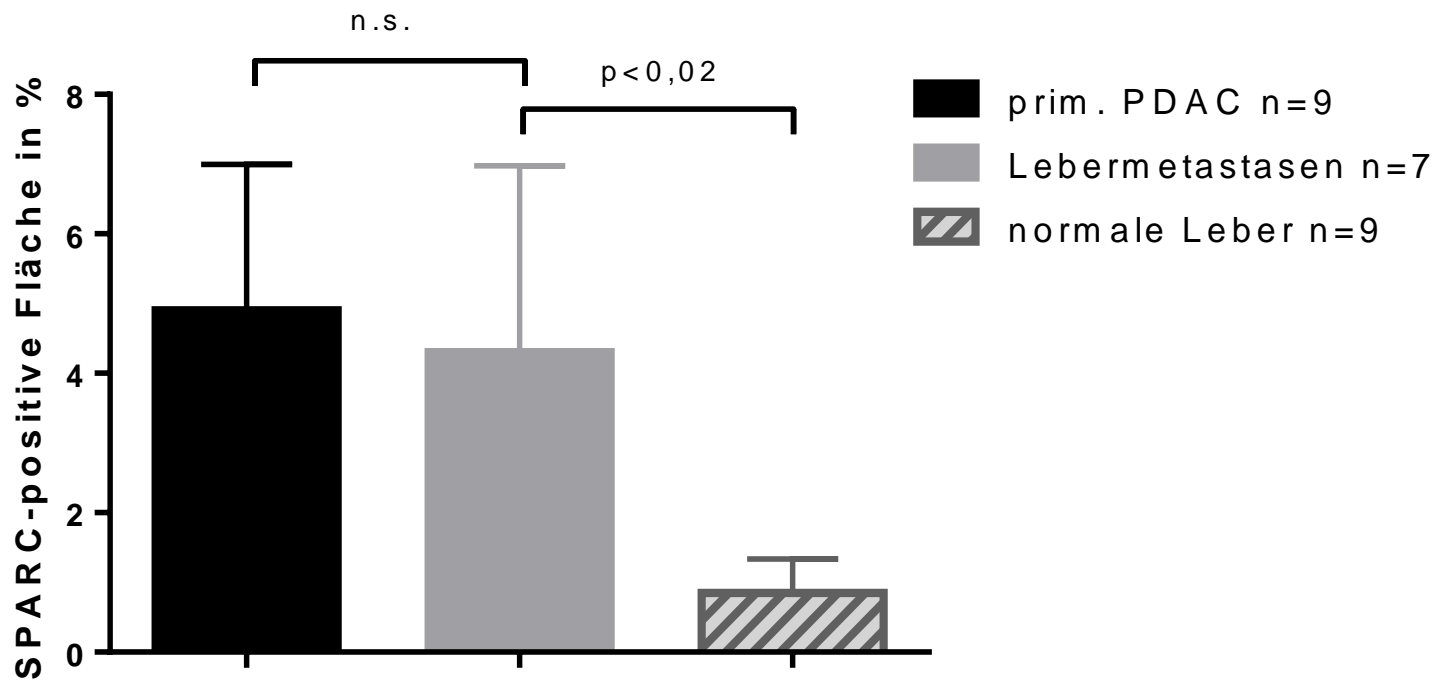

\section{Abbildung 38: SPARC-positive Fläche in \% in Primärtumoren, Lebermetastasen und normaler Leber}

Abbildung von Lukas Klein aus Hessmann et al. (2018), lizensiert unter CC-BY 4.0; http://dx.doi.org/10.1136/gutjnl-2016-311954
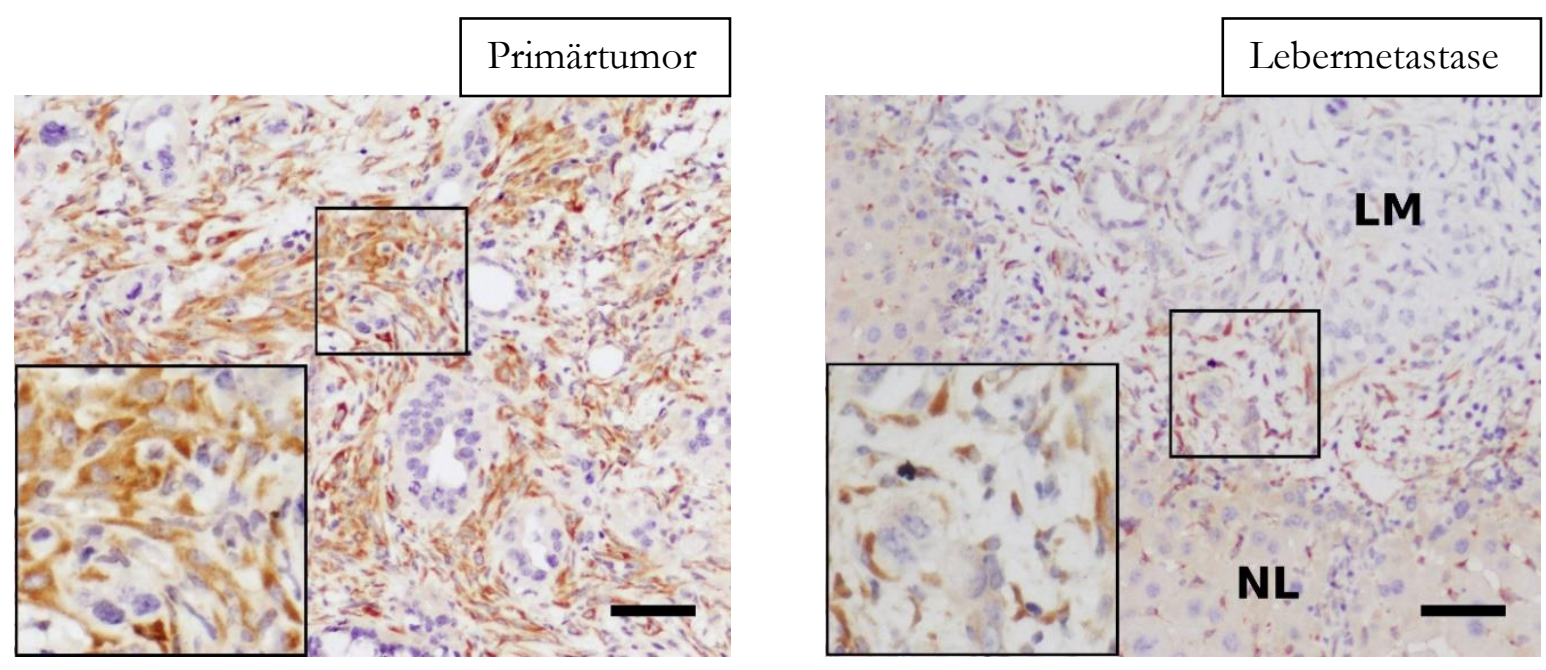

Abbildung 39: SPARC-Färbung für Primärtumor und Lebermetastase

Gegenüberstellung von SPARC-Färbungen in repräsentativen Arealen in PT (links) und Lebermetastase (LM) mit angrenzendem normalem Lebergewebe (NL) (rechts). Maßstab $50 \mu \mathrm{m}$.

Abbildung von Lukas Klein aus Hessmann et al. (2018), lizensiert unter CC-BY 4.0; http://dx.doi.org/10.1136/gutjnl-2016-311954 
Die in der CD31-IHC ermittelte MVD ist in PT und Metastasen vergleichbar niedrig, wohingegen normales Lebergewebe wie erwartet eine um ein Vielfaches (4-fach) erhöhte Blutgefäßdichte hatte (PT 11,5/400x-Feld vs. LM 12,75/400x-Feld vs. NL 45,6/400x-Feld).

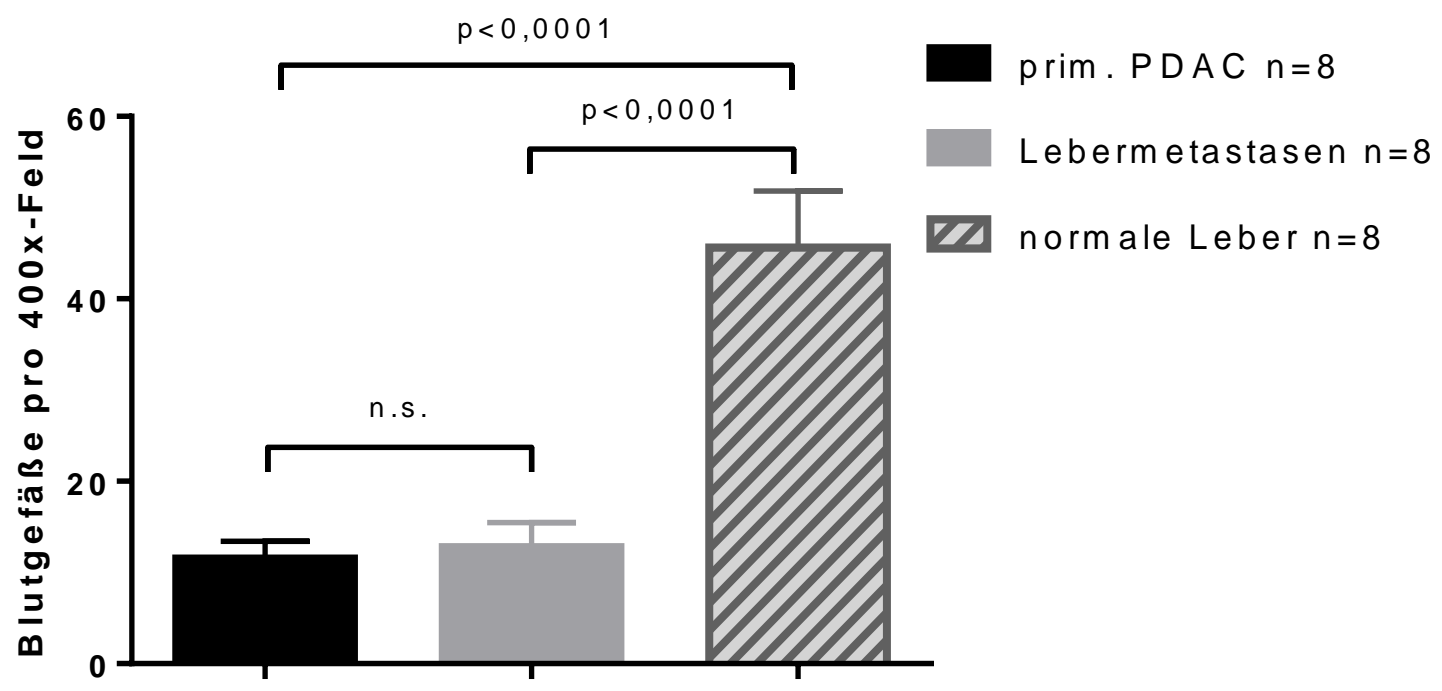

Abbildung 40: CD31-positive Blutgefäße pro hochauflösendem 400x-Gesichtsfeld in Primärtumoren, Lebermetastasen und normaler Leber

Die Gefäßdichte ist in gepaarten PT und LM um etwa das Vierfache niedriger als in umliegendem, normalem Lebergewebe. Zwischen PT und LM besteht kein signifikanter Unterschied der Gefäßdichte. Abbildung von Lukas Klein aus Hessmann et al. (2018), lizensiert unter CC-BY 4.0; http://dx.doi.org/10.1136/gutjnl-2016-311954
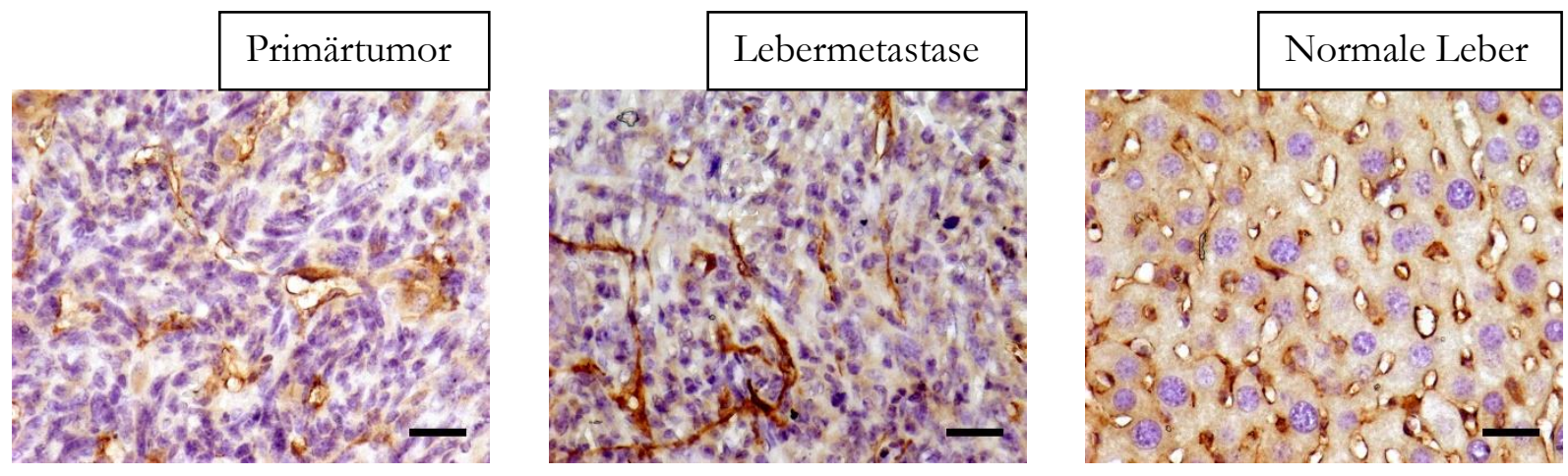

Abbildung 41: CD31-Färbung in Primärtumor, Lebermetastase und normalem Lebergewebe

Gegenüberstellung von CD31-Färbungen in repräsentativen Arealen in PT (links), LM (mittig) und normalem Lebergewebe (rechts). Maßstab $25 \mu \mathrm{m}$.

Abbildung von Lukas Klein aus Hessmann et al. (2018), lizensiert unter CC-BY 4.0; http://dx.doi.org/10.1136/gutjnl-2016-311954 
Weder für die Anzahl der apoptotischen Zellen, gemessen als Zahl der CC3-positiven Zellen pro hochauflösendem Gesichtsfeld, noch für die Anzahl der proliferierenden Zellen, gemessen als Zahl der Ki67-positiven Zellen, besteht ein Unterschied zwischen PT und ihren korrespondierenden LM. So fanden sich in PT durchschnittlich 2,4 (95\% KI 1,7-3,2) apoptotische Zellen pro Gesichtsfeld während in LM durchschnittlich 5,3 (95\% KI 0,9-9,6) apoptotische Zellen zu finden sind. Der Unterschied ist mit $\mathrm{p}=0,16$ statistisch nicht signifikant. Beim Blick auf die Proliferationsrate fanden sich in PT durchschnittlich 39,3 (95\% KI 32-46,5) proliferierende Zellen pro Gesichtsfeld während in LM durchschnittlich 73,7 (95\% KI 21,6-125,8) proliferierende Zellen zu finden sind. Auch dieser Unterschied ist mit $\mathrm{p}=0,12$ statistisch nicht signifikant.

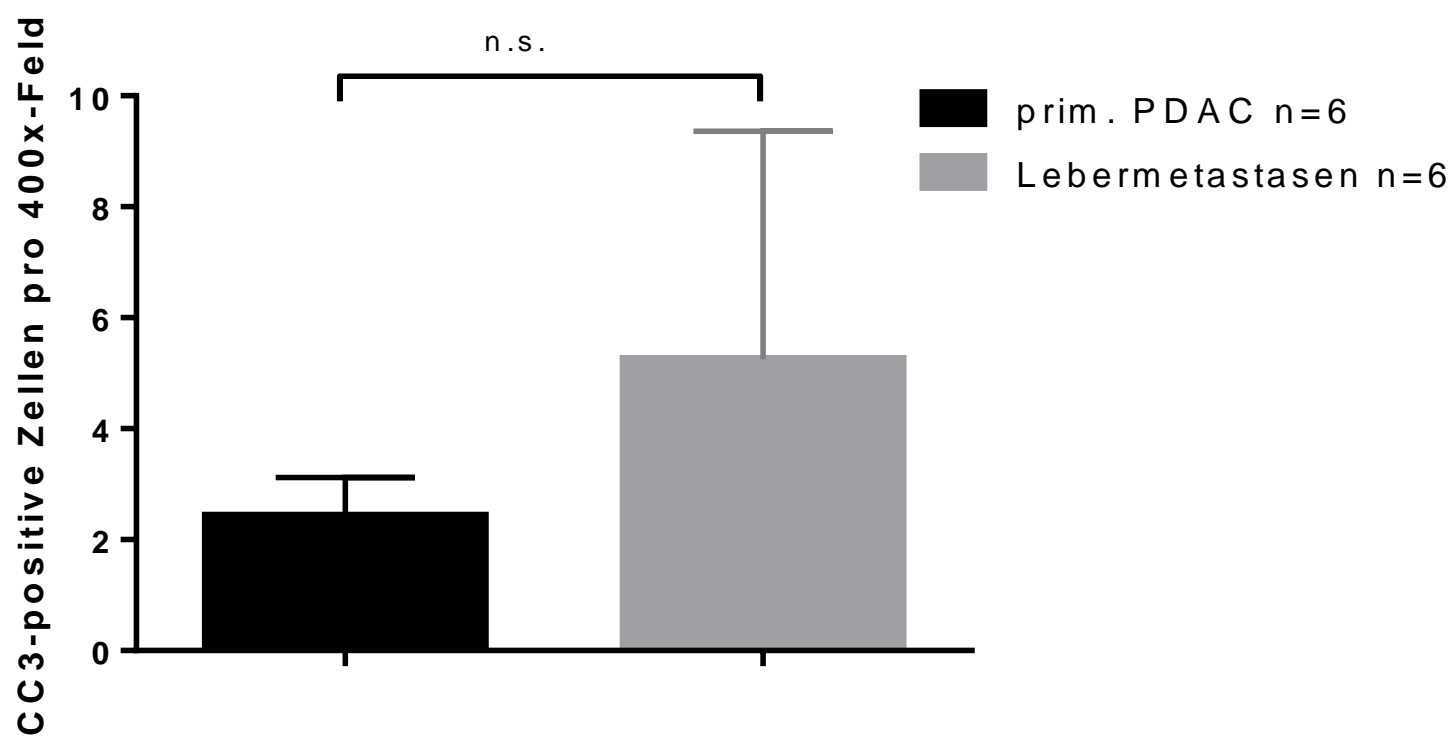

Abbildung 42: Cleaved-Caspase-3-positive Zellen pro hochauflösendem 400x-Gesichtsfeld als Apoptosemarker in Primärtumoren und Lebermetastasen

Zwischen gepaarten PT und LM gibt es keinen signifikanten Unterschied hinsichtlich apoptotischer Zellen.
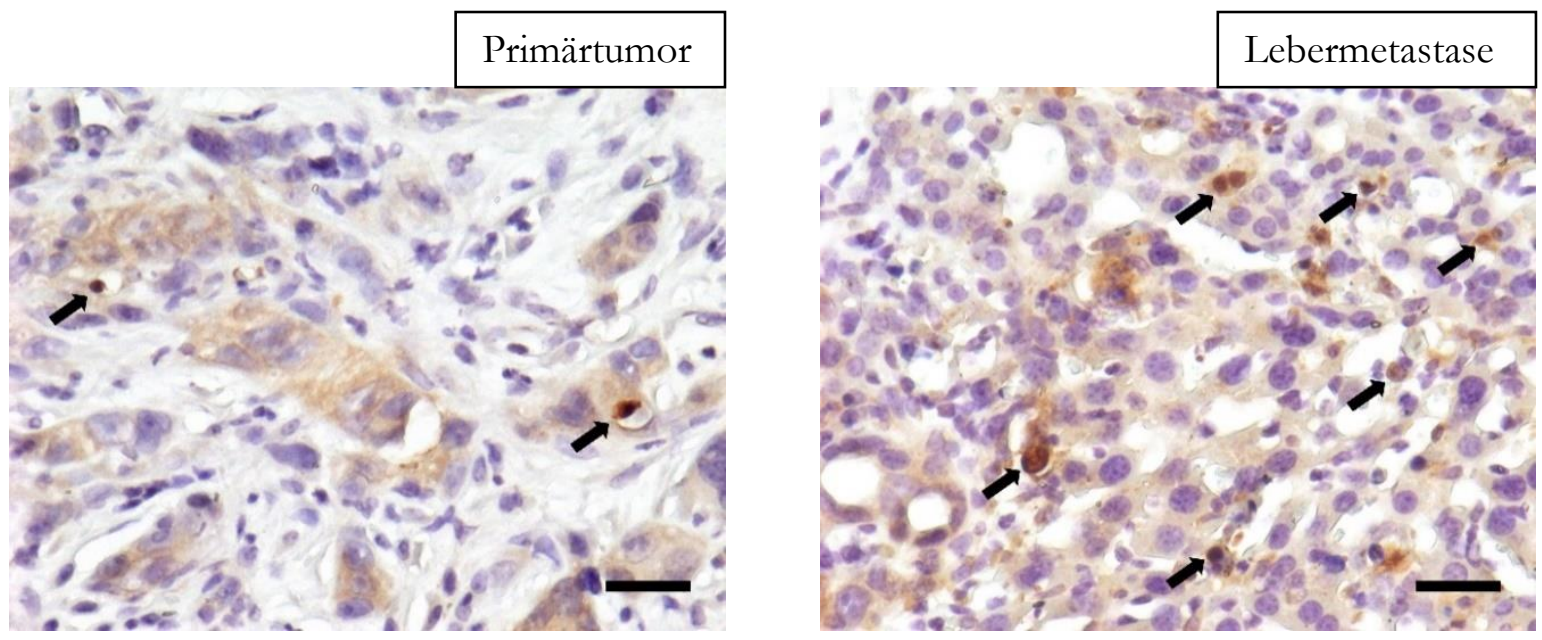

\section{Abbildung 43: Cleaved-Caspase-3-Färbung in Primärtumor und Lebermetastase}

Gegenüberstellung von CC3-Färbungen in repräsentativen Arealen in PT (links) und LM (rechts). Beispielhalft sind apoptotische, CC3-positive Zellen mit Pfeilen markiert. Maßstab $25 \mu \mathrm{m}$. 


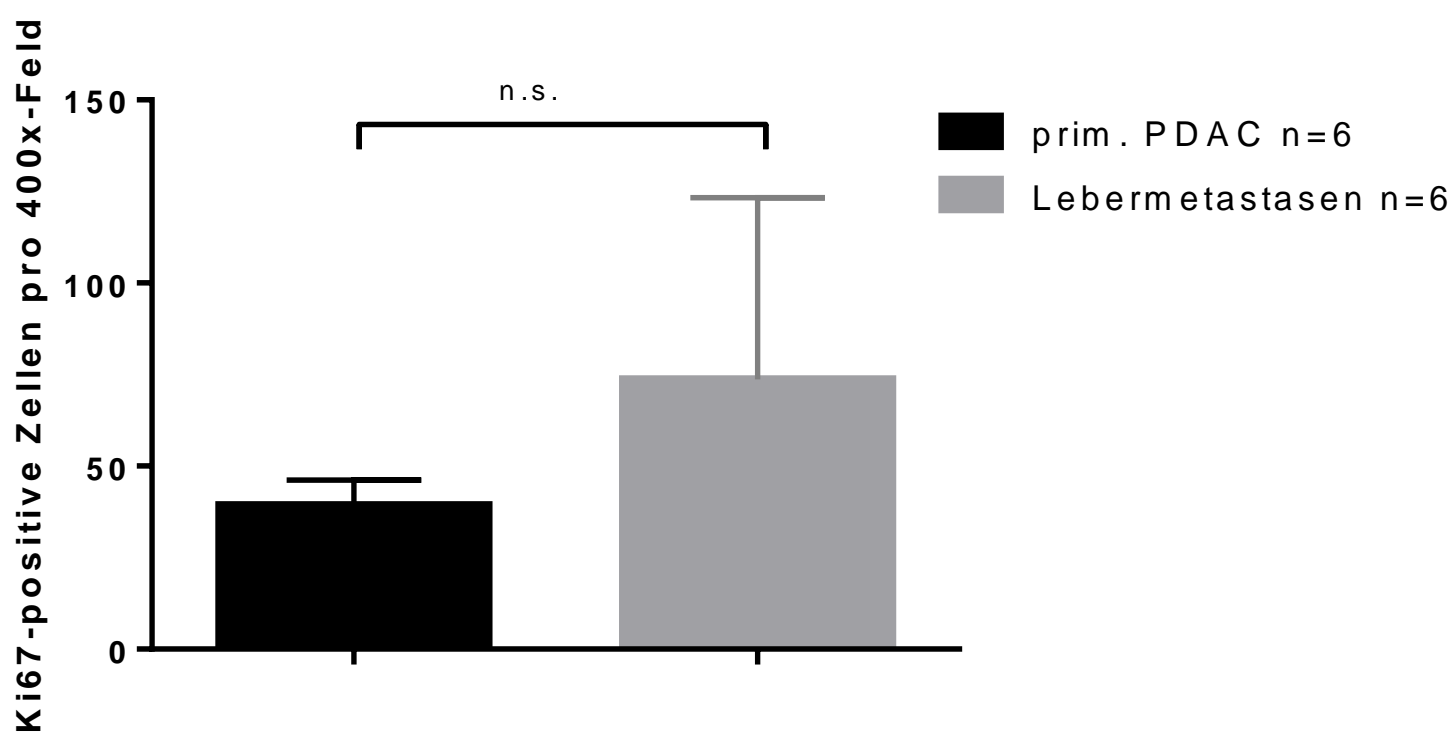

Abbildung 44: Ki67-positive Zellen pro hochauflösendem 400x-Gesichtsfeld als Proliferationsmarker in Primärtumoren und Lebermetastasen

Zwischen gepaarten PT und LM gibt es keinen signifikanten Proliferationsunterschied.
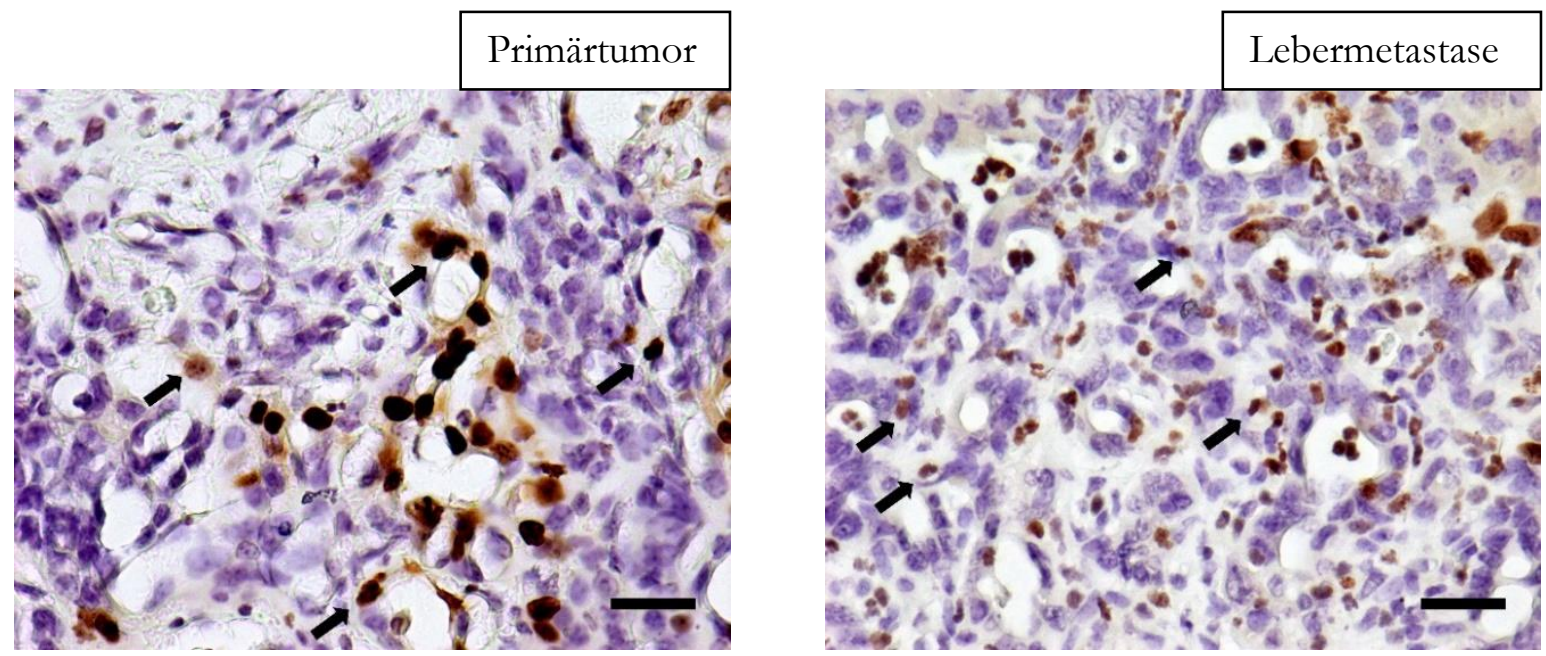

Abbildung 45: Ki67-Färbung in Primärtumor und Lebermetastase

Gegenüberstellung von Ki67-Färbungen in repräsentativen Arealen in PT (links) und LM (rechts). Beispielhaft sind proliferierende, Ki67-positive Zellen mit Pfeilen markiert. Maßstab $25 \mu \mathrm{m}$.

Um die Beobachtung des reduzierten Stromaanteils in Metastasen zu überprüfen, wurde ein Westernblot aus Lysaten von Primärtumormasse und resezierten LM aus jeweils fünf KPCMäusen sowie einer Gewebeprobe für NL angefertigt. Der Westernblot wurde nach dem beschriebenen Protokoll durchgeführt und neben HSP90 als Ladungskontrolle und dem epithelialen Marker E-Cadherin auf die drei Stromamarker SPARC, $\alpha$-SMA und Fibronektin analysiert. E-Cadherin ist als transmembranes Glykoprotein an der Zelladhäsion und am Aufbau des Zytoskeletts beteiligt und spielt auch in der Metastasierung eine Rolle (Rassow et al. 2008). 
Die Ladungskontrolle für das HSP90 ergab vergleichbare Ausgangswerte für alle Proben. Auch E-Cadherin war relativ gleichmäßig in allen Proben exprimiert. Hingegen fand sich in allen Primärtumorlysaten deutlich mehr $\alpha$-SMA als in den zugehörigen Proben aus Metastasen, was auf eine niedrigere Fibroblastendichte in den Metastasen schließen lässt. Auch in NL ließ sich vergleichbar wenig $\alpha$-SMA wie in den PT finden. Das Protein SPARC, welches von CAFs sowohl sezerniert als auch intrazellulär akkumuliert, gilt somit als Marker für zelluläres und extrazelluläres Stroma. Die Expression von SPARC war in primären PDAC in KPC-Mäusen deutlich erhöht gegenüber den LM, was in Einklang steht mit der Tendenz, welche sich in der IHC beobachten lässt. Genau wie für $\alpha$-SMA lässt sich im gesunden Lebergewebe ebenfalls keine SPARC-Expression nachweisen. Fibronektin ist ein wichtiges Protein der EZM, welches in vielen physiologischen Prozessen wie der Gewebsstabilität eine Rolle spielt. Im gesunden Pankreas spielt es jedoch eine eher untergeordnete Rolle und wird erst im Rahmen von Entzündungsprozessen wie Pankreatitis und dem PDAC von aktivierten Fibroblasten bzw. PSCs in großen Mengen sezerniert. Dementsprechend finden sich in den Proben aus primären KPC-Tumoren höhere Level an Fibronektin als in LM und NL.

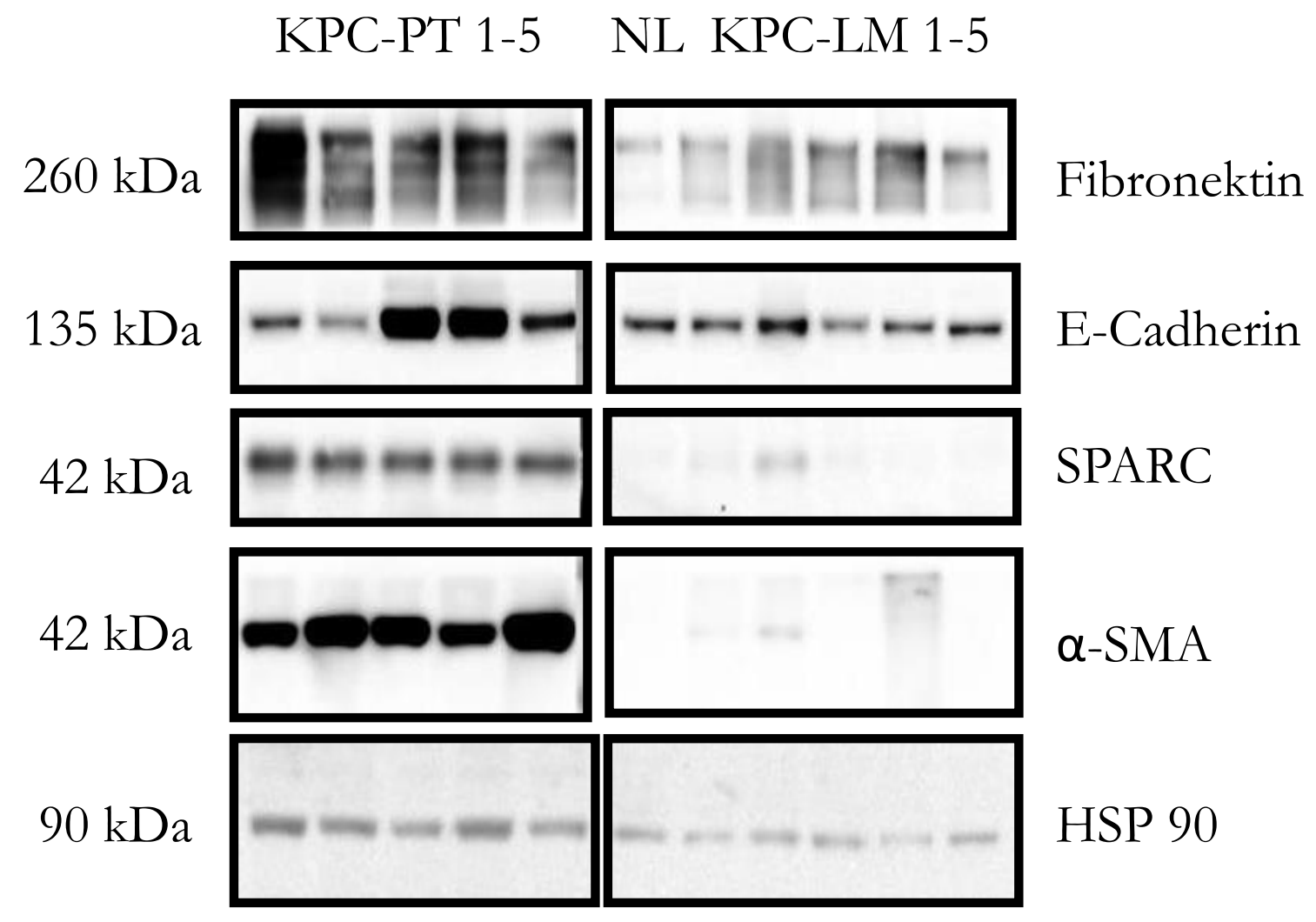

Abbildung 46: Westernblot aus Tumorgewebe und normalem Lebergewebe von KPCMäusen

Der Westernblot aus Tumorlysaten aus 5 KPC-Primärtumoren (KPC-PT), 5 KPC-Lebermetastasen (KPC-LM) und einer Probe normalen Lebergewebes (NL) zeigt deutlich reduzierte Proteinexpression von Fibronektin, SPARC und $\alpha$-SMA in LM gegenüber PT. Das ubiquitär exprimierte und als Ladungskontrolle dienende HSP 90 ist in allen Proben auf vergleichbarem Niveau exprimiert. Molekülmasse in Kilodalton $(\mathrm{kDa})$

Abbildung von Lukas Klein aus Hessmann et al. (2018), lizensiert unter CC-BY 4.0; http://dx.doi.org/10.1136/gutjnl-2016-311954 


\section{Diskussion}

\subsection{Vor- und Nachteile des KPC-Modells}

Die KPC-Maus ist das am besten charakterisierte Krebsmodell für das PDAC. Zwar werden das Modell und seine Vorteile anderen transgenen Mausmodellen gegenüber kritisch diskutiert, jedoch gilt es weithin als Goldstandard für die präklinische Untersuchung von neuen Therapieansätzen (Gopinathan et al. 2015). Obwohl das KPC-Modell einige Nachteile gegenüber anderen Krebsmodellen wie Zellkultur und Xenograftmodelle hinsichtlich hohem technischen, zeitlichen, finanziellen und personellen Aufwand hat, bietet es doch eine Reihe an Vorteilen. Diese machen es zu einer mittlerweile unverzichtbaren Komponente der Krebsforschung und wiegen viele der Nachteile auf. Einer der wertvollsten Vorteile der PDAC aus KPC-Mäusen liegt in der guten Rekapitulierung von entscheidenden Komponenten des Tumormikromilieus, welchem im PDAC eine herausragende Rolle für Aggressivität, Chemoresistenz und Metastasierung zugewiesen wird. So erlaubt dieses Modell die Adressierung von Gefäßdichte und Durchblutungssituation, Fibroblastendichte, EZM und einem funktionellen Immunsystem. Ein weiterer wichtiger Vorteil dieses Modells liegt in der großen Ähnlichkeit zu menschlichen PDAC bezüglich klinischer Aspekte wie hämorrhagischer Aszites, Kachexie und biliärer Obstruktion. Auch das Metastasierungsverhalten wird in Häufigkeit und bevorzugter Lebermetastasierung gut nachgezeichnet. Unter der Vielzahl an zur Verfügung stehenden transgenen Mausmodellen für das PDAC kommt die KPC-Maus mit ihrer großen Ähnlichkeit in vielen wichtigen Tumoreigenschaften dem menschlichen PDAC am nächsten. Trotzdem bleibt das KPC-Modell in vielen Aspekten unzulänglich und somit nur eines von vielen benötigten Krebsmodellen um der Komplexität dieser tödlichen Erkrankung gerecht zu werden (Hingorani et al. 2005; Frese und Tuveson 2007; Gopinathan et al. 2015).

Obwohl KPC-Tumoren genetisch heterogen und stromareich sind, bleiben sie dennoch in diesen Eigenschaften hinter menschlichen PDAC zurück (Hingorani et al. 2005). KPC-Tumoren durchlaufen zwar mit den PanIN-Läsionen die gleichen Vorläuferläsionen wie menschliche Tumoren, jedoch werden hier bereits embryonal in allen Zellen zeitgleich dieselben Mutationen aktiviert. Es werden mit Expression der Cre-Rekombinase über das Ablesen der Promotorregion PDX-1 am 9. Tag der Embryonalentwicklung in allen PDX-1 positiven Pankreasprogenitorzellen annähernd simultan eine Mutation des (Proto-)Onkogens KRAS sowie eine $\operatorname{Tr} 53^{\mathrm{R} 172 \mathrm{H}}$-Mutation des TSG $p 53$ aktiviert. Beide Mutationen werden also bereits während der Embryonalentwicklung induziert. Durch diese genetisch veränderte Ausgangslage aller PDX-1 exprimierenden Pankreaszellen in der frühen Embryonalphase und stochastisch auftretenden Mutationen, kommt es in der Folge zum Verlust der Heterozygotie in Bezug auf das zweite 253 Allel. Dies führt zur frühzeitigen und multifokalen Entstehung von PanINs, sodass bereits nach fünf Wochen einzelne (nicht invasive) Läsionen und nach zehn Wochen das volle Spektrum an PanINs beobachtet werden können (Hingorani et al. 2005). Aus den diversen PanINs entstehen parallel an vielen Stellen duktale Karzinome, sodass das gesamte Pankreas früh mit Karzinomen 
durchsetzt ist. Dies entspricht nicht dem Wachstum des menschlichen PDAC aus einem oder wenigen Zellklonen heraus in der Nachbarschaft von gesundem Pankreasgewebe. Es gibt Ideen diese Unzulänglichkeit durch Verwendung verschiedener Regulationssysteme und spezifischer Rekombinasen, die zu unterschiedlichen Zeitpunkten aktiviert werden, zu beheben (vgl. 1.3). Die große Komplexität der Initiation und schrittweisen Akkumulation weiterer Mutationen vermag aber auch so nicht in ihrer Gänze simuliert werden (Kondo et al. 2006; Frese und Tuveson 2007).

Auch wenn PDX-1 zu einer vorrangigen Expression von Cre in exokrinen pankreatischen Zellen führt, ist diese Spezifität doch begrenzt und KPC-Mäuse weisen gehäuft auch andere Neoplasien auf. Gades et al. beschreiben für KC-Mäuse ein gehäuftes Auftreten von Vulvapapillomen und Hingorani et al. beschreiben für ihre Kohorte KPC-Mäuse mehrere Ösophaguspapillome und Gallengangshyperplasien sowie einzelne hepatozelluläre Karzinome und nicht-kleinzellige Lungenkarzinome (Gades et al. 2008; Hingorani et al. 2005). Diese Zweitneoplasien können zu Komplikationen wie Blutungen und vorzeitigem Versterben und damit einem Ausscheiden aus der Studie führen.

Die Penetranz der Tumorentstehung wird in der Literatur mit nahezu 100\% angegeben (Hingorani et al. 2005). Diese Eigenschaft ist mit Blick auf den hohen Aufwand bei der Zucht und Genotypisierung dieser Modellorganismen von großer Bedeutung. In unserer Kohorte wurde trotz korrekter Genotypisierung bei 3 von 49 Mäusen (6,1\%) kein invasiver Tumor festgestellt, woraufhin diese Mäuse aus allen Analysen ausgeschlossen wurden.

\subsection{Besprechung der Versuchsbedingungen}

Während der gesamten Arbeit wurde darauf geachtet, die Versuchsbedingungen möglichst konstant zu halten, um die Vergleichbarkeit der Ergebnisse zu gewährleisten. So hatten alle Mäuse den gleichen genetischen Hintergrund, wurden unter gleichen Bedingungen gehalten und nach den gleichen Endpunktkriterien getötet. Bei Einbettung, Mikrotomie und Vorbereitung der Färbungen wurde nach den beschriebenen standardisierten Protokollen gearbeitet, um Einflussgrößen wie Schnittdicke, Latenzzeit zwischen Mikrotomie und Färbung, Antigendemaskierung sowie Entwicklungs- und Färbezeiten konstant zu halten. Jedes Protokoll wurde im Vorfeld an kleinen Stichproben getestet, um die Qualität der Färbung sicherzustellen und das Färbeprotokoll zu erproben. Bei einigen Protokollen konnte auf Erfahrungswerte aus der Arbeitsgruppe aufgebaut werden, für andere Färbungen mussten Antikörperkonzentrationen, Inkubationszeiten und Pufferauswahl getestet und optimiert werden.

Wichtige Grundlage für die Quantifizierbarkeit vieler Färbungen war die Einstellung von Grenzwerten in der planimetrischen Analyse bei gleichzeitiger Konstanthaltung der Bildqualität durch die in 2.2.2.5.2 beschriebene Standardisierung. Hierfür wurden stets im Vorfeld mehrere Bilder aus fünf bis sechs Mäusen unter verschiedenen Grenzwerten analysiert und die Grenzwerte, die die Merkmalsausprägung in allen Bildern realistisch abbilden, als Bewertungsmaßstab festgesetzt. 
So sorgfältig die Festsetzung der Grenzwerte auch durchgeführt wurde, bleiben doch immer Bilder und Mäuse, bei denen durch die planimetrische Analyse nach dem festgesetzten Bewertungsmaßstab augenscheinlich zu hohe oder zu niedrige Merkmalsausprägungen gemessen wurden. Obwohl bei durchschnittlich über 40 Bildern pro Maus und pro Färbung zu erwarten ist, dass ein großer Anteil der Abweichungen sich herausmittelt, kann es dennoch dazu kommen, dass für einzelne Individuen eine zu hohe oder niedrige Merkmalsausprägung ermittelt wird. Ein wichtiger Grund hierfür ist die unspezifische Hintergrundfärbung, die trotz großer Sorgfalt im Färbeprozess unterschiedlich stark zu Tage treten kann und durch den Algorithmus gegebenenfalls fälschlicherweise als positiv gewertet wird. Andererseits gibt es Bereiche mit Strukturen, die aufgrund ihrer Morphologie als positiv zu werten wären, aber nur relativ schwach angefärbt sind und fälschlicherweise als negativ gewertet werden. Als Negativkontrolle wurde normales Pankreasgewebe verwendet, welches negativ für Färbungen wie HA, SPARC, Kollagen und $\alpha$ SMA ist. Die Negativkontrolle belegt, dass das positive Signal im Tumorgewebe nicht durch unspezifische Färbung zustande kommt. Für noch nicht etablierte Färbetechniken wie SPARC wurden ebenfalls Positivkontrollen verwendet. So zeigt Hodengewebe ein charakteristisches Muster für SPARC-Färbungen und belegt so die Spezifität der Färbung (Sweetwyne et al. 2004).

Dennoch hat die planimetrische Beurteilung entscheidende Vorteile gegenüber der (weitestgehend) subjektiven Einteilung auf einer Ordinalskala in Kategorien wie beispielsweise hohe, mittlere und niedrige Expression eines Kandidatenproteins. So muss bei der subjektiven Einteilung an einer großen Vorauswahl an Bildern der eigene Maßstab gesetzt und geschärft werden und dieser für einzelne Färbungen an über 2500 Bildern korrekt und ohne größere Abweichungen angewandt werden. Die planimetrische Analyse läuft hingegen nach Festsetzung der Grenzwerte gleichförmig ab, lässt sich von anderen Untersuchern problemlos übernehmen und liefert rationalskalierte Ergebnisse. Aus diesen Gründen stellt die planimetrische Analyse das geeignete Verfahren für diese Arbeit dar.

Für einige Färbungen wie Ki67, CC3, und $\alpha$-SMA+Ki67 war es nicht möglich eine automatisierbare Quantifizierung der Parameter zu etablieren, da hier nicht die positiven Flächen vermessen, sondern Strukturen gezählt werden sollten. Gerade im stroma- und zellreichen PDAC ist es von großer Schwierigkeit einen Algorithmus zu finden, der Strukturen sicher als richtigpositiv misst. Sich überlagernde Zellkerne werden als einer erkannt, während kleine Artefakte fälschlicherweise als positive Zellkerne gewertet werden. Alle Einstellungen zur verbesserten Objekterkennung waren ungenügend und der Unterschied zwischen automatisch und manuell gezählten Strukturen war so eklatant, dass für die oben genannten Parameter eine manuell zählende Auswertung angestellt wurde. Hierbei wurde zwar ein kleinerer Teil der Tumorfläche analysiert, die ausgewerteten Areale wurden aber repräsentativ ausgewählt. Für einige Parameter wie CC3 war es nicht möglich neben den apoptotischen Zellen die Gesamtheit aller Zellen in der Hämatoxilingegenfärbung zu bestimmen, weswegen die Apoptoserate als Anzahl apoptotischer Zellen pro Gesichtsfeld angegeben wurde. Dies stellt zwar nicht das optimale Auswertungsverfahren dar, ist jedoch angesichts der Schwierigkeiten akzeptabel und liefert ausreichend gute Ergebnisse. 


\section{3 Überlebensanalyse}

\subsubsection{Besprechung des Studiendesigns und der Fragestellung}

Im ersten Teil der vorgelegten Studie handelt es sich um eine rein beobachtende Überlebensanalyse mit der Fragestellung, ob verschiedene Zusammensetzungen des Tumorstromas einen Einfluss auf die Überlebensdauer von KPC-Mäusen haben. Obwohl das KPC Mausmodell ein weit verbreitetes Mausmodell in der Pankreaskarzinomforschung ist, wurde diese Fragestellung bisher noch nicht wissenschaftlich bearbeitet. In der vorgelegten Arbeit wurde weder eine Form der Intervention oder Behandlung vorgenommen, noch wurden die Mäuse im Vorfeld in verschiedene Gruppen eingeteilt. Alle eingeschlossenen Mäuse hatten den gleichen, zum PDAC disponierenden genetischen Hintergrund (LSL-Kras ${ }^{\mathrm{G} 12 \mathrm{D} /+} ; \mathrm{LSL}-\operatorname{Trp} 53^{\mathrm{R} 172 \mathrm{H} /{ }^{+}} ; \mathrm{Pdx}-1-\mathrm{Cre}$ ). Die Mäuse wurden lediglich beobachtet und bei Erreichen der Endpunktkriterien (Aszitesbildung, Gewichtsverlust (>10\%), Körpertemperaturabfall, Piloerektion, Inaktivität und auffälliges Sozialverhalten) getötet. Die zu untersuchenden Organe wurden entnommen und die Überlebensdauer wurde festgehalten.

In verschiedenen Studien wurden humane Biopsate oder Gewebeproben aus Operationen auf vergleichbare Parameter untersucht und auf ihre prognostische Bedeutung hinsichtlich des Überlebens verglichen (Jamieson et al. 2011; Cheng et al. 2013; Mantoni et al. 2008; Bever et al. 2015; Wang et al. 2016; Erkan et al. 2008; Nishida et al. 2016). In diesen Studien konnte für verschiedenen Parameter eine Assoziation von hoher (HA, SPARC, MVD, ASI) bzw. niedriger (Stromadichte, Kollagen) Merkmalsausprägung mit einem verkürzten Überleben gefunden werden. Die Stichproben zu diesen Studien waren meist um ein Vielfaches größer. Eine Limitation der hier vorgelegten Arbeit war die mit $\mathrm{n}=46$ relativ kleine Stichprobe angesichts der Situation, dass aufgrund nicht durchgeführter Intervention keine besonders großen Gruppenunterschiede und damit keine starken Effekte zu erwarten waren. Da das PDAC ein hoch komplexes und multifaktorielles Geschehen ist, erwartet man die Auswirkung jedes einzelnen untersuchten Faktors als nicht besonders hoch. Bei kleiner zu erwartender Effektstärke bedarf es umso größerer Fallzahlen, um doch einen signifikanten Überlebensunterschied zu beobachten. Dies stellt für Parameter wie die Ki67-Proliferationsrate eine mögliche Erklärung dar, warum kein statistisch bedeutsamer Effekt zu beobachten war. Die Mehrzahl der univariaten Überlebenskurven verlaufen jedoch derart gekreuzt, dass auch eine deutlich größere Stichprobe keinen Effekt erwarten lassen würde. Hierbei muss beachtet werden, dass auch ein statistisch signifikanter Zusammenhang zwischen Parameterausprägung und Überleben nicht mit einem Kausalzusammenhang gleichzusetzen ist.

Die Einteilung der Gruppen für die univariaten Analysen (Kaplan-Meier-Kurven) anhand der Werte ober- und unterhalb des Medians stellt eine objektive und nachvollziehbarere Einteilung in hohe und niedrige Stromakonzentration dar. Die Gruppeneinteilung in der Literatur wird häufig nicht nachvollziehbar vorgenommen. So werden Grenzwerte für hohe und niedrige Merkmalsausprägung oft unkommentiert oder scheinbar willkürlich festgesetzt (Bever et al. 
2015; Cheng et al. 2013). In anderen Fällen wird beschrieben, dass die Methode nach Contal und O'Quigely's angewendet wird (Kim et al. 2017), eine Möglichkeit den Grenzwert und damit die Verteilung hin zu signifikanten Ergebnissen zu optimieren. In dieser Arbeit wurde sich daher bewusst gegen diese Optimierungsverfahren entschieden. Anstelle der Gruppeneinteilung anhand des Medians wären auch univariate Cox-Regressionen geeignete Analyseverfahren gewesen, diese wurden auch durchgeführt. Da univariate Cox-Regressionen aber ebenfalls für keinen Parameter einen Zusammenhang zum Überleben gefunden haben und somit keinen zusätzlichen Erkenntnisgewinn brachten, wurden diese Analysen nicht in der Arbeit aufgeführt.

Eine Schwäche der hier vorgestellten Arbeit besteht darin, dass bei den Mäusen keine weiteren Parameter wie Aszitesmenge, Kachexie oder biliäre Obstruktion erhoben wurden und auch die Metastasenlast in anderen Organsystemen nicht untersucht wurde. Einzig die EZM des PT mit den Überlebenszeiten wurden untersucht. Es kann daher nur spekuliert werden, ob bestimmte Charakteristika und Bestandteile des Tumorstromas im KPC-Mausmodell kausal das Tumorwachstum, Invasivität, und Metastasierung mit konsekutiver Aszitesbildung und biliärer Obstruktion fördern, oder ob das Tumorstroma über andere Signalwege und systemische Effekte (z.B. Tumormetabolismus, Kachexie) das Überleben beeinflusst.

\subsubsection{Auswirkungen der stromalen und epithelialen Parameter auf das Überleben}

Nach der ursprünglichen Betrachtung des Stromas als reine Begleitreaktion ist die herausragende Bedeutung des Tumormikromilieus im PDAC heute weitestgehend unbestritten, obwohl noch immer viele der Zusammenhänge nicht oder nur unzureichend verstanden sind. In einer Vielzahl an Studien wurden das Tumorstroma sowie seine intensiven Wechselwirkungen mit den Pankreaskarzinomzellen genauer charakterisiert. Dabei verfestigte sich die Sicht des Tumormikromilieus als partner in crime (Vonlaufen et al. 2008), welches entscheidend an Eigenschaften wie Tumorprogression, invasivem Wachstum, Metastasierung und Therapieresistenz des PDAC beteiligt ist. Es wurde eine Reihe stromaler Marker gefunden, die eine prognostische Bedeutung hinsichtlich des Überlebens darstellen oder als Biomarker für Therapieansprechen dienen. So sprachen Patienten mit hohem Hyaluronsäuregehalt auf die Therapie mit der Hyaluronidase PEGPH20 und nab-Paclitaxel plus Gemcitabin an und zeigten ein um 4 Monate verlängertes krankheitsfreies Überleben gegenüber der Kontrollgruppe ohne Hyaluronidase. Hingegen zeigte die Hyaluronidase keinen Effekt bei Patienten mit niedrigem Hyaluronsäuregehalt. Bezüglich des Gesamtüberlebens gab es keinen Unterschied zwischen hohem und niedrigem Hyaluronsäuregehalt (Hingorani et al. 2018). Mittlerweile weiß man, dass Anteile des Tumormikromilieus auch hemmend auf Tumorwachstum, Desmoplasie und Invasivität wirken und mit längerem Überleben in der Maus und dem Menschen einhergehen (Bever et al. 2015; Nishida et al. 2016; Rhim et al. 2014). So führte beispielsweise eine gezielte Reduktion der aktivierten Fibroblasten um 80\% im Mausmodell zu deutlich invasiveren und undifferenzierteren Tumoren und einem verkürzten Überleben (Özdemir et al. 2014). Auch in humanen Tumoren waren eine hohe Fibroblastendichte mit längerem Überleben assoziiert. Trotz des Wissens auch 
um hemmende Effekte, stellt das Tumorstroma heute einen wichtigen potenziellen Angriffspunkt für gezielte Therapieansätze im PDAC dar. Bei aller Eleganz neuer Modellorganismen wie endogenen transgenen Mausmodellen gab es in den letzten Jahren einige enttäuschende Beobachtungen hinsichtlich der Übertragbarkeit von Ergebnissen auf den Menschen, so auch in Hinblick auf gezielte Stroma-Pharmakotherapie („Stromatargeting“). So konnten vielversprechende Therapieansätze beispielsweise mit MMP-Inhibitoren (Marimastat oder BAY 12-9566) (Bramhall et al. 2002; Moore et al. 2003) oder die Blockade des Hedgehog-Signalwegs (Olive et al. 2009) nicht erfolgreich in die klinische Anwendung übertragen werden. Gerade aus diesem Grund ist es von großer Wichtigkeit das weit verbreitete KPC-Mausmodell genauer zu charakterisieren und Stromamarker in einem ersten Schritt auf ihr prognostisches Potential hin zu überprüfen.

In der Überlebensanalyse einzelner Parameter mittels Kaplan-Meier-Kurven konnte für keinen der untersuchten Parameter ein Zusammenhang zum Überleben festgestellt werden. Mögliche Erklärungsansätze und methodische Schwächen der Arbeit, wie eine kleine Stichprobe angesichts kleiner zu erwartender Effekte, wurden oben bereits diskutiert. Die multivariate CoxRegression konnte die drei Parameter Proliferationsrate (Ki67), Mitoserate (PHH3) und die Fibroblastenproliferationsrate ( $\alpha$-SMA+Ki67-Ratio) formal als unabhängige Einflussgrößen identifizieren, jedoch bedürfen diese Ergebnisse einer besonders kritischen Dikussion. In einem ersten Abschnitt wird diskutiert, wie diese formalen Ergebnisse angesichts der Literatur einzuordnen sind und welche Bedeutung für weitere Forschung im KPC-Mausmodell sich daraus möglicherweise ergeben. Anschliessend wird die Aussagekraft der Statistik nochmals kritisch diskutiert, wobei hier nicht die Wahl des statistischen Modells betrachtet wird, sondern auf mögliche Kolinearitäten eingegangen wird, welche die Aussagekraft der Ergebnisse einschränken kann.

Die (Gesamt-)Proliferationsrate, gemessen über den prozentualen Anteil von Ki67-positiven Zellen in \%, stellt formal einen positiven prognostischen Faktor dar. Eine hohe Proliferationsrate ist also mit einem längeren Überleben assoziiert, wohingegen für die Mitoserate, gemessen als prozentualen Anteil von PHH3-positiven Zellen, eine Assoziation mit einem kürzeren Überleben gefunden wurde. Die PHH3-Mitoserate stellt also formal einen negativen prognostischen Faktor dar. Diese Beobachtung ist interessant, da beide Marker etabliert sind um sich teilende (PHH3) beziehungsweise auch sich in der Vorbereitung zur Teilung befindende (Ki67) Zellen zu identifizieren. Im Gegensatz zu Ki67, welches alle nicht ruhenden Zellen identifiziert, ist PHH3 spezifisch für mitotische Zellen bis zur frühen Telophase. Dabei werden auch Zellen erfasst, die aufgrund CIN und Störungen im Zellteilungsprozess, wie sie in Neoplasien gehäuft auftreten, dauerhaft in dieser Phase verharren. CIN und aberrante Mitosefiguren sind typisch für undifferenzierte und besonders aggressive Karzinome. Allerdings korrelierten die PHH3Mitoserate und das Grading nicht miteinander, weshalb es unwahrscheinlich erscheint, dass dauerhaft in aberranten Mitosen verharrende Zellen substanziell zur Mitoserate beitragen. Vielmehr ist es plausibel, dass eine hohe Zellteilungsrate zu schnellem Tumorwachstum und hoher Krankheitslast führt. Die Assoziation von hoher Ki67-Proliferationsrate mit längerem Überleben lässt sich hiermit allerdings nicht erklären. Auch wenn die Ergebnisse aus menschlichen 
Operationspräparaten von Tumoren aus den bereits erläuterten Gründen nur bedingt auf das Mausmodell übertragbar sind, deuten sie hier doch deutlich in die Richtung, dass eine hohe Ki67-Proliferationsrate mit kürzerem Überleben assozii ert ist. Diese Beobachtung wurde von einem systematischen Review und einer Metaanalyse für PDAC bestätigt (Jamieson et al. 2011).

Die beiden Parameter Ki67 und PHH3 korrelieren gut miteinander (Korrelationskoeffizient = 0.54; vgl. Tabelle 19), allerdings ist die PHH3-Auswertung besser reproduzierbar, und der Marker ist in diversen Krebsentitäten mit dem Überleben (Colman et al. 2006) und dem klinischen Outcome assoziiert (Kim et al. 2017; Tetzlaff et al. 2013). So fanden Kim et al. (2017) für hohe PHH3-Mitoseraten in Tumoren von Brustkrebspatientinnen ein signifikant verkürztes krankheitsfreies Überleben.

Insgesamt bleiben die Ergebnisse, insbesondere für die Ki67-Proliferationsrate, sehr kritisch zu betrachten (siehe unten) und es bedarf weiterer Studien im KPC-Modell um sie zu überprüfen.

Die Fibroblastenproliferationsrate ist nach den Ergebnissen der Cox-Regression ebenfalls formal ein unabhängiger negativer prognostischer Faktor für das Überleben, eine hohe Fibroblastenproliferationsrate geht also mit einem höheren Risiko zu versterben einher. Die Gruppe der CAFs besteht zum größten Teil aus aktivierten PSCs und wird maßgeblich für die Sezernierung der EZM-Proteine wie HA, Kollagen, SPARC und Wachstumsfaktoren verantwortlich gemacht (Xu et al. 2010; Neesse et al. 2015). Trotz dieser Tatsache scheint kein linearer Zusammenhang zwischen dem EZM-Gehalt und der Fibroblastenaktivierung zu bestehen (Erkan et al. 2008; Wang et al. 2016). Die Fibroblastenaktivität wird über das Level der $\alpha$-SMA-Expression bestimmt und auch als Marker für die Stromaktivität betrachtet. In einer Studie von Bever et al. (2015) konnte in adjuvant chemotherapierten Patienten kein Zusammenhang der Stromaaktivität mit dem Überleben gefunden werden. Dennoch war in diesem Patientenkollektiv eine hohe Stromadichte mit längerem krankheitsfreiem Überleben sowie einem zehn Monate längeren Gesamtüberleben assoziiert. Die Stromadichte entspricht dem proportionalen Anteil des Tumorstromas am Gesamttumor. Der protektive Effekt von hoher Stromadichte konnte in einer anderen Studie für adjuvant therapierte Patienten mit Tumoren mit dem Staging T1 und T2 in einer multivariaten Regression bestätigt werden, nicht jedoch für höhere T-Stagings. Die Stromaaktivität zeigte auch hier keinen Einfluss auf das Überleben und andere klinisch relevante Endpunkte (Wang et al. 2016). Nicht zu verwechseln ist die Stromaaktivität mit dem von Erkan et al. (2008) vorgestellten aktivierten Stromaindex (ASI) welcher das Verhältnis von $\alpha$-SMApositiver Fläche zur Kollagen-positiven Fläche darstellt. Für einen hohen ASI, also eine hohe Dichte aktivierter Fibroblasten bei wenig Kollagen, wurde eine Assoziation zu längerem Überleben beschrieben. Weiter fanden Erkan und Kollegen, dass ein hoher Kollagenanteil im PT bei Operation die Prognose von PDAC-Patienten verbessert. Hingegen konnte für $\alpha$-SMA, entsprechend der Stromaaktivität, in dieser Untersuchung kein Einfluss auf das Überleben gefunden werden (Erkan et al. 2008). Interessanterweise wurden von Whatcott et al. (2015) in Operationspräparaten aus PT gegenteilige Ergebnisse gefunden, denen zufolge hohe EZM-Anteile von Kollagen I und IV sowie von HA mit verkürztem Überleben einhergehen. Für $\alpha$-SMA 
konnte auch hier kein signifikanter Zusammenhang zum Überleben hergestellt werden. Mögliche Erklärungen für die gegensätzlichen Beobachtungen hinsichtlich des Kollagengehalts könnten in den unterschiedlichen Färbemethoden für Kollagen liegen oder in unterschiedlichen präoperativen Behandlungen, die nicht vollständig dokumentiert sind. In Einklang zu stehen scheinen die Studien in Bezug auf die Rolle von $\alpha$-SMA beziehungsweise der Stromaaktivität, welche in multivariaten Analysen konsistent keinen prognostischen Marker darstellte (Whatcott et al. 2015; Erkan et al. 2008; Wang et al. 2016). Dieser fehlende Zusammenhang von Stromaaktivität und Überleben konnte auch in der hier vorgelegten Arbeit bezüglich des $\alpha$-SMA-Anteils an der EZM in KPC-Mäusen so gefunden werden. Mit Blick auf die widersprüchlichen Beobachtungen zum Kollagengehalt konnte in der hier vorgelegten Arbeit in der Picrosiriusfärbung für Kollagen (Typ I, II und III) kein Zusammenhang zum Überleben beobachtet werden. Gleichfalls zeigte auch der in Anlehnung an Erkan et al. berechnete ASI sowohl in univariater als auch multivariater Analyse keinen Zusammenhang zum Überleben (Whatcott et al. 2015; Erkan et al. 2008). Ein Erklärungsansatz für die Divergenz der Ergebnisse bezüglich des Kollagengehaltes liegt auch hier in den unterschiedlichen Färbemethoden: Picrosirius Rot vs. Anilin Blau (Erkan et al. 2008) vs. Kollagen-I-spezifische Immunfärbung (Whatcott et al. 2015). Weitere Erklärungsansätze sind die in den besprochenen Studien durchgeführten präoperativen Behandlungen, Operationen sowie adjuvante Chemotherapien und die Tatsache, dass ein Großteil der Untersuchungen in humanen Geweben durchgeführt wurde.

Neben der hohen Stromadichte (siehe oben) wurde in Studien auch die sogenannte „Stromafläche“ als Einflussgröße auf das Überleben identifiziert, wobei eine geringe Stromafläche mit einer schlechteren Prognose assoziiert war. Die Stromafläche wird gemessen als die Fläche des Tumors unter Ausschluss von Tumorzellen (CK19-positve Zellen) und duktaler Lumen (Nishida et al. 2016).

Es lässt sich zusammenfassen, dass viel Stroma sowie dichtes Stroma laut Literatur mit längerem Überleben einhergehen, während es fraglich ist, ob eine hohe Fibroblastendichte mit dem Überleben assoziiert ist. In Genexpressionsanalysen konnten Signaturen von aktiviertem sowie „normalem" Tumorstroma identifiziert werden. Aktiviertes Stroma ging mit verstärkter Expression von SPARC, Chemokinen wie CCL13 und CCL18 sowie der MMP9 (Gelatinase B) und MMP11 (Stromelysin 3) einher und war mit verkürztem Überleben assoziiert. So lebten Patienten mit aktiviertem Stroma nach der Tumorresektion neun Monate kürzer als Patienten mit normalem Stroma (Moffitt et al. 2015). Dies steht in Einklang zu den Ergebnissen von Erkan et al. (2008) und unterstreicht die Ergebnisse dieser Arbeit, dass schnell proliferierende Fibroblasten formal mit verkürztem Überleben assoziiert sind. Zwar bedeutet eine hohe Proliferationsrate der CAFs nicht automatisch auch eine hohe Expression von Genen für Proteine der EZM und Wachstumsfaktoren, aber eine schnell wachsende und das Tumorbild dominierende CAF-Population bedingt entscheidend die Aktivität des Stromakompartiments mit. Die in dieser Arbeit gewählte Methode zur Bestimmung der CAF-Proliferationsrate mittels Co-IF-Färbung auf doppelt positive Zellen für $\alpha$-SMA und Ki67 stellt sicher, dass nur aktivierte und nicht ruhende Fibroblasten erfasst werden. Bei allen Beobachtungen bleibt zu beachten, dass Tumoren der KPC-Maus 
menschlichen Tumoren sehr ähnlich sind, aber Ergebnisse nicht uneingeschränkt übertragbar sind. Unseres Wissens wurde die CAF-Proliferationsrate humaner PDAC noch nicht auf eine Assoziation zum Überleben hin überprüft. Obwohl sie sehr aufwendig zu erheben ist, stellt sie ein interessantes Ziel dar, um die Rolle der humanen CAFs in vivo besser zu verstehen.

Das für die EZM sehr bedeutsame Glykosaminoglykan HA verfehlte knapp das Signifikanzniveau und zeigte somit lediglich einen fraglichen bzw. grenzwertig statistisch-bedeutsamen Einfluss auf das Überleben. Tendenziell stand in KPC-Mäusen ein hoher HA-Anteil in den PT mit einem längeren Überleben in Verbindung. Dies steht im Kontrast zu Ergebnissen aus (humanen) OP-Präparaten, wo HA mit kurzen Überlebenszeiten assoziiert war (Cheng et al. 2013; Whatcott et al. 2015). In der Literatur ist HA in diversen Tumoren, darunter auch explizit das PDAC, über Bindung an Oberflächenrezeptoren wie CD44 und RHAMM eng mit TumorStroma-Interaktionen, der Ausschüttung von Zyto- und Chemokinen und folglich Tumorinitiation, Angiogenese und Tumorwachstum assoziiert. Auch wird beschrieben, dass HA das PDAC gegenüber der Immunabwehr abschirmt (Itano et al. 2008; Cheng et al. 2015; Sironen et al. 2011; Shepard 2015). Diese Beobachtungen unterstreichen die verkürzte postoperative Überlebenszeit bei hohen HA-Konzentrationen in humanen Geweben (Cheng et al. 2013; Whatcott et al. 2015) und stehen im Gegensatz zu den Ergebnissen der hier durchgeführten Untersuchungen an Mäusen. Mittlerweile wurden eine Reihe erfolgversprechender Phase-1/2-Studien mit der Hyaluronidase PEGPH20 in Kombination mit Chemotherapeutika durchgeführt (Hingorani et al. 2018; Hingorani et al. 2016a; Hingorani et al. 2016b; Wong et al. 2017). Präklinische Studien in KPC-Mäusen deuten darauf hin, dass die Monotherapie mit PEGPH20 sich nicht positiv auf das Überleben auswirkt (Provenzano et al. 2012; Jacobetz et al. 2013). Hier ging die PEGPH20-Monotherapie gegenüber dem Vehikel tendenziell mit einem verkürzten Überleben einher, allerdings war dieser Befund statistisch nicht signifikant (Jacobetz et al. 2013). Es kann also argumentiert werden, dass sowohl der Untersuchungszeitpunkt (Lebensende der Maus vs. Tumorresektion beim Menschen) als auch die Begleittherapie (keine Intervention bei der KPCMaus vs. Operation und adjuvante Chemotherapie in humanen Studien) einen Einfluss auf die Rolle von HA haben kann. Neben all den protumorigenen Effekten von HA mag es auch Situationen geben, in denen HA, zumindest im Mausmodell, eine protektive Wirkung entfaltet.

Der vielfach diskutierte Einfluss von HA auf den Gewebedruck und die daraus resultierende verminderte Perfusion durch Kompression der Tumorgefäße konnte in der vorliegenden Arbeit nicht beobachtet werden. So korrelierten weder die MVD noch die MLA mit dem Hyaluronsäuregehalt in den Tumoren. Neben Chemoresistenz wird die reduzierte Gefäßdichte auch als verantwortlich für die Hypoxie im PDAC diskutiert. Das PDAC ist im Vergleich zu umliegendem normalem Pankreasgewebe stark hypoxisch (Koong et al. 2000). In Studien wurde Hypoxie in verschiedenen Tumoren mit erhöhter Invasivität und Metastasierung sowie verkürztem Gesamtüberleben und krankheitsfreiem Überleben in Verbindung gebracht (Le et al. 2004). Unter diesen Gesichtspunkten lässt sich die Beobachtung erklären, dass tendenziell eine höhere Gefäßdichte im Mausmodell mit einem niedrigeren Risiko zu versterben einhergeht, wobei zu beachten bleibt, dass der Zusammenhang statistisch knapp nicht signifikant ist. Allerdings steht 
die Beobachtung im Widerspruch zu der Tatsache, dass in operierten und adjuvant chemotherapierten Patienten eine hohe Gefäßdichte mit einem um 16 Monate verkürzten Überleben einherging (31,4 vs. 15,2 Monate, $\mathrm{p}=0,004)$. Weiterhin waren diese Tumoren schlechter differenziert und es kam häufiger zu hämatogenen Metastasen (Nishida et al. 2016). Die Beobachtung von Nishida et al. (2016) spricht gegen die These, dass Chemoresistenz durch verminderte Durchblutung und mangelnde Anflutung von Chemotherapeutika bedingt ist. Eine mögliche Erklärung für die Diskrepanz zwischen der im KPC-Modell beobachteten Tendenz und den Ergebnissen aus der Literatur kann in dem Beobachtungszeitpunkt gesucht werden. Die Tumoren von Patienten wurden etliche Monate vor dem Versterben bzw. dem Ende der Nachverfolgungsperiode entnommen, während die Maustumoren am Lebensende untersucht wurden. Nishida et al. (2016) stellen die These auf, dass eine hohe MVD sowohl Gefäßinvasion als auch Fernmetastasierung erleichtert. Unter dieser Prämisse wäre es denkbar, dass eine hohe MVD zu einem frühen Zeitpunkt der Operation zu vermehrten Metastasen und schnellerem Versterben führt, während eine bessere Vaskularisierung zu späteren Zeitpunkten die Hypoxie reduziert und das Überleben verlängert. Einschränkend muss hinzugesagt werden, dass der von uns gefundene Einfluss der MVD auf das Überleben sehr klein (HR 0,99; $p=0,09)$ und statistisch formal nicht bedeutsam ist.

Unter den EZM-Komponenten des PDAC wurde der Einfluss von SPARC besonders intensiv und kontrovers diskutiert. SPARC steuert mittels seiner verschiedenen Strukturdomänen Wachstumsfaktoren wie TGF- $\beta$ und FGF, sowie MMPs und beeinflusst so Proliferation, Apoptose, Angiogenese, Zelladhäsion, Metastasierung und Tumorwachstum. Ein Überblick über die kontroverse Rolle von SPARC im PDAC wurde in der Einleitung gegeben (vgl. 1.5.2). SPARC kann in verschiedenen Tumoren sowohl tumorsupprimierende Effekte haben als auch protumorigen wirken. Es wird diskutiert, dass der positive wie negative Einfluss von SPARC auf Phänomene wie Tumorwachstum, Zellmigration und Proliferation teils konzentrationsabhängig ist (Vaz et al. 2015; Rempel et al. 2001). Zwar ist ein hoher SPARC-Anteil in vielen humanen Studien mit einer schlechten Prognose assoziiert, jedoch konnten andere Studien diesen Zusammenhang nicht bestätigen. Zu dieser Inkonsistenz der Rolle von SPARC in humanen Tumoren kommt die Tatsache, dass für SPARC in murinen PDAC-Modellen eher antitumorigene Effekte beobachtet wurden (Vaz et al. 2015; Gundewar et al. 2015). Die Ergebnisse bezüglich SPARC im Mausmodell decken sich also nicht oder nur partiell mit Ergebnissen aus humanen Studien. Diese Beobachtung unterstreicht die These, dass der Modellorganismus Maus entscheidenden Einfluss auf die Rolle von Stromaparametern im PDAC hat und zumindest mitverantwortlich ist für die teils widersprüchlichen Assoziationen von Merkmalsausprägung und Überleben in Mensch und Maus. In der Summe mögen diese vielschichtigen und teils widersprüchlich scheinenden Beobachtungen erklären, warum SPARC in der vorliegenden Arbeit keine Assoziation zum Überleben zeigte. 
Viele der Parameter wie aktivierte Fibroblasten ( $\alpha$-SMA), Kollagengehalt, SPARC-Gehalt und Hyaluronsäuregehalt stehen in Wechselwirkungen und beeinflussen sich vielfach indirekt. Dadurch können sich mögliche Effekte gegenseitig maskieren. Die multivariate Analyse mittels Cox-Regression ermöglicht es, alle anderen betrachteten Einflüsse kontrolliert zu halten, um so den betrachteten Parameter darauf zu prüfen, ob er eine unabhängige Einflussgröße auf das Überleben darstellt. Die in der vorwärtsselektierten multiplen Cox-Regression identifizierten Parameter Ki67, PHH3 und $\alpha$-SMA+Ki67-Ratio können im KPC-Mausmodell formal als unabhängige prognostische Einflussgrößen auf das Überleben betrachtet werden. Die hier vorgenommene Vorwärtsselektion stellt das adäquate Analyseverfahren dar, da hier im Vorfeld die Zahl der einbezogenen Variablen in Bezug auf das Einschlussniveau reduziert wird. Eine zu hohe Anzahl an eingeschlossenen Variablen kann zu falsch positiven Ergebnissen führen.

Im obigen Abschnitt wurde bereits erörtert, dass die drei als signifikant identifizierten Parameter kritisch zu betrachten sind, da sie das Signifikanzniveau zum Teil nur sehr knapp erreichen und auch die Hazard-Ratio einen nur sehr eingeschränkten Effekt erwarten lässt. Darüberhinaus ergeben sich bei genauer Betrachtung weitere Einschränkgen der statistischen Analyse. Wie im Ergebnisteil angesprochen, konnten in der erweiterten Gruppenanalyse für Kombinationen aus Ki67 und PHH3 (vgl. Abbildung 30, Seite 59) eine Gruppe von vier Individuen mit hohen Ki67und niedrigen PHH3-Werten identifiziert werden, welche deutlich längere Überlebenszeiten als das mediane Überleben von 160 Tagen aufzeigte. Diese vier Individuen scheinen entscheidend zu dem statistisch gesehen protektiven Effekt von Ki67 und dem prognostisch ungünstigen Effekt von PHH3 beizutragen oder diesen sogar vollständig zu begründen. Zwar haben wir keinen formalen Grund gesehen, diese Individuen aus den Berechnungen herauszunehmen, jedoch schränkt die Tatsache, dass der statstische Effekt sich weitestgehend auf die Überlebenszeiten von einer kleinen Untergruppe stützt, die Aussagekraft der multivariaten Cox-Regression weiter ein. Oben diskutierte Effekte müssen somit kritisch hinterfragt werden. In Zusammenschau mit der Tatsache, dass sowohl in univariater Analyse anhand der Caplan-Meyer-Kurven mit Einteilung entlang des Medians als auch in der univariaten Cox-Regression sich für keinen Parameter ein statistisch signifikanter Zusammenhang zum Überleben ergab, können oben diskutierte Ergbebnisse der multivariaten Cox-Regression nur sehr eingeschränkt als bedeutsam betrachtet werden. Es ist wahrscheinlich, dass die beobachteten Effekte lediglich Scheinzusammenhänge widerspiegeln. Es lässt sich aktuell also nicht mit Sicherheit sagen, dass Ki67, PHH3 und $\alpha$-SMA+Ki67-Ratio im KPC-Mausmodell einen protektiven bzw. verkürzenden Effekt bezüglich des Überlebens haben. Genauso kann für die beiden Parameter HA und MVD, welche in der multivariaten Cox-Regression als grenzwertig nicht-signifikante Einflussgrößen auf das Überleben identifiziert wurden, kein sicherer Effekt auf das Überleben im KPC-Mausmodell geschlussfolgert werden. 


\subsection{Desmoplasie in Lebermetastasen}

In einem zweiten Teil der Arbeit wurden PT und korrespondierende LM in Hinblick auf einige Stromaparameter verglichen. Metastasierung ist ein Phänomen von fundamentaler Wichtigkeit für das PDAC und daher ist es unbedingt notwendig, sie besser zu verstehen. Eine hohe Metastasenlast und in der Folge Organversagen, wie beispielsweise Leberversagen, sind häufige Mechanismen für die Letalität des PDAC (Houten und Reilley 1980; Yachida et al. 2010). Bei Diagnosestellung des PDAC im Menschen sind in der Mehrzahl der Fälle bereits radiologisch Metastasen nachweisbar, was die Operabilität und damit kurative Ansätze außerhalb von Studien unmöglich macht. Auch in kurativer Intention operierte Patienten ohne Hinweis auf Metastasierung erleiden trotz adjuvanter Chemotherapie in $72 \%$ Rezidive, was für eine sehr frühe hämatogene Streuung von Mikrometastasen und ihre Chemoresistenz spricht (Neoptolemos et al. 2004). Der Vergleich des Tumorstromas der LM mit dem des PT dient der genaueren Charakterisierung der stromalen Konfiguration in der LM. Insbesondere der paarweise Vergleich von Metastase und zugehörigem PT innerhalb eines Individuums ist zumeist nur im Mausmodell möglich, da bereits metastasierte Patienten nicht mehr operiert werden, sondern nur eine histologische Sicherung aus der Lebermetastase erfolgt (Whatcott et al. 2015).

Die niedrige Anzahl der berücksichtigten Mäuse $(n=6)$ liegt in der unterschiedlichen Menge an Metastasen begründet. Bei einigen Schnitten lag nicht ausreichend viel Metastasengewebe vor, oder dieses war in überfärbten Randbereichen lokalisiert, wo keine angemessene Auswertung vorgenommen werden konnte.

In einem mit dem KPC-Modell vergleichbaren Mausmodell (KPCY) fanden sich bei $96 \%$ beziehungsweise 91\% der Mäuse mit PDAC Einzelzell- beziehungsweise Nanometastasen (2-10 Zellen) in der Leber, während sich nur in circa 40\% der Fälle Makrometastasen (>1000 Zellen) fanden (Aiello et al. 2016). Entscheidende Voraussetzung für Metastasierung ist die Epithelialmesenchymale Transition (EMT), welche die Lösung von Zellen aus dem epithelialen Zellverband, das Durchbrechen der Basalmembran und die Invasion von Gefäßen erst ermöglicht. Mittlerweile gibt es Hinweise, dass EMT und Gefäßinvasion nicht auf invasive Karzinome beschränkt sind, sondern sich bereits in PanINs finden lassen (Rhim et al. 2012). Die Absiedelung von präneoplastischen Zellen vor der Entwicklung eines invasiven PDAC muss zwar nicht zwangsläufig zu Metastasen führen, unterstreicht aber, dass EMT und Metastasierung im PDAC sehr frühe Phänomene sind und erklärt auch das Phänomen, dass Patienten wenige Monate nach R0-Resektion eines PDAC Lebermetastasen entwickeln können.

Die Zahl der Metastasen lässt sich durch eine Chemotherapie deutlich reduzieren, jedoch stellt sie keinen kurativen Ansatz dar, da immer einzelne Metastasen und zirkulierende Tumorzellen verbleiben (Aiello et al. 2016). Die Leber ist mit circa 40-50\% der Fälle sowohl im Menschen als auch der Maus der häufigste Metastasierungsort des PDAC. Hepatische Sternzellen bzw. aktivierte hepatische Myofibroblasten können je nach Entzündungssituation unterschiedlich auf pankreatische Mikro- und Makrometastasen Einfluss nehmen und diese in einen Ruhezustand versetzen oder die Metastasenabsiedlung begünstigen (Lenk et al. 2017). In der hier vorgelegten 
Arbeit wurden lediglich Metastasen in der Leber analysiert. Dies ist bei der Einordnung der Ergebnisse zu beachten. Im Zusammenhang mit der Diskussion von Stromadepletierung und gezielter Stroma-Pharmakotherapie als neue Therapieansätze stellt sich die Frage, ob diese Ansätze sich neben den desmoplastischen PT potenziell auch auf Metastasen positiv auswirken (Whatcott et al. 2015). Angesichts der unbefriedigenden Ergebnisse bei der Reduktion von Fernmetastasen nach bereits erfolgter Operation in kurativer Intention und adjuvanter Chemotherapie wäre es ein großer Erfolg, wenn neue Therapieansätze auch die Metastasen gezielter angreifen würden. Dabei ist die Untersuchung des Tumorkompartiments LM in der KPC-Maus ein erster Schritt.

Bei der histologischen Betrachtung in der HE-Färbung erscheinen Morphologie und Desmoplasie in den von uns untersuchten PT und LM auf den ersten Blick vergleichbar stark ausgeprägt. Diese Beobachtung steht in Einklang mit der Beschreibung der Tumoren und ihren Metastasen durch Hingorani et al. (2005), den Erstbeschreibern des KPC-Modells. Trotzdem bedarf es einer genaueren und quantifizierenden Analyse des Tumorstromas in Metastasen, die bisher im KPC-Modell noch nicht erfolgt war. Die von uns gewählte Kombination von immunhistologischer Beurteilung und Analyse der Proteinkonzentrationen im Western-Blot stellt eine geeignete Methode dar, um das Tumormikromilieu in PT und LM adäquat zu adressieren.

Die desmoplastische Reaktion wird auch in Metastasen von aktivierten Fibroblasten getragen, deren Ursprung allerdings umstritten ist. So ist beschrieben, dass im Umfeld von Metastasen hepatische Sternzellen aktiviert werden, einen Phänotyp wie (Myo-)Fibroblasten im primären PDAC annehmen und regulatorisch auf (metastasierte) Pankreaskarzinomzellen wirken (Lenk et al. 2017). Andererseits wird die Co-Migration von Pankreaskarzinomzellen und Stromazellen, vornehmlich Fibroblasten, beschrieben. Diese Co-Migration erhöht sowohl die Absiedlungswahrscheinlichkeit als auch das Metastasenwachstum. Pankreaskarzinomzellen bringen PSCs bzw. CAFs mit an den Metastasierungsort und schaffen so die Ausgangslage für ein Tumormikromilieu in den Metastasen (Duda et al. 2010; Xu et al. 2010). Eine weitere Quelle für Myofibroblasten stellen laut neuerer Untersuchungen mesenchymale Stammzellen dar, aus denen eine Subpopulation von Myofibroblasten mit protumorigenen Eigenschaften hervorgeht (Mathew et al. 2016). Vermutlich spielen alle drei Phänomene, die Aktivierung residenter hepatischer Sternzellen, die Co-Migration von pankreatischen CAFs mit Krebszellen und mesenchymale Stammzellen, eine Rolle in der Rekrutierung von CAFs und der Entstehung des metastatischen Tumormikromilieus. In jedem Fall stellen diese Beobachtungen einen Erklärungsansatz dafür dar, warum auch Metastasen ein prominentes desmoplastisches Tumorstroma ausbilden. Auch wenn die radikale Depletierung von Fibroblasten zu aggressiveren und desmoplastischeren Tumoren führt (Rhim et al. 2014; Özdemir et al. 2014) stellen sie doch weiter ein interessantes Therapieziel dar, und es sollten insbesondere in Metastasen ihr Ursprung und ihre Interaktion mit Pankreaskarzinomzellen weiter untersucht werden. 
In der IHC wurde mit Kollagen-, HA-, SPARC- und $\alpha$-SMA-Gehalt, der MVD (CD31) sowie der Apoptose-(CC3) und Proliferationsrate (Ki67) eine Reihe von charakteristischen epithelialen und stromalen Markern untersucht.

Für Metastasen wurde ein gut 40\% niedrigerer Gehalt an Kollagen gegenüber den PT ermittelt. Dies deckt sich teilweise mit Ergebnissen, die in menschlichen Geweben gemacht wurden. Whatcott et al. (2015) untersuchten Tissue Microarrays von 50 menschlichen PDAC und ungepaarten Metastasen mittels spezifischer Immunfärbungen auf den Gehalt von Kollagen I, III und IV. Für Kollagen I und III konnten nur nicht signifikant erniedrigte Werte in Lebermetastasen gemessen werden, für Kollagen VI hingegen war die mittlere positive Fläche in den Metastasen gegenüber dem PT auch signifikant erniedrigt. Kollagen IV ist ein wichtiger Teil der Basalmembran, welche in desmoplastischen Tumoren wie dem PDAC kaum ausgebildet wird. In der hier vorliegenden Arbeit wurde Kollagen durch die Picrosiriusfärbung gemessen, welche Kollagen I, II und III anfärbt. Es ist denkbar, dass das von Whatcott und Kollegen nicht erfasste Kollagen II die ausschlaggebende Komponente darstellt und in Metastasen vermindert exprimiert wird.

Für $\alpha$-SMA konnten immunhistochemisch deutlich reduzierte Werte in LM nachgewiesen werden, was einer reduzierten Dichte aktivierter Fibroblasten bzw. CAFs entspricht. Dieses Ergebnis deckt sich mit der reduzierten Konzentration von $\alpha$-SMA in Metastasen im Westernblot. Diese Ergebnisse konnten in der AG Neeße an 11 gepaarten humanen PT und LM in der IHC bestätigt werden (Hessmann et al. 2018). Demgegenüber steht die Beobachtung von Whatcott et al. (2015), die für $\alpha$-SMA leicht erhöhte Werte in LM gefunden haben. In einer anderen Untersuchung in einem dem KPC-Modell sehr ähnlichen Mausmodell wurden für $\alpha$-SMA, Kollagen I und SPARC in Nano-, Mikro- und Milimetastasen (bis 1000 Zellen pro Metastase) niedrigere Werte als in pankreatischen PT gefunden. Dies deckt sich mit den hier vorgestellten Ergebnissen. Es wurde jedoch auch beschrieben, dass mit zunehmender Metastasengröße die stromalen Marker verstärkt exprimiert werden und das Erscheinungsbild durch Mesenchymalepitheliale Transition (MET) wieder epithelialer wird (Aiello et al. 2016). Diese Beobachtung zeigt, dass Metastasen, wie PT auch, keineswegs statisch sind. Stattdessen wandeln sich Metastasen in Zusammensetzung und Morphologie im Laufe der Zeit und bilden ein Tumormikromilieu aus, welches zunehmend (wieder) dem im PT ähnelt. In der hier vorliegenden Arbeit wurde jedoch nicht nach Metastasengröße unterteilt, was möglicherweise die Diskrepanzen erklärt.

Die in dieser Arbeit gemachte Beobachtung, dass Metastasen einen höheren Gehalt an HA aufweisen ist interessant angesichts der reduzierten oder gleichbleibenden Konzentration anderer Proteine des Metastasenstromas. Da die CAF-Dichte in Metastasen erniedrigt ist und dieser Zellpopulation die Hauptrolle bei der Sezernierung der EZM zugeschrieben wird, bedarf es entweder einer verstärkten Sekretion von HA durch Pankreaskarzinomzellen oder einer verstärkte HA-Synthese durch die reduzierte CAF-Population. In der Literatur ist ebenfalls beschrieben, dass oft keine Korrelation von Fibroblasten- und Stromadichte besteht (Wang et al. 
2016; Erkan et al. 2008). In einem verwandten Mausmodell wurde mit zunehmender Metastasengröße ein steigender HA-Gehalt gefunden, der für Mili- und Makrometastasen ebenfalls über dem für PT liegt (Aiello et al. 2016). Hingegen wurden in menschlichen Metastasen leicht niedrigere Konzentrationen für HA im Vergleich zu PT gefunden (Whatcott et al. 2015; Aiello et al. 2016). Angesichts dieser Beobachtung kann man spekulieren, dass es im Mausmodell Faktoren gibt, die dazu führen, dass in LM mehr HA exprimiert wird als in PT, während menschliche Metastasen ärmer an HA sind als die PT. Die HA-Konzentration ist in Studien zur Hyaluronidase PEGPH20 ein Marker für das Therapieansprechen (Hingorani et al. 2018). Dies würde angesichts hoher HA-Konzentrationen in Metastasen erklären, weshalb im Mausmodell in präklinischen Studien vielversprechende Ergebnisse gesehen wurden. Die aktuell laufende klinische Phase III Studie mit PEGPH20 und nab-pacltaxel/Gamcitabin (NCT02715804) wird zeigen, ob die Kombination aus PEGPH20 und kombinierter Chemotherapie suffizient die Metastasenlast reduzieren kann. In Studien wird die Wirkung von PEGPH20 auf Metastasen nur indirekt über das krankheitsfreie und das Gesamtüberleben erfasst, hier erscheint die Substanz aber aussichtsreich (Hingorani et al. 2018; Hingorani et al. 2016a; Wong et al. 2017).

Obwohl im Westernblot deutlich reduzierte Konzentrationen von SPARC in Metastasen gesehen wurden, konnte dieser Unterschied in der IHC nicht beobachtet werden. Wie erwartet war normales Lebergewebe, abgesehen von einer unspezifischen Hintergrundfärbung, negativ für SPARC. Auch in direkter Nachbarschaft zu Metastasen, wo eine Expression in Nähe zur Entzündungssituation im Tumorgewebe denkbar gewesen wäre, fand sich in normalem Lebergewebe keine relevante SPARC-Expression. Aiello et al. (2016) fanden in ihrem, dem KPC-Modell vergleichbaren, Mausmodell auch in der IHC für LM geringere SPARC-Konzentrationen als in PT. Sollten Metastasen wirklich weniger SPARC enthalten, bleibt neben der rein deskriptiven Komponente trotzdem die Frage, welche Implikationen diese Beobachtungen für die Prognose und Therapie von Metastasen haben. In der Literatur wurde die hohe Affinität von SPARC für Albumin, einem Bestandteil des Chemotherapeutikums nab-Paclitaxel (nanoparticle albuminbound-Paclitaxel), beschrieben. Intensiv wurde eine mögliche Wirkverstärkung und insbesondere eine Stromaablation über die selektive Anreicherung von nab-Paclitaxel in SPARC-dominierten (Tumor-)Geweben diskutiert (von Hoff et al. 2011). Im Xenograftmodell konnte für SPARC-reichere Tumoren auch ein verbessertes Ansprechen auf eine Gemcitabin+nab-Paclitaxel-Kombinationstherapie beobachtet werden. Dies deckt sich mit Beobachtungen in klinischen Studien, wo SPARC und Therapieansprechen positiv korrelierten. Deswegen wurde SPARC als potenzieller Biomarker für ein Therapieansprechen diskutiert (von Hoff et al. 2013b; von Hoff et al. 2011). Diese Assoziation wird jedoch kritisch gesehen und konnte in transgenen Mausmodellen und Phase-III-Studien nicht reproduziert werden (Neesse et al. 2014; Hidalgo et al. 2015), weswegen die Rolle von SPARC in der Chemosensitivierung angezweifelt wird. Allerdings ist bis heute wenig über die Rolle von SPARC in Metastasen bekannt und es bedarf weiterer Forschung um diese zu klären (Aiello et al. 2016). 
Beim Vergleich der vorliegenden Ergebnisse mit den Beobachtungen von Whatcott und Kollegen, ist es wichtig zu berücksichtigen, dass die dort erhobenen Daten neben der Leber in weiteren Metastasierungsorten wie Lunge und Peritoneum erhoben wurden. Auch wurden von ihnen für das Patientenkollektiv Behandlungen nicht erfasst, was eine Verfälschung der Ergebnisse durch vorausgehende Chemotherapien möglich macht. Weiterhin fand keine Analyse von korrespondierenden PT und Metastasen statt (Whatcott et al. 2015).

In der vorgelegten Arbeit unterschieden die Apoptose- und Proliferationsrate sich nicht signifikant zwischen den beiden Tumorkompartimenten. Dies ist bemerkenswert angesichts der unterschiedlichen Zusammensetzung des Tumorstromas in PT und LM. Durch unterschiedliche Aktivität von CAFs ( $\alpha$-SMA) und sezernierten EZM-Proteinen wie SPARC, Kollagen und HA wären vielfältige Auswirkungen auf die Viabilität denkbar. Die hier vorgestellten Ergebnisse bezüglich der Apoptose- und Proliferationsrate werden durch eine Studie von Aiello et al. (2016) in ihrem Mausmodell gestützt. Auch sie finden zwischen verschiedenen Metastasengrößen, welche mit unterschiedlicher Stromakomposition einhergehen, keinen Unterschied in der Proliferations- und Apoptoserate.

Insgesamt sprechen die Ergebnisse aus der IHC für ein reduziertes Tumorstroma in den LM gegenüber den PT, auch wenn für einige Stromakomponenten keine signifikante Erniedrigung gezeigt werden konnte. Die These des reduzierten Tumorstromas in Metastasen im KPC-Modell lässt sich durch die reduzierte Expression stromaler Proteine wie Fibronektin, $\alpha$-SMA und SPARC in KPC-Tumorlysaten untermauern. Diese Beobachtung weicht ab von den Ergebnissen aus menschlichen Metastasen, die Whatcott et al. (2015) zu dem Schluss kommen lassen, dass beide Tumorkompartimente vergleichbar hohe Stromaanteile haben. Die Arbeit von Aiello et al. (2016) fand zumindest für Kollagen, $\alpha$-SMA und SPARC in Nano-, Mikro- und Milimetastasen reduzierte Werte und fand gleichzeitig unsere Beobachtung einer verstärkten HA-Expression in Metastasen bestätigt. Auch wenn sich die Interpretation der IHC unterscheidet, kann festgehalten werden, dass beide Kompartimente im Vergleich zu gesundem Pankreas- und Lebergewebe ausgesprochen desmoplastisch sind.

Neben der Rolle des Tumorstromas bei der Progression, Invasivität, Metastasierung und Immunevasion (Hwang et al. 2008; Xu et al. 2010; Feldmann et al. 2008a; Feldmann et al. 2008b; Vonlaufen et al. 2008) wurde in letzter Zeit intensiv über die Mechanismen der Chemoresistenz diskutiert. Zwar verbessert die palliative Therapie mit dem Standardtherapeutikum Gemcitabin die Lebensqualität und verlängert das Überleben, jedoch ist der Überlebensvorteil mit wenigen Wochen klinisch irrelevant (Burris et al. 1997). Auch für die Kombination mit Erlotinib oder nab-Paclitaxel sowie für das FOLFIRINOX-Regime konnten nur sehr überschaubare Überlebensvorteile beschrieben werden (8-12 Monae versus 6 Monate), die aufgrund des Nebenwirkungsprofils nicht allen Patienten zugemutet werden können (von Hoff et al. 2013a; Conroy et al. 2011). Für andere Krebsentitäten konnte mit vergleichbaren Therapieregimen ein deutlich längeres progressionsfreies Überleben sowie ein längeres Gesamtüberleben beobachtet werden. Als entscheidende Gründe für das schlechte Therapieansprechen wurden die Hypovaskularität 
des PDAC sowie die aus der Minderdurchblutung folgende ungenügende Anreicherung der Chemotherapeutika diskutiert (Olive et al. 2009; Jacobetz et al. 2013). Insbesondere Komponenten der EZM wie HA und Kollagen erzeugen einen hohen interstitiellen Druck und machen das PDAC zu einem festen, zirrhösen Gewebe mit reduzierter Durchblutung. In der Literatur wird dieser Effekt der biophysikalischen Abschirmung des Tumors gegen das Anfluten von Chemotherapeutika als „biophysical drug barrier“ des Stromas bezeichnet (Feig et al. 2012; Provenzano et al. 2012). Im Mausmodell konnte gezeigt werden, dass eine Reduzierung des Tumorstromas zu sowohl einer vorübergehend besseren Durchblutung als auch höheren Konzentrationen von Chemotherapeutika im Tumorgewebe führte. In der Kombination mit Gemcitabin konnte gleichfalls ein verlängertes Überleben beobachtet werden (Olive et al. 2009). Auch für die gezielte Adressierung von Komponenten wie HA und Kollagen mittels Hyaluronidasen und $\mathrm{AT}_{1}$-Antagonisten konnten vergleichbare Beobachtungen gemacht werden (Jacobetz et al. 2013; Provenzano et al. 2012; Chauhan et al. 2013). Letztere Arbeiten schreiben HA die entscheidende Rolle bei der Erzeugung des hohen Gewebedrucks und der reduzierten Durchblutung zu.

Dies könnte erklären, warum in den hier untersuchten LM zwar insgesamt der Stromaanteil reduziert war, für die Gefäßdichte jedoch keine Unterschiede gefunden wurden. So waren im Gegensatz zum gut durchbluteten normalen Lebergewebe sowohl die untersuchten PT als auch die Metastasen ausgesprochen gefäßarm. Die MVD unterschied sich trotz reduzierten Tumorstromas in Metastasen nicht signifikant von der in PT. Gleichzeitig war, wie auch von Aiello et al. (2016) für Mili- und Makrometastasen bestätigt, der Hyaluronsäuregehalt in Metastasen gegenüber den PT deutlich erhöht. Es bleibt zu vermuten, dass diese Akkumulation von HA den reduzierten Kollagen- und Fibroblastenanteil kompensiert, die Durchblutungssituation der Metastasen negativ beeinflusst und sie der Durchblutung von PT angleicht. Bei genauerer Betrachtung der Gefäßdichte in menschlichen Metastasen fanden Aiello et al. (2016) für kleine LM eine fast doppelt so hohe MVD wie für PT, während kein Unterschied zwischen großen LM und PT beschrieben wurde. Auch hier gleichen sich Metastasen mit zunehmender Größe dem PT weiter an.

Dennoch gibt es mittlerweile eine Reihe an Studien, die bezweifeln, dass eine mechanistische Sicht auf biophysikalische Phänomene wie Gewebedruck und Durchblutung das substanzielle Therapieversagen ausreichend erklären (Neesse et al. 2013; Koay et al. 2014a; Koay et al. 2014b; Hessmann et al. 2018). Die Hemmung von Gemcitabin-inaktivierenden Enzymen führt beispielsweise zu deutlich höheren Gemcitabinkonzentrationen ohne das Therapieansprechen zu verbessern. Die Unterdrückung von Wachstumssignalen wie CTGF in Kombination mit Gemcitabin führte hingegen zu verringertem Tumorwachstum, erhöhter Apoptoserate und längerem Überleben in KPC-Mäusen, ohne dabei die Gemcitabinkonzentration im Tumorgewebe gegenüber der Kontrollgruppe zu verändern (Neesse et al. 2013). Dies verdeutlicht, dass nicht die biophysikalisch anflutende und zur Verfügung stehende Menge an Chemotherapeutikum entscheidend ist, sondern die biochemisch auch verwertbare Menge. Vielmehr ist es möglich 
durch gezielte Hemmung von EZM-Komponenten wie dem Wachstumsfaktor CTGF die Wirksamkeit von Chemotherapeutika zu steigern, ohne dabei die Durchblutung substantiell zu verändern.

Mittlerweile gibt es eine Reihe alternativer bzw. komplementärer Erklärungsansätze für das Versagen von Chemotherapien, welche die Rolle des Stromas als biophysikalische Anflutungsbarriere als einen Aspekt neben weiteren Mechanismen wie biochemischen Resistenzmechanismen und Verteilungseffizienz sehen. Mit Blick auf das Tumormikromilieu und die Fibroblastenpopulation ist die These des „drug scavenging“ durch Fibroblasten von besonderem Interesse (Hessmann et al. 2018). Sie besagt, dass CAFs relevante Mengen Gemcitabin aufnehmen, aktivieren und intrazellulär retinieren, wodurch sie den Wirkstoff den benachbarten Pankreaskarzinomzellen entziehen und so zur Chemoresistenz beitragen. Gleichzeitig scheinen die CAFs intrinsisch resistent gegenüber Gemcitabin zu sein. Sie zeigen keine signifikant vermehrte Apoptose gegenüber der Behandlung mit dem Vehikel. Hessmann et al. (2018) fanden insbesondere für kleine Metastasen eine starke Reduktion unter Gemcitabintherapie in KPC-Mäusen. Dies deckt sich mit der Beobachtung, dass kleine Metastasen einen geringeren Stromaanteil und insbesondere eine geringere Fibroblastendichte aufweisen (Aiello et al. 2016). Sie dürften somit höhere wirksame Gemcitabinkonzentrationen erreichen. Der niedrigere Anteil von CAFs in LM gegenüber PT spricht in der Folge auch für eine höhere Suszeptibilität der LM bezüglich klassischer Chemotherapien wie Gemcitabin. Gerade um diesen Effekt weiter zu verstärken, scheint es auch in Hinblick auf die Reduzierung des Metastasenlast sinnvoll zu sein, die vielfältigen Ansätze zur gezielten Stromareduktion zu verfolgen. Dabei sollte man immer die Beobachtung im Hinterkopf behalten, dass eine vollständige Ablation der Fibroblasten gegenläufige Effekte mit schnellerem Wachstum von aggressiveren (Primär-)Tumoren zeigen kann und keinesfalls erstrebenswert scheint (Rhim et al. 2014; Özdemir et al. 2014).

In der Zusammenschau der Ergebnisse zeigt sich, dass (Leber-)Metastasen und PT sich in der Zusammensetzung des Tumorstromas in einigen Punkten unterscheiden und keineswegs als identisch betrachtet werden können. Dennoch zeigen sich beide Kompartimente in ihrer Grundtendenz deutlich desmoplastisch. Es besteht die begründete Vermutung, dass Ansätze wie das gezielte Hemmen von verschiedenen Stromakomponenten, mit denen Aspekte wie aggressives Wachstumsverhalten und Therapieresistenz im PT derzeit angegangen werden, auch in Metastasen zu substanziellen Erfolgen führen könnten. Um dies zu prüfen bedarf es weiterführender Untersuchungen von Metastasen in zukünftigen Therapiestudien und einer weitergehenden Analyse der Unterschiede und Gemeinsamkeiten von Metastasen und PT auf stromaler Ebene. Nur so kann man zu einem genaueren Verständnis der Desmoplasie sowie der vielfältigen Interaktionen gelangen, um in einem nächsten Schritt noch gezielter einzelne Bestandteile des Tumormikromilieus anzugreifen. 


\section{$5 \quad$ Zusammenfassung}

Das duktale Pankreaskarzinom ist eine der aggressivsten Krebserkrankungen und geht mit einer ausgesprochen schlechten Prognose einher. Histologisch dominiert eine stark desmoplastische Stromareaktion, bestehend aus aktivierten tumorassoziierten Fibroblasten und Immunzellen sowie sezernierten Proteinen wie SPARC, Hyaluronsäure und Kollagen, das Bild des Pankreaskarzinoms. Die Gesamtheit des tumorassoziierten Stromas wird als Tumormikromilieu bezeichnet. Die Rolle des Stromas ist divers und unzureichend verstanden. So werden viele Komponenten des Stromas mit höherer Aggressivität, Immunevasion, Chemoresistenz und verkürztem Überleben assoziiert, gleichzeitig führte die weitestgehende Ablation von Fibroblasten und Stroma im Mausmodell zu noch aggressiveren Tumoren und verkürztem Überleben.

Seit 2005 existiert ein von Hingorani et al. entwickeltes transgenes Mausmodell (KPC, LSL-

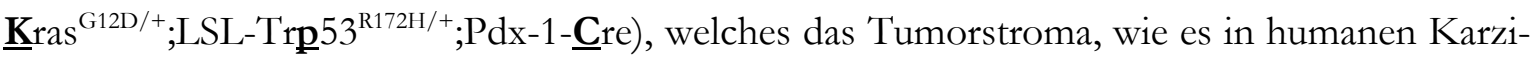
nomen beobachtet wird, rekapituliert. Die Mäuse entwickeln Cre-vermittelt unter Kontrolle von Mutationen in KRAS und Trp53 weitestgehend pankreasspezifisch Adenokarzinome. Ziel der Arbeit war es in diesem Mausmodell epitheliale und stromale Marker weiter zu charakterisieren und zu eruieren, ob für bestimmte epitheliale und stromale Komponenten ein Zusammenhang zum Überleben der Mäuse beobachtet werden kann. Dafür wurde das Stroma von Pankreaskarzinomen aus 46 KPC-Mäusen mittels Immunhistochemie und Immunfluoreszenz auf folgende Aspekte untersucht: Proliferationsrate, Mitoserate, Apoptoserate, Fibroblastenproliferationsrate, Gehalt von Kollagen, SPARC, Hyaluronsäure und $\alpha$-smooth muscle actin sowie Gefäßdichte, mittlere Gefäßfläche, Grading, Desmoplasie und den aktivierten Stromaindex.

In einer univariaten Analyse mittels Kaplan-Meier-Kurve konnte für keinen Parameter ein Zusammenhang zur Überlebensdauer der KPC-Mäuse gefunden werden. Eine multivariate CoxRegression hingegen zeigte, dass eine höhere Proliferationsrate (Ki67) mit längerem Überleben assoziiert war, während eine hohe Fibroblastenproliferationsrate $(\alpha$-SMA+Ki67) und Mitoserate (PHH3) mit kürzerem Überleben einhergingen. Diese Beobachtungen stehen im Kontrast zu einigen Ergebnissen aus humanen Geweben, werden jedoch auch von anderen Studien gestützt. Einschränkend muss hier auf Schwächen der statistischen Analyse hinsichtlich Kollinarität hingewiesen werden. Diese Tatsache unterstreicht die Komplexität des Tumormikromilieus im humanen und murinen Pankreaskarzinom.

Eine weitere Fragestellung dieser Arbeit war, ob und inwiefern sich das Tumorstroma in primären Pankreastumoren und korrespondierenden Lebermetastasen unterscheidet. Hierfür wurden Primärtumoren und korrespondierende Lebermetastasen von KPC-Mäusen mittels Immunhistochemie und Westernblot verglichen. In der Immunhistochemie zeigten sich Lebermetastasen ärmer an Kollagen und a-smooth muscle actin, enthielten jedoch mehr Hyaluronsäure als die Primärtumoren. Bezüglich SPARC-Gehalt und Gefäßdichte sowie Proliferations- und Apoptoserate konnte kein Unterschied zwischen beiden Kompartimenten gefunden werden. 
Der Westernblot aus Tumorlysaten zeigte für SPARC, a-smooth muscle actin und Fibronektin niedrigere Konzentrationen in Lebermetastasen als in Primärtumorgewebe. Es kann geschlussfolgert werden, dass Lebermetastasen stromaärmer sind als ihre Primärtumoren. Dennoch sind beide Tumorkompartimente deutlich desmoplastisch.

Diese Arbeitet leistet einen Beitrag dazu, das Tumorstroma des Pankreaskarzinoms im KPCMausmodell genauer zu charakterisieren und den Einfluss von Stromakomponenten auf das Gesamtüberleben zu untersuchen. 


\section{Summary}

Pancreatic ductal adenocarcinoma is amongst the most aggressive cancers and is associated with an extremely poor prognosis. From a histological perspective, pancreatic cancer is characterised by a distinct, widespread stromal reaction, involving activated, tumor-associated fibroblasts and immune cells as well as secreted proteins like SPARC, hyaluronic acid and collagen. The entire tumor-associated stroma is denominated as the tumor microenvironment. The role of the tumor stroma is complex and still not fully understood. Many components of the tumor stroma are associated with increased aggressiveness, immune evasion, chemoresistance and reduced survival. On the other hand, though, the extensive experimental ablation of fibroblasts and other stromal components has led to more aggressive tumors and reduced survival in mouse models.

In 2005 Hingorani et al. developed a genetically engineered mouse model (KPC, LSL-

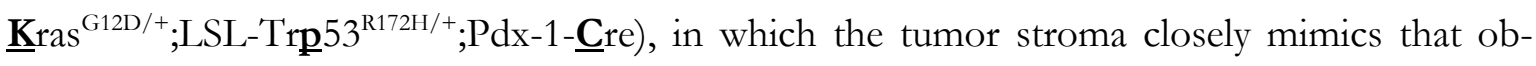
served in human pancreatic cancers. These mice gain mutations in KRAS and Trp53 under the activation of Cre and thus develop, as far as is currently possible, specific pancreatic adenocarcinomas. The aim of this thesis is to further characterize epithelial and stromal markers in the KPC mouse model and to evaluate if there is a correlation between those markers and the overall survival of the mice. Therefore, pancreatic adenocarcinomas of 46 KPC mice were stained and analyzed using immunohistochemistry and immunofluorescence techniques, focusing on the following parameters: proliferation rate, mitotic rate, apoptotic rate, fibroblast proliferation rate, content of collagen, SPARC, hyaluronic acid and $\alpha$-smooth muscle actin, as well as blood vessel density, mean lumen area, grading, desmoplasia and the activated stroma index.

A univariate analysis using the Kaplan-Meier estimator did not show a correlation between survival of the KPC mice and any of the analyzed parameters. However, multivariate analysis using a Cox proportional hazards regression did find an association between higher proliferation rates (Ki67) and prolonged survival, while higher fibroblast proliferation rate $(\alpha-\mathrm{SMA}+\mathrm{Ki} 67)$ and mitotic rate (PHH3) were associated with reduced survival. However, the results from the statistical analysis are likely biased by collinearity. These observations in mouse differ from some of the data obtained analysing human tissue. However, some other studies support the findings of this thesis. This fact further emphasizes the complexity of the tumor microenvironment in human and murine pancreatic cancer.

In addition, this thesis also investigated whether and to what extent the tumor stroma in primary pancreatic cancers differs from the stroma in corresponding liver metastases. To address this question, we used immunohistochemistry and western blotting analysis to compare primary tumors and their corresponding liver metastases in KPC mice. In immunohistochemical analysis, liver metastases appeared to have lower contents of collagen and $\alpha$-smooth muscle actin but 
contained higher levels of hyaluronic acid than the primary tumors. Using immunohistochemical analysis, we could not detect any difference regarding the levels of SPARC, vessel density, proliferation rate or apoptotic rate. Western blotting analysis of whole tumor tissue showed higher concentrations of SPARC, $\alpha$-smooth muscle actin and fibronectin in liver metastases than in the primary tumors. These results led us to conclude that liver metastases are containing less stroma than primary tumors. Nonetheless both tumor compartments are highly desmoplastic.

This thesis contributes to the further characterization of the tumor stroma of pancreatic adenocarcinomas in the KPC mouse model and provides data on the impact of components of the tumor microenvironment on the overall survival. 


\section{$7 \quad$ Literaturverzeichnis}

Aguirre AJ, Bardeesy N, Sinha M, Lopez L, Tuveson DA, Horner J, Redston MS, DePinho RA (2003): Activated Kras and Ink4a/Arf deficiency cooperate to produce metastatic pancreatic ductal adenocarcinoma. Genes Dev 17, 3112-3126

Aiello NM, Bajor DL, Norgard RJ, Sahmoud A, Bhagwat N, Pham MN, Cornish TC, Iacobuzio-Donahue CA, Vonderheide RH, Stanger BZ (2016): Metastatic progression is associated with dynamic changes in the local microenvironment. Nat Commun $\underline{7}, 12819$

Alison MR (1995): Assessing cellular proliferation: What's worth measuring? Hum Exp Toxicol 14, 935944

Almoguera C, Shibata D, Forrester K, Martin J, Arnheim N, Perucho M (1988): Most human carcinomas of the exocrine pancreas contain mutant c-K-ras genes. Cell $\underline{53}, 549-554$

American Cancer Society: Cancer Facts \& Figures 2018, American Cancer Association, Atlanta 2018

Amin S, Lucas AL, Frucht H (2013): Evidence for treatment and survival disparities by age in pancreatic adenocarcinoma: a population-based analysis. Pancreas $\underline{42}, 249-253$

Apte MV, Haber PS, Applegate TL, Norton ID, McCaughan GW, Korsten MA, Pirola RC, Wilson JS (1998): Periacinar stellate shaped cells in rat pancreas: identification, isolation, and culture. Gut $\underline{43}, 128$ 133

Bachem MG, Schneider E, Gross H, Weidenbach H, Schmid RM, Menke A, Siech M, Beger H, Grunert A, Adler G (1998): Identification, culture, and characterization of pancreatic stellate cells in rats and humans. Gastroenterology 115, 421-432

Bachem MG, Schunemann M, Ramadani M, Siech M, Beger H, Buck A, Zhou S, Schmid-Kotsas A, Adler G (2005): Pancreatic carcinoma cells induce fibrosis by stimulating proliferation and matrix synthesis of stellate cells. Gastroenterology $\underline{128}, 907-921$

Bailey P, Chang DK, Nones K, Johns AL, Patch A-M, Gingras M-C, Miller DK, Christ AN, Bruxner TJC, Quinn MC (2016): Genomic analyses identify molecular subtypes of pancreatic cancer. Nature $\underline{51}$, $47-52$

Basturk O, Hong SM, Wood LD, Adsay NV, Albores-Saavedra J, Biankin AV, La Brosens, Fukushima N, Goggins M, Hruban RH (2015): A revised classification system and recommendations from the Baltimore consensus meeting for neoplastic precursor lesions in the pancreas. Am J Surg Pathol $\underline{39}, 1730$ 1741

Beger HG, Büchler MW, Dralle H, Lerch MM, Malfertheiner P, Mössner J, Riemann JF (Hrsg.): Erkrankungen des Pankreas. Springer, Berlin 2013

Bennewith KL, Huang X, Ham CM, Graves EE, Erler JT, Kambham N, Feazell J, Yang GP, Koong A, Giaccia AJ (2009): The Role of Tumor Cell-Derived Connective Tissue Growth Factor (CTGF/CCN2) in Pancreatic Tumor Growth. Cancer Res $\underline{69}$, 775-784

Berlin JD, Catalano P, Thomas JP, Kugler JW, Haller DG, Benson A3 (2002): Phase III study of gemcitabine in combination with fluorouracil versus gemcitabine alone in patients with advanced pancreatic carcinoma: Eastern Cooperative Oncology Group Trial E2297. J Clin Oncol 20, 3270-3275

Bever KM, Sugar EA, Bigelow E, Sharma R, Laheru D, Wolfgang CL, Jaffee EM, Anders RA, JesusAcosta A de, Zheng L (2015): The prognostic value of stroma in pancreatic cancer in patients receiving adjuvant therapy. HPB (Oxford) 17, 292-298

Biankin AV, Waddell N, Kassahn KS, Gingras M-C, Muthuswamy LB, Johns AL, Miller DK, Wilson PJ, Patch A-M, Wu J (2012): Pancreatic cancer genomes reveal aberrations in axon guidance pathway genes. Nature $\underline{491}, 399-405$ 
Bramhall SR, Schulz J, Nemunaitis J, Brown PD, Baillet M, Buckels JAC (2002): A double-blind placebocontrolled, randomised study comparing gemcitabine and marimastat with gemcitabine and placebo as first line therapy in patients with advanced pancreatic cancer. Br J Cancer $\underline{87}, 161-167$

Burris HA3, Moore MJ, Andersen J, Green MR, Rothenberg ML, Modiano MR, Cripps MC, Portenoy RK, Storniolo AM, Tarassoff P (1997): Improvements in survival and clinical benefit with gemcitabine as first-line therapy for patients with advanced pancreas cancer: a randomized trial. J Clin Oncol 15 , 2403-2413

Calhoun ES, Jones JB, Ashfaq R, Adsay V, Baker SJ, Valentine V, Hempen PM, Hilgers W, Yeo CJ, Hruban RH (2003): BRAF and FBXW7 (CDC4, FBW7, AGO, SEL10) Mutations in Distinct Subsets of Pancreatic Cancer. Am J Pathol 163, 1255-1260

Cancer Genome Atlas Research Network (2014): Comprehensive Molecular Characterization of Urothelial Bladder Carcinoma. Nature 507, 315-322

Chauhan VP, Martin JD, Liu H, Lacorre DA, Jain SR, Kozin SV, Stylianopoulos T, Mousa AS, Han X, Adstamongkonkul P (2013): Angiotensin inhibition enhances drug delivery and potentiates chemotherapy by decompressing tumour blood vessels. Nat Commun 4, 2516

Cheng XB, Sato N, Kohi S, Yamaguchi K (2013): Prognostic impact of hyaluronan and its regulators in pancreatic ductal adenocarcinoma. PLoS One $\underline{8}$, e80765

Cheng XB, Kohi S, Koga A, Hirata K, Sato N (2015): Hyaluronan stimulates pancreatic cancer cell motility. Oncotarget $\underline{11}$, 4829-4840

Chiou SH, Winters IP, Wang J, Naranjo S, Dudgeon C, Tamburini FB, Brady JJ, Yang D, Gruner BM, Chuang CH (2015): Pancreatic cancer modeling using retrograde viral vector delivery and in vivo CRISPR/Cas9-mediated somatic genome editing. Genes Dev 29, 1576-1585

Chu GC, Kimmelman AC, Hezel AF, DePinho RA (2007): Stromal biology of pancreatic cancer. J Cell Biochem 101, 887-907

Clark CE, Hingorani SR, Mick R, Combs C, Tuveson DA, Vonderheide RH (2007): Dynamics of the immune reaction to pancreatic cancer from inception to invasion. Cancer Res $\underline{67}, 9518-9527$

Coleman SJ, Watt J, Arumugam P, Solaini L, Carapuca E, Ghallab M, Grose RP, Kocher HM (2014): Pancreatic cancer organotypics: High throughput, preclinical models for pharmacological agent evaluation. World J Gastroenterol 20, 8471-8481

Collins MA, Bednar F, Zhang Y, Brisset J-C, Galban S, Galban CJ, Rakshit S, Flannagan KS, Adsay NV, Di Pasca Magliano M (2012): Oncogenic Kras is required for both the initiation and maintenance of pancreatic cancer in mice. J Clin Invest $\underline{122}$, 639-653

Collisson EA, Sadanandam A, Olson P, Gibb WJ, Truitt M, Gu S, Cooc J, Weinkle J, Kim GE, Jakkula L (2011): Subtypes of pancreatic ductal adenocarcinoma and their differing responses to therapy. Nat Med 17, 500-503

Colman H, Giannini C, Huang L, Gonzalez J, Hess K, Bruner J, Fuller G, Langford L, Pelloski C, Aaron J (2006): Assessment and prognostic significance of mitotic index using the mitosis marker phosphohistone $\mathrm{H} 3$ in low and intermediate-grade infiltrating astrocytomas. Am J Surg Pathol $\underline{30}$, 657-664

Conroy T, Desseigne F, Ychou M, Bouche O, Guimbaud R, Becouarn Y, Adenis A, Raoul J-L, GourgouBourgade S, de la Fouchardière C (2011): FOLFIRINOX versus gemcitabine for metastatic pancreatic cancer. N Engl J Med $\underline{364}, 1817-1825$

Deutsche Gesellschaft für Gastroenterologie, Verdauungs- und Stoffwechselkrankheiten (DGVS), Deutsche Krebsgesellschaft (DKG), Leitlinienprogramm Onkologie der AWMF (Hrsg.): S3-Leitlinie Exokrines Pankreaskarzinom: Langversion, o.O. 2013 
Doi R, Imamura M, Hosotani R, Imaizumi T, Hatori T, Takasaki K, Funakoshi A, Wakasugi H, Asano T, Hishinuma S (2008): Surgery versus radiochemotherapy for resectable locally invasive pancreatic cancer: final results of a randomized multi-institutional trial. Surg Today $\underline{38}, 1021-1028$

Duda DG, Duyverman AMMJ, Kohno M, Snuderl M, Steller EJA, Fukumura D, Jain RK (2010): Malignant cells facilitate lung metastasis by bringing their own soil. Proc Natl Acad Sci USA 107, $21677-$ 21682

Dvorak HF (1986): Tumors: Wounds That Do Not Heal. N Engl J Med $\underline{315}$, 1650-1659

Egeblad M, Rasch MG, Weaver VM (2010): Dynamic interplay between the collagen scaffold and tumor evolution. Curr Opin Cell Biol 22, 697-706

Ellenrieder V, Alber B, Lacher U, Hendler SF, Menke A, Boeck W, Wagner M, Wilda M, Friess H, Buchler M (2000): Role of MT-MMPs and MMP-2 in pancreatic cancer progression. Int J Cancer $\underline{85}$, $14-20$

Erkan M, Michalski CW, Rieder S, Reiser-Erkan C, Abiatari I, Kolb A, Giese NA, Esposito I, Friess H, Kleeff J (2008): The activated stroma index is a novel and independent prognostic marker in pancreatic ductal adenocarcinoma. Clin Gastroenterol Hepatol $\underline{6}$, 1155-1161

Esposito I, Konukiewitz B, Schlitter AM, Kloppel G (2012): Neue Einblicke in die Entstehung des Pankreaskarzinoms. Die Rolle der atypischen flachen Lasionen in der Karzinogenese. Pathologe 33 Suppl 2, 189-193

Feig C, Gopinathan A, Neesse A, Chan DS, Cook N, Tuveson DA (2012): The pancreas cancer microenvironment. Clin Cancer Res $\underline{18}$, 4266-4276

Feig C, Jones JO, Kraman M, Wells RJB, Deonarine A, Chan DS, Connell CM, Roberts EW, Zhao Q, Caballero OL (2013): Targeting CXCL12 from FAP-expressing carcinoma-associated fibroblasts synergizes with anti-PD-L1 immunotherapy in pancreatic cancer. Proc Natl Acad Sci U S A $\underline{110}$, 20212-20217

Feldmann G, Maitra A (2008): Molecular genetics of pancreatic ductal adenocarcinomas and recent implications for translational efforts. J Mol Diagn $\underline{10}, 111-122$

Feldmann G, Fendrich V, McGovern K, Bedja D, Bisht S, Alvarez H, Koorstra J-BM, Habbe N, Karikari C, Mullendore M (2008a): An orally bioavailable small-molecule inhibitor of Hedgehog signaling inhibits tumor initiation and metastasis in pancreatic cancer. Mol Cancer Ther $\underline{7}, 2725-2735$

Feldmann G, Habbe N, Dhara S, Bisht S, Alvarez H, Fendrich V, Beaty R, Mullendore M, Karikari C, Bardeesy N (2008b): Hedgehog inhibition prolongs survival in a genetically engineered mouse model of pancreatic cancer. Gut $\underline{57}, 1420-1430$

Frese KK, Tuveson DA (2007): Maximizing mouse cancer models. Nat Rev Cancer 7, 645-658

Froeling FEM, Feig C, Chelala C, Dobson R, Mein CE, Tuveson DA, Clevers H, Hart IR, Kocher HM (2011): Retinoic acid-induced pancreatic stellate cell quiescence reduces paracrine Wnt-beta-catenin signaling to slow tumor progression. Gastroenterology 141, 1486-97, 1497.e1-14

Gades NM, Ohashi A, Mills LD, Rowley MA, Predmore KS, Marler RJ, Couch FJ (2008): Spontaneous Vulvar Papillomas in a Colony of Mice Used for Pancreatic Cancer Research. Comp Med 58, 271-275

Gerdes J, Schwab U, Lemke H, Stein H (1983): Production of a mouse monoclonal antibody reactive with a human nuclear antigen associated with cell proliferation. Int J Cancer $\underline{31}, 13-20$

Glimelius B, Hoffman K, Sjoden PO, Jacobsson G, Sellstrom H, Enander LK, Linne T, Svensson C (1996): Chemotherapy improves survival and quality of life in advanced pancreatic and biliary cancer. Ann Oncol 7, 593-600

Goggins M, Schutte M, Lu J, Moskaluk CA, Weinstein CL, Petersen GM, Yeo CJ, Jackson CE, Lynch HT, Hruban RH (1996): Germline BRCA2 gene mutations in patients with apparently sporadic pancreatic carcinomas. Cancer Res $\underline{56}, 5360-5364$ 
Gopinathan A, Morton JP, Jodrell DI, Sansom OJ (2015): GEMMs as preclinical models for testing pancreatic cancer therapies. Dis Model Mech $\underline{8}, 1185-1200$

Grindley ND, Whiteson KL, Rice PA (2006): Mechanisms of site-specific recombination. Annu Rev Biochem 포, 567-605

Guenet JL (2005): The mouse genome. Genome Res $\underline{15}$, 1729-1740

Guerra C, Schuhmacher AJ, Cañamero M, Grippo PJ, Verdaguer L, Pérez-Gallego L, Dubus P, Sandgren EP, Barbacid M (2007): Chronic pancreatitis is essential for induction of pancreatic ductal adenocarcinoma by K-Ras oncogenes in adult mice. Cancer Cell 11, 291-302

Gundewar C, Sasor A, Hilmersson KS, Andersson R, Ansari D (2015): The role of SPARC expression in pancreatic cancer progression and patient survival. Scand J Gastroenterol 50, 1170-1174

Hamada S, Masamune A, Takikawa T, Suzuki N, Kikuta K, Hirota M, Hamada H, Kobune M, Satoh K, Shimosegawa T (2012): Pancreatic stellate cells enhance stem cell-like phenotypes in pancreatic cancer cells. Biochem Biophys Res Commun 421, 349-354

Hasselluhn MC, Klein L, Patzak MS, Buchholz SM, Ströbel P, Ellenrieder V, Maisonneuve P, Neesse A (2020): Stromal Features of the Primary Tumor Are Not Prognostic in Genetically Engineered Mice of Pancreatic Cancer. Cells $\underline{9}, 58$

Hessmann E, Patzak MS, Klein L, Chen N, Kari V, Ramu I, Bapiro TE, Frese KK, Gopinathan A, Richards FM (2018): Fibroblast drug scavenging increases intratumoural gemcitabine accumulation in murine pancreas cancer. Gut 67, 497-507

Hezel AF, Kimmelman AC, Stanger BZ, Bardeesy N, DePinho RA (2006): Genetics and biology of pancreatic ductal adenocarcinoma. Genes Dev 20, 1218-1249

Hidalgo M (2010): Pancreatic cancer. N Engl J Med $\underline{362,1605-1617}$

Hidalgo M, Plaza C, Musteanu M, Illei P, Brachmann CB, Heise C, Pierce D, Lopez-Casas PP, Menendez C, Tabernero J (2015): SPARC Expression Did Not Predict Efficacy of nab-Paclitaxel plus Gemcitabine or Gemcitabine Alone for Metastatic Pancreatic Cancer in an Exploratory Analysis of the Phase III MPACT Trial. Clin Cancer Res 21, 4811-4818

Hingorani SR, Petricoin EF, Maitra A, Rajapakse V, King C, Jacobetz MA, Ross S, Conrads TP, Veenstra TD, Hitt BA (2003): Preinvasive and invasive ductal pancreatic cancer and its early detection in the mouse. Cancer Cell $\underline{4}, 437-450$

Hingorani SR, Wang L, Multani AS, Combs C, Deramaudt TB, Hruban RH, Rustgi AK, Chang S, Tuveson DA (2005): Trp53R172H and KrasG12D cooperate to promote chromosomal instability and widely metastatic pancreatic ductal adenocarcinoma in mice. Cancer Cell $\mathbf{7}, 469-483$

Hingorani SR, Harris WP, Beck JT, Berdov BA, Wagner SA, Pshevlotsky EM, Tjulandin SA, Gladkov OA, Holcombe RF, Korn R (2016a): Phase Ib Study of PEGylated Recombinant Human Hyaluronidase and Gemcitabine in Patients with Advanced Pancreatic Cancer. Clin Cancer Res 22, 2848-2854

Hingorani SR, Harris WP, Seery TE, Zheng L, Sigal D, Hendifar AE, Braiteh FS, Zalupski M, Baron AD, Bahary N (2016b): Interim results of a randomized phase II study of PEGPH20 added to nabpaclitaxel/gemcitabine in patients with stage IV previously untreated pancreatic cancer. J Clin Oncol $\underline{34}$, 439

Hingorani SR, Zheng L, Bullock AJ, Seery TE, Harris WP, Sigal DS, Braiteh F, Ritch PS, Zalupski MM, Bahary N (2018): HALO 202: Randomized Phase II Study of PEGPH20 Plus Nab-Paclitaxel/Gemcitabine Versus Nab-Paclitaxel/Gemcitabine in Patients With Untreated, Metastatic Pancreatic Ductal Adenocarcinoma. J Clin Oncol $\underline{36}$, 359-366

Houten L, Reilley AA (1980): An investigation of the cause of death from cancer. J Surg Oncol $\underline{13}, 111-$ 116 
Howlader N, Noone AM, Krapcho M, Garshell J MD, Altekruse SF, Kosary CL, Yu M RJ, Tatalovich Z, Mariotto A, Lewis DR et al. : SEER Cancer Statistics Review, 1975-2012. National Cancer Institute, Bethesda 2015; https://seer.cancer.gov/archive/csr/1975_2012/results_merged/sect_01_overview.pdf, abgerufen am: 23.04.2020

Hruban RH, Goggins M, Parsons J, Kern SE (2000): Progression Model for Pancreatic Cancer. Clin Cancer Res $\underline{6}$, 2969-2972

Hwang RF, Moore T, Arumugam T, Ramachandran V, Amos KD, Rivera A, Ji B, Evans DB, Logsdon CD (2008): Cancer-associated stromal fibroblasts promote pancreatic tumor progression. Cancer Res $\underline{68}, 918-926$

Imamura T, Iguchi $\mathrm{H}$, Manabe $\mathrm{T}$, Ohshio G, Yoshimura $\mathrm{T}$, Wang ZH, Suwa $\mathrm{H}$, Ishigami S, Imamura $\mathrm{M}$ (1995): Quantitative analysis of collagen and collagen subtypes I, III, and V in human pancreatic cancer, tumor-associated chronic pancreatitis, and alcoholic chronic pancreatitis. Pancreas $\underline{11}$, 357-364

Infante JR, Matsubayashi H, Sato N, Tonascia J, Klein AP, Riall TA, Yeo C, Iacobuzio-Donahue C, Goggins M (2007): Peritumoral fibroblast SPARC expression and patient outcome with resectable pancreatic adenocarcinoma. J Clin Oncol 25, 319-325

Itano N, Zhuo L, Kimata K (2008): Impact of the hyaluronan-rich tumor microenvironment on cancer initiation and progression. Cancer Sci $\underline{\text { 99, }}$ 1720-1725

Jacobetz MA, Chan DS, Neesse A, Bapiro TE, Cook N, Frese KK, Feig C, Nakagawa T, Caldwell ME, Zecchini HI (2013): Hyaluronan impairs vascular function and drug delivery in a mouse model of pancreatic cancer. Gut $\underline{62}, 112-120$

Jamieson NB, Carter CR, McKay CJ, Oien KA (2011): Tissue biomarkers for prognosis in pancreatic ductal adenocarcinoma: A systematic review and meta-analysis. Clin Cancer Res 17, 3316-3331

Johnson JI, Decker S, Zaharevitz D, Rubinstein LV, Venditti JM, Schepartz S, Kalyandrug S, Christian M, Arbuck S, Hollingshead M (2001): Relationships between drug activity in NCI preclinical in vitro and in vivo models and early clinical trials. Br J Cancer $\underline{84}$, 1424-1431

Jones L, Ghaneh P, Humphreys M, Neoptolemos JP (1999): The matrix metalloproteinases and their inhibitors in the treatment of pancreatic cancer. Ann N Y Acad Sci $\underline{880}, 288-307$

Jones S, Zhang X, Parsons DW, Lin JC-H, Leary RJ, Angenendt P, Mankoo P, Carter H, Kamiyama H, Jimeno A (2008): Core signaling pathways in human pancreatic cancers revealed by global genomic analyses. Science $\underline{321}, 1801-1806$

Junqueira, LCU., Carneiro, J. (Hrsg.): Histologie. 6., neu übers., überarb. und aktualisierte Auflage; Springer Medizin, Heidelberg 2005

Junqueira LCU, Bignolas G, Brentani RR (1979): Picrosirius staining plus polarization microscopy, a specific method for collagen detection in tissue sections. Histochem J $11,447-455$

Kaleağasıoğlu F, Berger MR (2014): SIBLINGs and SPARC families: their emerging roles in pancreatic cancer. World J Gastroenterol 20, 14747-14759

Kawaguchi Y, Cooper B, Gannon M, Ray M, MacDonald RJ, Wright CV (2002): The role of the transcriptional regulator Ptf1a in converting intestinal to pancreatic progenitors. Nat Genet $\underline{32}, 128-134$

Kim J-Y, Jeong HS, Chung T, Kim M, Lee JH, Jung WH, Koo JS (2017): The value of phosphohistone $\mathrm{H} 3$ as a proliferation marker for evaluating invasive breast cancers: A comparative study with Ki67. Oncotarget $\underline{8}, 65064-65076$

Kim SK, MacDonald RJ (2002): Signaling and transcriptional control of pancreatic organogenesis. Curr Opin Genet Dev 12, 540-547 
Kindler HL, Niedzwiecki D, Hollis D, Sutherland S, Schrag D, Hurwitz H, Innocenti F, Mulcahy MF, O'Reilly E, Wozniak TF (2010): Gemcitabine plus bevacizumab compared with gemcitabine plus placebo in patients with advanced pancreatic cancer: Phase III trial of the Cancer and Leukemia Group B (CALGB 80303). J Clin Oncol 28, 3617-3622

Kindler HL, Ioka T, Richel DJ, Bennouna J, Letourneau R, Okusaka T, Funakoshi A, Furuse J, Park YS, Ohkawa S (2011): Axitinib plus gemcitabine versus placebo plus gemcitabine in patients with advanced pancreatic adenocarcinoma: A double-blind randomised phase 3 study. Lancet Oncol 12, 256-262

Klein L, Hessmann E, Bapiro TE, Frese K, Richards FM, Jodrell DI, Gress TM, Ellenrieder V, Neesse A (2016): Gemcitabine delivery and stromal component analysis in primary murine pancreatic tumours and liver metastasis. Pancreatology $\underline{16}$, S17

Koay EJ, Baio FE, Ondari A, Truty MJ, Cristini V, Thomas RM, Chen R, Chatterjee D, Kang Y'a, Zhang $\mathrm{J}$ (2014a): Intra-tumoral heterogeneity of gemcitabine delivery and mass transport in human pancreatic cancer. Phys Biol 11, 65002

Koay EJ, Truty MJ, Cristini V, Thomas RM, Chen R, Chatterjee D, Kang Y'a, Bhosale PR, Tamm EP, Crane CH (2014b): Transport properties of pancreatic cancer describe gemcitabine delivery and response. J Clin Invest 124, 1525-1536

Kondo S, Takahashi Y, Shiozawa S, Ichise H, Yoshida N, Kanegae Y, Saito I (2006): Efficient sequential gene regulation via FLP-and Cre-recombinase using adenovirus vector in mammalian cells including mouse ES cells. Microbiol Immunol 무, 831-843

Koong AC, Mehta VK, Le QT, Fisher GA, Terris DJ, Brown JM, Bastidas AJ, Vierra M (2000): Pancreatic tumors show high levels of hypoxia. Int J Radiat Oncol Biol Phys 48, 919-922

Kromrey M-L, Bulow R, Hubner J, Paperlein C, Lerch MM, Ittermann T, Volzke H, Mayerle J, Kuhn JP (2018): Prospective study on the incidence, prevalence and 5-year pancreatic-related mortality of pancreatic cysts in a population-based study. Gut $\underline{67}, 138-145$

Laemmli UK (1970): Cleavage of structural proteins during the assembly of the head of bacteriophage T4. Nature 227, 680-685

Lang G: Histotechnik: Praxislehrbuch für die biomedizinische Analytik. 2. überarbeitete und aktualisierte Auflage; Springer, Wien 2013

Le Q-T, Denko NC, Giaccia AJ (2004): Hypoxic gene expression and metastasis. Cancer Metastasis Rev $\underline{23}, 293-310$

Leitlinie Pankreaskarzinom s. S3-Leitlinie Exokrines Pankreaskarzinom, 2013

Lenk L, Pein M, Will O, Gomez B, Viol F, Hauser C, Egberts J-H, Gundlach J-P, Helm O, Tiwari S (2017): The hepatic microenvironment essentially determines tumor cell dormancy and metastatic outgrowth of pancreatic ductal adenocarcinoma. Oncoimmunology 7, e1368603

Lertkiatmongkol P, Liao D, Mei H, Hu Y, Newman PJ (2016): Endothelial functions of PECAM-1 (CD31). Curr Opin Hematol 23, 253-259

Lowenfels AB, Maisonneuve P, Cavallini G, Ammann RW, Lankisch PG, Andersen, JR, Dimagno EP, Andren-Sandberg A, Domellof L (1993): Pancreatitis and the risk of pancreatic cancer. International Pancreatitis Study Group. N Engl J Med 328, 1433-1437

Lu C, Xu C-F, Wan X-Y, Zhu H-T, Yu C-H, Li Y-M (2015): Screening for pancreatic cancer in familial high-risk individuals: A systematic review. World J Gastroenterol 21, 8678-8686

Lynch TJ, Bell DW, Sordella R, Gurubhagavatula S, Okimoto RA, Brannigan BW, Harris PL, Haserlat SM, Supko JG, Haluska FG (2004): Activating mutations in the epidermal growth factor receptor underlying responsiveness of non-small-cell lung cancer to gefitinib. N Engl J Med 350, 2129-2139 
Magee JA, Piskounova E, Morrison SJ (2012): Cancer stem cells: impact, heterogeneity, and uncertainty. Cancer Cell 21, 283-296

Mahadevan D, von Hoff DD (2007): Tumor-stroma interactions in pancreatic ductal adenocarcinoma. Mol Cancer Ther $\underline{6}, 1186-1197$

Malka D (2002): Risk of pancreatic adenocarcinoma in chronic pancreatitis. Gut $\underline{51}, 849-852$

Mantoni TS, Schendel RRE, Rödel F, Niedobitek G, Al-Assar O, Masamune A, Brunner TB (2008): Stromal SPARC expression and patient survival after chemoradiation for non-resectable pancreatic adenocarcinoma. Cancer Biol Ther $\mathbf{7}, 1806-1815$

Mathew E, Brannon AL, Del Vecchio A, Garcia PE, Penny MK, Kane KT, Vinta A, Buckanovich RJ, Di Magliano MP (2016): Mesenchymal Stem Cells Promote Pancreatic Tumor Growth by Inducing Alternative Polarization of Macrophages. Neoplasia 18, 142-151

Modolell I, Guarner L, Malagelada JR (1999): Vagaries of clinical presentation of pancreatic and biliary tract cancer. Ann Oncol 10 Suppl 4, 82-84

Moffitt RA, Marayati R, Flate EL, Volmar KE, Loeza SGH, Hoadley KA, Rashid NU, Williams LA, Eaton SC, Chung AH (2015): Virtual microdissection identifies distinct tumor- and stroma-specific subtypes of pancreatic ductal adenocarcinoma. Nat Genet $\underline{47}, 1168$

Moore MJ, Hamm J, Dancey J, Eisenberg PD, Dagenais M, Fields A, Hagan K, Greenberg B, Colwell B, Zee B (2003): Comparison of gemcitabine versus the matrix metalloproteinase inhibitor BAY 12-9566 in patients with advanced or metastatic adenocarcinoma of the pancreas: A phase III trial of the National Cancer Institute of Canada Clinical Trials Group. J Clin Oncol 21, 3296-3302

Moore MJ, Goldstein D, Hamm J, Figer A, Hecht, JR, Gallinger S, Au HJ, Murawa P, Walde D, Wolff RA (2007): Erlotinib plus gemcitabine compared with gemcitabine alone in patients with advanced pancreatic cancer: a phase III trial of the National Cancer Institute of Canada Clinical Trials Group. J Clin Oncol 25, 1960-1966

National Cancer Institute USA (2018a): Surveillance, Epidemiology, and End Results (SEER) Program: 5-Year Relative Survival (Percent) by Year of Diagnosis for all cancer sites. https://seer.cancer.gov/archive/csr/1975_2012/browse_csr.php?sectionSEL=2\&pageSEL=sect_02_table.08.html\#table2, abgerufen am: 23.04.2020

National Cancer Institute USA (2018b): Surveillance, Epidemiology, and End Results (SEER) Program: 5-Year Relative Survival (Percent) by Year of Diagnosis for PDAC. https://seer.cancer.gov/archive/csr/1975_2012/browse_csr.php?sectionSEL=22\&pageSEL=sect_22_table.08.html, abgerufen am: 23.04.2020

Neesse A, Michl P, Frese KK, Feig C, Cook N, Jacobetz MA, Lolkema MP, Buchholz M, Olive KP, Gress TM (2011): Stromal biology and therapy in pancreatic cancer. Gut $\underline{60}$, 861-868

Neesse A, Frese KK, Bapiro TE, Nakagawa T, Sternlicht MD, Seeley TW, Pilarsky C, Jodrell DI, Spong SM, Tuveson DA (2013): CTGF antagonism with mAb FG-3019 enhances chemotherapy response without increasing drug delivery in murine ductal pancreas cancer. Proc Natl Acad Sci U S A $\underline{110}, 12325$ 12330

Neesse A, Frese KK, Chan DS, Bapiro TE, Howat WJ, Richards FM, Ellenrieder V, Jodrell DI, Tuveson DA (2014): SPARC independent drug delivery and antitumour effects of nab-paclitaxel in genetically engineered mice. Gut $\underline{63}$, 974-983

Neesse A, Algül H, Tuveson DA, Gress TM (2015): Stromal biology and therapy in pancreatic cancer: a changing paradigm. Gut $\underline{64}, 1476-1484$

Neoptolemos JP, Stocken DD, Friess H, Bassi C, Dunn JA, Hickey H, Beger H, Fernandez-Cruz L, Dervenis C, Lacaine F (2004): A randomized trial of chemoradiotherapy and chemotherapy after resection of pancreatic cancer. N Engl J Med $\underline{350}, 1200-1210$ 
Neoptolemos JP, Palmer DH, Ghaneh P, Psarelli EE, Valle JW, Halloran CM, Faluyi O, O'Reilly DA, Cunningham D, Wadsley J (2017): Comparison of adjuvant gemcitabine and capecitabine with gemcitabine monotherapy in patients with resected pancreatic cancer (ESPAC-4): A multicentre, open-label, randomised, phase 3 trial. Lancet $\underline{389}, 1011-1024$

Nishida T, Yoshitomi H, Takano S, Kagawa S, Shimizu H, Ohtsuka M, Kato A, Furukawa K, Miyazaki M (2016): Low Stromal Area and High Stromal Microvessel Density Predict Poor Prognosis in Pancreatic Cancer. Pancreas 45 , 593-600

Oettle H, Post S, Neuhaus P, Gellert K, Langrehr J, Ridwelski K, Schramm H, Fahlke J, Zuelke C, Burkart C (2007): Adjuvant chemotherapy with gemcitabine vs observation in patients undergoing curative-intent resection of pancreatic cancer: a randomized controlled trial. JAMA 297, 267-277

Okano K, Suzuki Y (2014): Strategies for early detection of resectable pancreatic cancer. World J Gastroenterol 20, 11230-11240

Olive KP, Tuveson DA, Ruhe ZC, Yin B, Willis NA, Bronson RT, Crowley D, Jacks T (2004): Mutant p53 gain of function in two mouse models of Li-Fraumeni syndrome. Cell $\underline{119}, 847-860$

Olive KP, Jacobetz MA, Davidson CJ, Gopinathan A, McIntyre D, Honess D, Madhu B, Goldgraben MA, Caldwell ME, Allard D (2009): Inhibition of Hedgehog signaling enhances delivery of chemotherapy in a mouse model of pancreatic cancer. Science $\underline{324}, 1457-1461$

Olivier M, Eeles R, Hollstein M, Khan MA, Harris CC, Hainaut P (2002): The IARC TP53 database: new online mutation analysis and recommendations to users. Hum Mutat $\underline{19}$, 607-614

Omary MB, Lugea A, Lowe AW, Pandol SJ (2007): The pancreatic stellate cell: a star on the rise in pancreatic diseases. J Clin Invest $\underline{117}, 50-59$

Özdemir BC, Pentcheva-Hoang T, Carstens JL, Zheng X, Wu CC, Simpson TR, Laklai H, Sugimoto H, Kahlert C, Novitskiy SV (2014): Depletion of carcinoma-associated fibroblasts and fibrosis induces immunosuppression and accelerates pancreas cancer with reduced survival. Cancer Cell 25, 719-734

Penchev VR, Rasheed ZA, Maitra A, Matsui W (2012): Heterogeneity and targeting of pancreatic cancer stem cells. Clin Cancer Res 18, 4277-4284

Perez-Mancera PA, Guerra C, Barbacid M, Tuveson DA (2012): What we have learned about pancreatic cancer from mouse models. Gastroenterology 142, 1079-1092

Poplin E, Feng Y, Berlin J, Rothenberg ML, Hochster H, Mitchell E, Alberts S, O'Dwyer P, Haller D, Catalano P (2009): Phase III, randomized study of gemcitabine and oxaliplatin versus gemcitabine (fixeddose rate infusion) compared with gemcitabine (30-minute infusion) in patients with pancreatic carcinoma E6201: A trial of the Eastern Cooperative Oncology Group. J Clin Oncol 27, 3778-3785

Porta M, Fabregat X, Malats N, Guarner L, Carrato A, de Miguel A, Ruiz L, Jariod M, Costafreda S, Coll S (2005): Exocrine pancreatic cancer: Symptoms at presentation and their relation to tumour site and stage. Clin Transl Oncol 7, 189-197

Provenzano PP, Cuevas C, Chang AE, Goel VK, Hoff DD von, Hingorani, SR (2012): Enzymatic targeting of the stroma ablates physical barriers to treatment of pancreatic ductal adenocarcinoma. Cancer Cell $\underline{21}, 418-429$

Quante AS, Ming C, Rottmann M, Engel J, Boeck S, Heinemann V, Westphalen CB, Strauch K (2016): Projections of cancer incidence and cancer-related deaths in Germany by 2020 and 2030. Cancer Med $\underline{5}$, 2649-2656

Rahib L, Smith BD, Aizenberg R, Rosenzweig AB, Fleshman JM, Matrisian LM (2014): Projecting cancer incidence and deaths to 2030: the unexpected burden of thyroid, liver, and pancreas cancers in the United States. Cancer Res 74, 2913-2921 
Raimondi S, Lowenfels AB, Am Morselli-Labate, Maisonneuve P, Pezzilli R (2010): Pancreatic cancer in chronic pancreatitis; aetiology, incidence, and early detection. Best Pract Res Clin Gastroenterol 24, 349_ 358

Rassow J, Hauser K, Netzker R, Deutzmann R: Biochemie (Duale Reihe). 2., aktualisierte Auflage; Thieme, Stuttgart 2008

Rehm H, Letzel T: Der Experimentator: Proteinbiochemie/Proteomics. 6. Auflage; Spektrum Akademischer Verlag, Heidelberg 2010

Rempel SA, Golembieski WA, Fisher JL, Maile M, Nakeff A (2001): SPARC modulates cell growth, attachment and migration of U87 glioma cells on brain extracellular matrix proteins. J Neurooncol $\underline{53}$, 149-160

Rhim AD, Mirek ET, Aiello NM, Maitra A, Bailey JM, McAllister F, Reichert M, Beatty GL, Rustgi AK, Vonderheide RH (2012): EMT and Dissemination Precede Pancreatic Tumor Formation. Cell $\underline{148}$, 349361

Rhim AD, Oberstein PE, Thomas DH, Mirek ET, Palermo CF, Sastra SA, Dekleva EN, Saunders T, Becerra CP, Tattersall IW (2014): Stromal elements act to restrain, rather than support, pancreatic ductal adenocarcinoma. Cancer Cell 25, 735-747

Richmond A, Su Y (2008): Mouse xenograft models vs GEM models for human cancer therapeutics. Dis Model Mech $1,78-82$

Robert Koch-Institut: Krebs in Deutschland für 2013/2014: 11. Ausgabe, Robert Koch-Institut, Berlin, 2017

Roberts TG, Goulart BH, Squitieri L, Stallings SC, Halpern EF, Chabner BA, Gazelle GS, Finkelstein SN, Clark JW (2004): Trends in the risks and benefits to patients with cancer participating in phase 1 clinical trials. JAMA $\underline{292}, 2130-2140$

Ross MH, Pawlina W: Histology: A text and atlas, 6. Auflage; Wolters Kluwer/Lippincott Williams \& Wilkins Health, Philadelphia 2011

Rowley DR (2014): Reprogramming the Tumor Stroma: A New Paradigm. Cancer Cell 26, 451-452

Rubio-Viqueira B, Jimeno A, Cusatis G, Zhang X, Iacobuzio-Donahue C, Karikari C, Shi C, Danenberg $\mathrm{K}$, Danenberg PV, Kuramochi H (2006): An in vivo platform for translational drug development in pancreatic cancer. Clin Cancer Res $\underline{12}$, 4652-4661

S3-Leitlinie Exokrines Pankreaskarzinom: Deutsche Gesellschaft für Gastroenterologie, Verdauungsund Stoffwechselkrankheiten (DGVS), Deutsche Krebsgesellschaft (DKG), Leitlinienprogramm Onkologie der AWMF (Hrsg.): S3-Leitlinie Exokrines Pankreaskarzinom: Langversion, o.O. 2013

Sabine VS, Faratian D, Kirkegaard-Clausen T, Bartlett JMS (2012): Validation of activated caspase-3 antibody staining as a marker of apoptosis in breast cancer. Histopathology $\underline{60}, 369-371$

Saotome T, Inoue H, Fujimiya M, Fujiyama Y, Bamba T (1997): Morphological and immunocytochemical identification of periacinar fibroblast-like cells derived from human pancreatic acini. Pancreas $\underline{14}$, 373-382

Schindelin J, Arganda-Carreras I, Frise E, Kaynig V, Longair M, Pietzsch T, Preibisch S, Rueden C, Saalfeld S, Schmid B (2012): Fiji: An open-source platform for biological-image analysis. Nat Methods $\underline{9}, 676-682$

Scholzen T, Gerdes J (2000): The Ki-67 protein: from the known and the unknown. J Cell Physiol 182, $311-322$

Sener SF, Fremgen A, Menck HR, Winchester DP (1999): Pancreatic cancer: A report of treatment and survival trends for 100,313 patients diagnosed from 1985-1995, using the National Cancer Database. J Am Coll Surg 189, 1-7 
Shepard HM (2015): Breaching the Castle Walls: Hyaluronan Depletion as a Therapeutic Approach to Cancer Therapy. Front Oncol $\underline{5}, 192$

Sherman MH, Yu RT, Engle DD, Ding N, Atkins AR, Tiriac H, Collisson EA, Connor F, van Dyke T, Kozlov S (2014): Vitamin D Receptor-Mediated Stromal Reprogramming Suppresses Pancreatitis and Enhances Pancreatic Cancer Therapy. Cell 159, 80-93

Shi C, Hruban RH, Klein AP (2009): Familial pancreatic cancer. Arch Pathol Lab Med 133, 365-374

Siegel RL, Miller KD, Jemal A (2016): Cancer statistics, 2016. CA Cancer J Clin 66, 7-30

Simeone DM, Maitra A (Hrsg.): Molecular Genetics of Pancreatic Cancer; Springer, New York 2013

Sinn M, Sinn BV, Striefler JK, Lindner JL, Stieler JM, Lohneis P, Bischoff S, Bläker H, Pelzer U, Bahra M (2014): SPARC expression in resected pancreatic cancer patients treated with gemcitabine: Results from the CONKO-001 study. Ann Oncol 25, 1025-1032

Sironen RK, Tammi M, Tammi R, Auvinen PK, Anttila M, Kosma V-M (2011): Hyaluronan in human malignancies. Exp Cell Res $\underline{317}$, 383-391

Slamon DJ, Leyland-Jones B, Shak S, Fuchs H, Paton V, Bajamonde A, Fleming T, Eiermann W, Wolter J, Pegram M (2001): Use of chemotherapy plus a monoclonal antibody against HER2 for metastatic breast cancer that overexpresses HER2. N Engl J Med 344, 783-792

Stocken DD, Buchler MW, Dervenis C, Bassi C, Jeekel H, Klinkenbijl JHG, Bakkevold KE, Takada T, Amano H, Neoptolemos JP (2005): Meta-analysis of randomised adjuvant therapy trials for pancreatic cancer. Br J Cancer 2ㅡ, 1372-1381

Stromnes IM, DelGiorno KE, Greenberg PD, Hingorani SR (2014): Stromal reengineering to treat pancreas cancer. Carcinogenesis $\underline{35}, 1451-1460$

Sweetwyne MT, Brekken RA, Workman G, Bradshaw AD, Carbon J, Siadak AW, Murri C, Sage EH (2004): Functional analysis of the matricellular protein SPARC with novel monoclonal antibodies. J Histochem Cytochem 르, 723-733

Tanaka M, Chari S, Adsay V, Fernandez-del Castillo C, Falconi M, Shimizu M, Yamaguchi K, Yamao K, Matsuno S, I A of Pancreatology (2006): International Consensus Guidelines for Management of Intraductal Papillary Mucinous Neoplasms and Mucinous Cystic Neoplasms of the Pancreas. Pancreatology $\underline{6}, 17-32$

Tetzlaff MT, Curry JL, Ivan D, Wang W-L, Torres-Cabala CA, Bassett RL, Valencia KM, McLemore MS, Ross MI, Prieto VG (2013): Immunodetection of phosphohistone H3 as a surrogate of mitotic figure count and clinical outcome in cutaneous melanoma. Mod Pathol 26, 1153-1160

Thompson LD, Becker RC, Przygodzki RM, Adair CF, Heffess CS (1999): Mucinous cystic neoplasm (mucinous cystadenocarcinoma of low-grade malignant potential) of the pancreas: a clinicopathologic study of 130 cases. Am J Surg Pathol 23, 1-16

Toole BP, Slomiany MG (2008): Hyaluronan: a constitutive regulator of chemoresistance and malignancy in cancer cells. Semin Cancer Biol 18, 244-250

van Duyne GD (2001): A structural view of cre-loxp site-specific recombination. Annu Rev Biophys Biomol Struct $\underline{30}, 87-104$

Vaz J, Ansari D, Sasor A, Andersson R (2015): SPARC: A Potential Prognostic and Therapeutic Target in Pancreatic Cancer. Pancreas 44, 1024-1035

Vogelstein B, Fearon ER, Hamilton SR, Kern SE, Preisinger AC, Leppert M, Nakamura Y, White R, Smits AM, Bos JL (1988): Genetic alterations during colorectal-tumor development. N Engl J Med $\underline{319}$, $525-532$ 
von Hoff DD, Ramanathan RK, Borad MJ, Laheru DA, Smith LS, Wood TE, Korn RL, Desai N, Trieu V, Iglesias JL (2011): Gemcitabine plus nab-paclitaxel is an active regimen in patients with advanced pancreatic cancer: A phase I/II trial. J Clin Oncol 29, 4548-4554

von Hoff DD, Ervin T, Arena FP, Chiorean EG, Infante J, Moore M, Seay T, Tjulandin SA, Ma WW, Saleh MN (2013a): Increased survival in pancreatic cancer with nab-paclitaxel plus gemcitabine. N Engl J Med $\underline{369}, 1691-1703$

von Hoff DD, Ervin TJ, Arena FP, Chiorean EG, Infante JR, Moore MJ, Seay TE, Tjulandin S, Ma WW, Saleh MN (2013b): Randomized phase III study of weekly nab -paclitaxel plus gemcitabine versus gemcitabine alone in patients with metastatic adenocarcinoma of the pancreas (MPACT). J Clin Oncol 31, LBA148-LBA148

Vonlaufen A, Joshi S, Qu C, Phillips PA, Xu Z, Parker NR, Toi CS, Pirola RC, Wilson JS, Goldstein D (2008): Pancreatic stellate cells: partners in crime with pancreatic cancer cells. Cancer Res $\underline{68}$, 2085-2093

Wachtler, F. (Hrsg.): Histologie: Lehrbuch der Zytologie, Histologie und mikroskopischen Anatomie des Menschen. 7., verb. Auflage; Facultas, Wien 2005

Waddell N, Pajic M, Patch A-M, Chang DK, Kassahn KS, Bailey P, Johns AL, Miller D, Nones K, Quek K (2015): Whole genomes redefine the mutational landscape of pancreatic cancer. Nature $\underline{518}, 495-501$

Wagner M, Redaelli C, Lietz M, Seiler CA, Friess H, Buchler MW (2004): Curative resection is the single most important factor determining outcome in patients with pancreatic adenocarcinoma. Br J Surg 91, 586-594

Wang LM, Silva MA, D'Costa Z, Bockelmann R, Soonawalla Z, Liu S, O'Neill E, Mukherjee S, McKenna WG, Muschel R (2016): The prognostic role of desmoplastic stroma in pancreatic ductal adenocarcinoma. Oncotarget $\underline{7}, 4183-4194$

Waterston RH, Lindblad-Toh K, Birney E, Rogers J, Abril JF, Agarwal P, Agarwala R, Ainscough R, Alexandersson M, An P (2002): Initial sequencing and comparative analysis of the mouse genome. Nature $\underline{420}, 520-562$

Whatcott CJ, Diep CH, Jiang P, Watanabe A, LoBello J, Sima C, Hostetter G, Shepard HM, Hoff DD von, Han H (2015): Desmoplasia in Primary Tumors and Metastatic Lesions of Pancreatic Cancer. Clin Cancer Res 21, 3561-3568

Wilentz RE, Geradts J, Maynard R, Offerhaus GJ, Kang M, Goggins M, Yeo CJ, Kern SE, Hruban RH (1998): Inactivation of the p16 (INK4A) tumor-suppressor gene in pancreatic duct lesions: loss of intranuclear expression. Cancer Res $\underline{58}, 4740-4744$

Wolfgang CL, Herman JM, Laheru DA, Klein AP, Erdek MA, Fishman EK, Hruban RH (2013): Recent progress in pancreatic cancer. CA Cancer J Clin $\underline{63}, 318-348$

Wong KM, Horton KJ, Coveler AL, Hingorani SR, Harris WP (2017): Targeting the Tumor Stroma: The Biology and Clinical Development of Pegylated Recombinant Human Hyaluronidase (PEGPH20). Curr Oncol Rep 19, 47

Xu Z, Vonlaufen A, Phillips PA, Fiala-Beer E, Zhang X, Yang L, Biankin AV, Goldstein D, Pirola RC, Wilson JS (2010): Role of pancreatic stellate cells in pancreatic cancer metastasis. Am J Pathol $\underline{177}, 2585$ 2596

Yachida S, Jones S, Bozic I, Antal T, Leary R, Fu B, Kamiyama M, Hruban RH, Eshleman JR, Nowak MA (2010): Distant Metastasis Occurs Late during the Genetic Evolution of Pancreatic Cancer. Nature $\underline{467}, 1114-1117$ 


\section{Danksagung}

An dieser Stelle bedanke ich mich bei all denen, die mich während der Erstellung dieser Dissertation begleitet und unterstützt haben.

An erster Stelle möchte ich mich bei Herrn Prof. Dr. Dr. Neeße für die Überlassung des überaus interessanten Themas und die hervorragende Betreuung während der Erstellung der Dissertation bedanken. Ich habe von den unzähligen Diskussionen, konstruktiven Vorschlägen und der Begleitung beim Verfassen der Dissertation sehr profitiert. Weiterhin bedanke ich mich für das vertrauensvolle Überlassen der wertvollen KPC-Gewebe und die Möglichkeit, an diesem spannenden Mausmodell forschen zu dürfen.

Mein Dank gilt weiter Iswarya Ramu, Melanie Patzak, Jutta Blumberg und Ulrike Wegner für die kompetente und engagierte Betreuung während der Durchführung des experimentellen Teils der Arbeit.

Herrn Prof. Dr. med. Ströbel aus der Abteilung Pathologie danke ich für die professionelle Beurteilung der Gewebe bezüglich Grading und Desmoplasie sowie die hilfreichen Erläuterungen während der gemeinsamen Begutachtung.

Den Mitarbeitern der zentralen Serviceeinheit des Instituts für Medizinische Statistik (UMG) danke ich für die geduldige Hilfe bei der statistischen Datenauswertung. Außerdem danke ich Herrn Prof. Patrick Maissoneuve (Mailand) für die zusätzliche statistische Beratung.

Weiterhin danke ich dem Cusanuswerk, dass mich in einzigartiger Weise während meines Studiums unterstützt hat und dessen Stipendium mir die Unabhängigkeit zur Erstellung dieser Dissertation ermöglicht hat. 


\section{Lebenslauf}

Als Sohn der Grundschullehrer Klemens und Susanne Klein wurde ich am 15. Januar 1991 in Twistringen, Deutschland geboren. Meine Kindheit verbrachte ich gemeinsam mit meinen Eltern und mit meinen beiden jüngeren Schwestern Charlotte und Henrike Klein in meiner Heimatstadt Twistringen. Dort besuchte ich die Grundschule Steller Straße und wechselte im Anschluss auf das Gymnasium Kolleg St. Thomas in Vechta. Im Jahr 2010 absolvierte ich am Gymnasium Antonianum in Vechta erfolgreich mein Abitur. Anschließend absolvierte ich als Wehrersatzdienst einen einjährigen Freiwilligendienst in Sicuani, Peru, in einem Heim für gehörlose Kinder und Kinder mit anderen Behinderungen.

Zum Wintersemester 2011/12 nahm ich das Medizinstudium an der Georg-August-Universität Göttingen auf und absolvierte dort 2013 und 2017 das 1. und 2. Staatsexamen in Medizin. 2014/15 verbrachte ich ein Auslandssemester an der Université Claude-Bernard-Lyon-I; Faculté de Médecine Lyon-Est und absolvierte dort Kurse der Neurologie, Gynäkologie und medizinischen Rehabilitation. Während des gesamten Studiums wurde ich durch ein Stipendium des Cusanuswerks sowohl finanziell als auch ideell gefördert. Im Mai 2019 schloss ich das Studium der Humanmedizin mit dem 3. Staatsexamen ab. Seit Oktober 2019 arbeite ich in der Klinik für Neurologie am Kantonsspital Aarau, Schweiz.

2015 nahm ich zum Ende des Sommersemesters die Promotionstätigkeit in der Arbeitsgruppe von Herrn Prof. Dr. Dr. Neeße auf. Dank der vielfältigen Unterstützung durch Herrn Prof. Dr. Dr. Neeße und aus der Arbeitsgruppe hatte ich 2016 die Gelegenheit einen Ausschnitt der Forschungsergebnisse auf dem jährlichen Treffen des European Pancreatic Clubs in Liverpool präsentieren zu dürfen. 